\title{
Cellular stress induces RIS dependent sleep and ALA dependent sedation via EGF receptor signaling in Caenorhabditis elegans
}

\author{
Dissertation \\ for the award of the degree \\ "Doctor rerum naturalium" \\ (Dr. rer. nat.) \\ of the Georg-August-Universität Göttingen \\ within the doctoral program Systems Neuroscience \\ of the Göttingen Graduate Center for Molecular Biosciences, Neurosciences and \\ Biophysics (GGNB) \\ submitted by \\ Jan Konietzka \\ from Frankfurt am Main, Germany
}

Göttingen, 2019 


\section{Thesis Committee Members}

Dr. Henrik Bringmann

( $1^{\text {st }}$ Reviewer)

Prof. Dr. Ralf Heinrich

( $2^{\text {nd }}$ Reviewer)

Dr. Oliver Valerius
Max Planck Research Group "Sleep and Waking”,

MPI for Biophysical Chemistry, Göttingen

Department of Cellular Neurobiology

Georg-August-Universität Göttingen

Research Group "Mass Spectrometry - Yeast group"

Georg-August-Universität Göttingen

\section{Examination Board Members}

Prof. Dr. Reinhard Schuh Max Planck Research Group "Molecular Organogenesis" MPI for Biophysical Chemistry, Göttingen

Prof. Dr. Andreas Stumpner Department of Cellular Neurobiology

Georg-August-Universität Göttingen

PD Dr. Gerd Vorbrüggen Research Group "Molecular Cell Dynamics"

Georg-August-Universität Göttingen

Date of oral examination: July 5, 2019 


\section{Affidavit}

I herewith declare that this thesis was produced entirely by myself and that I have only used sources and materials cited. The thesis has not been submitted to any other examination board for any other academic award.

Göttingen, April 30, 2019

Jan Konietzka 


\section{Summary}

Why do we sleep? This question is still unsolved, although sleep is such a fundamental behavioral state in all organism with a nervous system. Several physiological mechanisms, like memory consolidation, metabolic waste clearance, or immune system boosting, depend on sleep but none was sufficient to answer yet, why our consciousness has to shut off every night.

The nematode and model organism Caenorhabditis elegans has a minimalistic nervous system of exactly 302 neurons. Still, it provides three different types of sleep, which are linked to either-or one of two sleep neurons. The sleep-active neuron RIS controls developmentally-regulated lethargus sleep and environment-stimulated L1 arrest sleep. Stress-induced sleep (SIS) depends on the interneuron ALA. The clear structure of the nervous system, next to the straightforward genetic accessibility of $C$. elegans, made it an easy choice to use the worms for exploring sleep on a molecular level.

To investigate what defines RIS and ALA on the molecular level, I obtained different transcriptomes for both neurons. I got one transcriptome, which was based on RNA sequencing of fluorescence-activated cell sorted (FACS) RIS neurons. Additionally, Cao et al. (2018) used single-cell combinatorial indexing RNA sequencing to publish a data set of 42 '035 single cell transcriptomes, spanning all C. elegans L2 cells. From this data set, clusters representing RIS and ALA could be identified and used for the generation of transcriptomes for both cells, respectively.

The transcriptomes provided me with genes enriched in RIS, which were potentially important in sleep control in this neuron. I used mutated alleles of these genes for a behavioral sleep screen. A nonsense-allele of the invertebrate-type lysozyme ilys-4 and a gain-of-function allele of the epidermal growth factor receptor (EGFR) let-23 caused worms to sleep more in L1 arrest. Both were known to express in ALA, but I was able to confirm their additional expression in RIS via fluorescent reporters. I also showed the let23(gf) phenotype mainly depends on RIS.

SIS was known to be mediated via LET-23 in ALA. I used genetic ablations of ALA and RIS, and a RIS-specific knock-out of let-23 to demonstrate that SIS is also highly 
dependent on LET-23 signaling in RIS. Calcium imaging revealed that ALA activates broadly over the time span of SIS, while RIS activity correlates with individual sleep bouts of SIS. This is likely mediated via EGF signaling in ALA and RIS, as overexpression of EGF activated both neurons and caused movement quiescence of the worms. Next, I used optogenetic manipulation to show that ALA is able to activate RIS. This may function to some extent via the ALA neuropeptides encoded by flp-24, as shown in an overexpression experiment. I could confirm that worms survival after cellular stress is affected by ALA-induced sedation, but discovered survival does not depend on the RIS-induced sleep bouts.

In this thesis, I showed that SIS depends on EGF receptor signaling in RIS, besides the known pathway in ALA. RIS seems to be the major controller of sleep in the worm, as I now discovered that it is involved in all types of sleep in C. elegans. Furthermore, I demonstrated that stress-induced EGF receptor signaling acts parallel in ALA and RIS, which inherit different mechanistic properties and thus provide a discrete response. ALA sedates the worm, while RIS activity causes sleep bouts. This dual system allows the worm to fine-tune the behavioral response to cellular stress. Sedation and sleep representing distinct but interacting pathways in C. elegans might be a general principle, which also holds true in other organisms. 


\section{Table of Contents}

1. Introduction ......................................................................................................................... 1

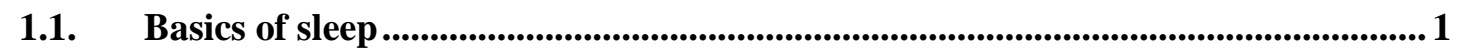

1.2. Complex sleep - REM \& NREM...................................................................................... 1

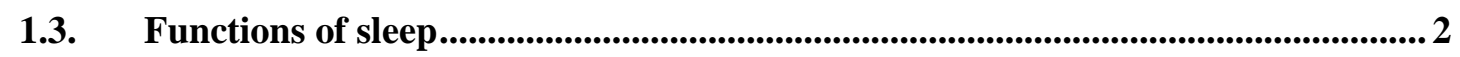

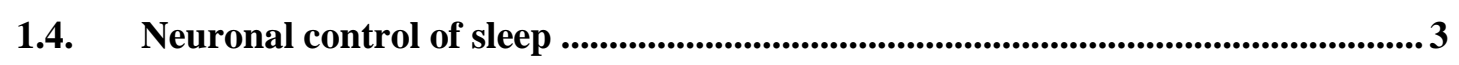

1.5. Molecular control of sleep ....................................................................................................... 3

1.6. Model organism Caenorhabditis elegans and its nervous system .......................... 4

1.7. Optogenetics in Caenorhabditis elegans .....................................................................5

1.8. Lethargus sleep and $\mathrm{L} 1$ arrest sleep in Caenorhabditis elegans ............................. 6

1.9. Stress-induced sleep in Caenorhabditis elegans ....................................................... 8

1.10. Conservation of sleep in Caenorhabditis elegans ....................................................... 9

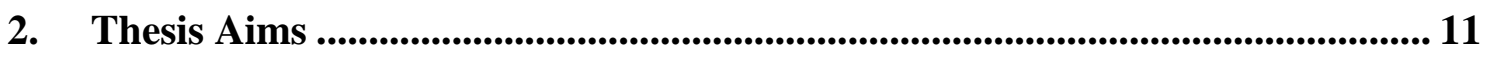

2.1. Aim 1 - Discover what defines RIS as a sleep-active neuron.................................. 11

2.2. Aim 2 - Identify the role of the EGF pathway in RIS and oppose it to ALA..... 12

3. Materials and Methods .................................................................................................. 13

3.1. Worm maintenance and strain genereation .......................................................... 13

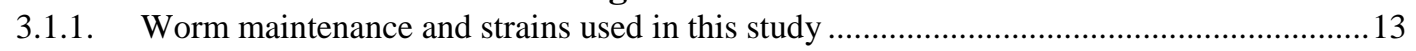

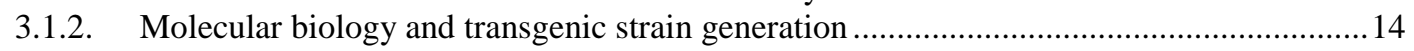

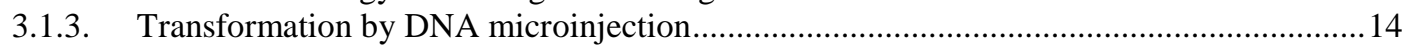

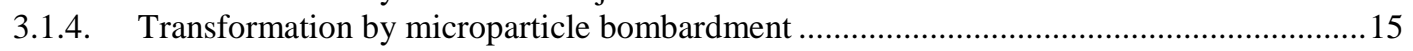

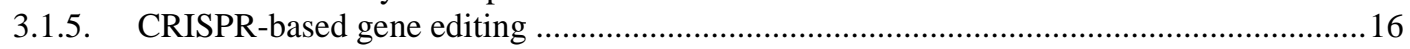

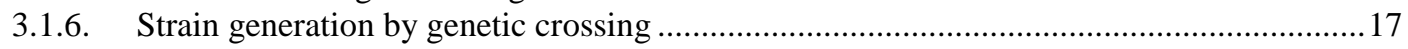

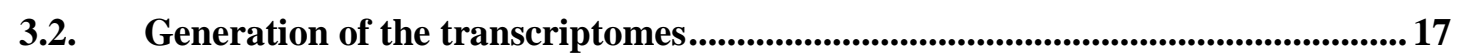

3.2.1. Transcriptome extraction from single-cell RNA sequencing data ....................................17

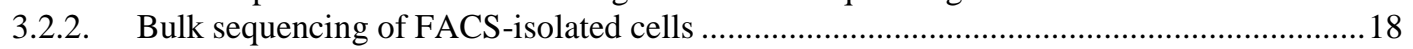

3.2.3. Transcriptome generation of bulk sequenced FACS-isolated cells ...................................18

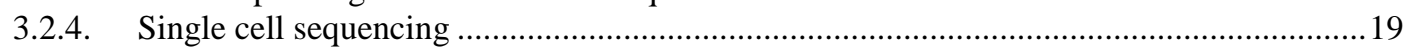

3.2.5. Differential expression analysis of RIS versus all cells ..................................................19

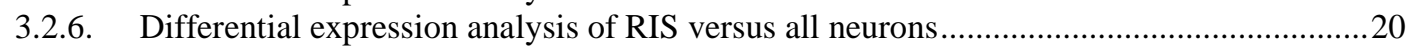

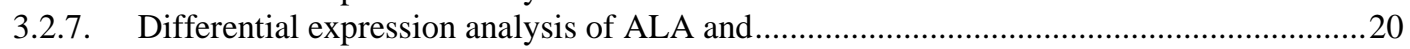

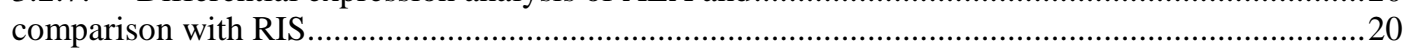

3.3. Microscopy imaging and behavioral analysis........................................................21

3.3.1. Long-term imaging using hydrogel microchambers ...................................................... 21

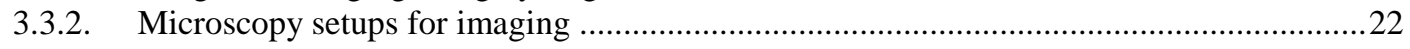

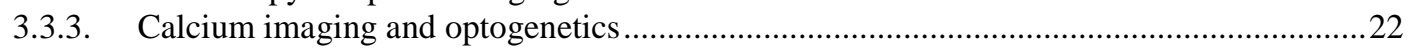

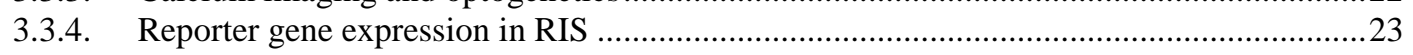

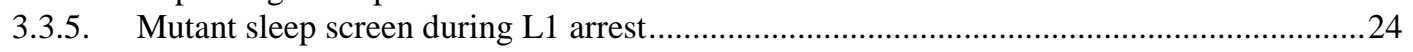

3.3.6. Induction of cellular stress by heat shock .......................................................................2

3.3.7. Induction of protein overexpression through temperature increase and $h s p-16.41 p \ldots \ldots . . .26$

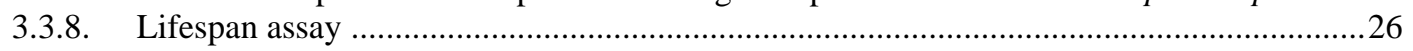

3.4. Quantification and statistical analysis ..................................................................22

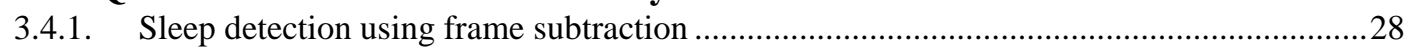

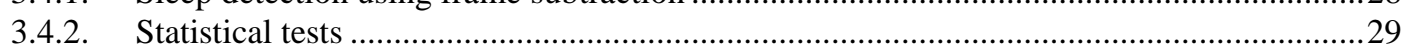

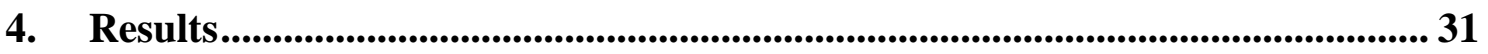

4.1. Single RIS neuron Transcriptome....................................................................................... 31

4.2. RIS transcriptome-based L1 arrest screen....................................................... 37 
4.3. The EGFR acts in ALA and RIS to induce sleep after cellular stress.................. 40

4.4. Cellular stress and EGF signaling depolarize ALA and RIS.................................45

4.5. ALA rather than RIS support survival after stress ................................................49

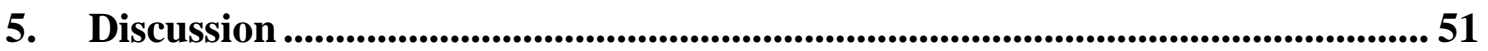

5.1. The starting point of this thesis .............................................................................5 51

5.2. Genes enriched in the sleep-active neuron RIS .................................................51

5.3. L1 arrest sleep screen .......................................................................................................5 53

5.4. RIS vs. ALA transcriptome....................................................................................56

5.5. EGF receptor signaling in RIS and ALA...............................................................5 57

5.6. ALA is a sedating and sleep-promoting neuron..................................................5 57

5.7. EGFR activates RIS to induce sleep bouts following cellular stress ......................58

5.8. Sedation is protective after cellular stress rather than sleep bouts .....................59

6. References............................................................................................................6 61

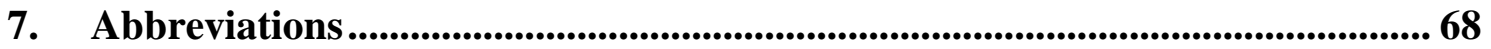

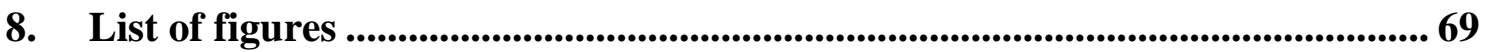

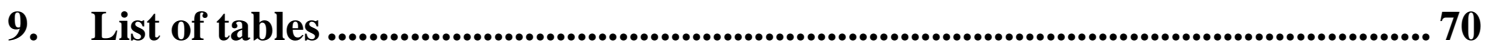

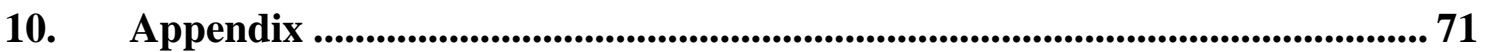

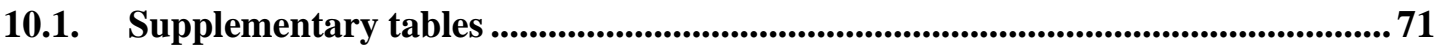

11. Acknowledgements .................................................................................................. 102 


\section{Introduction}

\subsection{Basics of sleep}

Why do we sleep? This question is not as easy to answer as the questions, why we have to eat, drink or breath. Although sleep is as much a physiological basic need as the other three, the lack of sleep causes within days severe physiological and cognitive problems in the organism and can ultimately lead to the death of it (Rechtschaffen \& Bergmann, 2002). Many physiological functions have been discovered happening during and being dependent on sleep, but none was sufficient yet to explain its existence.

Sleep is defined as a reversible but homeostatic regulated behavioral state of quiescence with an increased arousal threshold (Campbell \& Tobler, 1984; Siegel, 2008). It can be distinguished from a coma by its quick reversibility to wakefulness if a strong enough stimulus is applied. The increased arousal though can be lethal to the individual, e.g. a sleeping skink which becomes eaten by a predator snake (Shine, 1984). This means sleep is on a physiological level so essential that it could not be obliterated by evolution so far (Siegel, 2008). For its pivotal function also speaks the homeostatic regulation. It is possible to avoid sleeping for some time, but an increasing and homeostatic sleep drive forces the organism to sleep at one point.

Although its intrinsic function has not been discovered yet, many physiological processes happening during sleep have been identified. These might be secondary functions of sleep which were incorporated into the already existing state of behavioral quiescence during evolution. This seems plausible as different types of sleep can be found across the whole Animalia kingdom. A more complex type of sleep, for example, appears in mammals and birds. Sleep in those classes can be separated into two distinct and alternating phases, which are rapid eye movement sleep (REM) and non-rapid eye movement sleep (NREM) (Allada \& Siegel, 2008; Campbell \& Tobler, 1984).

\subsection{Complex sleep - REM \& NREM}

REM and NREM sleep can be easily identified by electroencephalogram (EEG) and electromyogram (EMG), which measure cortical activity and muscle tone, respectively. 
Introduction

The REM sleep features rapid movement of the eye, although skeletal muscles are paralyzed in a state called atonia. With EEG theta waves of 4 to $8 \mathrm{~Hz}$ and slow alpha waves can be found. Besides that, the brain shows activity similar to wake (Steriade, Timofeev, \& Grenier, 2001). Also blood pressure, pulse and body temperature resemble the wake state (Parmeggiani, 2003). In contrast NREM sleep features a decrease in body temperature and a slowdown of the heart rate (Parmeggiani, 2003). Brain metabolism is decreased, and electrophysiological activity is more synchronous (Maquet, 2000; Steriade et al., 2001). EEG measurements show higher voltage but slower waves in NREM sleep compared to the wake state. NREM sleep can be divided into three different substages according to their dominant EEG waves. The three stages are N1 "sleep onset", N2 "light sleep” and N3 “deep sleep” (Iber, Ancoli-Israel, Chesson, \& Quan, 2007).

\subsection{Functions of sleep}

With this broad range of diverse sleep phases, it is no surprise that sleep serves several function in the organism. First of all, the proposed function of saving energy might be an adaptive link rather than a function of sleep as stated in the review from Krueger et al. (2016). Discovered functions of sleep rather range from memory consolidation to the clearance of harmful metabolites in the brain like $\beta$-amyloid (Diekelmann \& Born, 2010; Xie et al., 2013). Also in certain circumstances sleep can counteract aging (Wu, Masurat, Preis, \& Bringmann, 2018). Further, a link to the immune system was revealed by presenting that a lack of sleep, for example, lead to increased tumor growth or has negative effects on graft rejections in mouse experiments (Hakim et al., 2014; Ruiz et al., 2017). Converse the immune response can also alter normal sleep pattern (Ruiz et al., 2017).

The recent hypothesis for the function of sleep focus on the modulation of brain connectivity and plasticity, like the idea that sleep tunes the brain for criticality (Krueger et al., 2016; Pearlmutter \& Houghton, 2009). These hypotheses are of particular interest as not only complex organism like mammals and birds but also evolutionary old organism like jellyfish have a sleep-like state (Nath et al., 2017). If sleep is already present in a simple nervous system like cnidarians have, its original function might be linked to the nervous system itself. 


\subsection{Neuronal control of sleep}

To understand the function of sleep the neuronal and molecular control of it has to be revealed. Sleep is promoted by sleep-active neuronal networks and nuclei, which also inhibit wake-active brain regions (Bringmann, 2018). During the wake state it is completely reversed, and the wake-active brain regions promote the wake state and inhibit parallel the sleep-active brain loci. This bidirectional interaction enables a fast switching from one brain state to the other in the format of a so-called "flip-flop" switch (Saper, Chou, \& Scammell, 2001; Saper, Scammell, \& Lu, 2005). Switching happens in the range of a few seconds (Takahashi, Kayama, Lin, \& Sakai, 2010; Wright, Badia, \& Wauquier, 1995). Interestingly such a "flip-flop" switch seems to be also present for REM and NREM sleep as they are mutually exclusive and inhibit each other (Lu, Sherman, Devor, \& Saper, 2006).

In the human the wake-active neuronal network consists of cholinergic neurons in the pedunculopontine and laterodorsal tegmental nuclei, noradrenergic neurons in the locus coeruleus, serotoninergic neurons in the dorsal and median raphe nuclei, dopaminergic neurons next to the dorsal raphe nucleus and also histaminergic neurons in the tuberomammillary nucleus (Saper, Fuller, Pedersen, Lu, \& Scammell, 2010).

The counterparts are $\gamma$-aminobutyric acid (GABA)ergic and peptidergic sleep-active neurons located to a large extent in the preoptic area (POA) of the hypothalamus. Other brain regions containing sleep-active neurons in the human are the basal forebrain, lateral hypothalamus, cortex, and the medulla of the brain stem (Bringmann, 2018).

\subsection{Molecular control of sleep}

Therefore, it is known which brain regions are at least responsible for sleep and also to a large extent which signaling molecules they use to induce sleep. This leads to the question of how sleep is regulated. It is known that sleep is controlled by different mechanisms, although they might overlap on the molecular level (Franken \& Dijk, 2009). 
Introduction

On the one hand, is circadian control, which mediates the timing of sleep in circadian rhythm dependent animals. While diurnal animals sleep during the night, it is vice versa in nocturnal animals. The top-level control is a master oscillator and pacemaker in the suprachiasmatic nucleus (Moore \& Eichler, 1972; Ralph, Foster, Davis, \& Menaker, 1990). On a genetic level the transcription factor CLOCK (Circadian Locomotor Output Cycles Kaput) is mediating the circadian rhythm. The protein CLOCK controls the expression of the gene period, which is a well-conserved and is needed for resetting of the circadian clock to light cues (Albrecht, Zheng, Larkin, Sun, \& Lee, 2001).

On the other hand, homeostatic and allostatic processes ensure that the organism sleeps enough by regulating sleep length and depth (Bringmann, 2018). Responsible neurons are located in the human brain for example in the median preoptic nucleus and the ventrolateral preoptic area. They are sleep-active and their activity increases in case of sleep deprivation (Alam, Kumar, McGinty, Alam, \& Szymusiak, 2014).

The upstream pathway of homeostatic sleep regulation is not known so far, but increased neuronal activity causes an increase in sleep drive (Krueger et al., 2016; Vyazovskiy, Borbély, \& Tobler, 2000). This lead to the hypothesis of sleep-promoting molecules, socalled somnogens, which accumulate during the wake state. Sleep drive would correlate to the amount of present somnogens. A highly likely candidate for a homeostatic sleepregulating somnogen is adenosine (Porkka-Heiskanen \& Kalinchuk, 2011). Other somnogens in turn, like cytokines, seem to induce allostatic sleep-regulating pathways. Particular the cytokines tumour-necrosis factor and interleukin-1 $\beta$ can increase sleep (Bryant, Trinder, \& Curtis, 2004). This is an additional hint for the link of sleep and the immune system.

\subsection{Model organism Caenorhabditis elegans and its nervous system}

Sleep is a very complex but on a molecular level still scarcely understood process. To unravel its mysteries, on the one hand, simple but on the other hand, sufficient enough complex model organism is needed, which is present in the form of Caenorhabditis elegans. 
C. elegans is a nematode and a commonly used model organism in neurobiology. It was the first organism with a fully sequenced genome, and 36\% of its 20'000 protein-coding genes have human homologs (The C. elegans Sequencing Consortium, 1998). For a significant portion of the $C$. elegans genes, mutated alleles exist which offers an easy option for experiments with genetic knock-outs. The biggest part of these alleles was created by the million mutation project (Thompson et al., 2013). One of the most fascinating features of those worms is its eutely. It has an invariant cell lineage which has been completely mapped (Sulston \& Horvitz, 1977).

Under normal conditions most of the worms found are self-fertile hermaphrodites, while just around $0.2 \%$ are males (Corsi, 2015). Self-fertile hermaphrodites are particular helpful in research as a single worm, e.g. carrying a new transgenic trait, can be used to start a new colony and homozygous hermaphrodites will produce genetically identical offspring(Altun \& Hall, 2009). Still, males exist and can be used for crossing purposes.

Each adult hermaphrodite hermaphrodite consists of precisely 959 somatic cells, from which 302 are neurons (Herman, 2006). These build an invariant nervous system and were sorted into 118 classes. So far 6'400 synapses and 900 gap junctions are known (White, Southgate, Thomson, \& Brenner, 1986). Other than hermaphrodites' males have 1031 cells including 383 neurons (Herman, 2006).

C. elegans neurons do not have classical action potentials with an influx of sodium ions (Lockery, Goodman, \& Faumont, 2009). They rather feature graded regenerative potentials, which are mediated by voltage-gated $\mathrm{Ca}^{2+}$ channels. The $\mathrm{Ca}^{2+}$ ions function as intracellular signaling molecules, like mediating the release of neurotransmitter via synaptic vesicle fusion (Chapman, 2008).

\subsection{Optogenetics in Caenorhabditis elegans}

This offers the option to directly measure neuronal activity, by measuring $\mathrm{Ca}^{2+}$ levels via the fluorescent calcium indicator GCaMP (Tian et al., 2009). Its fluorescence increases in the presence of $\mathrm{Ca}^{2+}$, for example when a graded regenerative potential is present in the neuron. 
Introduction

On the other way round, neurons can be artificially activated via light-gated ion channels. One example is the red-shifted variant of channelrhodopsin (ReaChr), which opens in the presence of green light in the range of $\lambda \sim 590-630 \mathrm{~nm}$ wavelength for $\mathrm{Ca}^{2+}$ ions (Lin, Knutsen, Muller, Kleinfeld, \& Tsien, 2013). This can trigger downstream processes like any regular intrinsic $\mathrm{Ca}^{2+}$ appearance. As C. elegans is susceptible to transgenic manipulation, both optogenetic tools can be genetically expressed in single target neurons given a specific genetic promoter is known.

\subsection{Lethargus sleep and $\mathrm{L} 1$ arrest sleep in Caenorhabditis elegans}

Most important, the worms feature phases of reversible but homeostatic regulated behavioral quiescence with an increased arousal threshold, which were therefore identified as sleep. In fact, the worms feature several different types of sleep.

One prominent form of sleep in C. elegans is lethargus sleep. If the worms are grown on $20^{\circ} \mathrm{C}$ they develop from a hatching egg to adulthood in roughly 48 hours. During this period the worms pass through four larval stages (L1 to L4), each separated by a molt and each molt preceded by a 60-90 minutes phase of lethargus sleep (Figure 2) (Altun \& Hall, 2009; Raizen et al., 2008). The timing of those molts are controlled by the protein LIM-42, while lim-42 is a homologue to the earlier mentioned period and thus hints to a conserved mechanism of sleep timing control (Jeon, 1999; Monsalve, Van Buskirk, \& Frand, 2011; Raizen et al., 2008).

A newly discovered form of sleep in C. elegans is called L1 arrest sleep. It appears after the L1 larvae does not find any food past hatching (Wu et al., 2018). After approximately 24 hours it starts to sleep in short bouts of around 5 minutes every hour. Frequency and length of these L1 arrest bouts increase with a further lack of food.

Both sleep types, lethargus and L1 arrest, were shown to be mediated via the single interneuron RIS (Turek, Lewandrowski, \& Bringmann, 2013; Wu et al., 2018). It is a GABAergic and peptidergic neuron, which is located on the dexter side in the ventral ganglion and projects a process to the nerve ring (Figure 1) (White et al., 1986). GCaMP measurements in RIS showed activity peaks upon the beginning of quiescence. 


\section{Introduction}

Furthermore, the exclusively release of RIS neuropeptides but not the release of GABA alone was sufficient to induce quiescence in the worm (Turek et al., 2013). More precise, the in RIS mainly present neuropeptide FLP-11 is needed for sleep induction (Turek, Besseling, Spies, König, \& Bringmann, 2016). FLP-11 expression is regulated via the AP2 transcription factor APTF-1, which itself is controlled via the GABAergic neuron defining transcription factor LIM-6 (Turek et al., 2016). Nonsense mutations in aptf-1 prevent movement quiescence in both sleep types, although feeding quiescence during lethargus sleep is not affected (Turek et al., 2013; Wu et al., 2018).

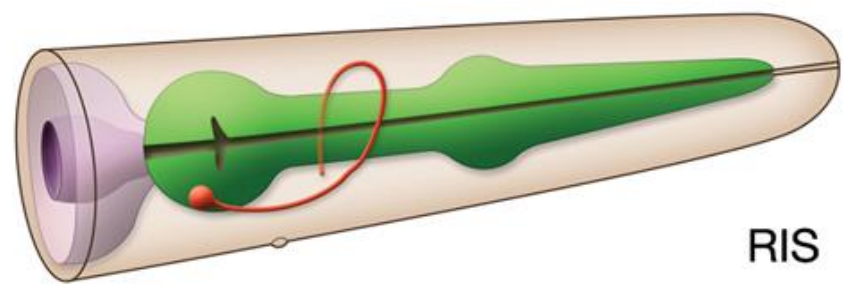

Figure 1 - Interneuron RIS

Schematic representation of a $C$. elegans head (anterior-right, dorsal-up). Including the interneuron RIS (red) projecting its process around the pharynx (green). The pharynx is connected to the intestine (rose, cut). This figure was adopted from WormAtlas. 


\section{Introduction}

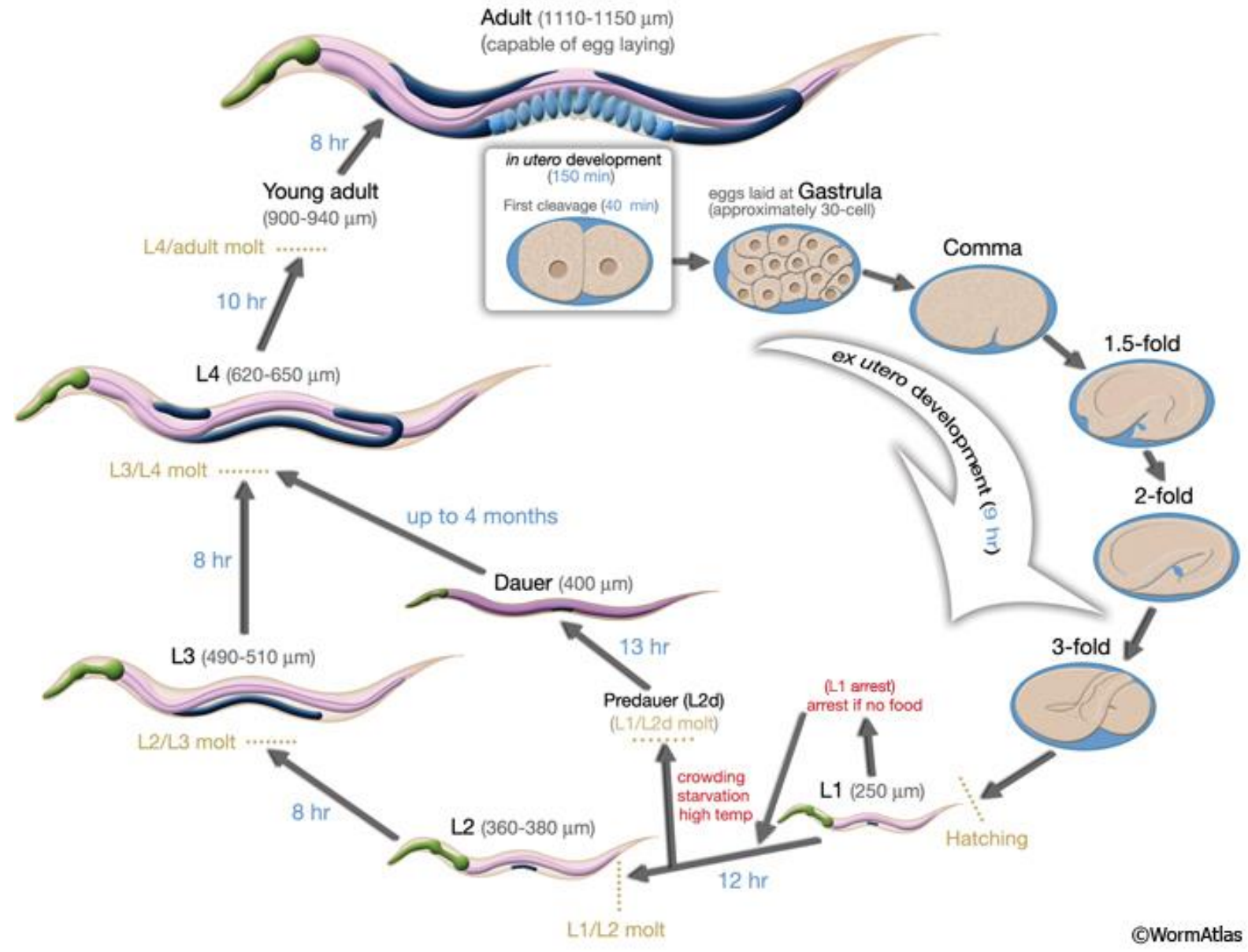

Figure $2-$ C. elegans life cycles

Life cycle of $C$. elegans from egg to egg-laying adult. In general, after hatching from the egg the worms goes through four larval stages (L1 - L4) until reaching adulthood. Each larval stage is ended by a phase of lethargus sleep and then molting. Larvae which do not find any food after hatching stop in a L1 arrest phase but continue developing regular after access to food supply. L1 larvae in a challenging environment can access an alternative developmental route and become resilient dauer larvae. Duration of each life stage is stated in blue, while the size is indicated in grey brackets. This figure was adopted from Altun and Hall (2009).

\subsection{Stress-induced sleep in Caenorhabditis elegans}

Stress-induced sleep (SIS) is a third and well-described type of sleep in C. elegans. Worms show a reversible feeding and locomotion quiescence subsequent to the exposure of various noxious stimuli (Hill, Mansfield, Lopez, Raizen, \& Van Buskirk, 2014). This includes hyperosmotic, alcohol, cold, tissue damage as well as heat stress. The worms show quiescence during the stimuli but also in a time window of approximately $60 \mathrm{~min}$ after. So far it has been reported that the quiescence after the stimuli is dependent on the interneuron ALA (Hill et al., 2014). It is located in the dorsal ganglion of the head and projects to the dorsal cord and, while passing the nerve ring, to the posterior end of the worm (Figure 3) (White et al., 1986). Like RIS, it is a peptidergic neuron and its 
Introduction

discovered neuropeptides are FLP-13, NLP-8, FLP-7, and FLP-24 (Nath, Chow, Wang, Schwarz, \& Sternberg, 2016; Nelson et al., 2014). Nonsense mutation alleles of the homeobox genes ceh-14 and ceh-17 cause the development of a nonfunctional ALA neuron, which is useful for ALA ablation experiments (C. Van Buskirk \& Sternberg, 2010).

ALA also expresses a epidermal growth factor receptor (EGFR) as well as its downstream pathway via PLC $\gamma$ (Cheryl Van Buskirk \& Sternberg, 2007). The C. elegans homolog names for EGF, its receptor and PLC $\gamma$ are respectively LIN-3, LET-23, and PLC-3. Besides various other functions LIN-3 has in the worm, it was shown that LIN-3 release upon a noxious stimulus causes some SIS via ALA neuropeptide release (Nath et al., 2016; Cheryl Van Buskirk \& Sternberg, 2007). The release of FLP-7 neuropeptides does not have an obvious quiescence effect, while FLP-13, NLP-8, and FLP-24 can inhibit locomotion and an avoidance response (Nath et al., 2016). FLP-13 neuropeptide release also causes feeding quiescence (Nelson et al., 2014).

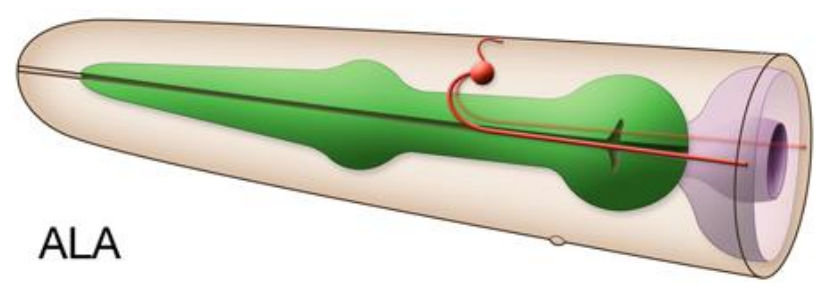

Figure 3 - Interneuron ALA

Schematic representation of a C. elegans head (anterior-left, dorsal-up). Including the interneuron ALA (red) projecting its process to the posterior end of the worm. The pharynx (green) is connected to the intestine (rose, cut). This figure was adopted from WormAtlas.

\subsection{Conservation of sleep in Caenorhabditis elegans}

It is very intriguing that not only sleep itself seems to exist across all animal phyla, but also the mechanisms controlling it seems to be conserved across the species. C. elegans features the GABAergic/peptidergic sleep-active neuron RIS, while humans have GABAergic/peptidergic sleep-active neurons in the POA, and fruit flies (Drosophila melanogaster) have them in four different main brain regions (Bringmann, 2018). The same is true for the link of EGF-signaling and sleep, which was not only found in 


\section{Introduction}

C. elegans but also in fruit flies and rabbits, for example (Foltenyi, Greenspan, \& Newport, 2007; Kushikata, Fang, Chen, Wang, \& Krueger, 1998). If sleep is so conserved, it is from great advantage to use the easily accessible model organism Caenorhabditis elegans with its simple nervous system of just 302 neurons to unravel on the one hand the function of sleep and on the other hand the molecular mechanisms behind it. 


\section{Thesis Aims}

One of the biggest unsolved mysteries in neuroscience are the molecular pathways of sleep control. To explore sleep on a molecular level in the mammalian model organism mouse or even in humans would be unnecessarily complicated, because of the complexity of the brain and its inaccessibility on a cellular level without damaging the organism. C. elegans in contrast is a widely used model organism for various scientific disciplines. The easy maintenance, genetic accessibility, transparency and invariant nervous system of precisely 302 neurons makes it also valuable for neuroscientific research. That is why I used $C$. elegans to unravel the molecular pathways of sleep control.

At the start of my thesis, the sleep-active neuron RIS and its conserved mechanism of sleep control via neuropeptides and GABA was known. The mainly in RIS present neuropeptide FLP-11 and its genetically control via transcription factor APTF-1 had been discovered. RIS is highly involved in sleep control, but the upstream mechanism of this control or other specialties of this neuron were utterly unknown. This lead to my first thesis aim:

\subsection{Aim 1 - Discover what defines RIS as a sleep-active neuron}

I obtained three different transcriptomes of RIS. They were produced by two different methods, fluorescence-activated cell sorting with following RNA sequencing (FACS/RNA-seq) and single-cell combinatorial indexing RNA sequencing (sci-RNA-seq). I checked the most enriched genes in those transcriptomes, if either $C$. elegans strains with severe mutations or fluorescent reporter expression for these genes existed. 102 genes were covered by strains with severe mutation alleles, and for 20 genes existed fluorescent reporter lines. I used the fluorescent reporters to confirm their expression in RIS and as a method of validation of the transcriptomes. Further, I screened all strains carrying a severe mutation allele for an L1 arrest sleep phenotype.

Interestingly, I found the EGF receptor signaling pathway expressed and enriched in RIS, which was known before, for its expression in ALA and mediating SIS via neuropeptide release in from this neuron. This occurrence led to my second thesis aim: 


\subsection{Aim 2 - Identify the role of the EGF pathway in RIS and oppose it to ALA}

I used several behavioral, genetic and optogenetic approaches to identify the role of the EGF pathway in RIS and ALA. Via genetically ablation of RIS and ALA, and conditional knock-outs of the EGF receptor let-23 in RIS combined with a heat shock, I analyzed SIS in young adult larvae. I checked with the help of the calcium ion sensor GCaMP the neuronal activity of ALA and RIS in case of a heat shock or EGF/LIN-3 overexpression. Also, that RIS can be activated by optogenetic stimulation of ALA and by overexpression of the ALA neuropeptide gene $f l p-24$. I could show ALA is a sedating neuron, while RIS directly induces sleep bouts. Finally, I confirmed worm survival after cellular stress depends on sedation of ALA, but is not affected by sleep bouts induced by RIS. 


\section{Materials and Methods}

All methods described in this thesis are part of the manuscript we are currently writing. The manuscript is entitled "Epidermal Growth Factor signaling promotes sleep-active neuron depolarization to increase sleep following cellular stress". It is based on a collaborative project. Sections not written by myself are pointed out directly in advance.

\subsection{Worm maintenance and strain genereation}

3.1.1. Worm maintenance and strains used in this study

C. elegans was cultured on Nematode Growth Medium (NGM) agarose plates seeded with E. coli OP50 and incubated at $20^{\circ} \mathrm{C}$ (Brenner, 1974; Stiernagle, 2006). A list of all C. elegans strains can be found in Table 2. 


\subsubsection{Molecular biology and transgenic strain generation}

All constructs were cloned using the MultiSite Gateway system (Invitrogen, Carlsbad, CA) with pCG150 (Addgene plasmid \#17247), which contains unc-119(+), as the destination vector for LR reactions (Merritt \& Seydoux, 2010). For verification, all constructs were Sanger sequenced. Genes encoding GCaMP3.35 and ReaChR were used that were codon-optimized for expression in C. elegans (Redemann et al., 2011). The following plasmids were generated and used in this study:

Table 1 - Constructs created and used for transgenic strain generation

\begin{tabular}{|l|l|}
\hline construct name & construct structure \\
\hline K351 & $\begin{array}{l}\text { flp-24p::SL1-GCaMP3.35-SL2::SL2-mKate2::unc-54 3'UTR, unc- } \\
119(+)\end{array}$ \\
\hline K358 & flp-24p::ReaChr::mKate2-unc-54 3'UTR, unc-119(+) \\
\hline
\end{tabular}

\subsubsection{Transformation by DNA microinjection}

DNA microinjection was used for the generation of transgenic C. elegans strains (Evans, 2006). A young adult hermaphrodite was transferred using a $\sim 0.5 \mu \mathrm{L}$ drop of Halocarbon oil 700 (Sigma) into a $\sim 2 \mu \mathrm{L}$ drop of the same oil on an agar pad. To generate the agar pad before the start of the injections, a drop of $3 \%$ agarose in water was placed onto a glass slide, flattened with a glass slide, and dried for one hour on a $95^{\circ} \mathrm{C}$ heating block before. The worm was gently positioned with an eyelash to fix it on the agarose surface. Next, the glass slide with the fixed worm was placed onto a microinjection microscope setup, which consisted of an inverted microscope (Nikon, Eclipse Ti-S), a micromanipulator (Eppendorf, Patchman) and an electrical microinjector (Eppendorf, FemtoJet). A microinjection needle (Eppendorf, Femtotips 2), pre-filled with DNA, was mounted on the microinjector. The needle was filled with DNA solution containing TE buffer, the target construct DNA, a co-injection marker DNA and was filled up with pCG150 DNA (Addgene plasmid \#17247 (Merritt \& Seydoux, 2010)) to a final concentration of $100 \mathrm{ng} / \mu \mathrm{L}$. As co-injection marker coel::RFP (unc-122p::RFP) was used, which expresses a red fluorophore in the coelomocytes (Addgene plasmid \#8938 (Miyabayashi, Palfreyman, Sluder, Slack, \& Sengupta, 1999)). 
The construct was injected at the following concentrations:

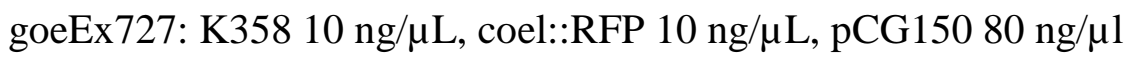

The needle was inserted carefully into one arm of the gonad with the help of a micromanipulator, and DNA solution was injected with an injection pressure of $29.0 \mathrm{psi}$ for an injection time of 0.4 seconds. Constant pressure was at $2.00 \mathrm{psi}$. The needle was retracted from the gonad and the worm was recovered with a $2 \mu \mathrm{L}$ drop of M9. The worm was retracted from the liquid using a platinum wire pick and a drop of bacteria and transferred to a fresh NGM plate. After growing the worm at $20^{\circ} \mathrm{C}$ for 48 hours, F1 larvae were inspected with a fluorescence microscope for the expression of the co-injection marker and positive transformants were selected.

\subsubsection{Transformation by microparticle bombardment}

A second method used for the creation of transgenes was gold microparticle bombardment. unc-119(ed3) were used for bombardment and transformants were selected based on phenotypic rescue conferred by the unc-119(+) present in the plasmid that was used for transformation (Praitis, Casey, Collar, \& Austin, 2000; Wilm, Demel, Koop, Schnabel, \& Schnabel, 1999). Gold microparticles (chemPUR) sized 0.3-3 $\mu \mathrm{m}$ were coated with the DNA using spermidine (Sigma-Aldrich, $50 \mathrm{mM}$ ) and polyvinylpyrrolidone (Sigma-Aldrich, P-5288, Mol. 360, $0.1 \mathrm{mg} / \mathrm{ml}$ in $96 \%$ EtOH). Synchronized young adult worms were transferred onto NGM plates, which contained a $1 \mathrm{~cm}$ diameter bacterial lawn in their center and were cooled down by placing them on ice prior to transferring the worms. $20 \mu \mathrm{L}$ of gold particle suspension was loaded onto the filter of a particle gun (Caenotec, Braunschweig). Helium (purity 5.0) was used at 8 bar to accelerate the particles into a vacuum chamber $(-0.4$ bar) onto the worms. Each construct was transformed eight times. Worms were recovered by cutting each NGM plate into six pieces after transformation and placing each piece onto a $12 \mathrm{~cm}$ NGM plate. Transformants were selected after two weeks incubation of the plates at $25^{\circ} \mathrm{C}$. To select motile transformants, a $1 \times 1 \mathrm{~cm}$ piece of an NGM plate seeded with OP50 was placed onto the plate and transformants were removed $0.5-1 \mathrm{~h}$ later from the bacterial lawn. 


\subsection{5. $\quad$ CRISPR-based gene editing}

CRISPR-based gene edited let-23(zh131) allele was kindly provided by Silvan Spiri and Prof. Dr. Alex Hajnal. They added a frt::gfp::3xFlag sequence in the 3' region of the let23 locus, and they added a second $f r t$ site $2 \mathrm{~kb}$ upstream of $f r t: \because g f p$ and 5 to the protein kinase domain in the let-23 locus (Figure 4).

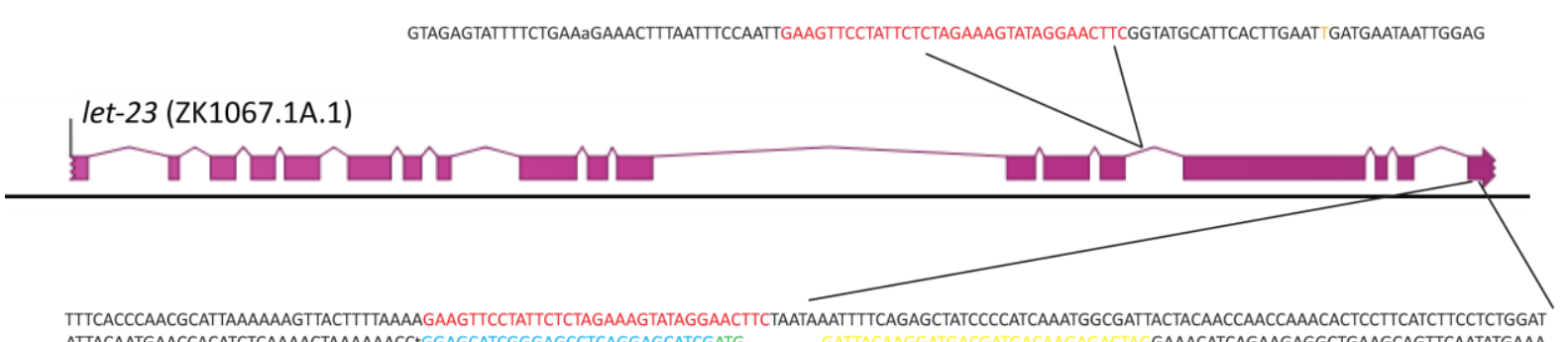

Figure 4-CRISPR/Cas9-based editing of the let-23 locus

A schematic representation of the generation of the conditional let-23 allele zh131. Sections shows let23(ZK1067.1A.1) on Chromosom II, Color coded sequences refer to insertions in zh131: Black: genomic sequence; Red: FRT sites; Orange: mutation of PAM for sgRNA3_let-23BtyrK; Blue: linker sequence; Orange: mutation of PAM; Green: GFP; Yellow: Flag Tag.

This figure was kindly provided by the research group of Prof. Dr. Alex Hajnal. 
The ilys-4(syb700) deletion allele was generated by SunyBiotech using CRISPR/Cas9 and deletes 1270 nucleotides (the entire coding region) of the ilys-4 gene between the following flanking sequences:

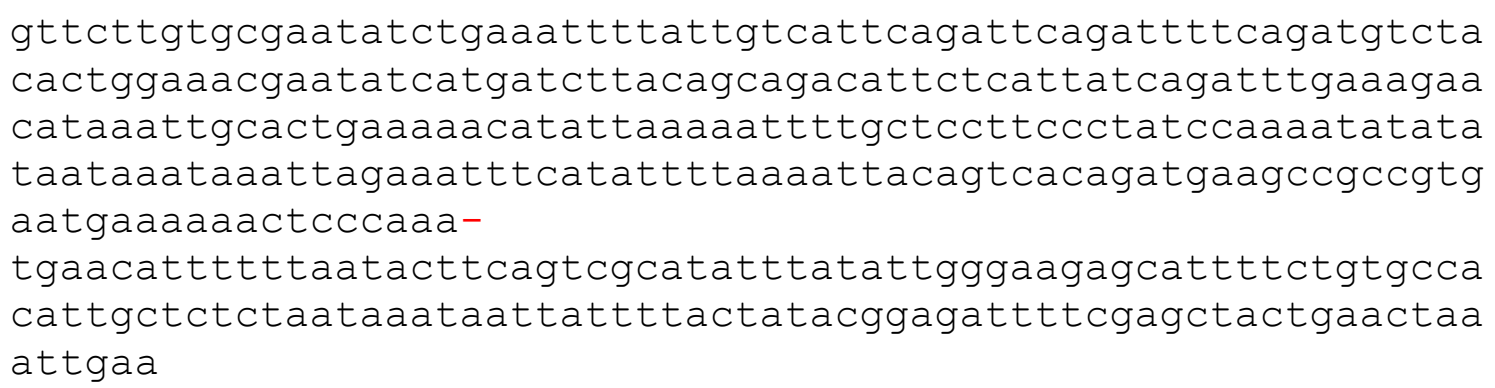

\subsubsection{Strain generation by genetic crossing}

Transgenes were backcrossed two times against N2. For following genotypes during strain crossing, the animals were genotyped using either Duplex PCR genotyping of single worms (mostly to detect deletions) (Ahringer, 2006), tetra-primer ARMS-PCR (to detect single nucleotide changes)(Ye, 2001), or sanger sequencing (to detect single nucleotide changes). Primers used for genotyping are listed in Table 3.

\subsection{Generation of the transcriptomes}

\subsubsection{Transcriptome extraction from single-cell RNA sequencing data}

Data generated via 'Bulk sequencing of FACS-isolated cells' was kindly provided by Prof. Dr. David M Miller III and based on the method described in Spencer et al. (2014). Generating and processing the transcriptomes "FACS/RNA-seq RIS vs. all", "sci-RNAseq RIS vs. all”, "sci-RNA-seq RIS vs. neurons", and "sci-RNA-seq ALA vs. neurons" was done by Dr. Andreas Leha from the "Medical Biometry and Statistical Bioinformatics" core facility at the UMG, Göttingen. Dr. Leha also kindly provided the following methods parts "Transcriptome generation of bulk sequenced FACS-isolated cells", "Single cell sequencing", "Differential expression analysis of RIS versus all neurons", "Differential expression analysis of RIS versus all cells", and "Differential expression analysis of ALA and comparison with RIS" for it. 


\subsubsection{Bulk sequencing of FACS-isolated cells}

RIS was specifically labelled using mKate 2 expression from the flp-11 promotor (Turek et al., 2016) and isolated from a population of synchronized L2 larvae via FACS. It is followed up by RNA sequencing of the sorted cells. This method has been used to generate several validated neural transcriptomes in C. elegans (Lim et al., 2016; Spencer et al., 2014).

\subsubsection{Transcriptome generation of bulk sequenced FACS-isolated cells}

To analyze data for bulk sequencing, Quality Control of the input reads was done using fastQC (version v0.11.2; Andrews, Simon, 2014, "FastQC A Quality Control tool for High Throughput Sequence Data" https://github.com/s-andrews/FastQC). Star (version 2.4.0) was used to align reads to the reference assembly WBcel235 of Caenorhabditis elegans (Dobin et al., 2013). Gene annotation was used from release 94. Multiqc (version 1.5) was used to facilitate quality control on the input data as well as the alignment statistics (Ewels, Magnusson, Lundin, \& Käller, 2016). Gene level counts were generated using RSEM (version 1.2.19) to deal with multimapping reads (Li \& Dewey, 2011). All downstream analyses have been performed in $\mathrm{R}$ (version 3.4.0; Core Team, 2018, R: A Language and Environment for Statistical Computing. Vienna, Austria: R Foundation for Statistical Computing. https://www.R-project.org/). Read counts were normalized using tximport (version 1.8.0) (Soneson, Love, \& Robinson, 2015). Counts per million (CPM) values were generated for first unbiased analyses. Correlation based clustering and a principal component analysis (PCA) analysis were conducted to assess sample structure and identify potentially problematic samples. Differential expression analysis was done using edgeR (version 3.24.3) fitting a negative binomial generalized log-linear model to the read counts for each gene (Robinson, McCarthy, \& Smyth, 2010). P values are results from a likelihood ratio test and have been adjusted for multiple testing using BenjaminiHochberg. The significance level was set to alpha $=5 \%$ for all statistical tests.

Three biological replicates of isolated RIS and three biological replicates of control cells (all cells) were collected and bulk sequenced. One RIS sample was excluded from the analysis as it did not cluster with the other replicates. 4'504 genes were down regulated in RIS according to this analysis of which 3'183 were statistically significant. 3'197 genes 
were up regulated of which 1'188 were statistically significant. Among the four most strongly enriched genes was flp-11, with an enrichment of 890-fold. Differential genes are listed in Table 4.

\subsubsection{Single cell sequencing}

For single-cell sequencing, the data set from Cao et al. (2017) was used in this analysis. To identify the transcriptome cluster corresponding to RIS within the neuronal sci-RNAseq clusters we used our previous observations that only RIS strongly and specifically expresses flp-11 neuropeptides (Turek et al., 2016). Gene counts and t-SNE based cell clusters were used as provided by the authors. Using the expression of the marker gene flp-11, one cluster was identified as the RIS cells. Cells with less than 70 UMI counts were discarded from the analysis. Only genes with at least one count in at least 5 cells were considered in the subsequent analysis. Differential expression analysis was done using edgeR (version 3.24.3)(Robinson et al., 2010), fitting a negative binomial generalized log-linear model to the read counts for each gene. $\mathrm{P}$ values are results from a likelihood ratio test and were adjusted for multiple testing using Benjamini-Hochberg. Differential expression analysis was performed twice, once comparing RIS genes to all other remaining genes and once comparing RIS genes to all other cells. The significance level was set to alpha $=10 \%$ for all statistical tests. All analyses have been performed in R (version 3.4.0; R Core Team 2018). The single cell count data by Cao et al. (2017) contains counts for 20’271 genes in 42'035 cells derived from L2 larvae. Cluster 13 was identified as the RIS cell cluster, containing 44 RIS cells.

\subsubsection{Differential expression analysis of RIS versus all cells}

Here the analysis was conducted on all 42'035 cells from the single-cell data set (Cao et al., 2017). Post filtering, there were 9'497 genes available in 39'634 cells (of which 44 were RIS cells) for differential expression analysis. The results were compared to the results obtain from Bulk-RNAseq data. 7'719 genes were down regulated in RIS according to this analysis of which 138 were statistically significant. 1'410 genes were up regulated of which 243 were statistically significant. The most strongly enriched gene was flp-11, with an enrichment of 588-fold. Differential genes listed in Table 5. 
Comparing the differentially and significantly expressed genes from the single-cell sequencing data set with the differentially and significantly genes from the bulk sequencing data set there were 228 genes present in both data sets. Comparing all differentially expressed genes from the single-cell sequencing data set with the differentially and significantly genes from the bulk sequencing data set there were 691 genes present in both data sets.

\subsubsection{Differential expression analysis of RIS versus all neurons}

Here the analysis was conducted on the 7'603 neuronal cells only. Post filtering, there were 9'497 genes available in 7'448 cells (of which 44 were RIS cells) for differential expression analysis. 8'100 genes were down regulated in RIS according to this analysis of which 6 were statistically significant. 1'331 genes were up regulated of which 60 were statistically significant. The most strongly enriched gene was flp-11, with an enrichment of 157-fold. Differential genes listed in Table 6.

Comparing the differentially and significantly expressed genes from the single-cell sequencing data set with the differentially and significantly genes from the bulk sequencing data set there were 58 genes present in both data sets. Comparing all differentially expressed genes from the single-cell sequencing data set with the differentially and significantly genes from the bulk sequencing data set there were 479 genes present in both data sets.

\subsubsection{Differential expression analysis of ALA and comparison with RIS}

Genes expressed in ALA were also extracted from the data set from Cao et al. (2017) as above. To identify the transcriptomes corresponding to ALA we used the previous observations that ALA expresses $n l p-24, f l p-13$, and $f l p-7$ neuropeptides (Nath et al., 2016; Nelson et al., 2014). Cells with less than 70 UMI counts were discarded from the analysis. Only genes with at least one count in at least 5 cells were considered in the subsequent analysis. Here the analysis was conducted on the 7'603 neuronal cells only. 
Post filtering, there were 9'497 genes available in 7'448 cells for differential expression analysis. 22 cells, which formed part of cluster 11, were identified as ALA (Cao et al., 2017). Differential expression analysis was done using edgeR [version 3.24.3; @edgeR] fitting a negative binomial generalized log-linear model to the read counts for each gene (Robinson et al., 2010). P values are results from a likelihood ratio test and have been adjusted for multiple testing using Benjamini-Hochberg. The significance level was set to alpha $=10 \%$ for all statistical tests. Differential expression analysis was performed comparing ALA cells to the remaining pan-neuronal cells. 8'286 genes were down regulated in RIS according to this analysis of which 0 were statistically significant. 1'189 genes were up regulated of which 22 were statistically significant. Among the top enriched genes were $n l p-24$, let-23, flp-7, and $n l p-8$, which have previously been demonstrated to be expressed in ALA, indicating that the ALA transcriptome was correctly identified (Nath et al., 2016; Cheryl Van Buskirk \& Sternberg, 2007). Differential genes listed in Table 7.

Pairwise correlations of $\log F C$ from tests vs pan-neuronal background were computed. Columns and rows were ordered following hierarchical clustering. All neuronal clusters with less than 100 cells were compared to the remaining pan-neuronal background. Based on the resulting $\operatorname{logFC}$, pairwise correlations and hierarchical clustering were calculated.

\subsection{Microscopy imaging and behavioral analysis}

\subsubsection{Long-term imaging using hydrogel microchambers}

Imaging of behavior and calcium activity was performed using Agarose Microchamber Imaging (AMI) as described (Bringmann, 2011; Turek, Besseling, \& Bringmann, 2015). Shortly, a polydimethylsiloxane (PDMS) mold was used to create microcompartments from melted 3\% high-melting agarose (Fisher Scientific GmbH) dissolved in S-Basal (Stiernagle, 2006). The following chamber sizes were used: $190 \mu \mathrm{m}$ x $190 \mu \mathrm{m}$ x $15 \mu \mathrm{m}$ (X length $x$ Y length $\times \mathrm{Z}$ depth) for L1, $370 \mu \mathrm{m} \times 370 \mu \mathrm{m} \times 45 \mu \mathrm{m}$ for adults. The microchambers were filled with either eggs (for L1 arrest experiments) or young adults (for heat shock experiments), sealed with a cover slip, and attached with double-side adhesive tape (Sellotape) into an opening milled into a $3.5 \mathrm{~cm}$ plastic Petri dish. An additional $2 \mathrm{~mL}$ volume of $3 \%$ high melting agarose was filled to form a ring around the 
agar block containing the micro compartments, serving as a moisture reservoir. The space between the agarose pad and the agarose ring of the Petri dish was filled with melted $3 \%$ low melting agarose dissolved in S-Basal. The sample equilibrated for at least $2 \mathrm{~h}$ before the start of imaging. For imaging, a home-made heating lid was used that kept the temperature at $25^{\circ} \mathrm{C}$ to avoid condensation.

\subsubsection{Microscopy setups for imaging}

Imaging was performed on either a TiE or Ti2 inverted microscope (Nikon) with an automated XY stage (Prior, Nikon). The following objectives were used: 40x 0.45 NA dry, or 60x 1.4 NA oil for reporter co-expression experiments, 10x NA 0.45 dry with DIC filter for L1 arrest experiments and 20x NA 0.75 dry with an additional 0.7 lens placed in the c-mount of the camera for all experiments with young adult worms. Adults were imaged using the 10x objective. L1s were imaged with the 20x objective. This constellation allowed fitting 1 and 30 chambers simultaneously onto the camera chip for adults and L1, respectively. Microscopes were equipped with red-light (Semrock BrightLine HC 785/62, $45 \mathrm{~mm}$ diameter) dia illumination for differential interference contrast (DIC), which was used for behavioral imaging. Standard filter sets were used for GFP/GCaMP (ET-EGFP, Chroma) and mKate2 (TexasRed, Chroma) fluorescence imaging and optogentic stimulation. Images were acquired using either am electron multiplying charge-coupled device (EMCCD) camera (iXon DU-897D-C00-\#BV, 512 x 512 pixels, Andor) or back-illuminated sCMOS camera (Prime 95B, 1'174 x 1'174 pixels, Photometrics) for fluorescence imaging. For experiments requiring only DIC imaging, an sCMOS camera (Neo, 2'560 x 2'160 pixels, Andor) was used. For fluorescence illumination and optogenetics an LED system was used (CoolLED). The LED system provided light with the wavelength of $488 \mathrm{~nm}$ for GFP excitation and 565 $\mathrm{nm}$ for mKate2 excitation and was triggered via the transistor-transistor logic (TTL) "fire out" signal of the camera. The software used to control the microscope and image acquisition was either iQ2/iQ3 (Andor) or NIS elements (Nikon).

\subsubsection{Calcium imaging and optogenetics}


For 490nm illumination for GCaMP imaging, light intensity was $0.16 \mathrm{~mW} / \mathrm{mm}^{2}$ using a 20x objective. EM gain was set to 200 and exposure time was $20 \mathrm{~ms}$. For $565 \mathrm{~nm}$ illumination (mKate2 imaging), light intensity for was $0.06 \mathrm{~mW} / \mathrm{mm}^{2}$ using a $20 \mathrm{x}$ objective. Light intensities were quantified using a light voltmeter (PM100A, Thorlabs). Samples were fixed on the microscope for long-term imaging experiments using a homemade aluminum sample holder for $3.5 \mathrm{~cm}$ plastic dishes. For ReaChR experiments, worms were fed with all-trans Retinal (Sigma, ATR). $20 \mu \mathrm{L}$ of a $0.2 \mathrm{mM}$ ATR solution was added to a seeded NGM plate and L3/L4 worms were placed on it. The plate was stored dark at $20^{\circ} \mathrm{C}$ in an incubator and were used for optogenetic experiments the following day. For control experiments worms grown without ATR were used.

For optogenetic experiments worms were placed into microchambers and imaged at a frame rate of 0.3 frame/s. The optogenetic experiment consisted of three parts. First, RIS GCaMP baseline activity was recorded for $5 \mathrm{~min}$, followed by a $5 \mathrm{~min}$ optogenetic activation period $\left(1.09 \mathrm{~mW} / \mathrm{mm}^{2}\right)$ while we continued to record GCaMP fluorescence. After the end of the activation period an additional 5 min of GCaMP fluorescence was recorded. Green light illumination for optogenetic activation was shuttered so that it only occurred in between the acquisitions. Each worm was probed optogenetically for 3 to 4 times with a break of at least 2 hours in between each trial. All trials for each worm were averaged to obtain one N. Individual worms that did not express ReaChR in the ALA neuron were identified post hoc and were censored.

\subsubsection{Reporter gene expression in RIS}

Genes enriched in the RIS transcriptome were tested with existing reporter strains reported in the literature to be expressed in RIS. Reporter strains expressing GFP were crossed with an mKate2-expressing reporter strain for RIS. mKate2 expression was

driven via the $f l p-11$ promoter. Cross progeny animals were immobilized in a $5 \mu \mathrm{L}$ drop of levamisole on a $200 \mu \mathrm{L}$ high-melting agarose pad on a glass slide and covered with a cover slip. Co-expression of both fluorescent gene reporters was either tested with a spinning disc system (488 nm, 565 nm lasers, Andor Revolution, Yokogawa CSU-X1, Nikon TiE) or on a standard widefield fluorescence microscope setup (Nikon TiE, LEDs $488 \mathrm{~nm}, 565 \mathrm{~nm})$. On both setups either 40x, 60x or 100x oil objectives were used. A 
z-stack was taken through the worm's head and the maximum projection was calculated. The gamma values for each color channel were adjusted for display.

\subsubsection{Mutant sleep screen during L1 arrest}

L1 arrest screening was done with AMI. Usually five strains plus a wild type (N2) control were filmed in one experiment. For this experiment, 12 pretzel stage eggs per strain were taken from a growing population and transferred into microchambers $(190 \mu \mathrm{m}$ x $190 \mu \mathrm{m}$ x $15 \mu \mathrm{m}$ ). Each egg was transferred using an eyelash into an individual chamber while care was taken to not transfer any food. The eggs of each strain were arranged in adjacent microchambers so that they formed a characteristic pattern and thus were unambiguously identifiable. After the agarose microchambers were sealed, they were placed into an incubator at $20^{\circ} \mathrm{C}$ in the absence of light for 48 hours, during which the worms hatched and arrested at the L1 larval stage. Then the arrested worms were imaged using DIC for $12 \mathrm{~h}$ with a frame rate of 0.2 frames/s and exposure time of $20 \mathrm{~ms}$ using a 10x objective combined with an additional $1.5 x$ lens (total magnification was $150 \mathrm{x}$ ). Sleep bouts were extracted for individual worms using frame subtraction and mutants with either significantly decreased or increased sleep fraction were retested. If the mutant strain had not yet been outcrossed against N2 after mutagenesis, it was outcrossed two times before retesting. If the phenotype persisted, it was outcrossed for an additional two times (to a total of $4 \mathrm{x}$ ) and tested again. Only mutations that produced a significant sleep phenotype after $4 \mathrm{x}$ outcrossing were scored as screen hits.

\subsubsection{Induction of cellular stress by heat shock}

All heat shock experiments were performed in young adult worms before the first egg was laid. AMI was used with chambers of the size $370 \mu \mathrm{m}$ x $370 \mu \mathrm{m} \times 45 \mu \mathrm{m} .8$ to 10 young adult worms were transferred into a $5 \mu \mathrm{L}$ drop of sterile distilled water placed on the agarose pad containing the microchambers with as little food as possible. While the liquid soaked into the agarose, individual worms were distributed into individual agarose microchambers with an eyelash. The microchambers were sealed with a cover slip and attached with double-faced adhesive tape to an opening of a metal plate that was part of a home-made temperature control device. The temperature control device contained the 


\section{Materials and Methods}

sample in a $10 \times 10 \mathrm{~mm}$ opening of a metal plate $(490 \times 200 \mathrm{~mm})$ and contact between the metal plate and the microchambers was created by filling the space with additional liquid agarose. The temperature of the metal plate and sample was measured by a Pt1000 temperature sensor that was placed in close proximity of the sample. Temperature was controlled by a Peltier element and its controller (Peltier-Controller TC0806, CoolTronic). The Peltier element transported energy from or to a metal grid acting as a heat sink, which itself was equilibrated with the surrounding air temperature using a small fan (Figure 5).

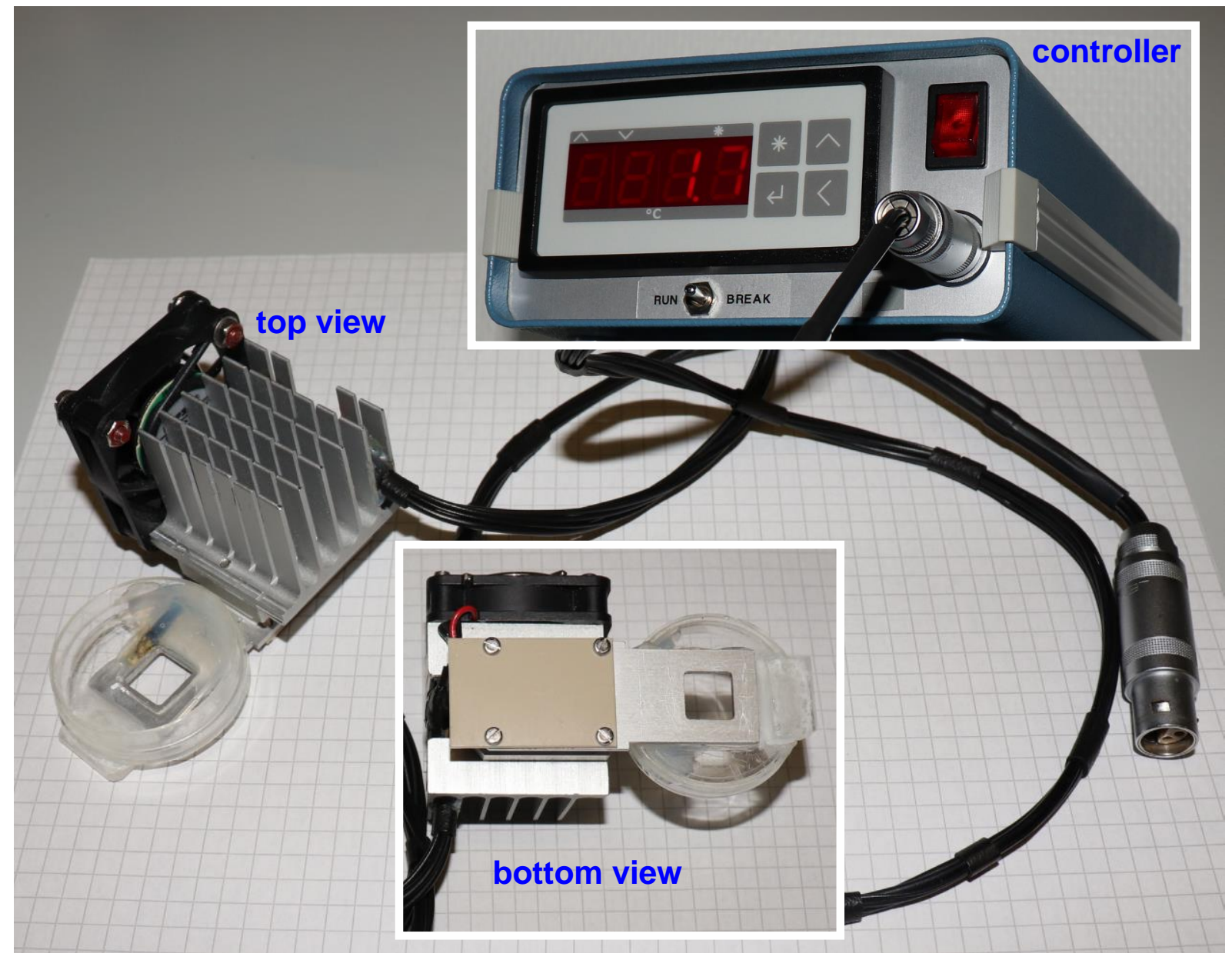

Figure 5 - Heat control device

An agarose microchamber on a glass slide can be placed in the hole of the metal plate (bottom view, right side), which is attached to a Peltier element. Heat is transported by the Peltier element from the metal plate to a metal grid, which is equilibrated with the surrounding air temperature using a small fan (top view). A small petri dish is also glued to the metal plate to allow the filling with agarose, serving as a moisture reservoir and creating contact between the metal plate and the microchambers. 
For the heat shock experiments, the device with the agarose pad and worms was stored in a dark $20^{\circ} \mathrm{C}$ incubator to equilibrate for 90 minutes. The device was then placed into a standard glass slide holder on an imaging microscope, connected to the Peltier controller and the temperature was set to $22^{\circ} \mathrm{C}$. The plastic dish containing the microchambers was closed by a heated lid, whose temperature was set to $25^{\circ} \mathrm{C}$ to avoid drying out of the sample and condensation on the lid. Each worm was imaged for 3 hours with a sampling rate of 0.05 frame/s. In the first 60 minutes, baseline activity was imaged. Then the heating lid temperature was turned to $37.5^{\circ} \mathrm{C}$ and after $3 \mathrm{~min}$ the Peltier-Controlled metal plate was set to $37,0^{\circ} \mathrm{C}$ for a duration of $20 \mathrm{~min}$ to deliver the heat shock. To end the heat shock, the Peltier-Controller was set to $22^{\circ} \mathrm{C}$ and the lid was set to $25,0^{\circ} \mathrm{C}$ again. After the end of the heat shock, imaging was continued for an additional $2 \mathrm{~h}$.

3.3.7. Induction of protein overexpression through temperature increase and $h s p-16.41 p$

For overexpression of $l i n-3$ and $f l p-24$, the $h s p-16.41$ promoter and a temperature increase was used (Nath et al., 2016; Cheryl Van Buskirk \& Sternberg, 2007). The handling procedure of delivering this temperature increase for inducing gene expression was the same as the procedure of delivering a heat shock. The only differences were the length and the magnitude of the temperature stimulus. The length was slightly increased from 20 to $30 \mathrm{~min}$ but the temperature was increased to only $30.0^{\circ} \mathrm{C}$ and the heating lid to only $30.5^{\circ} \mathrm{C}$, both for $30 \mathrm{~min}$. Worms were filmed for another 6 hours after the temperature increase, with $22^{\circ} \mathrm{C}$ and the lid set to $25.0^{\circ} \mathrm{C}$. Control experiments without the heat shockinducible transgene showed that this milder temperature increase was insufficient to trigger measurable stress-induced sleep.

\subsubsection{Lifespan assay}

Lifespan measurement were performed after heat shock similar to previously described. Briefly, a synchronized population of young adult worms was subjected to a heath shock and survival was followed (Hill et al., 2014; Kaeberlein et al., 2006). Worm populations were synchronized by isolating embryos and hatching them in the absence of food (Lewis $\&$ Fleming, 1995). For each strain, two $6 \mathrm{~cm}$ plates full with gravid hermaphrodites were 
taken. Worms were harvested by washing them off with $2 \mathrm{~mL} \mathrm{M9,} \mathrm{and} \mathrm{transfer} \mathrm{into} \mathrm{a} 1.5$ $\mathrm{mL}$ Eppendorf tube. Worm were pelleted by centrifugation at $4.8 * 10^{3} \mathrm{rcf}$, the supernatant was removed and $500 \mu \mathrm{L}$ of freshly prepared bleach solution was added to the pellet. To prepare the bleach solution, a stock solution of 1:1 1M NaOH solution and hypochlorite solution was diluted 1:2 with distilled water. Tubes with worms and bleach solution were mixed for 90 seconds by gentle manual agitation. Eggs were pelleted by centrifugation and the pellet was washed with $1 \mathrm{~mL} \mathrm{M9.} \mathrm{Pelleting} \mathrm{and} \mathrm{bleaching} \mathrm{was}$ repeated and followed by three washing steps with $1 \mathrm{~mL}$ of M9 each.

The isolated eggs were resuspended in $1 \mathrm{~mL}$ M9 and transferred to a clean $1.5 \mathrm{~mL}$ Eppendorf tube. The tube was placed on a spinning shaker overnight. On the next day eggs had hatched and larvae were arrested at the L1 stage. $200 \mu \mathrm{L}$ of each strain was pipetted on an NGM plate containing bacterial food. Worms were allowed to develop until the young adult stage in a dark $20^{\circ} \mathrm{C}$ incubator. For the heat shock a water bath (GFL, 1083) was heated to $40^{\circ} \mathrm{C}$, and the correct temperature was verified by the internal and an additional external thermometer of the water bath (Greisinger electronic, GMH3710). The temperature was monitored during the whole heat shock process. For each strain 50 young adult worms were transferred onto 5 NGM plates, to obtain exactly 10 worms per seeded plate. These plates were sealed with parafilm and simultaneously placed into the water bath. The plates were placed into the water so that the half that contained the agar with the worms was down and submerged in the water. After $20 \mathrm{~min}$, all plates were removed simultaneously from the bath and placed on ice for exactly 2 minutes. Water on the outside of the plates was removed with paper towels and the plates were stored in a dark incubator at $20^{\circ} \mathrm{C}$. Every $24 \mathrm{~h}$ worm survival was counted by an experimenter that was blind to the genotype of the worms. Each worm that was not spontaneously moving was stimulated with a short pulse (10-20 s) of blue LED light delivered by a stereomicroscope (Leica, M165 FC). If the worm reacted to this light stimulus it was scored as "alive". If no reaction was observed it was counted as "dead" and removed from the plate. Worms which could not be found on the plate, e.g. crawling up the plate wall and dry out, were counted as "censored".

\subsection{Quantification and statistical analysis}




\subsubsection{Sleep detection using frame subtraction}

All imaging data was saved as single tif files and were further analyzed using homemade MATLAB (MathWorks) routines. Sleep bouts were defined by immobility, which was detected using a frame subtraction algorithm as described (Nagy, Raizen, \& Biron, 2014). For the analysis, the image was cropped to only contain one microchamber containing one individual worm. For each frame, intensity values of each pixel were subtracted from the consecutive frame and the average of the absolute values for each frame was computed. The mean intensity was smoothed over 40 frames. The smooth function used was a robust version of a linear regression, which used weighted linear least squares and a 2nd degree polynomial model, by assigning lower weight to outliers in the regression (smooth ( $y$, method, 'rloess') ). Intensities of the smoothed data were then normalized with 1 presenting the highest intensity value, and 0 the lowest intensity value. A sleep bout during L1 arrest was defined as a smoothed normalized value that was lower than $40 \%$ of the maximum intensity for at least 120 seconds. The sleep bouts extracted from the data set for each worm were used to calculate the mean sleep bout length, sleep bout frequency, and fraction of time spent in sleep bouts. Individual traces in which no sleep bouts were visible by manual inspection were scored as not containing any sleep bouts. The fraction of time spent in quiescence was used as a main criterion to score phenotypes in the genetic screen. Data for different individuals was averaged and statistically compared with wild type N2 data obtained from an internal control (worms analyzed on the same agarose chip). In adult worms, sleep was defined by the same criteria as in L1 arrested larvae. To statistically compare after the heat shock, sleep data was binned by averaging data corresponding to time intervals of each $30 \mathrm{~min}$ following the heat shock.

Neuronal activity of the worms was measured with the green fluorescent calcium sensor GCaMP3 expressed either from the RIS-specific flp- 11 or from the ALA-specific $f l p-24$ promoter (Tian et al., 2009; Turek et al., 2016; Wu et al., 2018). RIS was extracted based on fluorescence intensity using a home-made MATLAB routine. For RIS extraction, the pixels of each frame were binned 4:1 and the highest intensity pixel was identified that defined the center of the RIS neuron. The $x-y$ position of this highest pixel was used to center a region of interest containing RIS and to crop this region from the original frame. The size of the region of interest was chosen to contain RIS and a limited amount of background (13 x 13 pixels for overexpression experiments and $21 \times 21$ pixels for 
optogenetic experiments). To identify RIS within the region of interest, its mean intensity was calculated and pixels that had a higher intensity than $25 \%$ of the mean of all pixels were counted as "signal". Pixels below 25\% mean signal intensity were counted as "background". To calculate RIS intensity, the mean of all "background" intensities was subtracted from the mean of all "signal" intensities. Accurate tracking by the software algorithm was manually controlled at four time points (first frame, the frame after $1 / 3$ of the movie, the frame after $2 / 3$ of the movie, and the last frame in the movie). Image series in which RIS could not be identified automatically were censored. ALA position was identified by manually selecting the center for cropping a region of interest. For this procedure, a semi-automatic MATLAB routine was used that performed the same downstream data analysis as the automatically tracking routine.

Neural intensities measured before applying the heat shock were used as baseline and data was normalized as difference over baseline $(\Delta \mathrm{F} / \mathrm{F})$. To determine sleep bouts in calcium imaging data sets, movement of the animal was detected based on the position of the center of the tracked head neuron. To extract sleep bouts, first the speeds were normalized, similar as described before but without any smoothing. Sleep was defined as time periods of less than $1.5 \%$ of the normalized movement speed.

\subsubsection{Statistical tests}

Statistical tests used were Wilcoxon rank tests for paired samples and Cox proportional hazards regression to test survival rates (both calculated in MATLAB). P values for differential expressed genes in the transcriptomes are results from a likelihood ratio test and have been adjusted for multiple testing using the Benjamini-Hochberg Procedure with a false discovery rate of $5 \%$ for FACS/RNA-seq data or $10 \%$ for sci-RNA-seq data, respectively (calculated in $\mathrm{R}$ ). The specific tests used are described in the figure captions and the results section. The graphs show mean \pm SEM unless noted. Compact boxplots were used for the visualization of L1 arrest screen data, with the box representing the 25\%-75\% range, the black dot representing the median and empty circle representing outliers. All other boxplot show individual data points, the box represents the $25 \%-75 \%$ range, and the thin gray line is the median. Whiskers for both types of boxplots corresponds to approximately $+/-2.7 \sigma$, which is 99.3 percent coverage if the data are 
Materials and Methods

normally distributed. Both types of boxplots were plotted via the (boxplot) function of MATLAB. For each experiment at least two biological replicates were performed and the number of biological replicates is stated in the figure legend. 


\section{Results}

All results described in this thesis are part of the manuscript we are currently writing. The manuscript is entitled "Epidermal Growth Factor signaling promotes sleep-active neuron depolarization to increase sleep following cellular stress". It is based on a collaborative project and the results presented in the section "Single RIS neuron Transcriptome" were produced by the collaboration partners as stated here: Generation of the FACS/RNA-seq raw data was done by research group of Professor David M. Miller, III, Ph.D., Vanderbilt University, Nashville, Tennessee, USA. The data used for the generation of all sci-RNAseq transcriptome was published by Cao et al. (2017). My colleague Max Fritz identified the clusters representing RIS and ALA neurons in the sci-RNA-seq data initially. Generation of the "FACS/RNA-seq RIS vs. all" transcriptome, and RIS sci-RNA-data transcriptomes "RIS vs all”, "RIS vs neuron", and "ALA vs neuron" from the present raw data was done by Dr. Andreas Leha from the Core Facility, Medical Biometry and Statistical Bioinformatics, „Universitätsmedizin Göttingen" (UMG), Germany.

The conditional allele let-23(zh131[FRT::let-23::FRT::GFP::LoxP::FLAG::let-23]) II., used in the section "The EGFR acts in ALA and RIS to induce sleep after cellular stress", was created and kindly provided by the research group of Prof. Dr. Alex Hajnal, University of Zurich, Switzerland.

\subsection{Single RIS neuron Transcriptome}

To identify the molecular pathways important in the sleep-active neuron RIS, I obtained three different RIS transcriptomes. One transcriptome was produced in a collaboration with the research group of Professor David M. Miller, III, Ph.D. via RNA-seq of fluorescence-activated cell sorted (FACS) RIS cells (Spencer et al., 2014). The other two transcriptome were extracted from the single cell transcriptome (SCT) dataset of Cao et al. (2017).

This Cao et al. dataset was produced by using sci-RNA-seq. They were able to create 42’035 SCTs spanning all L2 cells of C. elegans, which were sorted into according clusters. My colleague Max Fritz identified Cluster 13 as RIS, because of the highly enriched presence of the gene $f l p-11$ and aptf- 1 compared to all other neuronal clusters 
(Figure 6A and Figure 6B). Aptf- 1 is mainly and $f l p-11$ almost exclusively expressed in RIS (Turek et al., 2016, 2013). Cluster 13 had an $\operatorname{logFC}$ of 7.3 for $f l p-11$ compared to all neuronal clusters. In total, 60 genes were significantly upregulated, while 6 genes were significant less expressed in the 44 cluster 13 cells.

Gene expression of cluster 13 was also compared to gene expression in all L2 cells from the sci-RNA-seq data set and revealed a significantly enriched expression of aptf-1, C10C6.7, unc-25 and unc-47. These genes were reported before to be expressed in RIS (Jin, Jorgensen, Hartwieg, \& Horvitz, 1999; McIntire, Reimer, Schuske, Edwards, \& Jorgensen, 1997; Turek et al., 2016, 2013). It was an additional confirmation for cluster 13 consisting of RIS cells. In general this sci-RNA-seq RIS vs. all transcriptome had 381 significant differentially expressed genes, with 243 genes enriched and 138 de-enriched. So, two RIS sci-RNA-seq transcriptomes were obtained by either comparing cluster 13 to all L2 cells or to all neurons.

The transcriptome obtained by Prof. Miller group used FACS to collect a pool of RIS cells, which were used in the next step for RNA-seq (Spencer et al., 2014). They used a C. elegans strain HBR1261, which expresses the red fluorophore mKate2 under the flp11 promoter specifically in RIS. After dissociating L2 larvae, they were able to separate red glowing RIS neurons from all other non-fluorescent cells. Expression levels of genes in these RIS L2 cells were statistically compared to the gene expression of a dataset consisting of all C. elegans L2 cells. In the RIS dataset 1'188 genes were enriched and 3'183 genes were de-enriched.

An overlap list of the three transcriptomes, FACS/RNA-seq RIS vs all, sci-RNA-seq RIS vs all, sci-RNA-seq RIS vs neurons, contained 51 genes which were significantly enriched in all of them (Table 8). These genes are likely true-positive hits and might play a crucial role in RIS-dependent sleep regulation.

For validation of the combined RIS transcriptome, I checked the expression of 14 genes in RIS, for which fluorescent reporter strains were available. These strains were crossed with the RIS expressing mKate2 strain and checked under the microscope for colocalization. Six genes had already been reported before to express in RIS and were not checked again: unc-47 (McIntire et al., 1997), lim-6 (Hobert, Tessmar, \& Ruvkun, 1999), 
unc-25 (Jin et al., 1999), aptf-1 (Turek et al., 2013), C10C6.7 and flp-11 (Turek et al., 2016). The gene $s r d-32$ was recently reported to express in RIS but checked for confirmation (Vidal et al., 2018). Seven genes, nlp-11, ser-7, zig-2, sbt-1, ilys-4, plc-3 and let-23 I newly confirmed to express in RIS (Figure 6C and Figure 7). It is worth pointing out that three reporter, let-23,plc-3 and ilys-4 also expressed in the interneuron ALA (Gravato-Nobre, Vaz, Filipe, Chalmers, \& Hodgkin, 2016; C. Van Buskirk \& Sternberg, 2010; Cheryl Van Buskirk \& Sternberg, 2007). srd-32 was recently reported to express in RIS, which I confirmed here (Vidal et al., 2018). The three genes $n l p-11$, ser-7, and zig-2 just showed faint expression in RIS. Not all checked reporter strains colocalized in RIS as six strains did not show any visible expression there (Figure 8). These genes were $n l p-13, n l p-37, n l p-8, f l p-1$, ins-27, and ins-24.

A summary of the reporter check can be found in Figure 6D. Nine genes appeared in all three transcriptomes. The missing expression of six genes in RIS could be caused by either being false positive hits of the transcriptome or false negative reporter strains. The transcriptome derived from FACS/RNA-seq had all previously known and the newly discovered reporter. As it had a high number of enriched genes, more broadly expressed genes are presumably also in the list. The single-cell transcriptomes seemed to contain genes, which expressed in RIS much more specific. 


\section{Results}

A

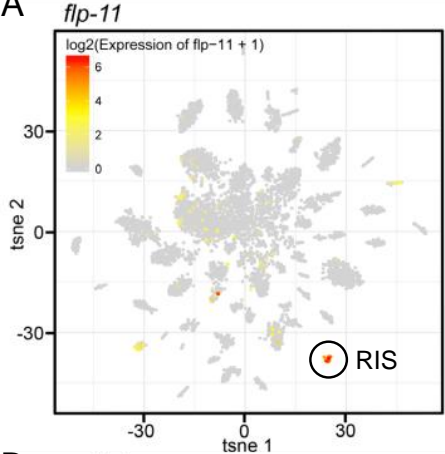

B

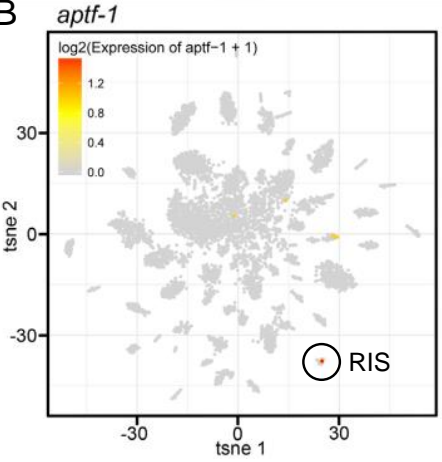

C Reporter

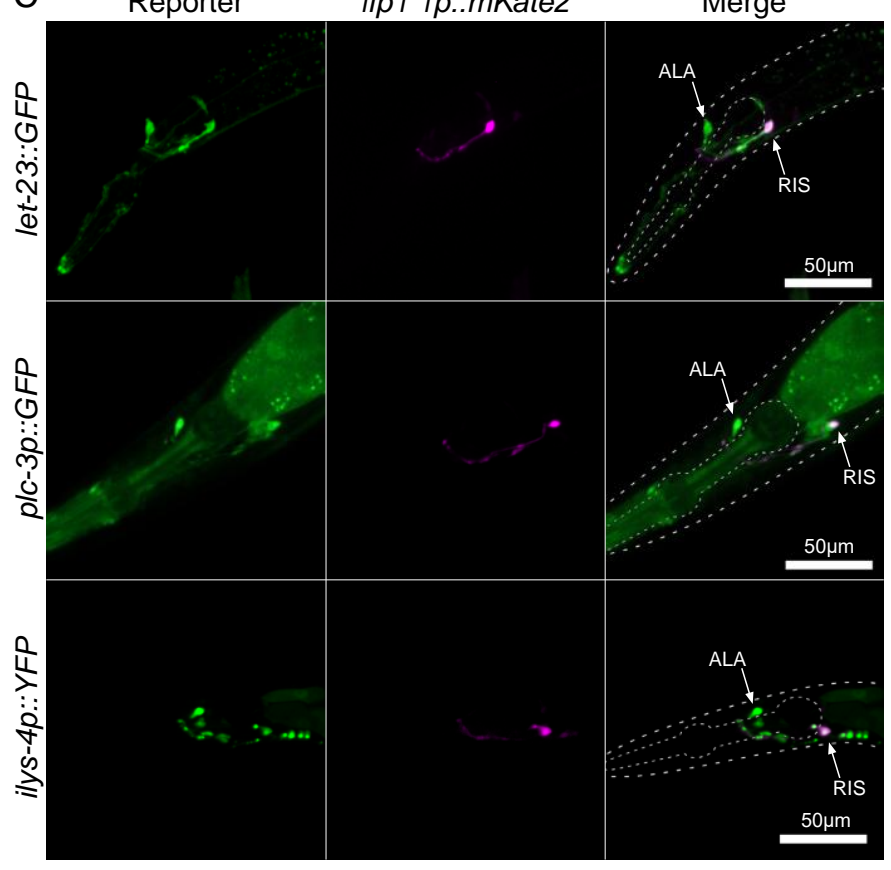

$\mathrm{D}$

\begin{tabular}{|l|l|ccc|}
\hline \multicolumn{1}{|c|}{ Gene } & \multicolumn{1}{|c|}{ Reporter } & $\begin{array}{c}\text { FACS/RNA-seq } \\
\text { [RIS vs all] }\end{array}$ & $\begin{array}{c}\text { sci-RNA-seq } \\
\text { [RIS vs all] }\end{array}$ & $\begin{array}{c}\text { sci-RNA-seq } \\
\text { [RIS vs neurons] }\end{array}$ \\
\hline flp-11 & Turek et al. (2016) & $\underline{\mathbf{9 , 8}}$ & $\underline{\mathbf{9 , 2}}$ & $\underline{\mathbf{7 , 3}}$ \\
C10C6.7 & Turek et al. (2016) & $\underline{\mathbf{9 , 8}}$ & $\underline{\mathbf{2 , 4}}$ & $\underline{\mathbf{1 , 1}}$ \\
aptf-1 & Turek et al. (2013) & $\underline{\mathbf{8 , 6}}$ & $\underline{\mathbf{1 , 3}}$ & $\underline{\mathbf{0 , 5}}$ \\
lim-6 & Hobert et al. (1999) & $\underline{\mathbf{7 , 2}}$ & 0,5 & 0,1 \\
unc-25 & Jin et al. (1999) & $\underline{\mathbf{6 , 2}}$ & 2,2 & 0,3 \\
unc-47 & Mclntire et al (1997) & $\underline{\mathbf{6 , 3}}$ & $\underline{\mathbf{1 , 7}}$ & 0,5 \\
srd-32 & Vidal et al. (2018) + Fig.7 & $\underline{\mathbf{6 , 6}}$ & 0,5 & 0,1 \\
let-23 & Fig.6C & $\underline{\mathbf{4 , 3}}$ & 2,2 & $\underline{\mathbf{1 , 5}}$ \\
plc-3 & Fig.6C & $\underline{\mathbf{3 , 4}}$ & $\underline{\mathbf{1 , 9}}$ & $\underline{\mathbf{1 , 0}}$ \\
ilys-4 & Fig.6C & $\underline{\mathbf{7 , 0}}$ & $\underline{\mathbf{3 , 4}}$ & 1,6 \\
sbt-1 & Fig.7 & $\underline{\mathbf{5 , 7}}$ & $\underline{\mathbf{4 , 1}}$ & $\underline{\mathbf{1 , 8}}$ \\
nlp-11 & Fig.7 & $\underline{\mathbf{7 , 5}}$ & $\underline{\mathbf{4 , 8}}$ & $\underline{\mathbf{2 , 7}}$ \\
ser-7 & Fig.7 & $\underline{\mathbf{4 , 7}}$ & $\underline{\mathbf{2 , 1}}$ & 0,8 \\
zig-2 & Fig.7 & 0,4 & $\underline{\mathbf{1 , 9}}$ & 0,6 \\
\hline nlp-8 & Fig.8 8 & $\underline{\mathbf{7 , 3}}$ & $\underline{\mathbf{5 , 1}}$ & $\underline{\mathbf{3 , 0}}$ \\
nlp-13 & Fig.8 & $\underline{\mathbf{7 , 5}}$ & $\underline{\mathbf{4 , 2}}$ & $\underline{\mathbf{2 , 2}}$ \\
nlp-37 & Fig.8 & 0,4 & $\underline{\mathbf{2 , 0}}$ & 0,7 \\
flp-1 & Fig.8 & 0,7 & $\underline{\mathbf{4 , 0}}$ & 1,7 \\
ins-24 & Fig.8 & $\underline{\mathbf{2 , 2}}$ & $\underline{\mathbf{1 , 8}}$ & 0,7 \\
ins-27 & Fig.8 & $\underline{\mathbf{3 , 3}}$ & $\underline{\mathbf{1 , 6}}$ & $\underline{\mathbf{0 , 6}}$ \\
\hline
\end{tabular}

Figure 6 - Sleep-active RIS neuron transcriptome computed from single-cell data

(A-B) Identification of RIS from sci-RNA-seq data. tsne-plots of all neuronal cells were color coded for log2 expression values of (A) flp-11 or (B) aptf-1.

(C-D) Validation of RIS enriched genes using fluorescent transgene reporters. (C) Example micrographs for let23::GFP, plc-3p::GFP, ilys-4p::GFP, and their co-localization with flp-11p::mKate2. Dashed lines display the outlines of the head and pharynx (anterior is left, dorsal is up). ALA and RIS are indicated with white arrows. Scale bar is $50 \mu \mathrm{m}$. (D) Table summarizing genes tested for fluorescence-reporter expression in RIS via colocalization of flp11p::mKate2 and comparison of RIS transcriptomes obtained by either bulk sequencing of FACS-isolated cells or sci-RNA-seq. Enrichment is displayed as log2FC and color coded with darker green color indicating more enrichment in RIS. Significantly enriched genes are displayed as bold and underlined. For statistical comparison a likelihood ratio test was used, adjusted for multiple testing using Benjamini-Hochberg ( $\alpha=5 \%$ for FACS/RNA-seq, $\alpha=10 \%$ for sci-RNA-seq). 


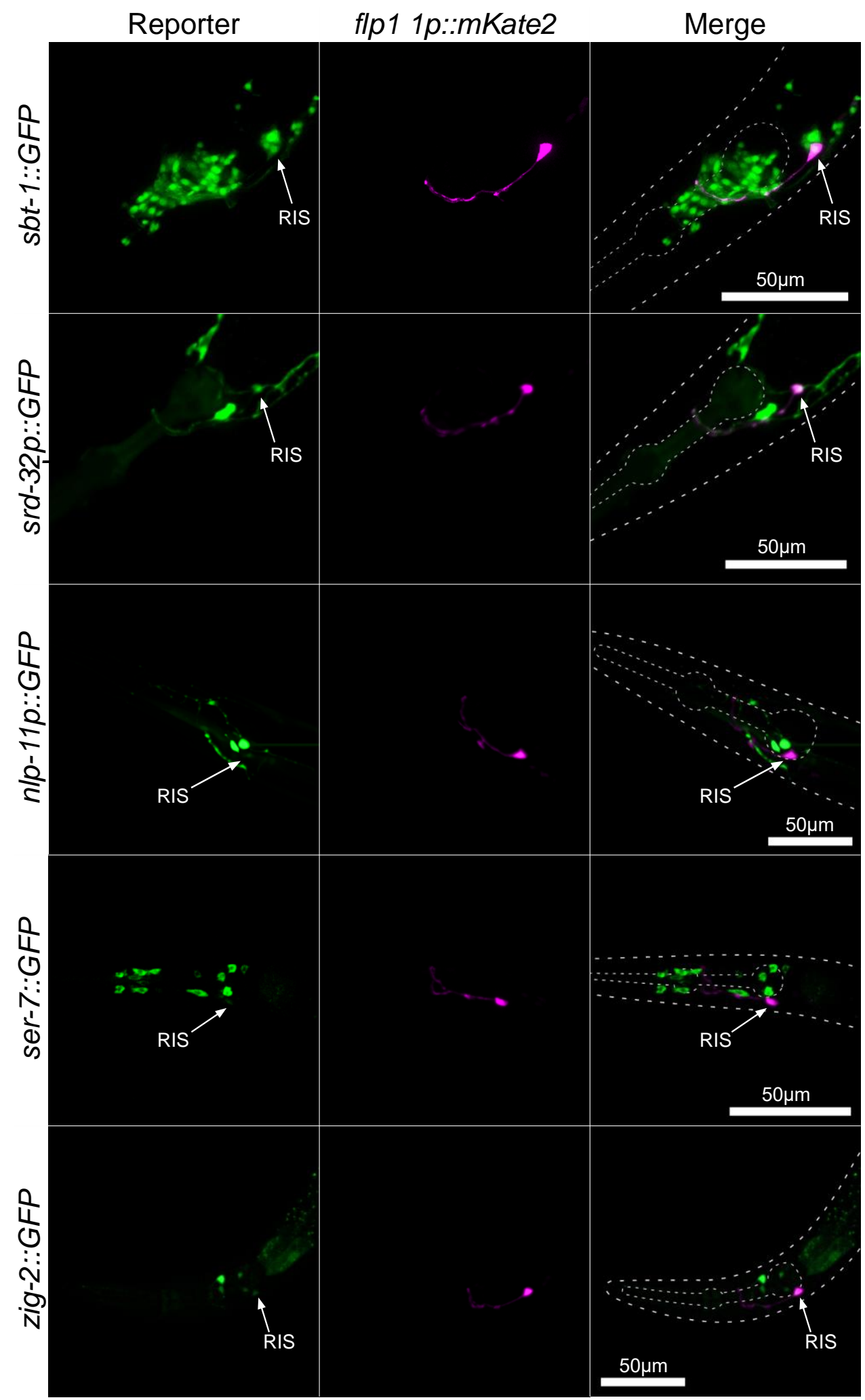

Figure 7-RIS enriched genes for which fluorescence transgene reporters are expressed in RIS

Validation of RIS enriched genes using fluorescent transgene reporters. Example micrographs for srd32p::GFP, sbt-1::GFP, nlp-11p::GFP, ser-7::GFP, zig-2::GFP, and their co-localization with flp-11p::mKate2. Dashed lines display the outlines of the head and pharynx (anterior is left, dorsal is up). RIS is indicated with a white arrow. Scale bar is $50 \mu \mathrm{m}$. 


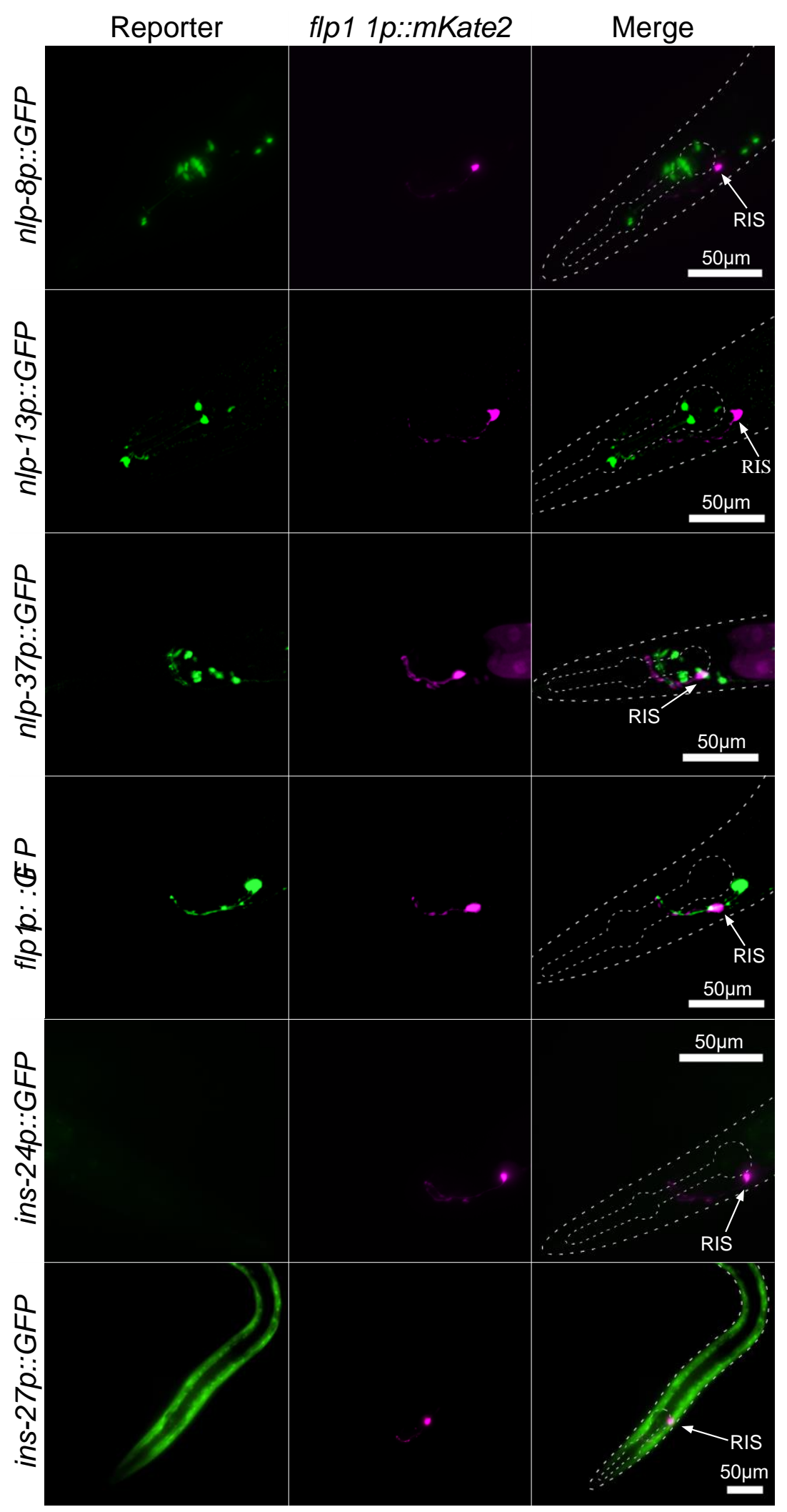

Figure 8 - RIS enriched genes for which fluorescent transgene reporters do not show RIS expression

Validation of RIS enriched genes using fluorescent transgene reporters. Example micrographs for $n|p-8 p:: G F P, n| p-13 p:: G F P, n \mid p-37 p:: G F P$, flp-1p::GFP, ins-24p::GFP, ins-27p::GFP, and their co-localization with flp-11p::mKate2. Dashed lines display the outlines of the head and pharynx (anterior is left, dorsal is up). RIS is indicated with white arrows. Scale bar is $50 \mu \mathrm{m}$. 


\subsection{RIS transcriptome-based L1 arrest screen}

To identify genes which play a role in the molecular control of RIS and sleep, I did a behavioral screen based on the newly obtained RIS transcriptomes. I was particular interested what really specifies RIS on a molecular level, so I focused on the sci-RNAseq transcriptome for the screen. I checked the top hits in the transcriptomes for the availability of severe genetic mutations. These were found via the online C. elegans gene and protein function search tool GExplore V1.4 (Hutter \& Suh, 2016). Missense mutations were excluded, while nonsense mutations, altered splicing sites, deletions, insertions, readthroughs, and complex changes were included in the screen. Approximately two-thirds of genes were covered with severe genetic mutations. 104 alleles were screened, with 43 alleles coming from the Million Mutation Project (MMP), 16 alleles from the "National Bioresource Project for the Experimental Animal Nematode C. elegans" from Japan and 45 alleles from other sources (Mitani, 2009; Thompson et al., 2013).

I used L1 arrest sleep for the behavioral screen, because it was not developmentally regulated like lethargus sleep. It was shown that $\mathrm{L} 1$ arrest is a robust sleep state (Wu et al., 2018). The L1 larvae were starved for 48 hours after hatching and then recorded with AMI for 12 hours. Worms showed short quiescence bouts without movement. Length and frequency of these bouts were quantified via image subtraction as well as the total quiescence fraction for the whole 12 hours (Nagy et al., 2014). Each strain carrying a mutation was statistically compared to N2 wild type worms. Strains which showed a significant difference were backcrossed against N2 wild type strain and their L1 arrest sleep was measured again. 16 alleles were excluded from the screen as the worms showed severe developmental problems. They often died in the egg or as an early L1 larvae, but if they still survived 48 hours without food, they were small and deformed so L1 arrest sleep could not be properly quantified. The excluded alleles were sma-1(e30), T21D12.12(gk191670), glb-23(gk205062), F54H5.5(gk335875), glb-32(gk360316), lmd4(gk389517), B0416.3(gk481746), lgc-4(gk509234), F57B10.4(gk712994), frpr16(gk722062), Y116A8B.4(gk869095), Y57G11C.36(gk961271), nhr-194(gk784872), ida-1(ok409), nlp-8(ok1799), and C39B10.1(ok2789).

Eight alleles showed movement quiescence, which deviated more than 50\% from the wild type mean and was significant (Figure 9A). Four alleles had less quiescence: 
aptf-1(gk794), flp-11(tm2706), goa-1(sa734), and frpr-3(gk240031). The other alleles showed more quiescence, e.g. $n h r-128(\mathrm{gk960157)}$. ilys -4 had two alleles, syb700 and $g k 402093$, which produced a similar increased fraction of L1 arrest sleep.

Another interesting hit was a gain-of-function allele (sa62) of let-23. This lead to a two times increased movement quiescence fraction in L1 arrest. As let-23 is the sole C. elegans homolog of the EGF receptor it was interesting to find out, that the two downstream pathways via PLC $\gamma /$ PLC-3 on the one side, and Grb2/SEM-5, Ras/LET-60, and Raf/LIN-45 on the other side were also enriched in the RIS transcriptome (Figure 9B). The IP3 receptor ITR-1, which is the downstream target of the PLC $\gamma /$ PLC-3, was de-enriched in Cluster 13. This was to be expected as it is broadly expressed in C. elegans (Moghal \& Sternberg, 2003). All canonical EGF signaling genes were expressed in RIS.

The presence of the EGF receptor signaling pathway in RIS suggests that not only ALA, but also RIS is involved in the EGF response to cellular stress (Cheryl Van Buskirk \& Sternberg, 2007). To check for more similarities an ALA vs. neurons sci-RNA-seq transcriptome was obtained similar to the RIS vs. neurons sci-RNA-seq transcriptome. A 22 cell-spanning sub-cluster of neuronal cluster 11 was identified to represent ALA because of the expression of $f l p-24, f l p-13$, and flp-7 (Nath et al., 2016; Nelson et al., 2014). ALA also expressed all canonical components of the EGF intracellular signaling pathway as previously reported (Figure 9C, Cheryl Van Buskirk and Sternberg 2007; Nath et al. 2016). Pairwise correlations of differential expression for all discernable neuronal transcriptomes and hierarchical clustering revealed a relatively low degree of similarity in gene expression for RIS and ALA (Figure 9D). Thus, ALA and RIS both express EGFR signaling components but otherwise their overall molecular contents are different suggesting that both neurons are activated by EGF but are functionally divergent. 
A

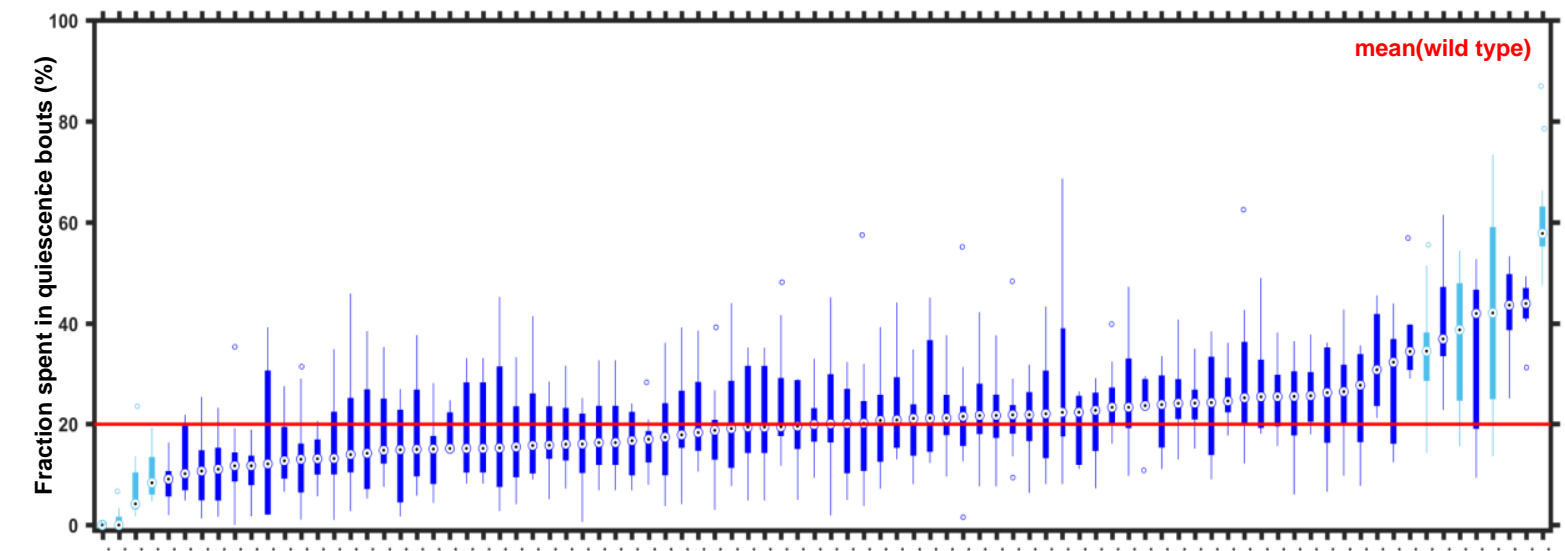

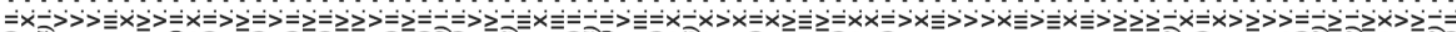
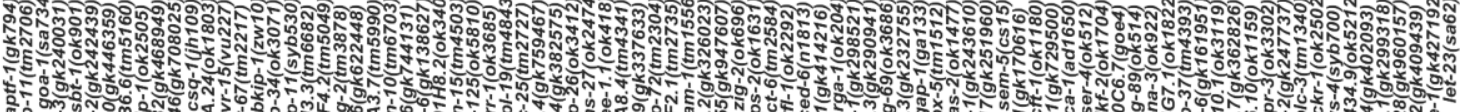

2. om

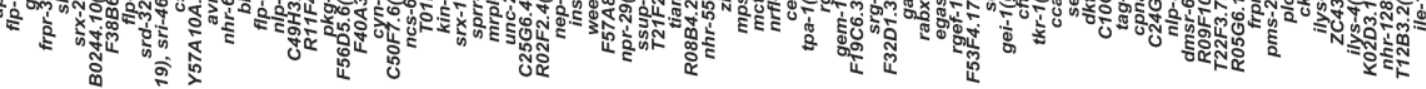

竞

B

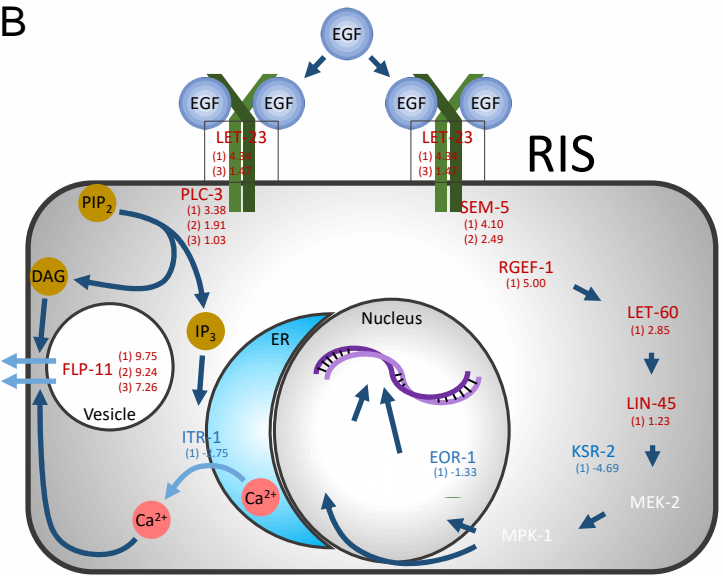

D

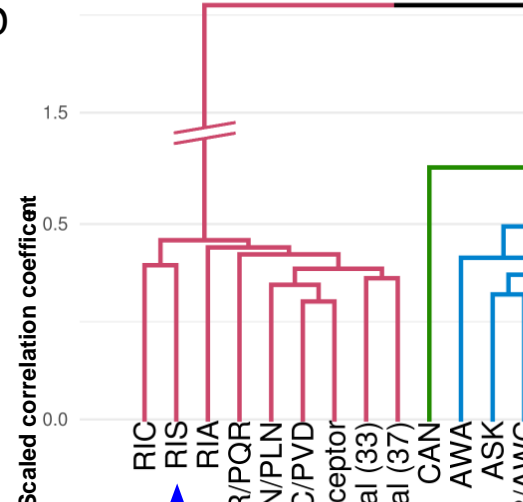

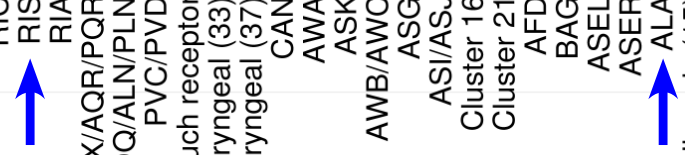

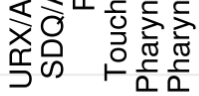

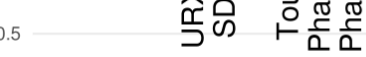

C

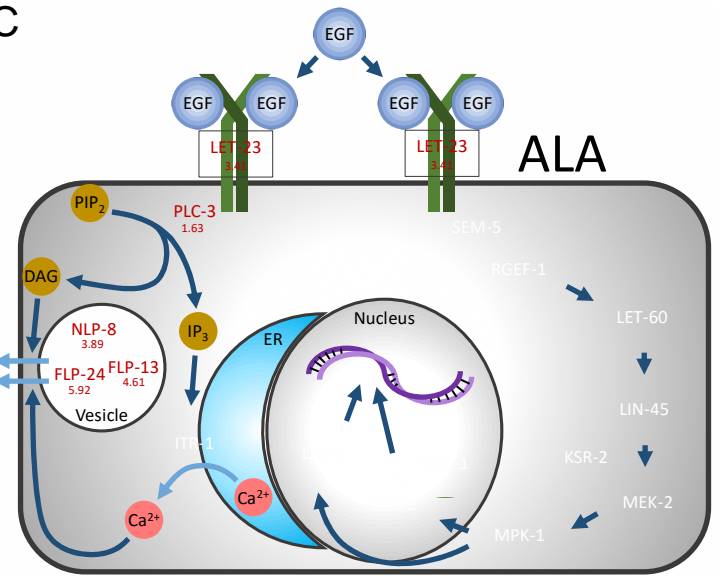

Correlation Based Clustering

Clusters are clustered according to the logFC 
Figure 9-The EGFR signaling machinery is expressed in both ALA and RIS neurons

(A) L1 arrest sleep screen for mutants of genes that are enriched in RIS. Every allele screened is represented by a blue boxplot (alleles are on the $x$-axis, fraction (\%) spent in movement quiescence on the $\mathrm{y}$-axis), wild type mean is displayed as a red line. Alleles that deviated more than $50 \%$ of the wild type mean and were significantly different to the respective control data are indicate in turquoise, $p<0.05$, Wilcoxon signed-rank test. The strongest increase of sleep is seen in a gain-of-function mutation of let-23. (B-C) Both ALA and RIS express EGF pathway components. Shown are enrichments of canonical EGFR signaling components in RIS (B) and ALA (C). Proteins (green) or neuropeptides (light blue), which were found to be significantly differentially expressed in at least one of the transcriptomes are indicated (enriched is red, de-enriched is blue, no significant change is white). (B) Gene expression changes are displayed as log2FC ((1) indicates RIS vs. all, FACS/RNA-seq; (2) indicates RIS vs. all, sci-RNA-seq; (3) indicates RIS vs. neuron, sci-RNA-seq). (C) Gene expression changes are displayed as log2FC (ALA vs. neuron, sci-RNA-seq). PIP2: phosphatidylinositol 4,5-bisphosphate, IP3: inositol trisphosphate, DAG: diacylglycerol, ER: endoplasmic reticulum. Likelihood ratio test, adjusted for multiple testing using Benjamini-Hochberg, $\alpha=5 \%$ for FACS/RNA-seq, $\alpha=10 \%$ for sci-RNA-seq.

(D) Despite an overlap of expression of EGFR signaling components, RIS and ALA are divergent in overall gene expression. Correlation-based clustering of all neuronal clusters identified from single-cell sequencing. Scaled correlation coefficient with 0 meaning perfect positive correlation and 2 meaning perfect negative correlation. Blue arrows indicate the clusters corresponding to RIS and ALA.

\subsection{The EGFR acts in ALA and RIS to induce sleep after cellular stress}

As the let-23(gf) allele produced a much-increased sleep in L1 arrest and I discovered it is expressed in both known sleep neurons, ALA and RIS, the question how much each neuron is contributing to the phenotype came up. To test their roles, I genetically ablated each neuron in the let-23(gf) mutation background and measured the L1 arrest quiescence fraction. RIS ablation was achieved by the $f l p-11$ promoter-driven expression of the apoptosis inducer egl-1 (Wu et al., 2018). ALA was functionally ablated by a mutation in the $C$. elegans homeobox gene ceh-17. The allele ceh-17(np1) disturbs the expression of a group of genes in ALA, including let-23 and plc-3, while additionally interfering with its process outgrowth (C. Van Buskirk \& Sternberg, 2010). RIS ablation completely eliminated L1 arrest sleep in the let-23(gf) mutant. ALA ablation on the other hand caused a decrease of L1 arrest quiescence duration, although still being increased compared to wildtype levels (Figure 10A). This result showed that both sleep neurons are responsible for the increased sleep in the let-23(gf) mutant. ALA caused some mild increase in the EGFR-triggered quiescence duration but RIS was needed to induce those sleep bouts in the first place while also increasing their summed duration. 
This result and the newly discovered occurrence of the EGFR signaling pathway in RIS led to the hypothesis that ALA is not the sole inducer of EGF-caused sleep, as previously reported (Hill et al., 2014; Nath et al., 2016; Nelson et al., 2014). To test this hypothesis, I heat shocked worms for 20 minutes at $37^{\circ} \mathrm{C}$ in a functionally ablated background of RIS, ALA, or both. RIS functionally ablation was caused by the mutated AP2 transcription factor aptf-1 (Turek et al., 2013). The heat shock was applied via a Peltier element to young adult worms in agarose microchambers. This setup allowed the quantification of sleep behavior before, during, and after the heat shock.

Wild-type worms showed no sleep before the heat shock, complete immobility during, and rhythmic bouts of quiescence until one hour after the heat shock. In the aptf-1(-) mutant, the number of worms quiescent during the heat shock was reduced by at least $20 \%$, and worms showed almost none quiescence after it. Worms with ceh-17(-) immobilized slower during the heat shock and had fewer sleep bouts after it. While wildtype worms showed SIS for around $40 \%$ of the first half hour after the heat shock, worms with an functionally ablated ALA showed less than $10 \%$ SIS and functionally ablated RIS had almost no SIS during that period. The ceh-17(-) and aptf-1(-) double mutant showed quiescence levels between the levels of the two alleles alone. Although a part of this quiescence seemed to come from an extension of the immobility caused by the heat shock, suggesting that double ablation perhaps caused some unspecific quiescence (Figure 10B-G). The experiment confirmed the previously reported influence of ALA on SIS (Goetting, Soto, \& Van Buskirk, 2018; Hill et al., 2014; Cheryl Van Buskirk \& Sternberg, 2007). Additionally, it was shown that RIS also takes a vital role in controlling SIS by being responsible for the induction of sleep bouts. 


\section{Results}
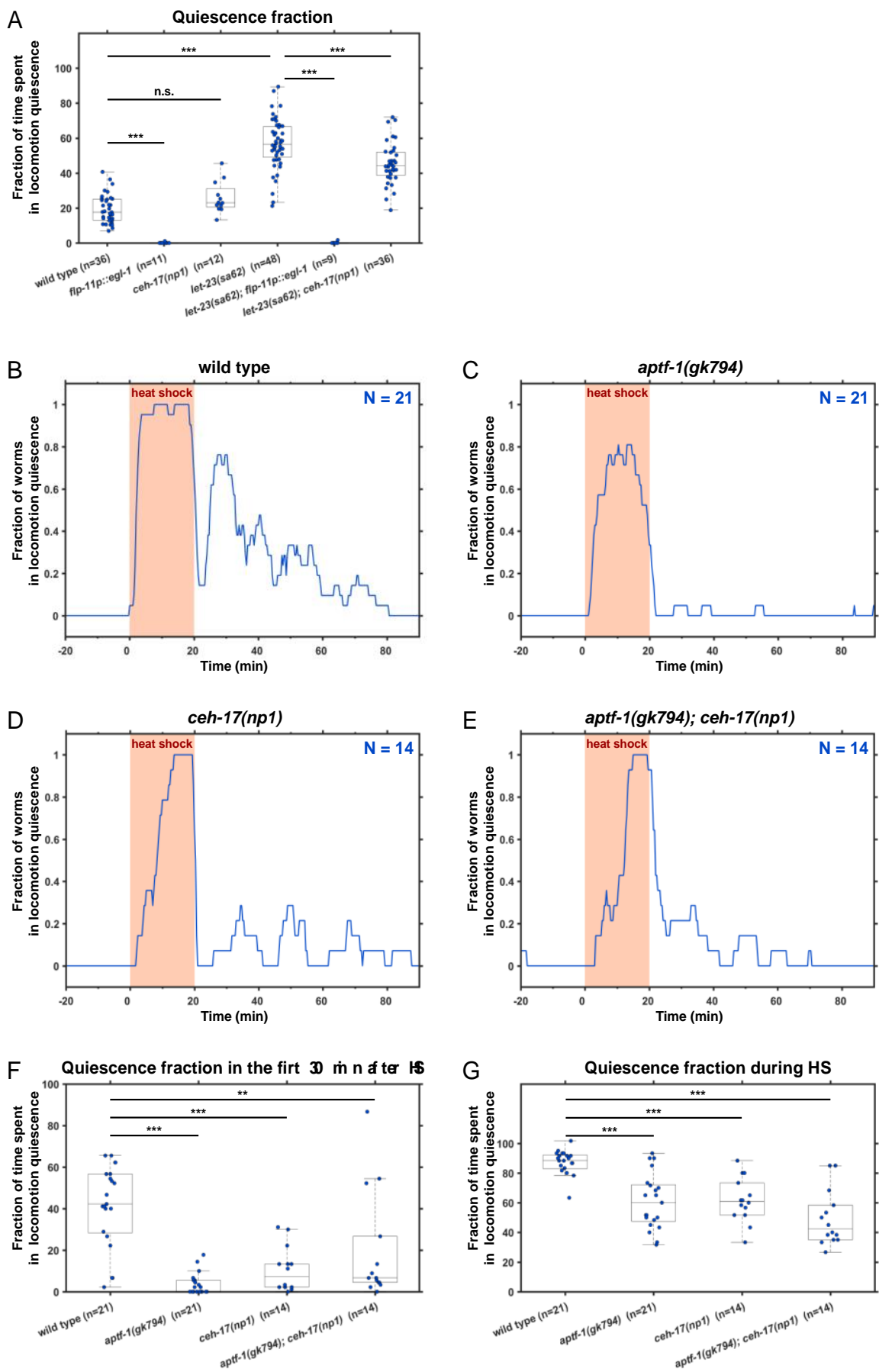

Figure 10 - ALA and RIS are required for sleep after EGFR activation and cellular stress

(A) ALA and RIS are required for sleep caused by let-23gf during L1 arrest. Fraction of time spent in sleep during L1 arrest was measured by quantifying locomotion quiescence. ceh-17(-) partially suppressed the increase of sleep caused by let-23gf. RIS-ablation suppressed virtually all sleeping behavior.

(B-E) ALA and RIS are required for sleep induced by cellular stress. The fraction of worms is shown vs. time, with the time during which the heat shock $\left(37^{\circ} \mathrm{C}\right)$ was applied is indicated in orange. $\mathrm{N}$ is number of worms; three biological replicates were performed for each genotype. (B) Wild type worms immobilized during heat shock and showed a series of consecutive quiescence bouts during the 60 minutes after the heat shock. (C) aptf-1(-) showed reduced movement quiescence during the heat shock and almost no quiescence was seen following the heat shock. (D) ceh-17(-) mutants took longer to immobilize during the heat shock and sleep bouts were reduced following the heat shock. (E) aptf-1(-); ceh-17(-) double mutation reduced quiescence, albeit not as strongly as aptf-1(-) alone.

(F-G) Quantification of locomotion quiescence. ${ }^{* * *}$ denotes statistical significance with $\mathrm{p}<0.001, * *$ denotes statistical significance with $p<0.01$, Wilcoxon signed-rank test. 
The neuronal ablation experiments showed that both ALA and RIS are required to promote sleep following EGFR activation. The question was if EGFR signaling was needed for SIS in RIS, like it was reported for ALA (Cheryl Van Buskirk \& Sternberg, 2007). This was checked via a specific knock-out of the EGFR gene let-23 in RIS. I used a conditional allele $z h 131$ of let-23, in which a critical exon is flanked by frt sites and can thus be removed through FLPase-induced recombination (Davis, Morton, Carroll, \& Jorgensen, 2008; Hubbard, 2014; Voutev \& Hubbard, 2008). Besides the frt sites, a gfp gene was incorporated close to the 3' end of the let-23 gene, so a LET-23::GFP fusion protein was produced. The FLPase expression in my experiments was driven by the unc-47 promoter, which expresses in RIS but not ALA. Via microscopy imaging, I could confirm that the fluorescent LET-23::GFP was present in ALA and RIS, while being absent in RIS in worms with unc-47p::FLP background (data not shown). Applying a heat shock $\left(37^{\circ} \mathrm{C}, 20 \mathrm{~min}\right)$ to worms carrying both, frt-flanked let-23 and unc-47::FLP, reduced SIS to roughly 50\% compared to the parental strains (Figure 11). Thus, EGF signaling is required in both ALA and RIS to promote sleep following heat shock. These results suggest a model in which EGF is released following cellular stress and activates both ALA and RIS, which act concertedly to induce sleep. The consistently stronger effect of RIS impairment on sleep bouts compared with ALA impairment suggests that ALA might act upstream of RIS. 
A

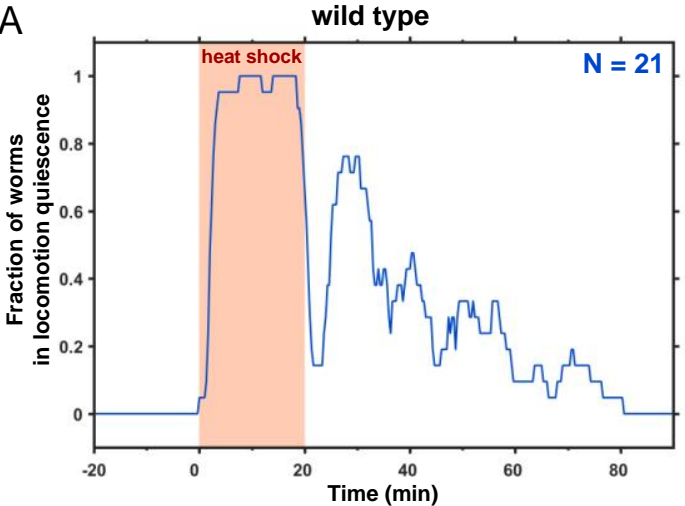

C

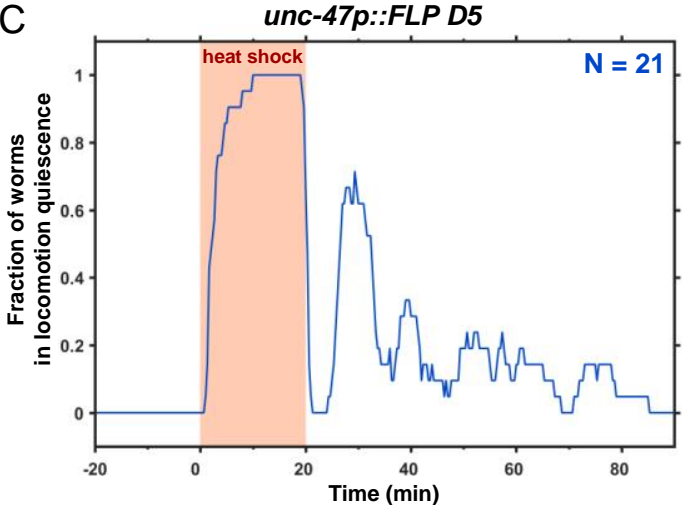

E Quiescence fraction in the firt $\mathbf{3 0}$ in $\mathbf{n}$ a ter $1 \$$

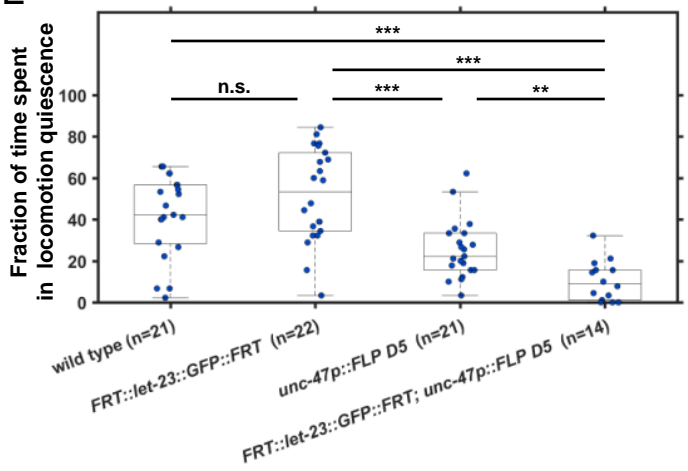

B

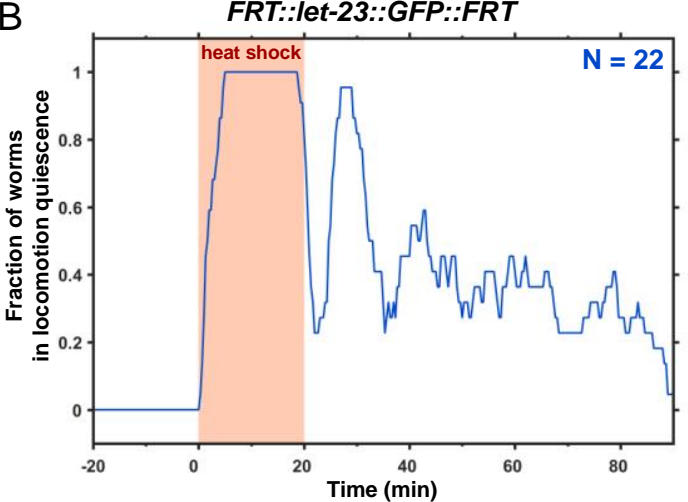

D

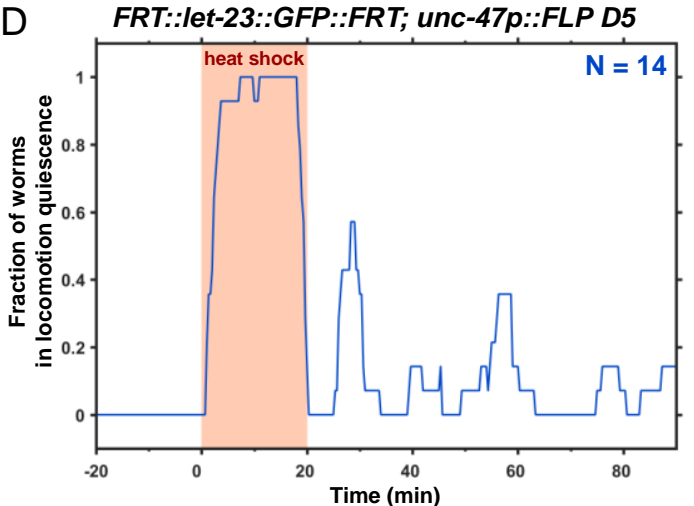

$\mathrm{F}$

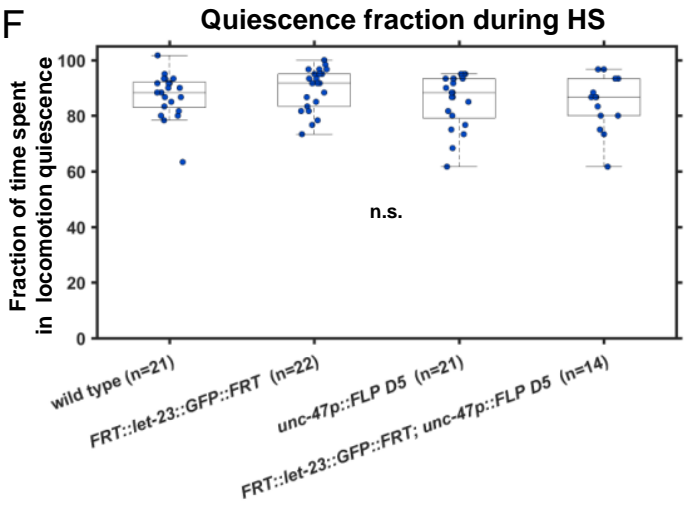

Figure 11 - EGFR is required in RIS to increase sleep after cellular stress

(A-D) RIS-specific knockdown of let-23 reveals a role for EGFR in RIS following cellular stress, in addition to the known role of EGFR in ALA (Cheryl Van Buskirk and Sternberg 2007). The heat shock $\left(37^{\circ} \mathrm{C}\right.$ ) is indicated in orange. $\mathrm{N}$ indicates number of worms; three biological replicates were performed for each genotype. (A) is the same data as in Fig.3B. (B-C) behavior of the parental strains following a heat shock. (B) The conditional allele of let-23, FRT::let-23::GFP::FRT, was created using CRISPR/Cas9.

(C) The recombinase (FLPase) was expressed in GABAergic neurons, unc-47p::FLP D5, which include RIS, but no expression was detectable in ALA with this promoter (data not shown).

(D) Worms with a conditional knockdown of let-23 in RIS, unc-47p::FLP D5; FRT::let 23::GFP::FRT, displayed reduced quiescence. (E-F) Quantification of locomotion quiescence during and after the heat shock in the conditional strain and in the parental controls. ${ }^{* * *}$ denotes statistical significance with $p<0.001$, Wilcoxon signed-rank test. 


\subsection{Cellular stress and EGF signaling depolarize ALA and RIS}

Calcium imaging and optogenetic manipulation of RIS and ALA have suggested that these neurons act through depolarization (Nelson et al., 2014; Turek et al., 2013). To test whether cellular stress and EGF depolarizes RIS and ALA, I measured calcium activity in these neurons after heat shock or overexpression of the EGF gene lin-3.

First, I measured the RIS activity with AMI in young adult, which were exposed to a $37^{\circ} \mathrm{C} 20$ min heat shock. RIS also showed an activity peak at the onset of the heat shock, which was reported before. Upon temperature increase, RIS activated strongly while the animal immobilized, which is consistent with a previously identified increase of RIS during temperature increase (Kotera et al., 2016). Following that, RIS showed rhythmic transients of around 10 minutes, which also highly correlated with worm quiescence bouts (Figure 12A). Typically, three to four consecutive RIS transients and sleep bouts lasting each for about 12 minutes were observed, with the first transient being the strongest and subsequent transients displaying reduced intensity until the succession of transients ceased after about one hour. RIS transients and behavioral quiescence correlation were already shown in lethargus and L1 arrest sleep (Turek et al., 2013; Wu et al., 2018). ALA ablation resulted in a strong reduction of RIS activity, hinting again that ALA might act upstream of RIS (Figure 12B).

To test for the effects of EGF upon RIS activation, I overexpressed this signaling protein using a heat-shock promoter. I induced expression with a temperature increase that is not sufficient to trigger subsequent sleep. Overexpression of EGF induced immobility and led to a strong increase of RIS calcium activity (Figure 12C). Immobilization of the worms after LIN-3 overexpression was reported before (Cheryl Van Buskirk \& Sternberg, 2007). RIS calcium imaging in let-23(gf) mutant animals showed that RIS is already active during baseline condition and cannot be activated much further following EGF overexpression (Figure 12D).

Next, I used calcium imaging in ALA, by expressing the calcium sensor GCaMP under the $f l p-24$ promoter. After a $37^{\circ} \mathrm{C} 20$ min heat shock, ALA activated to roughly $150 \%$ and slowly dropped again to baseline levels. Although the time ALA was active 
corresponded to the period worms showed quiescence bouts, ALA activity did not correlate well with the sleep state of the animal, i.e. correlation analysis showed that ALA did not activate specifically during sleep bouts but are more broadly associated with the time during which sleep bouts occur (Figure 12E). Overexpression of EGF increased the calcium activity of ALA substantially, the calcium increase was even much stronger than that following a heat shock (Figure 12F).

These results show that cellular stress and EGF increase calcium activity of RIS and ALA. Intriguingly, the activation kinetics of these neurons differed. ALA activity correlated with the time during which sleep bouts occurred, but calcium activity did not correlate strongly with the actual sleep state. By contrast, RIS activation transients directly correlated with the occurrence of sleep bouts. The different calcium kinetics of ALA and RIS suggest that these neurons act by different mechanisms, with ALA inducing sleep bouts indirectly and RIS inducing sleep bouts directly. Together with the reduction of RIS calcium transients in the absence of ALA these kinetic changes suggest that ALA activates RIS to induce sleep bouts. ALA activating RIS could be a second pathway to induce sleep next to RIS independent quiescence induction (Trojanowski, Nelson, Flavell, Fang-Yen, \& Raizen, 2015).

ALA has been proposed to induce sleep by calcium-induced secretion of multiple neuropeptides that may act by a diffusional mechanism, but ALA also has been shown to control locomotion behavior and sleep through synaptic mechanisms (Fry, Laboy, \& Norman, 2014; M. Katz, Corson, Iwanir, Biron, \& Shaham, 2018; Nath et al., 2016; Nelson et al., 2014). To test whether ALA activates RIS, I optogenetically activated ALA and recorded RIS depolarization via GCaMP activity. The red-shifted variant of the lightactivated channelrhodopsin ReaChR was expressed via the flp-24 promotor specifically in ALA. ReaChR in ALA was activated by green light in the presence of retinal for 5 minutes. RIS depolarized during ALA activation, which dropped to baseline levels after the stimuli had stopped (Figure 12G). This showed RIS could be activated by ALA. 
A

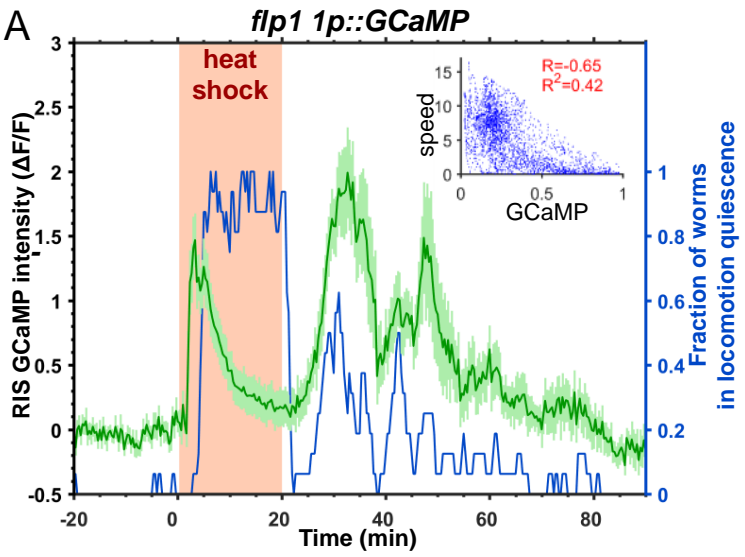

C

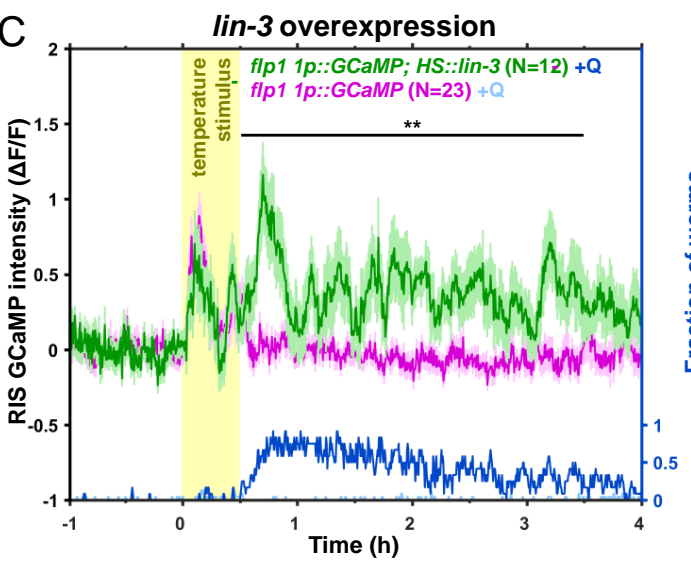

E
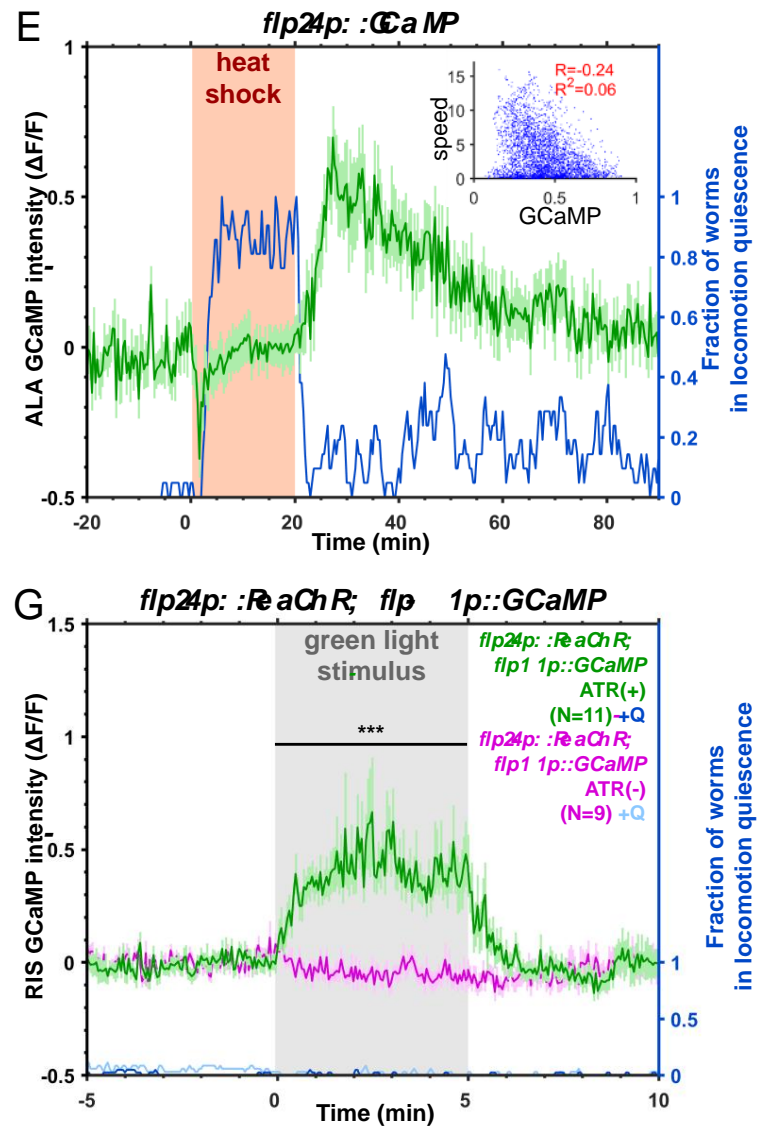
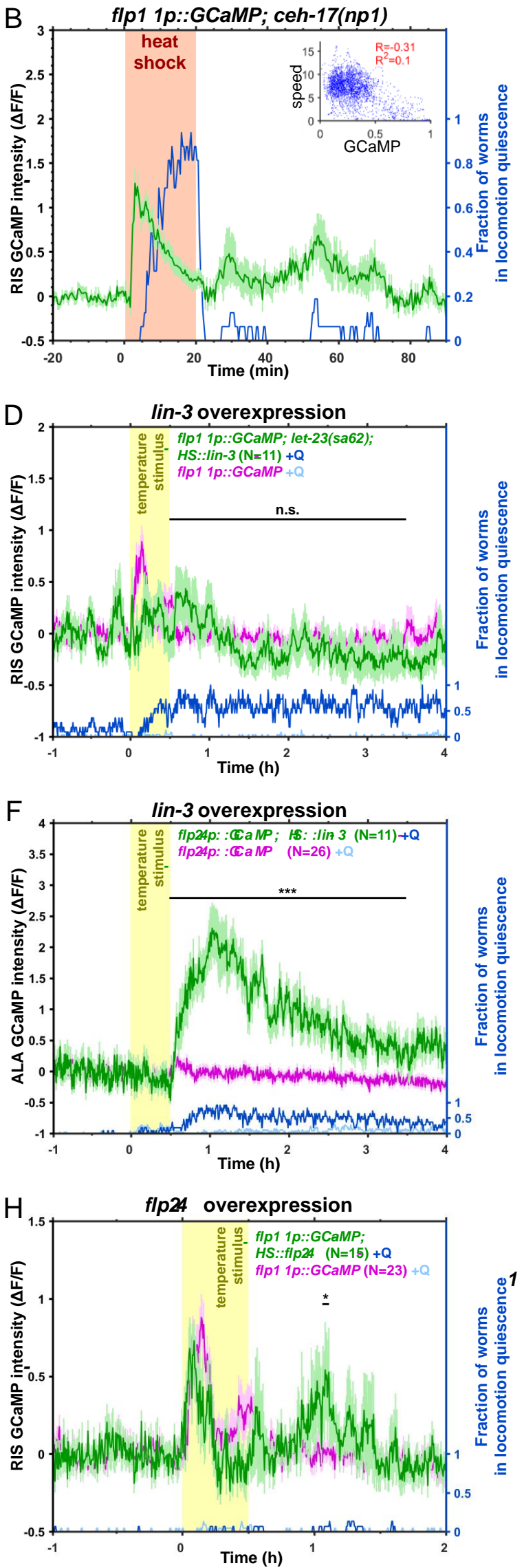
Figure 12 - Heat shock and EGF activate RIS and ALA, and ALA acts upstream of RIS

(A) Calcium activity of RIS following a heat shock $\left(37^{\circ} \mathrm{C}\right.$, orange). flp-11p::GCaMP intensities are shown in green, and the fraction of worms in locomotion quiescence is shown in blue. The insert shows a correlation of normalized, smoothed GCaMP intensities with speed $(\mu \mathrm{m} / \mathrm{s})$ for the first $60 \mathrm{~min}$ after the heat shock, with Spearman's rank correlation coefficient. Calcium activity peaks during the first part of the heat shock and shows several transients following the heat shock. RIS calcium transients correlate with locomotion quiescence.

(B) ceh-17(-) reduces RIS calcium activity following the heat shock.

(C) EGF over expression induces RIS calcium activity. Overexpression is induced by a temperature increase $\left(30^{\circ} \mathrm{C}\right.$, yellow). Control flp-11p::GCaMP (without EGF overexpression transgene) intensity (magenta) $\pm S E M$, according fraction of worms in movement quiescence (light blue).

(D) EGF over expression in let-23(gf) does not further increase RIS calcium activity. let-23(gf) leads to movement quiescence already before the heat shock, while no increase in GCaMP activity can be seen.

(E) A heat shock causes subsequent ALA calcium activation. GCaMP activity does not increase during the heat shock but after the heat shock. Neural activity and locomotion quiescence do not correlate well.

(F) EGF overexpression by temperature increase induces massive ALA activation.

(G) Optogenetic activation of ALA by green light (indicated in grey) causes RIS calcium activation (green). Control (without retinal) flp-11p::GCaMP intensity (magenta). Movement quiescence is shown in light blue.

(H) Overexpression of flp-24 by a heat shock promoter and temperature increase $\left(30^{\circ} \mathrm{C}\right.$, yellow) induces RIS calcium transients.

Error is $\pm \mathrm{SEM}, * * *$ denotes statistical significance with $\mathrm{p}<0.001, * *$ denotes statistical significance with $\mathrm{p}<0.01, *$ denotes statistical significance with $\mathrm{p}<0.05$, Wilcoxon signed-rank test.

As ALA releases sleep-inducing neuropeptides upon activation, I checked if overexpression of one of the most prominent neuropeptide genes in ALA, flp-24, could activate RIS. A heat shock promoter-driven overexpression of flp-24 was used. Overexpression was again achieved by a $30^{\circ} \mathrm{C} 30 \mathrm{~min}$ temperature stimulus, which did not trigger endogenous heat shock responses. RIS showed a modest but significant GCaMP activation after flp-24 overexpression in the worm (Figure 12H).

I demonstrated, ALA can act upstream of RIS to induce SIS via the neuropeptide FLP24. Although ALA activation strongly increases RIS activation during SIS, RIS is also able to induce SIS quiescence after EGF/LIN-3 activation by itself. Thus, a model emerges in which EGF activates both ALA and RIS, with ALA inducing behavioral quiescence that includes the promotion of RIS activation, which induces sleep bouts. 


\subsection{ALA rather than RIS support survival after stress}

ALA and RIS seemed to trigger SIS through two distinct mechanisms and ALA dependent SIS was shown to be beneficial for survival after cellular stress (Goetting et al., 2018; Hill et al., 2014). This raised the question if RIS dependent SIS is also beneficial for the lifespan of the worm after cellular stress. Worms carrying either the ceh-17(-), the aptf-1(-), or both mutations were heat shocked in a $40^{\circ} \mathrm{C}$ water bath for 20 minutes, and their survival was tracked. Worms with the ceh-17(-) or the double mutant died around 2 days earlier than wild type worms (Figure 13). The lifespan data of the ceh-17(-)mutation was in line with the literature (Hill et al., 2014). Aptf-1(-) mutant was indistinguishable from the wild type. ALA activity seemed to mediate protective functions for cellular stress independent of RIS and its acute quiescence bouts. ALA seemed to have a rather sedating effect compared to RIS induced acute sleep bouts. Although the function of those acute sleep bouts in the event of cellular stress is unknown so far, it was shown now that RIS is also an important player in SIS. Cellular stress causes two different types of behavioral quiescence via two different neurons with distinct mechanistic properties and functions. 
A

Life span after heat shock
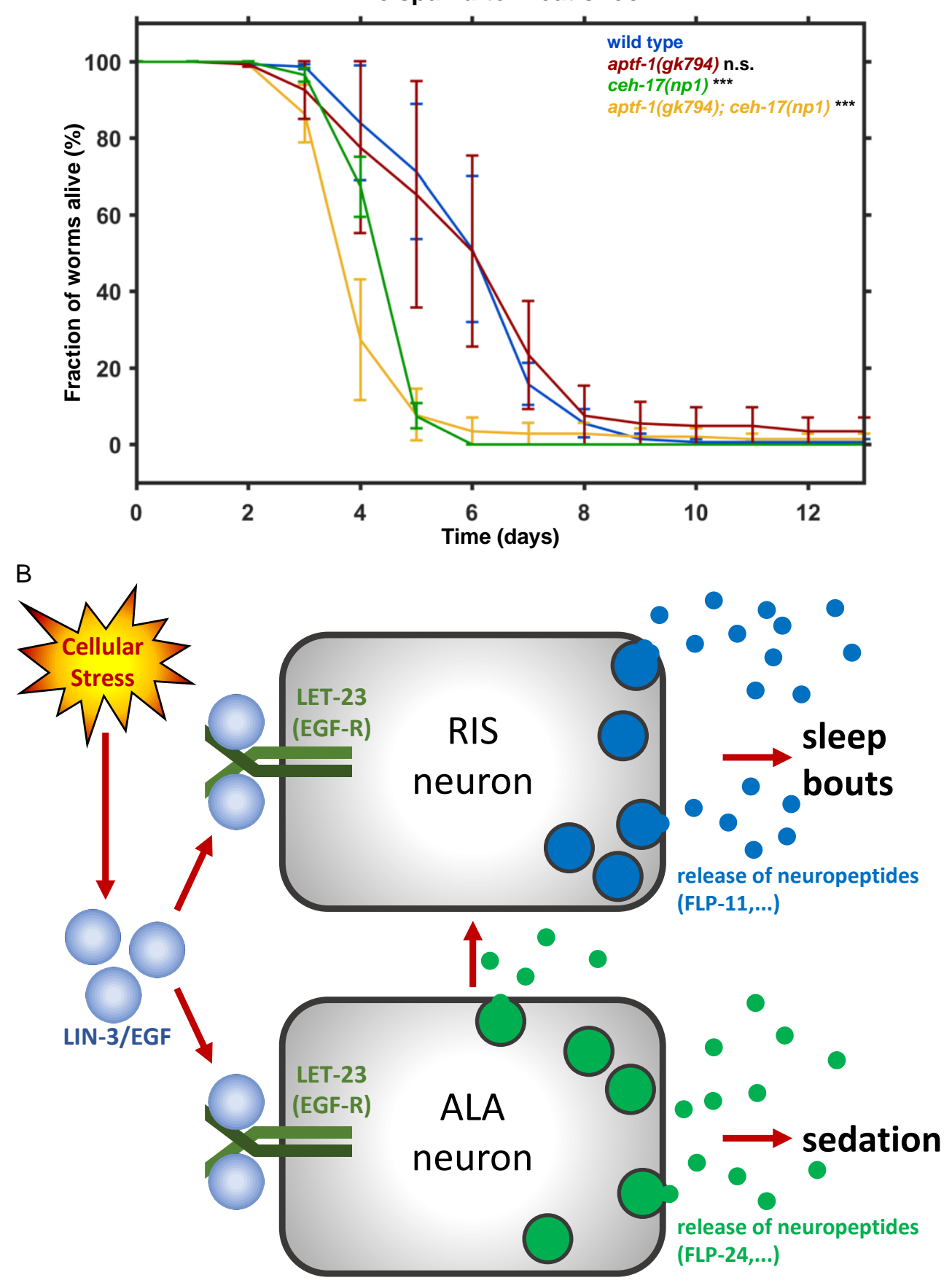

Figure 13 - ALA rather than RIS is required for survival following heat stress

(A) Survival of ALA and RIS mutants after heat shock $\left(40^{\circ} \mathrm{C}, 20 \mathrm{~min}\right)$. aptf-1(-) (red) did not show a different survival rate after the heat shock. ceh-17(-) and the ceh-17(-); aptf-1(-) double mutant died earlier than wildtype worms. Three biological replicates were performed, with $\mathrm{N}=50$ worms per allele per replicate. ${ }^{* * *}$ denotes statistical significance with $p<0.001$, Cox proportional hazards regression.

(B) Model for EGF-induced sedation and sleep through ALA and RIS neurons. Cellular stress leads to EGF release, which activates the RIS and ALA neurons via the EGF receptor. Both neurons release neuropeptides. ALA induces sedation and activates RIS. RIS induces sleep bouts. 


\section{Discussion}

The sections "ALA is a sedating and sleep-promoting neuron", "EGFR activates RIS to induce sleep bouts following cellular stress", and "Sedation is protective after cellular stress rather than sleep bouts" of this discussion are part of the manuscript we are currently writing, which is entitled "Epidermal Growth Factor signaling promotes sleepactive neuron depolarization to increase sleep following cellular stress".

\subsection{The starting point of this thesis}

Sleep is an essential biological process in all organism with a nervous system, although its basic function is still unknown. It exists in humans with a highly complex nervous system as well as in cnidarians with a rather simple and diffuse nervous system (Nath et al., 2017). Also, the nematode C. elegans, with a minimalistic nervous system of exactly 302 neurons in the adult hermaphrodite, shows different types of sleep. They range from developmental-controlled, over environment-stimulated to stress-induced sleep (Hill et al., 2014; Raizen et al., 2008; Wu et al., 2018). Two neurons controlling these sleep-types had been discovered in C. elegans so far.

On the one hand is the sleep-active neuron RIS, which is active during lethargus and L1 arrest sleep, and on the other hand the neuron ALA, which was known for its role in SIS (Hill et al., 2014). Former colleagues of me discovered that RIS expresses the transcription factor APTF-1, which controls the expression of the neuropeptides encoded by the flp-11 gene (Turek et al., 2016, 2013). The release of FLP-11 neuropeptides induces sleep in the worm. Further molecular mechanism of RIS had been unknown so far. I obtained three RIS transcriptomes to unravel what differs the sleep-active RIS from other neurons and cells in the worm.

\subsection{Genes enriched in the sleep-active neuron RIS}

The RIS transcriptomes I obtained differed largely in the way they were produced. The first transcriptome was based on RNA sequencing of FACS-sorted RIS neurons. The RNA-seq data was compared to an RNA-seq data set of all L2 cells. It revealed 4'371 
significant differentially expressed genes, with 1'188 enriched and 3'183 de-enriched genes in RIS. This was a quite high-number compared to the 66 (RIS vs. neurons) or 381 (RIS vs. all) significant differentially expressed genes of the transcriptomes, which were obtained by the second method: sci-RNA-seq. The high number of enriched genes in the FACS/RNA-seq transcriptome indicate a good sensitivity but might also mean genes were covered, which are more broadly expressed and so less specific for RIS.

For the second method, a published data set of 42'035 single-cell transcriptomes were used to identify one cluster with 44 cells as RIS (Cao et al., 2017). The single-cell transcriptomes had been gathered by sci-RNA-seq on L2 larval cells. Transcripts found in this cluster were either compared to transcripts of all other neurons or all other cells. The lower amount of enriched genes in RIS via sci-RNA-seq can be explained by the large amount of total analyzed cells, which vice versa led to less identified transcripts per individual cell. As every worm cell is sampled several times, e.g., 44 times for RIS and 22 times for ALA, the expression profile should cover the most abundant transcripts and be highly representative for the given cell type (Cao et al., 2017).

To confirm the validity of the transcriptomes, reporter strains for 20 significant enriched genes in RIS in at least one of the transcriptome were used to confirm their expression in RIS. Seven of these strains had been confirmed to express in RIS before. They included unc-47, unc-25, lim-6, aptf-1,flp-11, C10C6.7 and srd-32 (Hobert et al., 1999; Jin et al., 1999; McIntire et al., 1997; Turek et al., 2016, 2013; Vidal et al., 2018). Six reporters did not express in RIS. It is noteworthy that four were a reporter for neuropeptide encoding genes: $n l p-8, n l p-13, n l p-37$, and $f l p-1$. The other two were insulin-related genes: ins-24 and ins-27. Their belonging to those two signal peptide groups could indicate a mechanistic problem with a reporter for those genes, and the missing expression is a falsenegative result. At least $n l p-8$ and $n l p-13$ might be candidates for false-negative expression, as they are highly enriched in all three RIS transcriptomes. Still, there is the other possibility of false-positive transcriptome enrichment for those six genes.

Finally, there were seven reporters, which were suspected to express in RIS by the transcriptomes and were newly confirmed by co-localization with RIS specific mKate 2 expression. The seven genes were: let-23, plc-3, ilys-4, sbt-1, nlp-11, ser-7, and zig-2. The three genes let-23, plc-3, and ilys-4, had been previously described to also express in 


\section{Discussion}

ALA (Gravato-Nobre et al., 2016; C. Van Buskirk \& Sternberg, 2010; Cheryl Van Buskirk \& Sternberg, 2007). With 14 gene-reporters expressing in RIS and just six not expressing, the transcriptomes seemed to be reasonably accurate to represent the molecular-intracellular environment of RIS. To increase their informative value, an overlap list was produced, with all genes significantly enriched in RIS in all three transcriptomes.

\subsection{L1 arrest sleep screen}

As I was interested in the difference of RIS compared to other neurons, I used the sciRNA-seq RIS versus pan-neuronal cells transcriptome. To screen for RIS-dependent sleep phenotypes, lethargus and L1 arrest sleep would have been an option. L1 arrest sleep seemed more suitable as it is independent of developmental regulation (Wu et al., 2018).

In theory for each gene in $C$. elegans a mutated allele exists, which is available for research. However, not every mutation is severe and inhibits protein function. The best options for functional null alleles are mutations, which cause an early stop codon or a frameshift in the genetic code. Deletions of nucleotides or mutations which affect splice sites can also disturb proper protein work. In contrast, single nucleotide changes might affect the translation of single amino acid but could be even silent mutations and hence have a low chance to produce an obvious phenotype. Therefore, for screening, only alleles with a given chance to produce an altered sleep phenotypes had been used. Alleles with early stop codons, frameshift mutation or affected splice sites covered around $2 / 3$ of all genes. Excluding 16 alleles, because of severe developmental problems in the strain, 87 genes have been screened for L1 arrest.

Of 89 screened alleles, two genes were covered by two different alleles, over $90 \%$, did not produce any significant sleep phenotype in the end. One group of strains, mainly coming from the MMP, had an initially increased sleep fraction. When these strains were crossed back against wild type worms and selected for the allele of interest the sleep phenotype was no longer present. Also, 12 of the 16 excluded strains derived from the MMP. 


\section{Discussion}

The main issue with strains of the MMP is that they often carry over 400 mutations per strain if compared to wild type N2 strain (Thompson et al., 2013). Many of these are in non-coding regions or if they are actually in coding regions are just missense mutations. For two strains in which I lost a promising sleep phenotype after backcrossing, I went back and checked in the database which other genes were affected. In both strains, six other genes had nonsense mutations by early stop codons. I crossed both strains back against the wild type and selected in the offspring for each of the different nonsense mutations respectively. None of the backcrossed strains showed the sleep phenotype of the parental strain (data not shown). The phenotype might have come from one of the missense mutations, a non-coding but regulating gene region or maybe even from an interaction of several mutations. As there were at this point countless possibilities causing the phenotypes and no proof that they were RIS dependent it was not feasible to track them further down.

Two alleles produced a decreased sleep fraction phenotype in the L1 arrest screen. One gene was goa-1, the ortholog of human $\mathrm{G}$ protein subunit alpha 01 . The allele goa-1(sa734) was a nonsense mutation by an early stop codon. It is known to produce a hyperactivity phenotype in the worm, and so the decreased L1 arrest sleep phenotype would fit to it (Robatzek \& Thomas, 2000).

The second allele with less L1 arrest sleep was $s b t-1(o k 901)$, which was additionally confirmed to express in RIS via my reporter analysis. SBT-1 is the ortholog of the human neuroendocrine chaperone 7B2, which binds to the prohormone convertase 2 and is needed for cleavage of larger peptide precursors (Lindberg, Tu, Muller, \& Dickerson, 1998). Worms carrying the sbt-1(ok901) allele were completely missing some of their neuropeptides, which are present in the wild type. Present neuropeptides in sbt-1(ok901) worms, were less abundant compared to the wild type (Husson \& Schoofs, 2007). A conclusion from this could be, RIS is expressing $s b t-1$ to process FLP-11. Missing SBT1 might lead to less matured FLP-11 neuropeptides which could be released upon RIS activation, and thus less sleep would be induced.

One mutated gene which produced an increased L1 arrest sleep phenotype was ilys-4. The increased quiescence of the MMP allele ilys-4(gk402093) persisted after four times backcrossing against the wild type. The ilys-4p::GFP reporter also expressed in RIS. A 


\section{Discussion}

sleep phenotype and confirmed expression in RIS made ilys-4 an interesting target for further analysis. A complete genetic deletion of ilys-4 was produced via CRISPR-Cas9 gene editing, which also reproduced the increased L1 arrest sleep phenotype.

ILYS-4 belongs to the invertebrate-type lysozyme family, which covers six known proteins in $C$. elegans. They are expressed in various tissues, like pharynx, intestine, excretory system, coelomocytes, or the nervous system. Their function is thought to be a defense against pathogens and also being related to digestion (Schulenburg \& Boehnisch, 2008). ILYS-4 differs from the five other ILYS proteins, because it has 14 instead of 16 cysteines and is presumably the only ILYS protein with intact isopeptidase functionality (Gravato-Nobre et al., 2016). In a maximum likelihood analysis, ilys-4 seems more closely related to ilys -4 genes of other nematodes, e.g., Caenorhabditis remanei and Caenorhabditis briggsae, than the other ilys genes of $C$. elegans itself. It indicates a specialized function for ilys-4 (Schulenburg \& Boehnisch, 2008). The fact, it is not only expressed in RIS, but also in ALA, like the EGF receptor signaling pathway makes it an interesting target for further analysis in the future.

The most strong increased sleep phenotype coming out from the L1 arrest screen was a gain-of-function allele of let-23. A gene, which I showed to be expressed in both sleeprelated neurons, RIS and ALA. LET-23 is the C. elegans homologue of the EGF receptor. The gain-of-function allele let-23(sa62) is caused by a single point mutation which converts cysteine 359 to tyrosine and is close to the extracellular major ligand-binding domain of LET-23. So far, it was known for producing a ligand-independent, but semidominant multi-vulva phenotype (W. S. Katz et al., 1996). Homozygous null alleles for let-23, e.g., mn23 and sy10, are lethal (Aroian, Lesa, \& Sternberg, 1994). Worms die already as embryos in the eggs or shortly after hatching and therefore could not be screened in L1 arrest sleep. Tissue-specific rescue of let-23 $3_{\text {null }}$ by expressing exogenous let-23 under the $d p y-7$ promoter did not recover the lethal phenotype (data not shown).

As let-23 is expressed in ALA and RIS, it was of interest which neuron caused the increased L1 arrest sleep phenotype. To check ALA dependency, let-23(gf) was crossed with ceh-17(np1) a loss-of-function allele, which causes a non-functional ALA (C. Van Buskirk \& Sternberg, 2010). RIS dependency was checked by crossing let-23(gf) with a RIS specific expression of an apoptosis activator construct, flp-11p::egl-1 (Conradt \& 


\section{Discussion}

Horvitz, 1998). Let-23(gf) in the ceh-17(-) background reduced the increased L1 arrest sleep phenotype, but the worms were still sleeping more than wild-type ones. In the flp-11p::egl-1 background, L1 arrest sleep was almost completely gone, similar to flp-11p::egl-3 alone. This showed a partial influence of ALA on the let-23(gf) phenotype but also the dependency of L1 arrest sleep on RIS at all.

It raised two questions, (1) if ALA and RIS have more in common on the molecular level than the EGF receptor and (2) if RIS also plays a role in SIS, which was just linked to ALA in the literature (Hill et al., 2014; Nath et al., 2016; Nelson et al., 2014).

\subsection{RIS vs. ALA transcriptome}

It was interesting to find the EGF receptor enriched in RIS, which was known for its role in SIS via ALA. It was shown before that SIS was linked to ALA, and L1 arrest and lethargus sleep were linked to RIS without any report of interaction so far (Hill et al., 2014; Turek et al., 2013). The enrichment of the EGF receptor worm homologue LET-23 and the downstream phospholipase PLC-3, as well as the confirmed gene expression via reporter of let-23 and plc-3, raised the question if the sleep controlling neurons RIS and ALA are more similar than thought before. With the massive sci-RNA-seq data set available it was possible to also extract an ALA transcriptome from it.

The comparison of the sci-RNA-seq transcriptomes of RIS and ALA, each vs. neurons, revealed an overlap of 4 enriched genes. One neurotransmitter encoding genge, $n l p-8$, and the worm homologue of the peptidylglycine alpha-amidating monooxygenase(PAM), pgal-1. PAM modifies post-translational many signaling peptides (Glauder, Ragg, Rauch, \& Engels, 1990; Shaye \& Greenwald, 2011). The other two overlapping genes were part of the EGF signaling pathway, let-23, and plc-3. An additional pairwise correlation confirmed the general difference in gene expression between RIS and ALA. Apart from the interneuron RIC, RIS does not cluster well in the pairwise correlation with any other neuron, highlighting the peculiarity of RIS.

The expression of the EGF receptor machinery in RIS indicated that this sleep-active neuron also plays a role in SIS. It would mean that RIS is involved in all known types of sleep in the worm and hence increase its significance in sleep control even more. 


\subsection{EGF receptor signaling in RIS and ALA}

The EGF receptor has two major intracellular downstream signaling pathways. The first induces gene expression via the Ras/ERK pathway and includes in C. elegans the proteins SEM-5(Grb2), LET-341(mSOS), LET-60(Ras), LIN-45(Raf), MEK-2(MEK) and MPK1(MAPK,ERK) (Rongo, 2011). Most of these genes were significantly enriched in RIS in the three different transcriptomes but surprisingly not in the ALA sci-RNA-seq transcriptome. In the second pathway, the EGF receptor LET-23 activates the phospholipase PLC-3, which uses phosphatidylinositol 4,5-bisphosphate (PIP2) to produce diacylglycerol (DAG) and inositol 1,4,5-trisphosphate (IP3). IP3 binds to the IP3 receptor ITR-1 at the endoplasmatic reticulum to release $\mathrm{Ca}^{2+}$ into the cytosol (Iwasa, $\mathrm{Yu}$, Xue, \& Driscoll, 2010). let-23 and plc-3 were both enriched in the ALA transcriptome and RIS transcriptomes. itr-1 was de-enriched in the FACS/RNAseq RIS transcriptome while not significantly changed in the other transcriptomes, which is of no surprise as it is widely expressed throughout various tissues in the worm (Baylis, Furuichi, Yoshikawa, Mikoshiba, \& Sattelle, 1999).

The expression of several EGF receptor signaling pathway components in RIS and ALA suggested that both neurons can be activated by EGF. However, their general difference in gene expression although indicated that they might inherit different mechanistic properties and show a different cellular response.

\subsection{ALA is a sedating and sleep-promoting neuron}

ALA expresses the EGF receptor machinery and was shown to release a cocktail of neuropeptides upon activation by EGF, including those encoded by the $f l p-13, n l p-8$, and $n l p-24$ neuropeptide genes. The peptides encoded by these genes act in parallel to induce sleep behavior and inhibit specific behaviors such as feeding (Nath et al., 2016; Nelson et al., 2014; Cheryl Van Buskirk \& Sternberg, 2007). Without a functioning ALA, fewer worms showed sleep bouts after a heat shock, but some sleep bouts were still present. In contrast, if RIS was missing, almost no sleep was present any more after the heat shock. ALA activity increased rapidly to a plateau in the experiments after EGF signaling, either via noxious heat shock or EGF/LIN-3 overexpression, and then slowly dropped over time 


\section{Discussion}

to wild-type levels again. During that time worms showed bouts of behavioral quiescence, although they did not directly correlate with ALA activity. ALA seemed to be a sedating and sleep promoting neuron.

It looks like the sedating and sleep promoting property are achieved by two parallel pathways. For the first pathway, it was shown, that neuropeptides, which were released by ALA in case of cellular stress, caused inhibition of behavioral activities like feeding, independently of RIS (Trojanowski et al., 2015). This might work via inhibition of wakepromoting neurons directly and thus inhibiting active behaviors over prolonged time periods causing sedation or lethargy (Nath et al., 2016; Nelson et al., 2014). It was shown, that ALA is able to inhibit AVE and other command interneurons for example (Fry et al., 2014; M. Katz et al., 2018).

In the second pathway, ALA activates or boosts RIS activity, which then causes sleep in the worm. I showed that stress-caused RIS activation was decreased in the absence of ALA and also, that optogenetic ALA activation was able to stimulate RIS.

In general, sedation has some similarities to sleep, such as reduced voluntary movement and reduced responsiveness to stimulation. It differs from sleep by not displaying the fast switching properties that cause the succession of sleep bouts as well as quick reversibility. Nevertheless, sedation is associated with increased sleep, indicating that these two behaviors are causally linked.

\subsection{EGFR activates RIS to induce sleep bouts following cellular stress}

Stress-induced EGF signaling does not only work via ALA but also via the sleep-active neuron RIS. The EGF receptor LET-23 was found to be expressed in RIS just as the $C$. elegans homologue of the LET-23 downstream target, PLC-3. It is the worm homologue of the phospholipase C gamma. Activation of LET-23 leads via PLC-3 to an increase of intracellular $\mathrm{Ca}^{2+}$ concentration (Cheryl Van Buskirk \& Sternberg, 2007). This is presumably also true in RIS, where increased excitability could lead to an increase in the probability of strong RIS calcium transients. Experiments supporting this hypothesis showed an increase in $\mathrm{Ca}^{2+}$ in RIS after heat shock stress or EGF overexpression, 


\section{Discussion}

indicated via the calcium sensor GCaMP. In the let-23(gf) background RIS could not be activated further via EGF overexpression, which is in agreement with literature as the LET-23(gf) functions ligand-independent (W. S. Katz et al., 1996).

In contrast to ALA, RIS activated already during the onset of a noxious heat shock. Activation dropped to wild-type levels again, if the heat shock continued longer than a few minutes. RIS activation during the onset of a heat shock was shown before (Kotera et al., 2016). Quiescence during the heat shock was to some extend RIS dependent, but not all of it. This suggested a second pathway paralyzing the worm during a continued heat shock.

After the end of the heat shock, RIS showed around one to four short but strong transients which highly correlated with movement quiescence bouts in each worm. This correlation of RIS and quiescence was in line with the results for other types of sleep in the worm (Turek et al., 2013; Wu et al., 2018). It verified, RIS is a sleep-active neuron during SIS and thus in all known types of sleep in C. elegans.

The induction of SIS via EGF receptor signaling in ALA was previously known (Hill et al., 2014). However, I was able to show, that EGF acts via two parallel pathways to induce SIS. The EGF activation of ALA causes inhibition of specific behaviors over longer time scales and can additionally amplify the probability of RIS activity. RIS can also be activated by EGF itself and inhibits systemic behaviors on short time scales. Two different pathways via two neurons allow the organism to orchestrate the physiological response on different levels of specificity and time scales. In the end, all known types of sleep in C. elegans are controlled by RIS activity.

\subsection{Sedation is protective after cellular stress rather than sleep bouts}

One of the assumed functions of sleep is to be protective or respectively allow the organism to recover, e.g., in the case of stress. Lifespan measurements of C. elegans worms after a heat shock showed a drop in longevity in the absence of a functional ALA (Hill et al., 2014). I reproduced these results but could not find an effect vice versa in the absence of a functional RIS. It rather seemed sedation via ALA was necessary for survival after several days, more than RIS dependent sleep. ALA has been shown to inhibit feeding 


\section{Discussion}

independently of RIS (Trojanowski et al., 2015). Reduced food intake increases health and longevity, suggesting that ALA might, at least in part, act by reducing food intake following cellular stress (Kapahi, Kaeberlein, \& Hansen, 2017). RIS on the other hand might have a beneficial effect on the nervous system at the onset and after the heat shock, which does not translate in life span effects after several days.

This would mean EGF receptor signaling activates two different parallel pathways to cope with cellular stress. EGF receptor signaling is already known to promote healthy aging via $p l c-3$ and itr- 1 on the one hand, and regulating lifespan via the Ras-MAPK pathway and the PLZF transcription factors EOR-1 and EOR-2 on the other hand (Iwasa et al., 2010; Liu, Rogers, Murphy, \& Rongo, 2011; Yu \& Driscoll, 2011). This is even more relevant as EGF signaling is highly conserved across all animal phyla and was also shown to promote sleep in other species, like fruit flies and rabbits (Foltenyi et al., 2007; Kushikata et al., 1998). It seems that EGF signaling is highly involved in various pathways and species promoting a healthy organism.

Stress-induced EGF receptor signaling in C. elegans hinted an interesting interaction of ALA-dependent sedation and RIS-induced sleep. In general, there might be distinct protective functions for sedation and sleep, not only in worms but also other complex organism. 


\section{References}

Ahringer, J. (Ed.). (2006). Reverse genetics. Retrieved from http://www.wormbook.org

Alam, Md. A., Kumar, S., McGinty, D., Alam, Md. N., \& Szymusiak, R. (2014).

Neuronal activity in the preoptic hypothalamus during sleep deprivation and recovery sleep. Journal of Neurophysiology, 111(2), 287-299. https://doi.org/10.1152/jn.00504.2013

Albrecht, U., Zheng, B., Larkin, D., Sun, Z. S., \& Lee, C. C. (2001). MPer1 and mper2 are essential for normal resetting of the circadian clock. Journal of Biological Rhythms, 16(2), 100-104. https://doi.org/10.1177/074873001129001791

Allada, R., \& Siegel, J. M. (2008). Unearthing the Phylogenetic Roots of Sleep. Current Biology, 18(15), R670-R679. https://doi.org/10.1016/j.cub.2008.06.033

Altun, Z. F., \& Hall, D. H. (2009). INTRODUCTION TO C. elegans ANATOMY. In L. A. Herndon (Ed.), WormAtlas.

Aroian, R. V., Lesa, G. M., \& Sternberg, P. W. (1994). Mutations in the Caenorhabditis elegans let-23 EGFR-like gene define elements important for cell-type specificity and function. The EMBO Journal, 13(2), 360-366.

Baylis, H. A., Furuichi, T., Yoshikawa, F., Mikoshiba, K., \& Sattelle, D. B. (1999). Inositol 1,4,5-trisphosphate receptors are strongly expressed in the nervous system, pharynx, intestine, gonad and excretory cell of Caenorhabditis elegans and are encoded by a single gene (itr-1). Journal of Molecular Biology, 294(2), 467-476. https://doi.org/10.1006/jmbi.1999.3229

Brenner, S. (1974). The genetics of Caenorhabditis elegans. Genetics, 77(1), 71-94.

Bringmann, H. (2011). Agarose hydrogel microcompartments for imaging sleep- and wake-like behavior and nervous system development in Caenorhabditis elegans larvae. Journal of Neuroscience Methods, 201(1), 78-88. https://doi.org/10.1016/j.jneumeth.2011.07.013

Bringmann, H. (2018). Sleep-Active Neurons: Conserved Motors of Sleep. Genetics, 208(4), 1279-1289. https://doi.org/10.1534/genetics.117.300521

Bryant, P. A., Trinder, J., \& Curtis, N. (2004). Sick and tired: Does sleep have a vital role in the immune system? Nature Reviews. Immunology, 4(6), 457-467. https://doi.org/10.1038/nri1369

Campbell, S. S., \& Tobler, I. (1984). Animal sleep: A review of sleep duration across phylogeny. Neuroscience \& Biobehavioral Reviews, 8(3), 269-300. https://doi.org/10.1016/0149-7634(84)90054-X

Cao, J., Packer, J. S., Ramani, V., Cusanovich, D. A., Huynh, C., Daza, R., ... Shendure, J. (2017). Comprehensive single-cell transcriptional profiling of a multicellular organism. Science, 357(6352), 661-667. https://doi.org/10.1126/science.aam8940

Chapman, E. R. (2008). How Does Synaptotagmin Trigger Neurotransmitter Release? Annual Review of Biochemistry, 77(1), 615-641. https://doi.org/10.1146/annurev.biochem.77.062005.101135

Conradt, B., \& Horvitz, H. R. (1998). The C. elegans protein EGL-1 is required for programmed cell death and interacts with the Bcl-2-like protein CED-9. Cell, 93(4), 519-529.

Corsi, A. K. (2015). A Transparent window into biology: A primer on Caenorhabditis elegans. WormBook, 1-31. https://doi.org/10.1895/wormbook.1.177.1

Davis, M. W., Morton, J. J., Carroll, D., \& Jorgensen, E. M. (2008). Gene activation using FLP recombinase in C. elegans. PLoS Genetics, 4(3), e1000028. https://doi.org/10.1371/journal.pgen.1000028 
Diekelmann, S., \& Born, J. (2010). The memory function of sleep. Nature Reviews Neuroscience, 11(2), 114-126. https://doi.org/10.1038/nrn2762

Dobin, A., Davis, C. A., Schlesinger, F., Drenkow, J., Zaleski, C., Jha, S., ... Gingeras, T. R. (2013). STAR: ultrafast universal RNA-seq aligner. Bioinformatics (Oxford, England), 29(1), 15-21. https://doi.org/10.1093/bioinformatics/bts635

Ewels, P., Magnusson, M., Lundin, S., \& Käller, M. (2016). MultiQC: summarize analysis results for multiple tools and samples in a single report. Bioinformatics (Oxford, England), 32(19), 3047-3048. https://doi.org/10.1093/bioinformatics/btw354

Foltenyi, K., Greenspan, R. J., \& Newport, J. W. (2007). Activation of EGFR and ERK by rhomboid signaling regulates the consolidation and maintenance of sleep in Drosophila. Nature Neuroscience, 10(9), 1160-1167. https://doi.org/10.1038/nn1957

Franken, P., \& Dijk, D.-J. (2009). Circadian clock genes and sleep homeostasis. European Journal of Neuroscience, 29(9), 1820-1829. https://doi.org/10.1111/j.1460-9568.2009.06723.x

Fry, A. L., Laboy, J. T., \& Norman, K. R. (2014). VAV-1 acts in a single interneuron to inhibit motor circuit activity in Caenorhabditis elegans. Nature Communications, 5, 5579. https://doi.org/10.1038/ncomms6579

Glauder, J., Ragg, H., Rauch, J., \& Engels, J. W. (1990). Human peptidylglycine alphaamidating monooxygenase: cDNA, cloning and functional expression of a truncated form in COS cells. Biochemical and Biophysical Research Communications, 169(2), 551-558.

Goetting, D. L., Soto, R., \& Van Buskirk, C. (2018). Food-Dependent Plasticity in Caenorhabditis elegans Stress-Induced Sleep Is Mediated by TOR-FOXA and TGF- $\beta$ Signaling. Genetics, 209(4), 1183-1195. https://doi.org/10.1534/genetics.118.301204

Gravato-Nobre, M. J., Vaz, F., Filipe, S., Chalmers, R., \& Hodgkin, J. (2016). The Invertebrate Lysozyme Effector ILYS-3 Is Systemically Activated in Response to Danger Signals and Confers Antimicrobial Protection in C. elegans. PLOS Pathogens, 12(8), e1005826. https://doi.org/10.1371/journal.ppat.1005826

Hakim, F., Wang, Y., Zhang, S. X. L., Zheng, J., Yolcu, E. S., Carreras, A., ... Gozal, D. (2014). Fragmented Sleep Accelerates Tumor Growth and Progression through Recruitment of Tumor-Associated Macrophages and TLR4 Signaling. Cancer Research, 74(5), 1329-1337. https://doi.org/10.1158/0008-5472.CAN$13-3014$

Herman, M. (2006). Hermaphrodite cell-fate specification. WormBook. https://doi.org/10.1895/wormbook.1.39.1

Hill, A. J., Mansfield, R., Lopez, J. M. N. G., Raizen, D. M., \& Van Buskirk, C. (2014). Cellular Stress Induces a Protective Sleep-like State in C. elegans. Current Biology, 24(20), 2399-2405. https://doi.org/10.1016/j.cub.2014.08.040

Hobert, O., Tessmar, K., \& Ruvkun, G. (1999). The Caenorhabditis elegans lim-6 LIM homeobox gene regulates neurite outgrowth and function of particular GABAergic neurons. Development (Cambridge, England), 126(7), 1547-1562.

Hubbard, E. J. A. (2014). FLP/FRT and Cre/lox recombination technology in $C$. elegans. Methods (San Diego, Calif.), 68(3), 417-424. https://doi.org/10.1016/j.ymeth.2014.05.007

Husson, S. J., \& Schoofs, L. (2007). Altered neuropeptide profile of Caenorhabditis elegans lacking the chaperone protein 7B2 as analyzed by mass spectrometry. FEBS Letters, 581(22), 4288-4292. https://doi.org/10.1016/j.febslet.2007.08.003 
Hutter, H., \& Suh, J. (2016). GExplore 1.4: An expanded web interface for queries on Caenorhabditis elegans protein and gene function. Worm, 5(4), e1234659. https://doi.org/10.1080/21624054.2016.1234659

Iber, C., Ancoli-Israel, S., Chesson, A., \& Quan, S. (2007). The AASM Manual for the Scoring of Sleep and Associated Events: Rules, Terminology, and Technical Specifications. III. Presented at the Westchester. Westchester.

Iwasa, H., Yu, S., Xue, J., \& Driscoll, M. (2010). Novel EGF pathway regulators modulate $C$. elegans healthspan and lifespan via EGF receptor, PLC-gamma, and IP3R activation. Aging Cell, 9(4), 490-505. https://doi.org/10.1111/j.14749726.2010.00575.x

Jeon, M. (1999). Similarity of the C. elegans Developmental Timing Protein LIN-42 to Circadian Rhythm Proteins. Science, 286(5442), 1141-1146. https://doi.org/10.1126/science.286.5442.1141

Jin, Y., Jorgensen, E., Hartwieg, E., \& Horvitz, H. R. (1999). The Caenorhabditis elegans Gene unc-25 Encodes Glutamic Acid Decarboxylase and Is Required for Synaptic Transmission But Not Synaptic Development. The Journal of Neuroscience, 19(2), 539-548. https://doi.org/10.1523/JNEUROSCI.19-0200539.1999

Kaeberlein, T. L., Smith, E. D., Tsuchiya, M., Welton, K. L., Thomas, J. H., Fields, S., ... Kaeberlein, M. (2006). Lifespan extension in Caenorhabditis elegans by complete removal of food. Aging Cell, 5(6), 487-494. https://doi.org/10.1111/j.1474-9726.2006.00238.x

Kapahi, P., Kaeberlein, M., \& Hansen, M. (2017). Dietary restriction and lifespan: Lessons from invertebrate models. Ageing Research Reviews, 39, 3-14. https://doi.org/10.1016/j.arr.2016.12.005

Katz, M., Corson, F., Iwanir, S., Biron, D., \& Shaham, S. (2018). Glia Modulate a Neuronal Circuit for Locomotion Suppression during Sleep in C. elegans. Cell Reports, 22(10), 2575-2583. https://doi.org/10.1016/j.celrep.2018.02.036

Katz, W. S., Lesa, G. M., Yannoukakos, D., Clandinin, T. R., Schlessinger, J., \& Sternberg, P. W. (1996). A point mutation in the extracellular domain activates LET-23, the Caenorhabditis elegans epidermal growth factor receptor homolog. Molecular and Cellular Biology, 16(2), 529-537.

Kotera, I., Tran, N. A., Fu, D., Kim, J. H., Byrne Rodgers, J., \& Ryu, W. S. (2016). Pan-neuronal screening in Caenorhabditis elegans reveals asymmetric dynamics of AWC neurons is critical for thermal avoidance behavior. ELife, 5. https://doi.org/10.7554/eLife.19021

Krueger, J. M., Frank, M. G., Wisor, J. P., \& Roy, S. (2016). Sleep function: Toward elucidating an enigma. Sleep Medicine Reviews, 28, 46-54. https://doi.org/10.1016/j.smrv.2015.08.005

Kushikata, T., Fang, J., Chen, Z., Wang, Y., \& Krueger, J. M. (1998). Epidermal growth factor enhances spontaneous sleep in rabbits. American Journal of PhysiologyRegulatory, Integrative and Comparative Physiology, 275(2), R509-R514. https://doi.org/10.1152/ajpregu.1998.275.2.R509

Lewis, J. A., \& Fleming, J. T. (1995). Basic culture methods. Methods in Cell Biology, 48, 3-29.

Li, B., \& Dewey, C. N. (2011). RSEM: accurate transcript quantification from RNASeq data with or without a reference genome. BMC Bioinformatics, 12, 323. https://doi.org/10.1186/1471-2105-12-323

Lim, M. A., Chitturi, J., Laskova, V., Meng, J., Findeis, D., Wiekenberg, A., ... Zhen, M. (2016). Neuroendocrine modulation sustains the C. elegans forward motor state. ELife, 5. https://doi.org/10.7554/eLife.19887 
Lin, J. Y., Knutsen, P. M., Muller, A., Kleinfeld, D., \& Tsien, R. Y. (2013). ReaChR: a red-shifted variant of channelrhodopsin enables deep transcranial optogenetic excitation. Nature Neuroscience, 16(10), 1499-1508. https://doi.org/10.1038/nn.3502

Lindberg, I., Tu, B., Muller, L., \& Dickerson, I. M. (1998). Cloning and functional analysis of C. elegans 7B2. DNA and Cell Biology, 17(8), 727-734. https://doi.org/10.1089/dna.1998.17.727

Liu, G., Rogers, J., Murphy, C. T., \& Rongo, C. (2011). EGF signalling activates the ubiquitin proteasome system to modulate C. elegans lifespan. The EMBO Journal, 30(15), 2990-3003. https://doi.org/10.1038/emboj.2011.195

Lockery, S. R., Goodman, M. B., \& Faumont, S. (2009). First report of action potentials in a C. elegans neuron is premature. Nature Neuroscience, 12(4), 365-366; author reply 366. https://doi.org/10.1038/nn0409-365

Lu, J., Sherman, D., Devor, M., \& Saper, C. B. (2006). A putative flip-flop switch for control of REM sleep. Nature, 441(7093), 589-594. https://doi.org/10.1038/nature04767

Maquet. (2000). Functional neuroimaging of normal human sleep by positron emission tomography. Journal of Sleep Research, 9(3), 207-231. https://doi.org/10.1046/j.1365-2869.2000.00214.x

McIntire, S. L., Reimer, R. J., Schuske, K., Edwards, R. H., \& Jorgensen, E. M. (1997). Identification and characterization of the vesicular GABA transporter. Nature, 389(6653), 870-876. https://doi.org/10.1038/39908

Merritt, C., \& Seydoux, G. (2010). Transgenic solutions for the germline. WormBook: The Online Review of C. Elegans Biology, 1-21. https://doi.org/10.1895/wormbook.1.148.1

Mitani, S. (2009). Nematode, an Experimental Animal in the National BioResource Project. Experimental Animals, 58(4), 351-356. https://doi.org/10.1538/expanim.58.351

Miyabayashi, T., Palfreyman, M. T., Sluder, A. E., Slack, F., \& Sengupta, P. (1999). Expression and Function of Members of a Divergent Nuclear Receptor Family in Caenorhabditis elegans. Developmental Biology, 215(2), 314-331. https://doi.org/10.1006/dbio.1999.9470

Moghal, N., \& Sternberg, P. W. (2003). The epidermal growth factor system in Caenorhabditis elegans. Experimental Cell Research, 284(1), 150-159.

Monsalve, G. C., Van Buskirk, C., \& Frand, A. R. (2011). LIN-42/PERIOD Controls Cyclical and Developmental Progression of C. elegans Molts. Current Biology, 21(24), 2033-2045. https://doi.org/10.1016/j.cub.2011.10.054

Moore, R. Y., \& Eichler, V. B. (1972). Loss of a circadian adrenal corticosterone rhythm following suprachiasmatic lesions in the rat. Brain Research, 42(1), 201-206. https://doi.org/10.1016/0006-8993(72)90054-6

Nagy, S., Raizen, D. M., \& Biron, D. (2014). Measurements of behavioral quiescence in Caenorhabditis elegans. Methods, 68(3), 500-507. https://doi.org/10.1016/j.ymeth.2014.03.009

Nath, R. D., Bedbrook, C. N., Abrams, M. J., Basinger, T., Bois, J. S., Prober, D. A., ... Goentoro, L. (2017). The Jellyfish Cassiopea Exhibits a Sleep-like State. Current Biology, 27(19), 2984-2990.e3. https://doi.org/10.1016/j.cub.2017.08.014

Nath, R. D., Chow, E. S., Wang, H., Schwarz, E. M., \& Sternberg, P. W. (2016). C. elegans Stress-Induced Sleep Emerges from the Collective Action of Multiple Neuropeptides. Current Biology, 26(18), 2446-2455. https://doi.org/10.1016/j.cub.2016.07.048 
Nelson, M. D., Lee, K. H., Churgin, M. A., Hill, A. J., Van Buskirk, C., Fang-Yen, C., \& Raizen, D. M. (2014). FMRFamide-like FLP-13 Neuropeptides Promote Quiescence following Heat Stress in Caenorhabditis elegans. Current Biology, 24(20), 2406-2410. https://doi.org/10.1016/j.cub.2014.08.037

Parmeggiani, P. L. (2003). THERMOREGULATION AND SLEEP. 11.

Pearlmutter, B. A., \& Houghton, C. J. (2009). A New Hypothesis for Sleep: Tuning for Criticality. Neural Computation, 21, 1622-1641.

Porkka-Heiskanen, T., \& Kalinchuk, A. V. (2011). Adenosine, energy metabolism and sleep homeostasis. Sleep Medicine Reviews, 15(2), 123-135. https://doi.org/10.1016/j.smrv.2010.06.005

Praitis, V., Casey, E., Collar, D., \& Austin, J. (2000). Creation of Low-Copy Integrated Transgenic Lines in Caenorhabditis elegans. Genetics, 157(3)1217-1226.

Raizen, D. M., Zimmerman, J. E., Maycock, M. H., Ta, U. D., You, Y., Sundaram, M. V., \& Pack, A. I. (2008). Lethargus is a Caenorhabditis elegans sleep-like state. Nature, 451(7178), 569-572. https://doi.org/10.1038/nature06535

Ralph, M. R., Foster, R. G., Davis, F. C., \& Menaker, M. (1990). Transplanted suprachiasmatic nucleus determines circadian period. Science (New York, N.Y.), 247(4945), 975-978.

Rechtschaffen, A., \& Bergmann, B. M. (2002). Sleep Deprivation in the Rat: An Update of the 1989 Paper. Sleep, 25(1), 18-24. https://doi.org/10.1093/sleep/25.1.18

Redemann, S., Schloissnig, S., Ernst, S., Pozniakowsky, A., Ayloo, S., Hyman, A. A., \& Bringmann, H. (2011). Codon adaptation-based control of protein expression in C. elegans. Nature Methods, 8(3), 250-252. https://doi.org/10.1038/nmeth.1565

Robatzek, M., \& Thomas, J. H. (2000). Calcium/calmodulin-dependent protein kinase II regulates Caenorhabditis elegans locomotion in concert with a $\mathrm{G}(\mathrm{o}) / \mathrm{G}(\mathrm{q})$ signaling network. Genetics, 156(3), 1069-1082.

Robinson, M. D., McCarthy, D. J., \& Smyth, G. K. (2010). edgeR: a Bioconductor package for differential expression analysis of digital gene expression data. Bioinformatics (Oxford, England), 26(1), 139-140. https://doi.org/10.1093/bioinformatics/btp616

Rongo, C. (2011). Epidermal growth factor and aging: a signaling molecule reveals a new eye opening function. Aging, 3(9), 896-905. https://doi.org/10.18632/aging.100384

Ruiz, F. S., Andersen, M. L., Guindalini, C., Araujo, L. P., Lopes, J. D., \& Tufik, S. (2017). Sleep influences the immune response and the rejection process alters sleep pattern: Evidence from a skin allograft model in mice. Brain, Behavior, and Immunity, 61, 274-288. https://doi.org/10.1016/j.bbi.2016.12.027

Saper, Chou, T. C., \& Scammell, T. E. (2001). The sleep switch: hypothalamic control of sleep and wakefulness. Trends in Neurosciences, 24(12), 726-731.

Saper, Fuller, P. M., Pedersen, N. P., Lu, J., \& Scammell, T. E. (2010). Sleep State Switching. Neuron, 68(6), 1023-1042. https://doi.org/10.1016/j.neuron.2010.11.032

Saper, Scammell, T. E., \& Lu, J. (2005). Hypothalamic regulation of sleep and circadian rhythms. Nature, 437(7063), 1257-1263. https://doi.org/10.1038/nature04284

Schulenburg, H., \& Boehnisch, C. (2008). Diversification and adaptive sequence evolution of Caenorhabditis lysozymes (Nematoda: Rhabditidae). BMC Evolutionary Biology, 8(1), 114. https://doi.org/10.1186/1471-2148-8-114

Shaye, D. D., \& Greenwald, I. (2011). OrthoList: a compendium of C. elegans genes with human orthologs. PloS One, 6(5), e20085. https://doi.org/10.1371/journal.pone.0020085 
Shine, R. (1984). Reproductive Biology and Food Habits of the Australian Elapid Snakes of the Genus Cryptophis. Journal of Herpetology, 18(1), 33. https://doi.org/10.2307/1563669

Siegel, J. M. (2008). Do all animals sleep? Trends in Neurosciences, 31(4), 208-213. https://doi.org/10.1016/j.tins.2008.02.001

Soneson, C., Love, M. I., \& Robinson, M. D. (2015). Differential analyses for RNAseq: transcript-level estimates improve gene-level inferences. F1000Research, 4 , 1521. https://doi.org/10.12688/f1000research.7563.2

Spencer, W. C., McWhirter, R., Miller, T., Strasbourger, P., Thompson, O., Hillier, L. W., ... Miller, D. M. (2014). Isolation of Specific Neurons from C. elegans Larvae for Gene Expression Profiling. PLoS ONE, 9(11), e112102. https://doi.org/10.1371/journal.pone.0112102

Steriade, M., Timofeev, I., \& Grenier, F. (2001). Natural Waking and Sleep States: A View From Inside Neocortical Neurons. Journal of Neurophysiology, 85(5), 1969-1985. https://doi.org/10.1152/jn.2001.85.5.1969

Stiernagle, T. (2006). Maintenance of C. elegans. Retrieved from http://www .wormbook.org

Sulston, J. E., \& Horvitz, H. R. (1977). Post-embryonic cell lineages of the nematode, Caenorhabditis elegans. Developmental Biology, 56(1), 110-156. https://doi.org/10.1016/0012-1606(77)90158-0

Takahashi, K., Kayama, Y., Lin, J. S., \& Sakai, K. (2010). Locus coeruleus neuronal activity during the sleep-waking cycle in mice. Neuroscience, 169(3), 11151126. https://doi.org/10.1016/j.neuroscience.2010.06.009

The $C$. elegans Sequencing Consortium. (1998). Genome Sequence of the Nematode $C$. elegans: A Platform for Investigating Biology. Science, 282(5396), 2012-2018. https://doi.org/10.1126/science.282.5396.2012

Thompson, O., Edgley, M., Strasbourger, P., Flibotte, S., Ewing, B., Adair, R., ... Waterston, R. H. (2013). The million mutation project: A new approach to genetics in Caenorhabditis elegans. Genome Research, 23(10), 1749-1762. https://doi.org/10.1101/gr.157651.113

Tian, L., Hires, S. A., Mao, T., Huber, D., Chiappe, M. E., Chalasani, S. H., ... Looger, L. L. (2009). Imaging neural activity in worms, flies and mice with improved GCaMP calcium indicators. Nature Methods, 6(12), 875-881. https://doi.org/10.1038/nmeth.1398

Trojanowski, N. F., Nelson, M. D., Flavell, S. W., Fang-Yen, C., \& Raizen, D. M. (2015). Distinct Mechanisms Underlie Quiescence during Two Caenorhabditis elegans Sleep-Like States. The Journal of Neuroscience: The Official Journal of the Society for Neuroscience, 35(43), 14571-14584. https://doi.org/10.1523/JNEUROSCI.1369-15.2015

Turek, M., Besseling, J., \& Bringmann, H. (2015). Agarose Microchambers for Longterm Calcium Imaging of Caenorhabditis elegans. Journal of Visualized Experiments: JoVE, (100), e52742. https://doi.org/10.3791/52742

Turek, M., Besseling, J., Spies, J.-P., König, S., \& Bringmann, H. (2016). Sleep-active neuron specification and sleep induction require FLP-11 neuropeptides to systemically induce sleep. ELife, 5. https://doi.org/10.7554/eLife.12499

Turek, M., Lewandrowski, I., \& Bringmann, H. (2013). An AP2 Transcription Factor Is Required for a Sleep-Active Neuron to Induce Sleep-like Quiescence in $C$. elegans. Current Biology, 23(22), 2215-2223. https://doi.org/10.1016/j.cub.2013.09.028 
Van Buskirk, C., \& Sternberg, P. W. (2010). Paired and LIM class homeodomain proteins coordinate differentiation of the $C$. elegans ALA neuron. Development, 137(12), 2065-2074. https://doi.org/10.1242/dev.040881

Van Buskirk, Cheryl, \& Sternberg, P. W. (2007). Epidermal growth factor signaling induces behavioral quiescence in Caenorhabditis elegans. Nature Neuroscience, 10(10), 1300-1307. https://doi.org/10.1038/nn1981

Vidal, B., Aghayeva, U., Sun, H., Wang, C., Glenwinkel, L., Bayer, E. A., \& Hobert, O. (2018). An atlas of Caenorhabditis elegans chemoreceptor expression. PLOS Biology, 16(1), e2004218. https://doi.org/10.1371/journal.pbio.2004218

Voutev, R., \& Hubbard, E. J. A. (2008). A "FLP-Out" system for controlled gene expression in Caenorhabditis elegans. Genetics, 180(1), 103-119. https://doi.org/10.1534/genetics.108.090274

Vyazovskiy, V., Borbély, A. A., \& Tobler, I. (2000). Unilateral vibrissae stimulation during waking induces interhemispheric EEG asymmetry during subsequent sleep in the rat. Journal of Sleep Research, 9(4), 367-371.

White, J. G., Southgate, E., Thomson, J. N., \& Brenner, S. (1986). The Structure of the Nervous System of the Nematode Caenorhabditis elegans. Philosophical Transactions of the Royal Society of London. Series B, Biological Sciences, 314(1165,), 1-340.

Wilm, T., Demel, P., Koop, H. U., Schnabel, H., \& Schnabel, R. (1999). Ballistic transformation of Caenorhabditis elegans. Gene, 229(1-2), 31-35.

Wright, K. P., Badia, P., \& Wauquier, A. (1995). Topographical and Temporal Patterns of Brain Activity During the Transition From Wakefulness to Sleep. Sleep, 18(10), 880-889. https://doi.org/10.1093/sleep/18.10.880

Wu, Y., Masurat, F., Preis, J., \& Bringmann, H. (2018). Sleep Counteracts Aging Phenotypes to Survive Starvation-Induced Developmental Arrest in C. elegans. Current Biology, 28(22), 3610-3624.e8. https://doi.org/10.1016/j.cub.2018.10.009

Xie, L., Kang, H., Xu, Q., Chen, M. J., Liao, Y., Thiyagarajan, M., ... Nedergaard, M. (2013). Sleep Drives Metabolite Clearance from the Adult Brain. Science, 342(6156), 373-377. https://doi.org/10.1126/science.1241224

Ye, S. (2001). An efficient procedure for genotyping single nucleotide polymorphisms. Nucleic Acids Research, 29(17), 88e-888. https://doi.org/10.1093/nar/29.17.e88

Yu, S., \& Driscoll, M. (2011). EGF signaling comes of age: promotion of healthy aging in C. elegans. Experimental Gerontology, 46(2-3), 129-134. https://doi.org/10.1016/j.exger.2010.10.010 


\section{Abbreviations}

AMI

Agarose microchamber imaging

ATR

All-trans-retinal

CPM

Counts per million

CLOCK

Circadian Locomotor Output Cycles Kaput

DIC

Differential interference contrast

EEG

Electroencephalogram

EGF

Epidermal growth factor

EGFR

EGF receptor

EMG

Electromyogram

FACS

Fluorescence-activated cell sorting

GABA

$\gamma$-aminobutyric acid

L1/L2/L3/L4

Larval state $1 / 2 / 3 / 4$

MMP

Million mutation project

NREM

Non rapid eye movement sleep

NGM

Nematode growth medium

PCA

Principal component analysis

PDMS

Polydimethylsiloxane

POA

Preoptic area

ReaChR

Red-shifted variant of channelrhodopsin

REM

Rapid eye movement sleep

RNA-seq

RNA sequencing

SCT

Single cell transcriptome

SIS

Stress-induced sleep

sci-RNA-seq

single-cell combinatorial indexing RNA sequencing 


\section{List of figures}

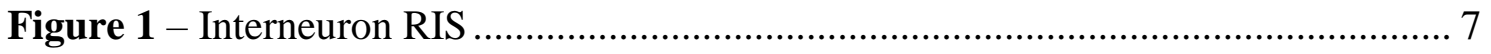

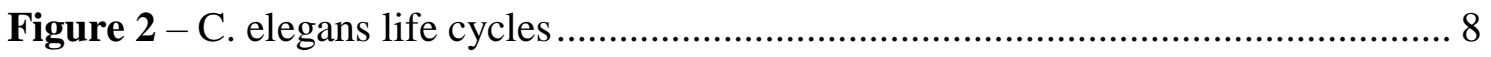

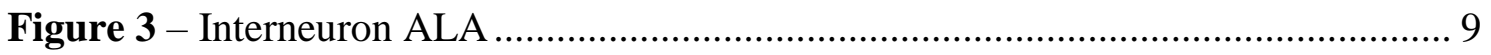

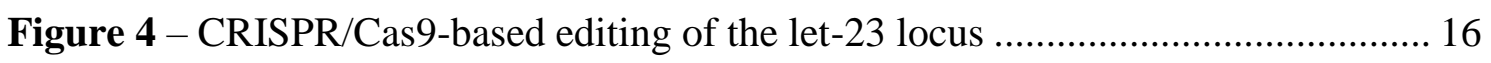

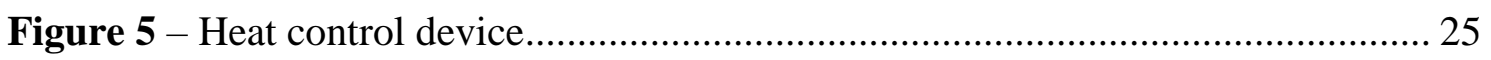

Figure 6 - Sleep-active RIS neuron transcriptome computed from single-cell data ..... 34

Figure 7 - RIS enriched genes for which fluorescence transgene reporters are expressed

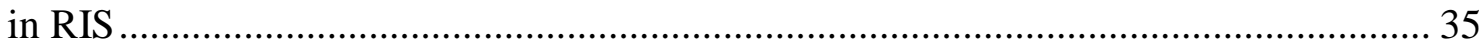

Figure 8 - RIS enriched genes for which fluorescent transgene reporters do not show

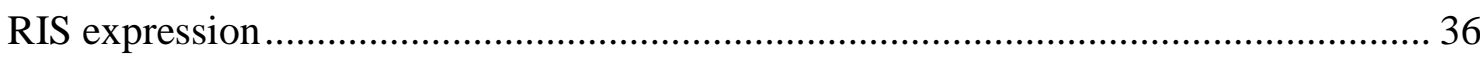

Figure 9 - The EGFR signaling machinery is expressed in both ALA and RIS neurons

Figure 10 - ALA and RIS are required for sleep after EGFR activation and cellular

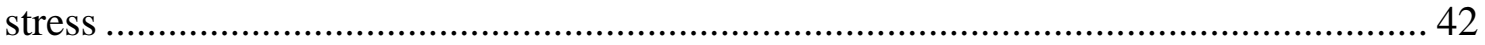

Figure 11 - EGFR is required in RIS to increase sleep after cellular stress .................. 44

Figure 12 - Heat shock and EGF activate RIS and ALA, and ALA acts upstream of

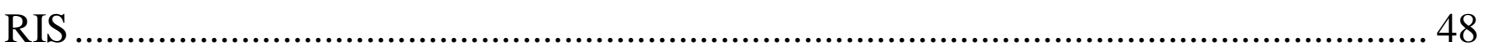

Figure 13 - ALA rather than RIS is required for survival following heat stress.......... 50 


\section{List of tables}

Table 1 - Constructs created and used for transgenic strain generation

Table 2 - C. elegans strains used throughout all experiments in this thesis. . 71

Table 3 - All primers used throughout this thesis and the regarding band sizes 75

Table 4 - All significantly differentially expressed genes of the "FACS/RNA-seq RIS vs. all" transcriptome and their $\log \mathrm{FC}$

Table 5 - All significantly differentially expressed genes of the "sci-RNA-seq RIS vs. all" transcriptome and their $\log \mathrm{FC}$ 96

Table 6 - All significantly differentially expressed genes of the "sci-RNA-seq RIS vs. neurons" transcriptome and their $\log \mathrm{FC}$ 98

Table 7 - All significantly differentially expressed genes of the "sci-RNA-seq ALA vs. neurons" transcriptome and their $\log \mathrm{FC}$. 99

Table 8 - Genes enriched in all three RIS transcriptomes 100 


\section{Appendix}

\subsection{Supplementary tables}

Table 2 - C. elegans strains used throughout all experiments in this thesis.

\begin{tabular}{|c|c|c|}
\hline strain & genotype & backcrossed \\
\hline $\mathrm{AH} 12$ & gap-1(ga133) X. & $\mathrm{x} 4$ \\
\hline AH5059 & let-23(zh131[FRT::let-23::FRT::GFP::LoxP::FLAG::let-23]) II. & \\
\hline AQ866 & ser-4(ok512) III. & $x 5$ \\
\hline BC16236 & dpy-5(e907) l; sEx16236[rCesT17E9.2a::GFP + pCeh361]. & $\mathrm{xO}$ \\
\hline CB30 & $s m a-1(e 30) \mathrm{V}$. & $\mathrm{x} 1$ \\
\hline CB6785 & unc-119(ed3) III; eEx650[ilys-4p::GFP + unc-119(+)]. & $x 2$ \\
\hline CG625 & $\begin{array}{l}\text { unc-103(n1213) pha-1(e2123) III; him-5(e1490) V; } \\
\text { rgEx235[plc-3p::YFP + pha-1(+)]. }\end{array}$ & \\
\hline DA1641 & $\begin{array}{l}\text { lin-15B\&lin-15A(n765) X; adEx1641[CO9B7.1::GFP + lin- } \\
\text { 15(+)]. }\end{array}$ & \\
\hline FX01512 & rabx-5(tm1512) III. & $\mathrm{x} 0$ \\
\hline FX01556 & tiam-1(tm1556) I. & $x 0$ \\
\hline FX02304 & ssup-72(tm2304) II. & $\mathrm{x} 0$ \\
\hline FX02584 & $m c t-6(t m 2584) X$ & $\mathrm{x} 0$ \\
\hline FX02735 & T21F2.1(tm2735) X. & $x 0$ \\
\hline FX03878 & pkg-2(tm3878) IV. & $x 0$ \\
\hline FX04341 & F57A8.4(tm4341) V. & $x 0$ \\
\hline FX04393 & nlp-37(tm4393)X. & $x 0$ \\
\hline FX04503 & kin-15(tm4503) II. & $x 0$ \\
\hline FX05049 & R11F4.2(tm5049) II. & $x 0$ \\
\hline FX05160 & F38B6.6(tm5160) X. & $x 0$ \\
\hline FX05990 & F40A3.7(tm5990) V. & $x 0$ \\
\hline FX06682 & C49H3.3(tm6682) IV. & $x 0$ \\
\hline FX17081 & cyn-10(tm6703) II. & $x 0$ \\
\hline FX18630 & mrpl-19(tm4843) I. & $x 0$ \\
\hline FX30291 & unc-25(tm2727) III. & $x 0$ \\
\hline HA328 & $\begin{array}{l}\text { lin-15B\&lin-15A(n765) X; rtEx233[nlp-11p::GFP + lin- } \\
15(+)] \text {. }\end{array}$ & \\
\hline HA329 & $\begin{array}{l}\text { lin-15B\&lin-15A(n765) X; rtEx234[nlp-13p::GFP + lin- } \\
\text { 15(+)]. }\end{array}$ & \\
\hline HBR1261 & goels288[flp-11p::mKate2::unc-54-3'utr, unc-119(+)]. & $x 2$ \\
\hline HBR1361 & $\begin{array}{l}\text { goels304[flp-11p::SL1-GCaMP3.35-SL2::mKate2-unc-54- } \\
\text { 3'UTR, unc-119(+)]. }\end{array}$ & $x 2$ \\
\hline HBR1777 & $\begin{array}{l}\text { goels384 [fIp-11p::egl-1::SL2-mKate2-flp-11-3'UTR, unc- } \\
119(+)] \text {. }\end{array}$ & $\mathrm{x} 0$ \\
\hline
\end{tabular}




\begin{tabular}{|c|c|c|}
\hline strain & genotype & backcrossed \\
\hline HBR183 & $c c a-1(a d 1650) X$ & $\mathrm{x} 0$ \\
\hline HBR1857 & $\begin{array}{l}\text { ceh-17(np1) I; goels304[flp-11p::SL1-GCaMP3.35- } \\
\text { SL2::mKate2-unc-54-3'UTR, unc-119(+)]. }\end{array}$ & $\mathrm{x} 0$ \\
\hline HBR2026 & C50F7.6(gk744131)IV. & $x 4$ \\
\hline HBR2040 & $c k r-1(0 k 2502) l$. & $x 2$ \\
\hline HBR2043 & R09F10.1(ok3119) X. & $\mathrm{x} 1$ \\
\hline HBR2047 & zig-2(ok696) X. & $\mathrm{x} 1$ \\
\hline HBR2066 & R02F2.4(gk382575) III. & $x 2$ \\
\hline HBR2067 & $F 32 D 1.3(g k 232755) \mathrm{V}$. & $\mathrm{x} 4$ \\
\hline HBR2068 & $n c s-6(g k 138627)$ II. & $x 2$ \\
\hline HBR2073 & gei-1(gk170616) III. & $x 2$ \\
\hline HBR2086 & $s r x-2(g k 242439)$ V. & $x 2$ \\
\hline HBR2088 & ceh-17(np1) l; aptf-1(gk794) II. & $\mathrm{x} 0$ \\
\hline HBR2107 & ilys-4(gk402093) IV. & $\mathrm{x} 4$ \\
\hline HBR2108 & srd-32(gk468949) V. & $x 2$ \\
\hline HBR2193 & $\begin{array}{l}\text { goeEx727[flp-24p::ReaChR::mKate2-unc-54 3'UTR, unc- } \\
\text { 122p::dsRed]; goels304[flp-11p::SL1-GCaMP3.35- } \\
\text { SL2::mKate2-unc-54-3'UTR, unc-119(+)]. }\end{array}$ & $\mathrm{x} 0$ \\
\hline HBR2195 & $\begin{array}{l}\text { let-23(sa62) II; goels304[flp-11p::SL1-GCaMP3.35- } \\
\text { SL2::mKate2-unc-54-3'UTR, unc-119(+)]; him-5(e1490) V; } \\
\text { syls197[hs::LIN-3C(cDNA) + myo-2p::dsRed + pha-1(+)]. }\end{array}$ & $\mathrm{x} 0$ \\
\hline HBR2205 & $\begin{array}{l}\text { syEx1286[hsp16-41p::flp-24, myo-2p::dsRed, KS+]; } \\
\text { goels304[pflp-11::SL1-GCaMP3.35-SL2::mKate2-unc-54- } \\
\text { 3'UTR, unc-119(+)]. }\end{array}$ & $\mathrm{x} 0$ \\
\hline HBR2238 & $\begin{array}{l}\text { bqSi542[unc-47p::FLP D5 + unc-119(+)]; let- } \\
\text { 23(zh131[FRT::let-23::FRT::GFP::LoxP::FLAG::let-23] II. }\end{array}$ & $\mathrm{x} 0$ \\
\hline HBR2239 & bqSi542[unc-47p::FLP D5 + unc-119(+)] & $x 2$ \\
\hline HBR2256 & $\begin{array}{l}\text { goeEx737[flp-24p::SL1-GCaMP3.35-SL2::SL2-mKate2::unc- } \\
54 \text { 3'UTR, unc-119(+)]. }\end{array}$ & $\mathrm{x} 0$ \\
\hline HBR2257 & $\begin{array}{l}\text { goeEx737[flp-24p::SL1-GCaMP3.35-SL2::SL2-mKate2::unc- } \\
54 \text { 3'UTR, unc-119(+)]; him-5(e1490) V; syls197 [hs::LIN- } \\
\text { 3C(cDNA) + myo-2p::dsRed + pha-1(+)]. }\end{array}$ & $\mathrm{x} 0$ \\
\hline HBR227 & aptf-1(gk794) II. & $\mathrm{x} 10$ \\
\hline HBR507 & flp-11(tm2706)X. & $x 7$ \\
\hline HBR763 & C10C6.7(goe4) IV. & $x 0$ \\
\hline HT1757 & unc-119(ed3) III; wwls34[ins-24p::GFP + unc-119(+)]. & $\mathrm{x} 0$ \\
\hline HT1768 & unc-119(ed3) III; wwls35[ins-27p::GFP + unc-119(+)]. & $\mathrm{x} 0$ \\
\hline IB16 & ceh-17(np1) I. & $x 0$ \\
\hline JD596 & $a v r-15(v u 227) V$ & $x 2$ \\
\hline JT734 & goa-1(sa734) I. & $x 3$ \\
\hline KJ355 & csq-1(jh109) $X$. & $x 6$ \\
\hline
\end{tabular}




\begin{tabular}{|c|c|c|}
\hline strain & genotype & backcrossed \\
\hline LSC1264 & sprr-1(ok3685) IV. & $\mathrm{x} 4$ \\
\hline LSC87 & IstEx6[pdf-2p::GFP + myo-3p::mCherry]. (pdf-2 = nlp-37) & \\
\hline MB5 & lin-15(ts); him5(e1490); rtEx277[Pnlp-8::GFP+lin-15(+)]. & \\
\hline MT4433 & ced-6(n1813) III. & \\
\hline MU1255 & $n h r-67(t m 2217) I V$. & $x 2$ \\
\hline N2 & wild type & \\
\hline NY2072 & yn/s72[flp-1p::GFP]. & $x 0$ \\
\hline $\mathrm{OH} 14368$ & $\begin{array}{l}\text { pha-1(e1323) III; him-5(e1490) V; otEx6710[srd-32p::GFP } \\
+ \text { pha-1(+)]. }\end{array}$ & \\
\hline $\mathrm{OH} 4836$ & ot/s7[zig-2::GFP + rol-6(su1006)]. & $x 2$ \\
\hline PHX530 & $n l p-11(s y b 530)$ II. & $\mathrm{x} 0$ \\
\hline PHX700 & ilys-4(syb700) IV. & $\mathrm{x} 0$ \\
\hline PS1839 & let-23(sa62) II. & \\
\hline PS2746 & $\begin{array}{l}\text { dpy-20(e1282) IV; syEx234[let-23::GFP + pBS + (pMH86) } \\
d p y-20(+)] .\end{array}$ & \\
\hline PS4886 & plc-3(tm1340) II. & \\
\hline RB1001 & cpna-3(ok922) IV. & $\mathrm{x} 0$ \\
\hline RB1136 & R05G6.10(ok1159) IV. & $\mathrm{x} 0$ \\
\hline RB1151 & $c f t-1(o k 1180) \mathrm{V}$ & $\mathrm{x} 0$ \\
\hline RB1245 & rga-1(ok204) II. & $\mathrm{x} 0$ \\
\hline RB1399 & T01H8.2(ok340) I. & $\mathrm{x} 0$ \\
\hline RB1431 & $m p s-2(o k 1631)$ II. & $\mathrm{x} 0$ \\
\hline RB1468 & $d k f-2(0 k 1704) V$ & $\mathrm{x} 0$ \\
\hline RB1512 & Y57A10A.24(ok1803) II. & $\mathrm{x} 0$ \\
\hline RB1523 & C24G7.1(ok1822) I. & $\mathrm{x} 0$ \\
\hline RB1911 & ins-27(ok2474) I. & $\mathrm{x} 0$ \\
\hline RB2110 & C39B10.1(ok2789) X. & $\mathrm{x} 0$ \\
\hline RB2269 & flp-34(ok3071) V. & $x 0$ \\
\hline RB2472 & nep-26(ok3412) II. & $x 0$ \\
\hline RB2627 & srg-69(ok3686) II. & $x 0$ \\
\hline RB5001 & ZC434.9(ok5212) I. & $x 0$ \\
\hline RB5002 & srx-125(ok5810) V. & $x 0$ \\
\hline RB669 & wee-1.1(ok418) II. & $x 0$ \\
\hline UP148 & sem-5(cs15) X. & $x 2$ \\
\hline VC1309 & nlp-8(ok1799) I. & $x 0$ \\
\hline VC1795 & $n r f l-1$ (ok2292) IV. & $x 1$ \\
\hline VC1909 & flp-1(ok2505) IV. & $\mathrm{x} 1$ \\
\hline VC20129 & gem-1(gk298521) X. & $x 0$ \\
\hline VC20159 & F19C6.3(gk290941)X. & $x 0$ \\
\hline
\end{tabular}




\begin{tabular}{|c|c|c|}
\hline strain & genotype & backcrossed \\
\hline VC20199 & $p m s-2(g k 247737) \mathrm{V}$. & $x 0$ \\
\hline VC20231 & rgef-1(gk243610) V. & $\mathrm{x} 0$ \\
\hline VC20263 & $g / b-23(g k 205062) I V$. & $\mathrm{xO}$ \\
\hline VC20307 & T21D12.12(gk191670) IV. & $x 0$ \\
\hline VC20312 & R08B4.2(gk326023)X. & $x 0$ \\
\hline VC20416 & $n h r-55(g k 947607) \mathrm{V}$. & $x 0$ \\
\hline VC20449 & K02D3.1(gk299318)X. & $x 0$ \\
\hline VC20489 & $n h r-128(g k 960157) \mathrm{V}$. & $\mathrm{x} 0$ \\
\hline VC20519 & F54H5.5(gk335875) II. & $x 0$ \\
\hline VC20522 & $n p r-29(g k 337633)$ III. & $x 0$ \\
\hline VC20554 & F53F4.17(gk251960) V. & $x 0$ \\
\hline VC20624 & $g / b-32(g k 360316) V$ & $x 0$ \\
\hline VC20630 & T22F3.7(gk362826) V. & $x 0$ \\
\hline VC20743 & Imd-4(gk389517) V. & $x 0$ \\
\hline VC226 & ida-1(ok409) III. & $x 0$ \\
\hline VC2565 & frpr-3(ok3302) V. & $x 0$ \\
\hline VC273 & tag-89(ok514) IV. & $\mathrm{x} 1$ \\
\hline VC30075 & T12B3.2(gk409439) IV. & $x 0$ \\
\hline VC30104 & $t p a-1(g k 414216) I V$. & $x 0$ \\
\hline VC30160 & ile-1(gk427192) I. & $x 0$ \\
\hline VC30245 & B0244.10(gk446359) III. & $x 0$ \\
\hline VC40013 & frpr-3(gk240031) V. & $x 0$ \\
\hline VC40057 & $d m s r-6(g k 161951) \|$. & $\mathrm{x} 0$ \\
\hline VC40140 & B0416.3(gk481746)X. & $x 0$ \\
\hline VC40198 & $\operatorname{lgc}-4(g k 509234) X$ & $\mathrm{x} 0$ \\
\hline VC40407 & F56D5.6(gk622448) IV. & $\mathrm{x} 0$ \\
\hline VC40500 & Y57G11C.36(gk961271) IV. & $\mathrm{x} 0$ \\
\hline VC40589 & ZK1307.7(gk708119), sri-46(gk708025) II. & $\mathrm{x} 0$ \\
\hline VC40598 & F57B10.4(gk712994) I. & $x 0$ \\
\hline VC40613 & frpr-16(gk722062) II. & $\mathrm{x} 0$ \\
\hline VC40626 & $t k r-1(g k 729500) I I I$. & $\mathrm{x} 0$ \\
\hline VC40630 & Y51H7C.13(gk732116) II. & $x 0$ \\
\hline VC40679 & C25G6.4(gk759467)X. & $\mathrm{x} 0$ \\
\hline VC40734 & $n h r-194(g k 784872) V$. & $x 0$ \\
\hline VC40893 & Y116A8B.4(gk869095) IV. & $\mathrm{x} 0$ \\
\hline VC975 & egas-2(ok1477) V. & $\mathrm{x} 0$ \\
\hline ZW477 & bkip-1(zw10) II. & $x 4$ \\
\hline
\end{tabular}


Appendix

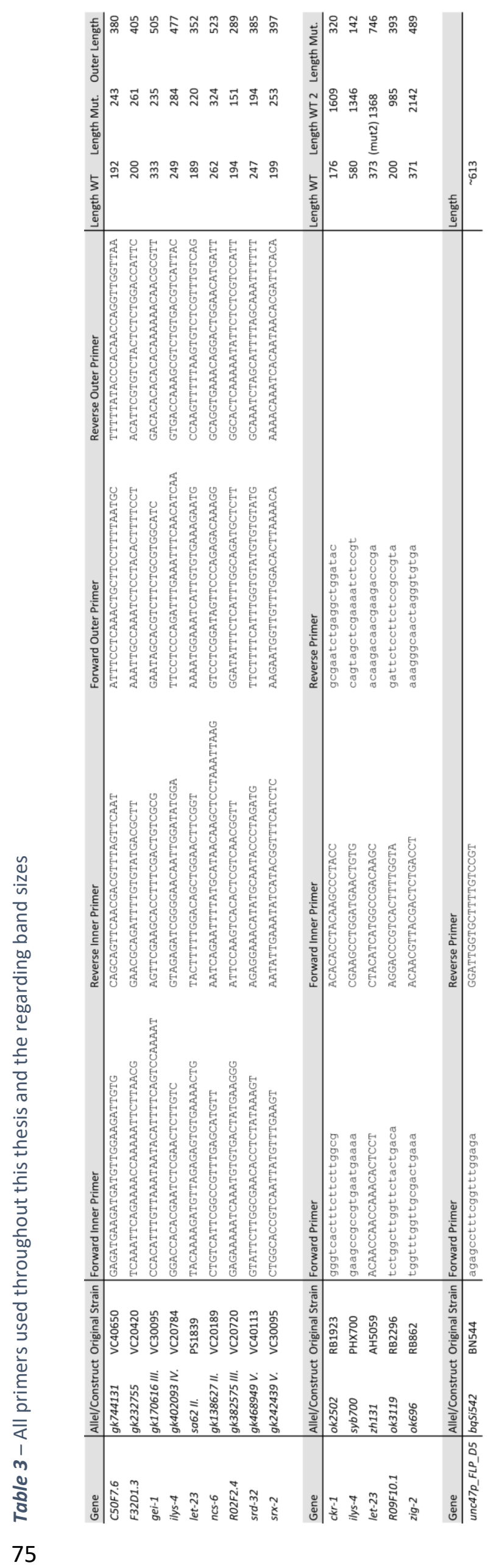




\section{Appendix}

Table 4 - All significantly differentially expressed genes of the "FACS/RNA-seq RIS vs. all" transcriptome and their $\log F C$

\begin{tabular}{|c|c|}
\hline gene & $\log F C$ \\
\hline C10C6.7 & 9,77 \\
\hline F46C5.7 & 10,12 \\
\hline F46C5.4 & 9,84 \\
\hline flp-11 & 9,75 \\
\hline ZK1307.7 & 9,49 \\
\hline$s r x-2$ & 9,72 \\
\hline ser-4 & 8,39 \\
\hline aptf-1 & 8,59 \\
\hline$t k r-1$ & 8,40 \\
\hline T05A8.3 & 7,83 \\
\hline F36D4.4 & 7,24 \\
\hline R11F4.2 & 8,80 \\
\hline F36G3.3 & 7,39 \\
\hline$c k r-1$ & 8,69 \\
\hline K02F2.5 & 7,89 \\
\hline T05E7.4 & 7,89 \\
\hline Y57G11C.46 & 8,55 \\
\hline rcan-1 & 8,16 \\
\hline C09G1.5 & 8,28 \\
\hline arrd-26 & 7,07 \\
\hline sprr-2 & 7,61 \\
\hline srg-69 & 9,83 \\
\hline$n c s-6$ & 6,70 \\
\hline hsp-70 & 9,70 \\
\hline C47E8.3 & 6,19 \\
\hline sto-5 & 5,93 \\
\hline T04A8.18 & 6,31 \\
\hline$B 0361.4$ & 6,66 \\
\hline ptr-5 & 5,79 \\
\hline tiam-1 & 5,87 \\
\hline$s b t-1$ & 5,72 \\
\hline egl-3 & 6,80 \\
\hline ida-1 & 5,82 \\
\hline ace-3 & 7,31 \\
\hline F14B6.2 & 5,95 \\
\hline nac-3 & 5,58 \\
\hline unc-47 & 6,27 \\
\hline$d m s r-2$ & 6,80 \\
\hline T10G3.8 & 5,93 \\
\hline sue-1 & 7,00 \\
\hline R07A4.2 & 6,57 \\
\hline frpr-7 & 6,31 \\
\hline T19D7.5 & 6,86 \\
\hline C25G6.4 & 6,87 \\
\hline F56A12.2 & 7,82 \\
\hline pde-3 & 7,07 \\
\hline unc-25 & 6,16 \\
\hline npr-32 & 7,53 \\
\hline pgal-1 & 5,92 \\
\hline$n / p-13$ & 7,47 \\
\hline exp-2 & 6,56 \\
\hline H35B03.1 & 5,76 \\
\hline pghm-1 & 5,55 \\
\hline $\lg c-53$ & 6,57 \\
\hline DH11.5 & 5,34 \\
\hline ZK742.7 & 6,22 \\
\hline$d m s r-6$ & 6,24 \\
\hline
\end{tabular}

\begin{tabular}{|c|c|}
\hline gene & $\log F C$ \\
\hline$u b c-3$ & 4,97 \\
\hline$n / p-11$ & 7,52 \\
\hline egl-21 & 5,21 \\
\hline cal-4 & 5,07 \\
\hline$n / p-8$ & 7,34 \\
\hline T27C4.1 & 7,10 \\
\hline rhgf-2 & 4,88 \\
\hline $\lim -6$ & 7,22 \\
\hline npr-29 & 5,80 \\
\hline frm-8 & 5,63 \\
\hline W02C12.2 & 4,60 \\
\hline$s c d-1$ & 5,67 \\
\hline H17B01.5 & 7,48 \\
\hline dop-1 & 5,66 \\
\hline unc-119 & 5,82 \\
\hline$h s p-16.11$ & 7,29 \\
\hline$h s p-16.48$ & 7,85 \\
\hline C08G5.7 & 6,58 \\
\hline igcm-2 & 6,80 \\
\hline kin-1 & 4,62 \\
\hline sta-1 & 4,88 \\
\hline K03B4.4 & 4,90 \\
\hline ZK1073.2 & 5,85 \\
\hline$c a b-1$ & 5,11 \\
\hline $\lg c-4$ & 5,76 \\
\hline$p t b-1$ & 4,62 \\
\hline$n p r-4$ & 5,59 \\
\hline sad-1 & 4,80 \\
\hline H10E21.5 & 6,30 \\
\hline bus-8 & $-5,88$ \\
\hline srd-32 & 6,64 \\
\hline$s p v-1$ & 5,05 \\
\hline nep-26 & 6,18 \\
\hline cutl-15 & 5,21 \\
\hline Y39A1A.24 & 5,90 \\
\hline arrd-17 & 6,32 \\
\hline$z t f-14$ & 6,43 \\
\hline$r a b x-5$ & 5,73 \\
\hline F32D1.3 & 5,03 \\
\hline ZC581.9 & 4,99 \\
\hline casy-1 & 5,17 \\
\hline Y51H4A.1 & 4,77 \\
\hline $\lg c-39$ & 5,06 \\
\hline Y51A2D.18 & $-6,38$ \\
\hline F21D12.3 & 5,63 \\
\hline T10G3.2 & 7,35 \\
\hline unc-46 & 5,33 \\
\hline tag-89 & 6,83 \\
\hline$a e x-6$ & 5,81 \\
\hline$g / b-18$ & 4,72 \\
\hline agmo-1 & $-8,83$ \\
\hline ZK512.7 & $-5,52$ \\
\hline$g g r-2$ & 6,16 \\
\hline ilys-4 & 7,04 \\
\hline Y43F8B.2 & 4,63 \\
\hline$d r n-1$ & 5,95 \\
\hline T10B5.4 & 5,48 \\
\hline
\end{tabular}

\begin{tabular}{|c|c|}
\hline gene & $\log F C$ \\
\hline unc-104 & 4,09 \\
\hline$h s p-110$ & 5,45 \\
\hline$g / b-23$ & 6,41 \\
\hline$m c p-1$ & 5,69 \\
\hline pgp-1 & $-6,14$ \\
\hline T14B4.8 & 4,72 \\
\hline feh-1 & 4,31 \\
\hline M05D6.6 & 5,39 \\
\hline F10E7.9 & 4,70 \\
\hline egl-18 & 4,94 \\
\hline F27C1.2 & 4,55 \\
\hline pdfr-1 & 4,34 \\
\hline C04E12.4 & $-6,07$ \\
\hline rund-1 & 6,51 \\
\hline jmjd-2 & 5,00 \\
\hline$h s p-16.1$ & 8,03 \\
\hline gst-11 & 6,61 \\
\hline Y44A6D.2 & 3,97 \\
\hline bed-2 & 6,55 \\
\hline wrk-1 & 4,12 \\
\hline ugt-60 & $-6,34$ \\
\hline zig-5 & 5,94 \\
\hline C44H4.6 & 5,63 \\
\hline unc-51 & 4,00 \\
\hline $\mathrm{C} 32 \mathrm{H} 11.8$ & $-6,34$ \\
\hline C05D12.7 & 5,58 \\
\hline ZK652.8 & 5,66 \\
\hline$R 107.5$ & 6,26 \\
\hline C01C4.3 & 5,26 \\
\hline gei-3 & 4,29 \\
\hline C35E7.11 & 4,96 \\
\hline acy-2 & 5,92 \\
\hline AH9.6 & 4,32 \\
\hline cmk-1 & 4,99 \\
\hline T11G6.3 & $-6,05$ \\
\hline C34C6.3 & 4,78 \\
\hline$n h x-9$ & $-6,18$ \\
\hline unc- 77 & 4,21 \\
\hline gcy-29 & 7,54 \\
\hline unc-57 & 4,11 \\
\hline E04F6.4 & $-6,02$ \\
\hline bus-18 & $-6,15$ \\
\hline ZK1025.3 & $-5,47$ \\
\hline frpr-6 & 5,29 \\
\hline$m p z-1$ & 3,80 \\
\hline ilcr-1 & 4,26 \\
\hline T05F1.11 & $-6,55$ \\
\hline myo-2 & $-5,13$ \\
\hline col-131 & $-7,41$ \\
\hline col-65 & $-4,91$ \\
\hline ZK822.2 & 5,41 \\
\hline pkg-2 & 3,58 \\
\hline unc-13 & 3,67 \\
\hline Y40B10A.9 & 5,56 \\
\hline W07E11.1 & 3,72 \\
\hline R05D3.9 & $-5,77$ \\
\hline snt-4 & 4,53 \\
\hline
\end{tabular}

\begin{tabular}{|c|c|}
\hline gene & $\log F C$ \\
\hline$m a b-7$ & $-5,40$ \\
\hline $\mathrm{col}-43$ & $-4,27$ \\
\hline$g l b-7$ & 6,68 \\
\hline$i r x-1$ & 4,00 \\
\hline T12A7.2 & 3,92 \\
\hline ador-1 & 5,79 \\
\hline F21C10.9 & $-6,09$ \\
\hline col-41 & $-5,40$ \\
\hline rskn-1 & 4,79 \\
\hline R04E5.8 & 4,23 \\
\hline clec-42 & $-6,37$ \\
\hline $\mathrm{C} 32 \mathrm{H} 11.11$ & $-13,00$ \\
\hline C30G7.2 & 4,60 \\
\hline wnk-1 & 3,50 \\
\hline T01B7.9 & 6,29 \\
\hline$a b t s-3$ & 4,56 \\
\hline $\mathrm{C} 30 \mathrm{H} 6.5$ & $-6,63$ \\
\hline lpr-7 & $-6,15$ \\
\hline$n h x-1$ & $-7,05$ \\
\hline VC5.2 & $-6,53$ \\
\hline$k / p-4$ & 3,70 \\
\hline R13H4.7 & 6,13 \\
\hline sprr-1 & 6,43 \\
\hline$d p y-4$ & $-4,01$ \\
\hline snt-3 & 5,18 \\
\hline K11C4.2 & 4,33 \\
\hline T06D8.10 & $-5,82$ \\
\hline$s n b-1$ & 4,59 \\
\hline avr-15 & 4,08 \\
\hline Imd-3 & 3,45 \\
\hline$a c p-1$ & $-8,19$ \\
\hline$o d r-2$ & 5,39 \\
\hline F20D6.8 & 4,47 \\
\hline F44E5.5 & 8,61 \\
\hline$n h r-62$ & $-6,79$ \\
\hline$a b u-12$ & $-5,91$ \\
\hline$n p r-17$ & 5,39 \\
\hline wrt-1 & $-5,62$ \\
\hline$f l p-27$ & 3,58 \\
\hline D1014.5 & $-5,09$ \\
\hline nra-1 & 5,21 \\
\hline lact-4 & 5,05 \\
\hline let-23 & 4,34 \\
\hline sipa-1 & 3,72 \\
\hline acox-1.5 & $-5,45$ \\
\hline egl-9 & 3,57 \\
\hline F54G2.1 & 3,65 \\
\hline unc-80 & 3,38 \\
\hline Y54G2A.26 & 4,32 \\
\hline pmp-2 & $-6,30$ \\
\hline T01G1.2 & 5,57 \\
\hline Y40C5A.4 & 4,49 \\
\hline$m / t-10$ & $-4,92$ \\
\hline Y41E3.7 & 4,38 \\
\hline T02E9.5 & 4,36 \\
\hline$d p y-13$ & $-4,12$ \\
\hline suro-1 & $-6,20$ \\
\hline
\end{tabular}




\section{Appendix}

\begin{tabular}{|l|r|}
\hline gene & logFC \\
\hline R07E3.6 & $-6,22$ \\
\hline M153.4 & 3,89 \\
\hline sto-6 & 4,92 \\
\hline C24B5.1 & 6,36 \\
\hline nhx-3 & $-6,87$ \\
\hline B0024.4 & $-6,89$ \\
\hline C01H6.4 & $-6,27$ \\
\hline glb-32 & 5,31 \\
\hline B0457.2 & $-5,85$ \\
\hline nfki-1 & 3,84 \\
\hline C35C5.8 & $-5,42$ \\
\hline B0334.13 & $-5,99$ \\
\hline sqt-3 & $-3,89$ \\
\hline F38B6.6 & 4,81 \\
\hline calf-1 & 3,74 \\
\hline F55D10.4 & 5,28 \\
\hline lad-2 & 4,48 \\
\hline nhr-238 & $-6,87$ \\
\hline C34F6.10 & 3,53 \\
\hline ugt-2 & $-6,66$ \\
\hline mam-2 & $-7,84$ \\
\hline alr-1 & 4,56 \\
\hline ZK180.5 & $-4,81$ \\
\hline osm-8 & $-7,34$ \\
\hline C32H11.5 & $-6,20$ \\
\hline frm-7 & $-5,15$ \\
\hline egl-15 & $-6,08$ \\
\hline T06A4.1 & $-6,21$ \\
\hline C05E7.2 & $-5,79$ \\
\hline C49C3.9 & $-6,63$ \\
\hline best-3 & $-6,86$ \\
\hline R02D3.1 & $-5,08$ \\
\hline wdfy-3 & 3,50 \\
\hline sfrp-1 & $-5,96$ \\
\hline nhl-1 & $-6,64$ \\
\hline Y38C1AB.1 & $-6,59$ \\
\hline cnt-1 & 3,97 \\
\hline acr-19 & 5,03 \\
\hline oga-1 & 4,03 \\
\hline dos-3 & 7,75 \\
\hline Y53F4B.45 & 3,27 \\
\hline col-174 & $-6,11$ \\
\hline tpa-1 & 3,44 \\
\hline wrt-3 & $-6,61$ \\
\hline C38C6.3 & $-6,46$ \\
\hline T04C9.1 & 3,30 \\
\hline mbk-2 & 3,20 \\
\hline F43D2.6 & $-6,74$ \\
\hline kcnl-1 & 3,51 \\
\hline wts-1 & $-5,63$ \\
\hline aat-5 & $-5,95$ \\
\hline dyn-1 \\
\hline cdh-10 \\
\hline svh-4 & 3,53 \\
\hline zmp-2 \\
\hline tag-180 \\
\hline pamn-1 \\
\hline
\end{tabular}

\begin{tabular}{|l|r|}
\hline gene & logFC \\
\hline cdgs-1 & 3,57 \\
\hline col-90 & $-4,25$ \\
\hline Y53F4B.27 & $-6,27$ \\
\hline C50D2.2 & 4,12 \\
\hline pqn-89 & 3,54 \\
\hline rimb-1 & 3,74 \\
\hline T07F12.4 & 5,24 \\
\hline F23H12.5 & $-6,52$ \\
\hline dnj-5 & 3,30 \\
\hline tyr-6 & $-7,16$ \\
\hline T16G12.1 & $-5,45$ \\
\hline col-14 & $-4,44$ \\
\hline F32B5.7 & 3,84 \\
\hline flp-26 & 5,67 \\
\hline dop-5 & 4,57 \\
\hline col-103 & $-3,61$ \\
\hline T04F3.1 & $-4,37$ \\
\hline oac-1 & $-6,50$ \\
\hline nlp-33 & $-4,43$ \\
\hline plc-3 & 3,38 \\
\hline W05H12.1 & 4,11 \\
\hline Y56A3A.6 & $-5,52$ \\
\hline F13H8.11 & $-7,11$ \\
\hline col-168 & $-3,66$ \\
\hline C37C3.7 & $-6,91$ \\
\hline clec-225 & $-6,91$ \\
\hline Y54G2A.76 & $-3,96$ \\
\hline pqn-13 & $-7,62$ \\
\hline sma-6 & $-7,37$ \\
\hline saeg-1 & 3,20 \\
\hline F41E7.1 & $-7,32$ \\
\hline daf-5 & 3,68 \\
\hline F44E7.7 & $-8,20$ \\
\hline F52G3.1 & 3,25 \\
\hline grl-15 & $-4,04$ \\
\hline goa-1 & 3,24 \\
\hline F44E5.4 & 8,70 \\
\hline sea-2 & 3,53 \\
\hline T05H4.7 & $-7,02$ \\
\hline bah-1 & $-6,26$ \\
\hline glb-12 & 5,65 \\
\hline dhp-1 & $-6,56$ \\
\hline lonp-2 & $-6,62$ \\
\hline npr-13 & 5,03 \\
\hline mtm-6 & 4,43 \\
\hline slc-17.8 & $-6,61$ \\
\hline ced-6 & 3,54 \\
\hline R74.8 & 4,17 \\
\hline T10B10.4 & 4,51 \\
\hline sqst-2 & $-7,08$ \\
\hline F56F10.2 & 3,48 \\
\hline F47G9.4 & $-5,37$ \\
\hline unc-32 & 5,07 \\
\hline K10C8.4 & \\
\hline dep-1 & \\
\hline T03F7.7 & forpr-19 \\
\hline
\end{tabular}

\begin{tabular}{|l|r|}
\hline gene & logFC \\
\hline sulp-4 & 4,31 \\
\hline hum-6 & $-4,60$ \\
\hline col-156 & $-5,38$ \\
\hline R07D5.2 & 5,70 \\
\hline ttll-12 & 3,98 \\
\hline ugt-63 & $-6,56$ \\
\hline gpdh-1 & $-6,74$ \\
\hline nas-25 & $-6,42$ \\
\hline E01G6.1 & $-5,80$ \\
\hline ZK262.2 & $-6,53$ \\
\hline Y105C5B.25 & 4,47 \\
\hline unc-79 & 3,47 \\
\hline rol-8 & $-3,81$ \\
\hline col-160 & $-3,42$ \\
\hline col-12 & $-3,47$ \\
\hline F26E4.7 & $-6,09$ \\
\hline cdka-1 & 3,92 \\
\hline W03G11.4 & 3,43 \\
\hline F28E10.1 & 3,15 \\
\hline qui-1 & 3,75 \\
\hline C35E7.2 & 4,05 \\
\hline nstp-2 & $-5,92$ \\
\hline acox-1.4 & $-5,20$ \\
\hline lips-3 & $-5,79$ \\
\hline C25F9.4 & $-5,75$ \\
\hline dpy-8 & $-4,43$ \\
\hline ubc-17 & 5,09 \\
\hline rpm-1 & 3,26 \\
\hline nlf-1 & 4,31 \\
\hline elt-3 & $-5,69$ \\
\hline col-161 & $-4,06$ \\
\hline C08B6.4 & $-6,60$ \\
\hline nfm-1 & $-6,51$ \\
\hline xhd-1 & $-4,41$ \\
\hline grl-16 & $-4,86$ \\
\hline dmsr-3 & 5,81 \\
\hline dos-1 & $-5,63$ \\
\hline F53F1.4 & $-3,79$ \\
\hline col-166 & $-3,34$ \\
\hline wrt-2 & $-6,06$ \\
\hline K08D8.5 & $-6,48$ \\
\hline col-58 & $-5,12$ \\
\hline nhr-176 & $-7,10$ \\
\hline mec-12 & 3,21 \\
\hline E04F6.6 & $-5,53$ \\
\hline F01D5.1 & $-5,02$ \\
\hline C53D5.5 & $-4,90$ \\
\hline glna-2 & $-6,83$ \\
\hline R07E4.1 & 4,00 \\
\hline F14B8.5 & $-5,89$ \\
\hline C46H11.2 & $-6,52$ \\
\hline F54C1.1 & $-7,25$ \\
\hline F43C9.2 & 3,05 \\
\hline cln-3.3 & $-6,32$ \\
\hline phat-2 & $-6,61$ \\
\hline C24A1.3 \\
\hline R03G5.6 \\
\hline
\end{tabular}

\begin{tabular}{|l|r|}
\hline gene & logFC \\
\hline unc-2 & 3,74 \\
\hline C04F1.1 & $-5,26$ \\
\hline gtr-1 & 5,49 \\
\hline nas-15 & $-7,41$ \\
\hline puf-9 & $-4,36$ \\
\hline H43E16.1 & $-6,05$ \\
\hline K07C11.4 & $-5,81$ \\
\hline R11.2 & 5,41 \\
\hline F54C9.7 & 4,70 \\
\hline nurf-1 & 4,76 \\
\hline C23H4.3 & $-6,43$ \\
\hline exc-7 & 3,36 \\
\hline scd-2 & 3,82 \\
\hline kcC-1 & $-5,42$ \\
\hline dnj-13 & 3,88 \\
\hline C53C7.5 & 3,97 \\
\hline F07A11.5 & $-3,86$ \\
\hline ZK370.4 & 2,91 \\
\hline C02B8.12 & $-7,00$ \\
\hline dmsr-1 & 3,98 \\
\hline H04M03.12 & 5,03 \\
\hline F07H5.8 & $-7,01$ \\
\hline F52H2.4 & 4,43 \\
\hline gldc-1 & $-4,61$ \\
\hline C12D12.1 & $-6,08$ \\
\hline pll-1 & 3,42 \\
\hline unc-9 & 3,66 \\
\hline npr-23 & 4,03 \\
\hline cyp-43A1 & $-5,55$ \\
\hline C32D5.12 & $-6,14$ \\
\hline nhr-212 & $-7,72$ \\
\hline dkf-2 & 2,95 \\
\hline lgc-43 & $-5,24$ \\
\hline ZC247.2 & $-5,13$ \\
\hline sol-2 & 4,38 \\
\hline F57H12.6 & $-3,91$ \\
\hline Ipr-5 & $-3,99$ \\
\hline clec-33 & $-7,45$ \\
\hline C05C8.7 & $-3,90$ \\
\hline F08D12.3 & $-6,35$ \\
\hline C02E7.7 & $-4,11$ \\
\hline doxa-1 & $-7,36$ \\
\hline C32C4.1 & 4,43 \\
\hline col-169 & $-3,56$ \\
\hline npr-16 & 4,27 \\
\hline Y54E10BL.3 & 3,90 \\
\hline M02G9.1 & $-6,23$ \\
\hline T22B11.4 & $-4,27$ \\
\hline F17C11.2 & 3,58 \\
\hline tmc-1 & $-7,18$ \\
\hline ZK1055.6 & $-6,29$ \\
\hline CcCp-1 & 3,37 \\
\hline unc-108 & 3,58 \\
\hline K10D11.5 & $-6,23$ \\
\hline elt-6 & 4,57 \\
\hline T03D8.6 & $-5,01$ \\
\hline ugt-55 & \\
\hline
\end{tabular}




\section{Appendix}

\begin{tabular}{|l|r|}
\hline gene & logFC \\
\hline C35A5.10 & $-6,45$ \\
\hline K09F5.6 & 3,58 \\
\hline F55A11.7 & $-5,17$ \\
\hline ugt-36 & $-8,71$ \\
\hline bkip-1 & 4,20 \\
\hline Y40H7A.10 & $-5,90$ \\
\hline K10D3.4 & $-5,18$ \\
\hline acl-5 & $-5,39$ \\
\hline C02E7.6 & $-3,65$ \\
\hline crn-6 & $-6,04$ \\
\hline eif-2Bdelta & $-5,55$ \\
\hline col-147 & $-3,28$ \\
\hline lim-8 & $-4,96$ \\
\hline C15B12.4 & $-6,32$ \\
\hline snt-1 & 3,77 \\
\hline C14B4.2 & $-5,95$ \\
\hline rgs-6 & 3,66 \\
\hline C46F11.6 & 3,91 \\
\hline prx-6 & $-6,36$ \\
\hline acs-14 & $-4,05$ \\
\hline Y37A1A.4 & $-7,71$ \\
\hline W10G11.19 & $-5,57$ \\
\hline ZK381.2 & $-7,18$ \\
\hline col-94 & $-3,21$ \\
\hline nsy-1 & 2,87 \\
\hline col-159 & $-3,16$ \\
\hline F11C1.7 & 3,14 \\
\hline F54D5.15 & $-7,18$ \\
\hline ugt-5 & $-6,37$ \\
\hline fbxl-1 & 3,20 \\
\hline vglu-3 & $-6,51$ \\
\hline K02E10.4 & $-6,07$ \\
\hline kin-19 & 3,45 \\
\hline chil-13 & $-6,25$ \\
\hline pah-1 & $-4,02$ \\
\hline nhr-132 & $-5,79$ \\
\hline sqt-1 & $-3,69$ \\
\hline col-46 & $-5,71$ \\
\hline nhr-71 & 4,12 \\
\hline pept-1 & $-5,62$ \\
\hline C32H11.6 & $-6,12$ \\
\hline col-93 & $-3,20$ \\
\hline F13B12.4 & $-5,33$ \\
\hline sem-5 & 4,10 \\
\hline C54G4.4 & $-7,68$ \\
\hline scp-1 & 4,95 \\
\hline unc-10 & 3,18 \\
\hline rgs-1 & 4,16 \\
\hline jip-1 & $-6,13$ \\
\hline ZK1025.4 & $-6,10$ \\
\hline F37A4.3 \\
\hline lips-15 & $-6,60$ \\
\hline T19D12.9 & $-6,60$ \\
\hline F38A6.4 & $-5,67$ \\
\hline Y7A9A.1 \\
\hline nhr-69 & $-8,11$ \\
\hline nhr-206 \\
\hline
\end{tabular}

\begin{tabular}{|l|r|}
\hline gene & logFC \\
\hline unc-40 & 3,38 \\
\hline nas-32 & $-6,51$ \\
\hline myo-1 & $-3,93$ \\
\hline F49E10.2 & $-6,45$ \\
\hline tba-7 & $-6,62$ \\
\hline acr-2 & 4,21 \\
\hline T19D12.6 & 2,92 \\
\hline cls-2 & 3,11 \\
\hline Y106G6H.1 & $-5,25$ \\
\hline prk-1 & $-5,02$ \\
\hline C05E11.7 & $-6,25$ \\
\hline C05C12.6 & 5,29 \\
\hline elo-5 & $-3,41$ \\
\hline H11E01.3 & 3,73 \\
\hline F17C8.6 & 4,49 \\
\hline F49F1.5 & $-3,44$ \\
\hline C27D8.3 & $-5,03$ \\
\hline pho-4 & $-5,53$ \\
\hline syd-9 & 3,37 \\
\hline C15B12.1 & $-5,71$ \\
\hline C05D12.3 & $-4,48$ \\
\hline col-10 & $-3,14$ \\
\hline efl-3 & $-6,37$ \\
\hline nhr-90 & $-5,22$ \\
\hline Y38C1AB.5 & $-5,80$ \\
\hline grd-6 & $-6,00$ \\
\hline flp-34 & 4,61 \\
\hline zip-11 & $-6,61$ \\
\hline clec-28 & $-7,03$ \\
\hline pmp-1 & $-4,82$ \\
\hline plc-2 & $-6,08$ \\
\hline col-115 & $-6,85$ \\
\hline F39H12.2 & $-8,25$ \\
\hline F22F7.2 & $-5,99$ \\
\hline ser-7 & 4,65 \\
\hline col-77 & $-3,91$ \\
\hline clec-37 & $-5,75$ \\
\hline Igc-21 & $-5,10$ \\
\hline gpb-1 & 3,41 \\
\hline C34C12.7 & $-5,22$ \\
\hline C17H12.4 & $-5,53$ \\
\hline F55C12.4 & 4,76 \\
\hline F46C8.8 & $-6,83$ \\
\hline skpo-2 & $-6,06$ \\
\hline T19D12.10 & $-6,71$ \\
\hline K10D11.3 & $-7,11$ \\
\hline F49C12.6 & $-6,35$ \\
\hline arrd-15 & 4,42 \\
\hline clec-230 & $-3,63$ \\
\hline C11H1.7 & 3,25 \\
\hline F14D12.1 & $-8,09$ \\
\hline T24C12.3 & $-6,17$ \\
\hline F30H5.3 & $-6,11$ \\
\hline C34B4.3 & $-5,90$ \\
\hline oxa-1 & $-6,35$ \\
\hline ram-2 & $-3,49$ \\
\hline let-4 & $-5,50$ \\
\hline
\end{tabular}

\begin{tabular}{|l|r|}
\hline gene & logFC \\
\hline unc-62 & $-3,31$ \\
\hline glt-3 & $-5,82$ \\
\hline nhr-205 & $-5,70$ \\
\hline spe-15 & 3,76 \\
\hline col-91 & $-4,13$ \\
\hline drap-1 & 3,53 \\
\hline ZK6.11 & $-3,72$ \\
\hline fard-1 & $-6,08$ \\
\hline cutl-23 & 4,02 \\
\hline T19C3.2 & $-4,60$ \\
\hline tbb-6 & $-5,27$ \\
\hline W01A8.6 & $-5,12$ \\
\hline R10D12.8 & $-6,05$ \\
\hline cdh-7 & $-4,64$ \\
\hline clec-180 & $-4,02$ \\
\hline R05H10.1 & $-5,19$ \\
\hline ttr-15 & $-3,47$ \\
\hline F42G2.2 & $-6,36$ \\
\hline B0228.6 & 4,25 \\
\hline mlt-4 & $-6,04$ \\
\hline cft-1 & $-5,93$ \\
\hline F48F7.3 & $-8,37$ \\
\hline T14G11.1 & 3,61 \\
\hline T07H6.1 & $-7,01$ \\
\hline Y18H1A.9 & $-3,98$ \\
\hline mct-6 & 3,10 \\
\hline lys-2 & $-4,15$ \\
\hline anat-1 & 3,36 \\
\hline Y102A11A.6 & $-6,20$ \\
\hline hif-1 & 2,93 \\
\hline Y47D3B.1 & $-5,43$ \\
\hline T21C9.9 & $-8,64$ \\
\hline flr-1 & $-6,57$ \\
\hline acox-1.2 & $-6,25$ \\
\hline rab-3 & 3,47 \\
\hline ccdc-149 & 3,43 \\
\hline H14E04.3 & 5,35 \\
\hline orc-1 & $-6,31$ \\
\hline ugt-65 & $-5,44$ \\
\hline mltn-1 & $-6,80$ \\
\hline lin-41 & 2,69 \\
\hline del-10 & $-7,04$ \\
\hline best-24 & $-5,45$ \\
\hline lars-2 & $-4,66$ \\
\hline inos-1 & 2,80 \\
\hline F30A10.2 & $-6,01$ \\
\hline dpy-21 & 2,78 \\
\hline col-133 & $-2,98$ \\
\hline acs-1 & $-4,34$ \\
\hline srp-1 & $-5,95$ \\
\hline apl-1 & 3,14 \\
\hline Y59C2A.3 \\
\hline kcnl-2 & $-6,35$ \\
\hline ugt-61 \\
\hline F16F9.4 \\
\hline ZC132.3 & $-6,39$ \\
\hline W02F12.2 \\
\hline
\end{tabular}

\begin{tabular}{|l|r|}
\hline gene & logFC \\
\hline mca-1 & $-3,65$ \\
\hline ugt-40 & $-5,85$ \\
\hline T13C2.2 & $-6,02$ \\
\hline ric-4 & 3,95 \\
\hline math-26 & $-6,49$ \\
\hline C54C8.4 & $-6,46$ \\
\hline Y41D4B.17 & $-6,12$ \\
\hline ZC455.1 & $-5,83$ \\
\hline Y46D2A.2 & $-5,17$ \\
\hline cyp-14A2 & $-7,46$ \\
\hline col-3 & $-2,92$ \\
\hline F10C2.3 & $-6,07$ \\
\hline nhr-16 & $-8,54$ \\
\hline C04F5.8 & $-5,95$ \\
\hline C26B9.3 & $-3,29$ \\
\hline col-180 & $-3,17$ \\
\hline ceh-79 & $-8,48$ \\
\hline T20F10.5 & 3,67 \\
\hline F48G7.4 & 4,67 \\
\hline Y39G8B.10 & $-5,36$ \\
\hline ver-3 & $-5,17$ \\
\hline M05D6.5 & 3,45 \\
\hline src-2 & $-7,24$ \\
\hline lact-5 & $-6,10$ \\
\hline M03E7.4 & $-6,39$ \\
\hline bgnt-1.8 & $-8,49$ \\
\hline akt-2 & 3,17 \\
\hline pqn-32 & $-5,35$ \\
\hline F32B4.5 & 2,58 \\
\hline Y39D8A.1 & $-6,06$ \\
\hline cah-6 & 4,71 \\
\hline C46C2.2 & 3,22 \\
\hline spp-13 & $-3,15$ \\
\hline math-4 & $-6,14$ \\
\hline F31A3.5 & 4,15 \\
\hline fbxa-38 & $-6,85$ \\
\hline glb-10 & 5,83 \\
\hline col-144 & $-3,75$ \\
\hline kin-16 & $-5,85$ \\
\hline math-3 & $-5,69$ \\
\hline F41C3.2 & $-6,34$ \\
\hline hsp-16.2 & 7,09 \\
\hline egl-8 & 2,70 \\
\hline glo-3 & $-5,72$ \\
\hline oac-29 & $-6,28$ \\
\hline lgc-50 & 4,84 \\
\hline unc-26 & 2,87 \\
\hline C36C9.10 & 4,66 \\
\hline B0403.6 & $-6,36$ \\
\hline col-92 & $-4,19$ \\
\hline pmt-2 & $-6,27$ \\
\hline crb-1 & \\
\hline C52G5.2 & $-3,24$ \\
\hline miz-1 & \\
\hline rbf-1 & \\
\hline col-146 & acd-3 \\
\hline
\end{tabular}




\section{Appendix}

\begin{tabular}{|l|r|}
\hline gene & logFC \\
\hline Y37F4.1 & 5,94 \\
\hline lact-8 & $-5,27$ \\
\hline F59B2.3 & $-4,79$ \\
\hline ZK822.5 & $-5,12$ \\
\hline nep-17 & $-4,14$ \\
\hline ctsa-2 & $-4,36$ \\
\hline Irp-1 & $-3,40$ \\
\hline F18F11.4 & $-6,12$ \\
\hline ugt-11 & $-6,21$ \\
\hline Y38F1A.8 & $-6,78$ \\
\hline rft-1 & $-6,55$ \\
\hline Y51H4A.7 & $-4,67$ \\
\hline R102.4 & $-3,48$ \\
\hline K05B2.4 & $-6,41$ \\
\hline chil-23 & $-6,06$ \\
\hline Y97E10C.1 & 2,68 \\
\hline fut-6 & $-8,06$ \\
\hline nlr-1 & 3,46 \\
\hline C05D2.8 & $-5,98$ \\
\hline acd-5 & $-8,37$ \\
\hline pqn-67 & $-6,01$ \\
\hline F40E10.6 & 3,33 \\
\hline cnc-8 & $-3,00$ \\
\hline mrpl-22 & 3,08 \\
\hline lam-1 & $-7,69$ \\
\hline F44G4.7 & $-7,18$ \\
\hline fbxa-219 & $-7,65$ \\
\hline ptr-18 & $-5,33$ \\
\hline F53B3.6 & $-2,99$ \\
\hline K10H10.12 & $-5,15$ \\
\hline F46C8.1 & $-6,80$ \\
\hline F59A7.8 & $-7,85$ \\
\hline B0205.4 & $-6,32$ \\
\hline nhr-23 & $-4,34$ \\
\hline ttr-29 & $-5,93$ \\
\hline chs-2 & $-4,76$ \\
\hline F25D1.5 & $-6,04$ \\
\hline spp-7 & $-8,05$ \\
\hline F21D5.3 & $-3,91$ \\
\hline M04C3.1 & $-5,42$ \\
\hline R03E9.2 & $-6,63$ \\
\hline rig-1 & 3,58 \\
\hline C53C9.2 & $-3,97$ \\
\hline svop-1 & 3,55 \\
\hline che-11 & $-7,02$ \\
\hline T07F10.1 & $-6,87$ \\
\hline dct-6 & $-5,31$ \\
\hline tyr-4 & $-5,86$ \\
\hline ZK1073.1 & 3,80 \\
\hline ifp-1 & $-4,83$ \\
\hline T12A2.1 & $-7,08$ \\
\hline clec-86 & $-5,26$ \\
\hline vps-33.2 & $-4,67$ \\
\hline chd-7 & 2,44 \\
\hline F57F5.3 & $-8,75$ \\
\hline AC3.5 & $-3,19$ \\
\hline ncx-8 & $-6,06$ \\
\hline
\end{tabular}

\begin{tabular}{|l|r|}
\hline gene & logFC \\
\hline abu-14 & $-4,56$ \\
\hline mom-4 & $-5,04$ \\
\hline dmd-6 & 2,50 \\
\hline F17C11.12 & $-5,09$ \\
\hline hpo-34 & $-3,34$ \\
\hline K10C2.1 & $-4,88$ \\
\hline Y16B4A.2 & $-5,58$ \\
\hline let-60 & 2,85 \\
\hline C55A6.4 & $-2,96$ \\
\hline F42G4.5 & $-6,02$ \\
\hline F55D12.5 & $-5,57$ \\
\hline hum-9 & $-4,65$ \\
\hline T09B4.8 & $-4,69$ \\
\hline F46G10.2 & $-5,65$ \\
\hline str-176 & $-7,65$ \\
\hline T07F10.6 & $-7,43$ \\
\hline R12E2.15 & $-3,91$ \\
\hline clec-57 & $-4,88$ \\
\hline osm-5 & $-5,44$ \\
\hline tyra-2 & 3,66 \\
\hline F53B3.3 & $-6,51$ \\
\hline C05D11.9 & $-5,04$ \\
\hline gst-13 & $-3,16$ \\
\hline Y37A1A.2 & $-6,05$ \\
\hline samt-1 & $-4,00$ \\
\hline his-19 & $-6,83$ \\
\hline his-21 & $-6,83$ \\
\hline his-51 & $-6,83$ \\
\hline his-53 & $-6,83$ \\
\hline C26C6.9 & $-3,21$ \\
\hline pcp-1 & $-3,82$ \\
\hline Y106G6H.14 & $-7,46$ \\
\hline T23F11.4 & 3,90 \\
\hline T10E10.4 & $-5,96$ \\
\hline nep-12 & $-6,70$ \\
\hline irk-1 & 3,93 \\
\hline H06H21.8 & $-6,60$ \\
\hline fmo-1 & $-4,80$ \\
\hline C10A4.10 & $-8,20$ \\
\hline aldo-2 & $-2,84$ \\
\hline klo-1 & $-4,48$ \\
\hline daf-6 & $-7,95$ \\
\hline Y69H2.9 & $-6,15$ \\
\hline Y38A10A.2 & $-7,14$ \\
\hline col-170 & $-3,50$ \\
\hline T01D1.8 & $-8,08$ \\
\hline C30G12.2 & $-7,83$ \\
\hline ent-7 & $-6,25$ \\
\hline cng-2 & $-8,00$ \\
\hline T19D12.4 & $-5,84$ \\
\hline gar-3 & $-6,60$ \\
\hline wdr-48 & $-6,21$ \\
\hline pepm-1 & $-6,19$ \\
\hline F01G10.10 \\
\hline lin-24 & -02 \\
\hline C33E10.8 & \\
\hline ugt-9 & \\
\hline
\end{tabular}

\begin{tabular}{|l|r|}
\hline gene & logFC \\
\hline C17H11.1 & 5,29 \\
\hline E02H1.5 & $-7,97$ \\
\hline ckr-2 & 4,03 \\
\hline orc-4 & $-6,20$ \\
\hline pqn-65 & 2,63 \\
\hline cla-1 & 3,10 \\
\hline Y39A1A.14 & $-6,41$ \\
\hline trpl-3 & $-8,41$ \\
\hline pkc-1 & 2,61 \\
\hline C56A3.5 & $-4,65$ \\
\hline tbc-19 & $-8,22$ \\
\hline Y113G7B.14 & $-10,83$ \\
\hline fbxa-51 & $-7,95$ \\
\hline fbxa-2 & $-6,46$ \\
\hline F16C3.2 & $-4,47$ \\
\hline Y55F3BR.2 & $-4,94$ \\
\hline col-66 & $-5,19$ \\
\hline nipi-4 & $-5,04$ \\
\hline Iron-15 & $-7,78$ \\
\hline F55G1.15 & $-5,74$ \\
\hline dpf-6 & $-4,71$ \\
\hline jud-4 & $-6,16$ \\
\hline ZK742.3 & $-6,37$ \\
\hline lin-10 & 2,75 \\
\hline T28H11.8 & $-4,71$ \\
\hline chpf-2 & $-6,75$ \\
\hline nspc-19 & $-7,97$ \\
\hline fipr-21 & $-3,86$ \\
\hline fbxa-92 & $-7,04$ \\
\hline cyp-35A5 & $-7,72$ \\
\hline Co1B10.4 & $-6,57$ \\
\hline col-39 & $-3,38$ \\
\hline M176.5 & 2,91 \\
\hline C03G6.5 & $-6,83$ \\
\hline R07B1.9 & $-7,25$ \\
\hline pqn-8 & $-7,06$ \\
\hline thoc-2 & 2,50 \\
\hline T21B6.3 & $-4,86$ \\
\hline T24D3.2 & $-10,54$ \\
\hline C26B2.8 & $-6,26$ \\
\hline ptr-3 & $-7,68$ \\
\hline otpl-7 & $-6,03$ \\
\hline ZK816.1 & 5,90 \\
\hline bmy-1 & 4,52 \\
\hline col-48 & $-6,04$ \\
\hline C15C8.4 & $-7,00$ \\
\hline twk-14 & $-5,66$ \\
\hline fbf-2 & $-6,47$ \\
\hline C30G12.1 & $-6,42$ \\
\hline fbxa-90 & $-4,81$ \\
\hline ZK1025.5 & $-7,55$ \\
\hline C49C8.5 & $-4,46$ \\
\hline F53C11.1 & $-5,28$ \\
\hline sec-6 & 2,63 \\
\hline T10B10.3 & 4,03 \\
\hline F36F2.7 & $-7,17$ \\
\hline D1086.2 & $-6,58$ \\
\hline
\end{tabular}

\begin{tabular}{|l|r|}
\hline gene & logFC \\
\hline ctn-1 & 2,74 \\
\hline tbc-16 & 3,95 \\
\hline pac-1 & 2,45 \\
\hline nas-29 & $-6,41$ \\
\hline afmd-2 & $-5,98$ \\
\hline Y64H9A.2 & $-4,19$ \\
\hline F58G6.7 & $-7,25$ \\
\hline flr-4 & $-6,97$ \\
\hline T07G12.2 & $-6,16$ \\
\hline nrx-1 & 3,64 \\
\hline F19C7.2 & $-5,97$ \\
\hline M02B1.3 & 3,20 \\
\hline axl-1 & $-6,75$ \\
\hline F46G10.4 & $-6,78$ \\
\hline F11F1.1 & $-6,66$ \\
\hline nhx-4 & 3,82 \\
\hline kcnl-4 & $-6,06$ \\
\hline col-125 & $-3,19$ \\
\hline nhr-17 & 3,88 \\
\hline nep-11 & 3,05 \\
\hline F40E10.5 & $-4,86$ \\
\hline unc-82 & $-4,12$ \\
\hline ugt-21 & $-6,14$ \\
\hline acd-2 & $-6,65$ \\
\hline ZC449.7 & $-6,85$ \\
\hline D1007.13 & $-5,61$ \\
\hline ZC449.2 & $-6,00$ \\
\hline mes-4 & $-5,70$ \\
\hline ani-3 & $-7,06$ \\
\hline prk-2 & $-5,76$ \\
\hline catp-1 & $-5,93$ \\
\hline K09C4.5 & $-5,85$ \\
\hline dod-19 & $-3,98$ \\
\hline F54E7.6 & $-6,37$ \\
\hline B0280.13 & $-7,99$ \\
\hline R06A10.4 & $-7,54$ \\
\hline F23H12.3 & $-6,13$ \\
\hline cln-3.1 & $-5,96$ \\
\hline istr-1 & 2,70 \\
\hline try-3 & $-6,03$ \\
\hline cks-1 & $-7,57$ \\
\hline acdh-6 & $-7,55$ \\
\hline mam-8 & $-4,83$ \\
\hline par-1 & 2,46 \\
\hline nlp-35 & 4,43 \\
\hline ZK185.5 & $-6,10$ \\
\hline F58F9.3 & $-8,18$ \\
\hline F13B6.1 & $-10,72$ \\
\hline clec-64 & $-7,89$ \\
\hline C31B8.7 & $-7,60$ \\
\hline K11H12.11 & $-6,15$ \\
\hline octr-1 & $-6,11$ \\
\hline C44H9.6 & $-5,10$ \\
\hline fshr-1 \\
\hline B0252.1 \\
\hline T04A11.1 \\
\hline T04A11.4 & \\
\hline
\end{tabular}




\section{Appendix}

\begin{tabular}{|l|r|}
\hline gene & logFC \\
\hline his-35 & 2,83 \\
\hline F21D9.4 & $-6,91$ \\
\hline F02A9.1 & 4,80 \\
\hline folt-2 & $-5,61$ \\
\hline clec-227 & $-5,22$ \\
\hline B0454.6 & $-10,44$ \\
\hline C45G7.13 & $-7,16$ \\
\hline igdb-2 & $-5,61$ \\
\hline col-167 & $-2,90$ \\
\hline nxf-2 & $-6,13$ \\
\hline ZC239.15 & $-10,71$ \\
\hline C50B8.5 & $-6,32$ \\
\hline T24B8.4 & $-4,68$ \\
\hline ugt-7 & $-4,53$ \\
\hline cdh-5 & $-6,10$ \\
\hline cyp-35D1 & $-6,75$ \\
\hline Y50D4B.6 & $-6,04$ \\
\hline cyp-13A10 & $-6,20$ \\
\hline slc-17.3 & $-6,11$ \\
\hline degt-1 & $-6,37$ \\
\hline grl-5 & $-4,60$ \\
\hline T13H5.6 & $-6,30$ \\
\hline nhr-108 & $-6,01$ \\
\hline M28.8 & $-5,66$ \\
\hline C17B7.5 & $-6,82$ \\
\hline K01B6.3 & $-10,45$ \\
\hline unc-73 & 2,46 \\
\hline F28H6.6 & $-7,03$ \\
\hline C52A10.1 & $-3,96$ \\
\hline sur-6 & 2,46 \\
\hline rga-5 & $-4,36$ \\
\hline nca-2 & 3,31 \\
\hline C25F9.5 & $-6,15$ \\
\hline Y75B8A.16 & $-6,12$ \\
\hline R07E5.4 & $-6,18$ \\
\hline cpt-4 & $-5,68$ \\
\hline nas-38 & $-5,33$ \\
\hline kal-1 & 3,61 \\
\hline Y53C12B.7 & $-5,89$ \\
\hline sbp-1 & $-4,77$ \\
\hline best-8 & $-7,37$ \\
\hline C12D5.10 & $-6,41$ \\
\hline linc-7 & 6,33 \\
\hline cyp-31A2 & 4,94 \\
\hline abch-1 & $-5,75$ \\
\hline C53B7.3 & $-3,48$ \\
\hline tag-10 & $-4,66$ \\
\hline Y57G11A.4 & $-4,49$ \\
\hline T04F8.8 & $-2,88$ \\
\hline clec-229 & $-6,12$ \\
\hline gcy-21 & $-7,63$ \\
\hline col-137 & $-3,03$ \\
\hline bbs-5 & $-5,72$ \\
\hline unc-36 \\
\hline gtl-2 & \\
\hline To2B11.6 & \\
\hline dyf-1 & \\
\hline & \\
\hline
\end{tabular}

\begin{tabular}{|l|r|}
\hline gene & logFC \\
\hline ZK418.6 & $-6,14$ \\
\hline F26A1.9 & $-5,87$ \\
\hline osta-2 & 2,88 \\
\hline T01G5.1 & $-5,55$ \\
\hline Y47D3A.14 & $-7,47$ \\
\hline col-117 & $-2,73$ \\
\hline Y18H1A.14 & $-7,49$ \\
\hline T19C9.10 & $-8,21$ \\
\hline nhr-98 & $-10,16$ \\
\hline sago-2 & $-7,08$ \\
\hline Y73F8A.5 & 3,51 \\
\hline mlt-3 & $-4,23$ \\
\hline sri-40 & $-8,22$ \\
\hline K10G9.2 & 3,89 \\
\hline T14A8.2 & $-5,84$ \\
\hline col-158 & $-4,09$ \\
\hline nhr-7 & $-6,50$ \\
\hline cpin-1 & $-5,22$ \\
\hline C09G1.4 & 3,29 \\
\hline Y34B4A.5 & $-5,78$ \\
\hline F13H8.3 & $-5,83$ \\
\hline apt-9 & 3,45 \\
\hline C39B10.1 & 4,16 \\
\hline grl-8 & 3,88 \\
\hline ndg-4 & $-5,64$ \\
\hline pck-2 & $-2,98$ \\
\hline ncs-4 & $-6,10$ \\
\hline C49H3.12 & $-7,54$ \\
\hline Y57G11C.31 & $-3,45$ \\
\hline bus-4 & $-6,12$ \\
\hline C46H11.7 & $-7,26$ \\
\hline rab-37 & 3,78 \\
\hline W01C9.2 & $-7,46$ \\
\hline lgc-10 & 5,20 \\
\hline W01F3.2 & $-5,60$ \\
\hline rgef-1 & 4,99 \\
\hline dop-3 & 4,00 \\
\hline K07E3.4 & $-3,56$ \\
\hline T13H10.2 & $-5,62$ \\
\hline henn-1 & 3,39 \\
\hline Y119C1B.6 & 5,54 \\
\hline Y2H9A.4 & $-7,29$ \\
\hline C08B6.10 & $-3,14$ \\
\hline haf-4 & $-3,72$ \\
\hline C08F11.3 & $-10,29$ \\
\hline D1054.9 & $-3,66$ \\
\hline mxt-1 & $-3,87$ \\
\hline prx-2 & $-6,30$ \\
\hline fkb-5 & $-4,61$ \\
\hline ksr-2 & $-4,69$ \\
\hline Y57G11C.22 & 3,61 \\
\hline cyp-35A3 & $-6,55$ \\
\hline fasn-1 & $-2,68$ \\
\hline gcy-8 & $-6,36$ \\
\hline T07G12.3 & $-7,44$ \\
\hline snt-7 & 5,55 \\
\hline che-14 & $-6,26$ \\
\hline
\end{tabular}

\begin{tabular}{|l|r|}
\hline gene & logFC \\
\hline col-13 & $-2,98$ \\
\hline R10D12.1 & $-7,29$ \\
\hline C32E8.6 & $-7,12$ \\
\hline polk-1 & $-5,28$ \\
\hline Y119D3B.12 & 3,23 \\
\hline nsf-1 & 3,15 \\
\hline F13D11.4 & $-4,56$ \\
\hline sqst-5 & $-7,34$ \\
\hline C16C10.1 & $-6,89$ \\
\hline Y62E10A.19 & $-2,92$ \\
\hline clec-3 & $-6,90$ \\
\hline F47B8.5 & $-5,31$ \\
\hline col-162 & $-4,99$ \\
\hline C26D10.6 & 3,10 \\
\hline cah-1 & 3,49 \\
\hline T21F4.1 & $-3,04$ \\
\hline deg-3 & $-5,45$ \\
\hline twk-34 & $-5,85$ \\
\hline cutl-11 & $-9,99$ \\
\hline pqn-62 & $-6,01$ \\
\hline aat-6 & $-7,34$ \\
\hline F41B4.1 & $-6,05$ \\
\hline col-130 & $-3,27$ \\
\hline F35C11.4 & $-6,36$ \\
\hline tag-244 & $-6,10$ \\
\hline pept-3 & 3,19 \\
\hline nas-30 & $-4,96$ \\
\hline kin-15 & 2,62 \\
\hline swt-3 & $-4,99$ \\
\hline F27C8.2 & $-6,51$ \\
\hline try-10 & $-5,67$ \\
\hline C04G6.2 & $-5,83$ \\
\hline pat-9 & $-5,43$ \\
\hline ctc-3 & 2,45 \\
\hline Y9C9A.16 & $-5,95$ \\
\hline mab-9 & $-4,88$ \\
\hline ceh-92 & $-6,48$ \\
\hline F56D5.6 & $-4,47$ \\
\hline ZC84.6 & $-6,43$ \\
\hline F13H8.6 & $-9,89$ \\
\hline frm-2 & $-4,71$ \\
\hline Iron-1 & $-7,56$ \\
\hline R10E8.1 & $-6,45$ \\
\hline fut-2 & $-6,58$ \\
\hline nab-1 & 2,46 \\
\hline best-18 & $-4,60$ \\
\hline let-805 & $-2,47$ \\
\hline lgc-11 & $-5,98$ \\
\hline F44G3.10 & $-5,65$ \\
\hline Y102A11A.2 & $-10,33$ \\
\hline wee-1.3 & $-7,67$ \\
\hline M03F4.6 \\
\hline acr-7 & $-5,75$ \\
\hline H10E21.4 \\
\hline F23F12.3 & $-5,79$ \\
\hline zipt-2.1 & $-4,56$ \\
\hline slc-17.1 \\
\hline
\end{tabular}

\begin{tabular}{|l|r|}
\hline gene & logFC \\
\hline scl-6 & $-6,82$ \\
\hline R193.2 & $-4,58$ \\
\hline arrd-20 & 4,89 \\
\hline E01G6.2 & 3,68 \\
\hline dmd-4 & $-6,42$ \\
\hline lev-10 & 2,66 \\
\hline C16D9.4 & $-10,24$ \\
\hline F10C1.9 & $-5,36$ \\
\hline cyp-13A6 & $-5,83$ \\
\hline D1022.4 & $-3,06$ \\
\hline clh-2 & $-4,82$ \\
\hline W06H8.5 & 3,15 \\
\hline ogdh-2 & $-2,94$ \\
\hline F36H9.5 & $-9,89$ \\
\hline F13D12.6 & $-3,64$ \\
\hline F42C5.4 & $-5,60$ \\
\hline K08B5.2 & $-7,18$ \\
\hline best-4 & $-6,63$ \\
\hline Y69A2AL.2 & $-9,95$ \\
\hline F56A4.10 & $-5,69$ \\
\hline fbxa-166 & $-7,66$ \\
\hline K04G11.3 & $-6,67$ \\
\hline D2007.2 & $-6,72$ \\
\hline F55G11.8 & $-3,54$ \\
\hline pgp-2 & $-4,42$ \\
\hline klu-1 & 4,07 \\
\hline dct-1 & 4,47 \\
\hline ech-9 & $-6,33$ \\
\hline T02B5.3 & $-6,38$ \\
\hline C55B6.1 & $-7,38$ \\
\hline ceh-62 & 4,14 \\
\hline C15F1.1 & $-5,91$ \\
\hline zag-1 & 3,88 \\
\hline ugt-6 & $-5,22$ \\
\hline Y44A6C.1 & 3,33 \\
\hline lap-2 & 2,64 \\
\hline T06G6.6 & $-4,10$ \\
\hline F33G12.6 & 2,79 \\
\hline F32H5.4 & $-5,97$ \\
\hline peli-1 & 4,46 \\
\hline F32D8.3 & $-9,62$ \\
\hline Y73B6BL.47 & 4,48 \\
\hline fzr-1 & 2,69 \\
\hline otpl-3 & $-4,96$ \\
\hline T05H4.15 & $-7,37$ \\
\hline F09A5.2 & $-6,99$ \\
\hline H10D18.5 & 2,59 \\
\hline ctc-1 & 2,76 \\
\hline unc-18 & 2,64 \\
\hline B0403.5 & $-6,89$ \\
\hline F36D1.7 & $-3,49$ \\
\hline clec-36 & $-5,91$ \\
\hline F36G9.3 & $-10,11$ \\
\hline bus-1 & $-3,81$ \\
\hline dus-2 \\
\hline best-16 & \\
\hline C26B9.5 & \\
\hline
\end{tabular}




\section{Appendix}

\begin{tabular}{|l|r|}
\hline gene & logFC \\
\hline F35A5.8 & 2,87 \\
\hline cpr-6 & $-3,78$ \\
\hline daf-11 & $-9,71$ \\
\hline Clec-53 & $-5,77$ \\
\hline C13A2.1 & $-6,26$ \\
\hline gtl-1 & $-5,26$ \\
\hline C49A9.2 & $-6,55$ \\
\hline F45D11.14 & $-5,62$ \\
\hline F28H7.3 & $-2,75$ \\
\hline oac-51 & $-5,10$ \\
\hline F15B10.3 & $-9,43$ \\
\hline C50F4.6 & 2,63 \\
\hline T23G5.3 & $-8,29$ \\
\hline M05D6.9 & $-7,11$ \\
\hline T17H7.7 & $-5,39$ \\
\hline C15C6.1 & $-6,41$ \\
\hline cyp-35C1 & $-4,65$ \\
\hline Y54E10A.6 & $-6,23$ \\
\hline nhr-125 & $-6,03$ \\
\hline T18D3.7 & 3,18 \\
\hline M01B2.8 & $-9,49$ \\
\hline F58H7.1 & $-6,50$ \\
\hline Y47G6A.14 & $-9,77$ \\
\hline T07F12.1 & $-6,10$ \\
\hline H03E18.2 & $-6,98$ \\
\hline E04F6.15 & $-6,74$ \\
\hline C46E1.3 & $-6,83$ \\
\hline ugt-25 & $-4,96$ \\
\hline sys-1 & $-7,19$ \\
\hline R10E8.8 & $-7,06$ \\
\hline math-37 & $-9,67$ \\
\hline lipl-1 & $-5,98$ \\
\hline C04E6.12 & 3,18 \\
\hline B0348.5 & $-6,22$ \\
\hline C27B7.7 & $-7,18$ \\
\hline fbxa-175 & $-6,71$ \\
\hline R03H10.2 & $-5,51$ \\
\hline F59B10.4 & $-5,94$ \\
\hline ZK669.5 & $-6,29$ \\
\hline ugt-33 & $-7,27$ \\
\hline cutl-5 & $-6,14$ \\
\hline hpo-6 & $-3,69$ \\
\hline F11E6.8 & $-5,24$ \\
\hline asd-1 & 3,85 \\
\hline T20D4.3 & $-10,46$ \\
\hline egl-6 & $-9,22$ \\
\hline Y39B6A.8 & $-6,90$ \\
\hline igcm-4 & 3,74 \\
\hline F54D5.5 & $-9,10$ \\
\hline best-9 & $-6,62$ \\
\hline sams-1 & $-3,30$ \\
\hline F56F10.1 & $-3,03$ \\
\hline math-34 & $-9,55$ \\
\hline ZK973.1 & $-4,91$ \\
\hline H20E11.1 & $-4,13$ \\
\hline R07G3.8 & $-5,79$ \\
\hline cth-2 & $-2,81$ \\
\hline
\end{tabular}

\begin{tabular}{|l|r|}
\hline gene & logFC \\
\hline ptr-16 & $-5,41$ \\
\hline K11D12.9 & $-6,66$ \\
\hline asns-1 & $-5,58$ \\
\hline xbx-9 & $-4,31$ \\
\hline F26F12.5 & $-9,04$ \\
\hline moe-3 & $-9,91$ \\
\hline M03C11.1 & 3,57 \\
\hline xbx-6 & 2,50 \\
\hline ins-5 & $-9,41$ \\
\hline par-5 & 3,26 \\
\hline Y67D2.4 & $-5,51$ \\
\hline EGAP9.3 & $-5,92$ \\
\hline F11E6.9 & $-3,02$ \\
\hline hot-9 & $-9,59$ \\
\hline T16A9.3 & $-6,59$ \\
\hline F15B9.8 & $-4,90$ \\
\hline Y4C6B.7 & $-2,49$ \\
\hline inx-6 & $-5,66$ \\
\hline nhr-110 & $-9,06$ \\
\hline pals-14 & $-6,72$ \\
\hline acdh-12 & $-3,28$ \\
\hline Y22D7AL.9 & $-7,32$ \\
\hline dgn-1 & $-4,74$ \\
\hline unc-45 & $-6,35$ \\
\hline algn-14 & $-6,54$ \\
\hline T01D3.6 & $-5,11$ \\
\hline nstp-3 & $-4,13$ \\
\hline fbxa-190 & $-9,58$ \\
\hline puf-8 & $-5,99$ \\
\hline mth-1 & $-5,79$ \\
\hline F18E9.4 & $-6,04$ \\
\hline F35C11.5 & $-9,29$ \\
\hline srh-30 & $-6,51$ \\
\hline T25B9.1 & $-2,55$ \\
\hline chil-24 & $-4,67$ \\
\hline D1007.8 & $-9,50$ \\
\hline R12C12.9 & $-4,87$ \\
\hline asp-12 & $-6,61$ \\
\hline set-15 & $-7,23$ \\
\hline C31H5.6 & $-5,65$ \\
\hline fbxa-182 & $-9,56$ \\
\hline T05A8.5 & $-9,11$ \\
\hline cyp-37B1 & $-4,55$ \\
\hline his-43 & $-8,71$ \\
\hline gst-27 & $-2,52$ \\
\hline fah-1 & $-2,88$ \\
\hline set-32 & $-6,63$ \\
\hline bro-1 & $-9,00$ \\
\hline his-18 & $-9,26$ \\
\hline C09F9.7 & $-9,51$ \\
\hline C49F5.7 & $-2,83$ \\
\hline R12H7.4 & $-7,23$ \\
\hline Y53G8AR.7 & $-6,52$ \\
\hline brf-1 & $-4,20$ \\
\hline K04C2.5 & $-7,04$ \\
\hline F23F1.6 & $-9,08$ \\
\hline F35H8.2 & $-10,21$ \\
\hline
\end{tabular}

\begin{tabular}{|l|r|}
\hline gene & logFC \\
\hline E01G4.5 & $-9,01$ \\
\hline F20D6.10 & $-7,01$ \\
\hline K10D11.6 & $-6,55$ \\
\hline T20D4.13 & $-6,46$ \\
\hline Y97E10AR.4 & $-9,40$ \\
\hline zig-3 & $-4,75$ \\
\hline M03F8.1 & $-6,97$ \\
\hline F10D11.6 & $-4,25$ \\
\hline T09A5.4 & $-9,13$ \\
\hline C32H11.3 & $-7,27$ \\
\hline R10E4.1 & 2,31 \\
\hline C47E12.3 & $-4,29$ \\
\hline Y4C6B.3 & $-9,05$ \\
\hline ptr-20 & $-5,81$ \\
\hline ZK287.1 & 2,84 \\
\hline C49F5.8 & $-6,67$ \\
\hline R12E2.14 & $-2,52$ \\
\hline T04G9.4 & $-2,63$ \\
\hline C08B6.3 & $-5,65$ \\
\hline chil-22 & $-6,79$ \\
\hline E02H4.7 & $-5,67$ \\
\hline math-42 & $-6,02$ \\
\hline F28B4.3 & $-3,59$ \\
\hline C15H9.4 & $-9,34$ \\
\hline ifta-1 & $-6,51$ \\
\hline C17F4.2 & $-10,06$ \\
\hline C28G1.5 & $-3,46$ \\
\hline F55A11.6 & $-3,08$ \\
\hline F57B1.9 & $-6,65$ \\
\hline tbc-18 & 3,18 \\
\hline ugt-46 & $-4,66$ \\
\hline aat-4 & $-7,59$ \\
\hline D2089.3 & $-6,12$ \\
\hline K01A6.6 & 4,81 \\
\hline W01C9.1 & $-6,94$ \\
\hline C42D4.3 & $-3,34$ \\
\hline Y37H2A.1 & 3,06 \\
\hline C35A5.5 & $-6,26$ \\
\hline daf-16 & 2,21 \\
\hline F55G1.1 & $-7,48$ \\
\hline bli-5 & $-7,00$ \\
\hline gei-13 & $-4,66$ \\
\hline che-7 & $-6,90$ \\
\hline C05B5.5 & $-7,59$ \\
\hline tol-1 & 2,77 \\
\hline ZC513.14 & $-6,42$ \\
\hline his-38 & $-6,85$ \\
\hline snn-1 & 3,13 \\
\hline Y105E8A.25 & $-3,20$ \\
\hline cgt-2 & $-9,29$ \\
\hline ztf-18 & $-4,49$ \\
\hline ZC116.1 \\
\hline K02E7.5 & $-9,35$ \\
\hline Iron-11 & $-6,57$ \\
\hline hpr-17 & 7,23 \\
\hline K10G4.5 \\
\hline hsp-16.41 \\
\hline
\end{tabular}

\begin{tabular}{|l|r|}
\hline gene & logFC \\
\hline fbxa-21 & $-10,04$ \\
\hline F53F1.6 & $-10,07$ \\
\hline frpr-15 & $-8,79$ \\
\hline C35A11.2 & $-6,82$ \\
\hline tnc-2 & $-2,59$ \\
\hline Y7A9C.1 & $-6,11$ \\
\hline Y18D10A.23 & $-8,93$ \\
\hline C13C4.6 & $-9,36$ \\
\hline Clec-26 & $-7,06$ \\
\hline F01D5.5 & $-3,50$ \\
\hline F21C10.4 & $-9,15$ \\
\hline F07H5.10 & $-8,91$ \\
\hline srsx-27 & $-7,18$ \\
\hline Y45G12C.4 & $-8,98$ \\
\hline C48E7.6 & $-5,23$ \\
\hline akap-1 & 3,81 \\
\hline srw-71 & $-9,13$ \\
\hline T19D2.2 & 2,71 \\
\hline tre-5 & $-6,47$ \\
\hline atf-5 & $-2,95$ \\
\hline daf-14 & 3,49 \\
\hline T03F6.3 & $-5,12$ \\
\hline ugt-44 & $-5,87$ \\
\hline mig-13 & $-7,01$ \\
\hline T26C5.5 & 3,10 \\
\hline Y53F4B.25 & $-6,57$ \\
\hline tmem-231 & $-5,62$ \\
\hline ZK1225.1 & $-8,86$ \\
\hline nhr-93 & $-7,70$ \\
\hline K08H2.7 & $-9,40$ \\
\hline spe-10 & $-5,48$ \\
\hline D2030.2 & $-3,48$ \\
\hline H23N18.4 & $-6,83$ \\
\hline knl-1 & $-5,53$ \\
\hline egl-4 & 2,13 \\
\hline nspc-3 & $-10,49$ \\
\hline pgp-3 & $-4,65$ \\
\hline cil-7 & $-5,65$ \\
\hline ncr-2 & $-8,71$ \\
\hline Y61A9LA.7 & $-5,01$ \\
\hline nep-22 & $-3,79$ \\
\hline C18G1.8 & $-6,72$ \\
\hline B0205.9 & $-5,19$ \\
\hline C27A2.8 & $-5,70$ \\
\hline dsl-7 & $-7,25$ \\
\hline egl-19 & 2,89 \\
\hline frpr-16 & 3,86 \\
\hline F55G11.2 & $-3,27$ \\
\hline fbxa-101 & $-6,76$ \\
\hline F13D2.1 & $-3,74$ \\
\hline C37C3.10 & $-8,77$ \\
\hline nep-18 & $-9,65$ \\
\hline grd-7 & $-6,44$ \\
\hline clec-21 & $-5,39$ \\
\hline amx-1 & 2,98 \\
\hline hda-3 & $-10,52$ \\
\hline clec-38 \\
\hline
\end{tabular}




\section{Appendix}

\begin{tabular}{|l|r|}
\hline gene & logFC \\
\hline oig-8 & $-5,98$ \\
\hline hlh-33 & $-9,29$ \\
\hline apd-3 & 2,61 \\
\hline W03D8.11 & $-6,64$ \\
\hline B0334.3 & $-3,26$ \\
\hline pqn-37 & $-5,72$ \\
\hline nphp-1 & $-5,61$ \\
\hline C06B8.2 & $-5,93$ \\
\hline taf-7.1 & $-5,52$ \\
\hline R08C7.4 & $-6,43$ \\
\hline ZC412.3 & $-3,04$ \\
\hline his-58 & $-7,54$ \\
\hline kbp-2 & $-6,34$ \\
\hline snf-12 & $-5,26$ \\
\hline F59D12.3 & $-7,57$ \\
\hline ZC376.3 & $-5,82$ \\
\hline acox-3 & $-3,50$ \\
\hline zipt-22 & $-6,50$ \\
\hline ghi-1 & $-6,27$ \\
\hline ets-4 & $-4,36$ \\
\hline F49D11.6 & $-6,67$ \\
\hline Y39B6A.29 & $-6,61$ \\
\hline R02D5.7 & $-6,04$ \\
\hline his-59 & $-6,59$ \\
\hline mls-2 & $-6,40$ \\
\hline ZK1010.8 & $-9,04$ \\
\hline Y38H6C.20 & $-6,92$ \\
\hline C16B8.2 & $-7,01$ \\
\hline nhr-210 & $-7,47$ \\
\hline C35B8.3 & $-4,80$ \\
\hline F54D1.1 & $-9,64$ \\
\hline grk-1 & 2,52 \\
\hline set-27 & $-6,04$ \\
\hline unc-105 & $-5,92$ \\
\hline zim-2 & $-8,88$ \\
\hline C50C3.1 & $-9,28$ \\
\hline ZK6.8 & $-6,80$ \\
\hline T07A5.1 & $-6,22$ \\
\hline plx-2 & $-5,50$ \\
\hline M02D8.5 & $-7,44$ \\
\hline B0222.11 & $-7,23$ \\
\hline C50B8.6 & $-6,75$ \\
\hline rbr-2 & 2,35 \\
\hline mis-12 & $-6,74$ \\
\hline T26C5.2 & $-5,24$ \\
\hline saps-1 & $-4,54$ \\
\hline F53G12.4 & $-6,90$ \\
\hline K02C4.2 & $-5,36$ \\
\hline R07B1.13 & $-9,93$ \\
\hline Igc-36 & $-7,25$ \\
\hline F09C12.6 & $-8,79$ \\
\hline Y105E8A.8 & $-9,28$ \\
\hline B0507.10 & $-9,23$ \\
\hline W04G5.4 & $-6,48$ \\
\hline C50F2.4 & $-5,69$ \\
\hline col-119 & $-3,44$ \\
\hline Y17G7B.17 & 3,53 \\
\hline & \\
\hline
\end{tabular}

\begin{tabular}{|l|r|}
\hline gene & logFC \\
\hline Y39H10B.2 & $-6,66$ \\
\hline Y66D12A.19 & $-7,07$ \\
\hline mam-3 & $-4,28$ \\
\hline arrd-13 & 3,55 \\
\hline chil-19 & $-4,87$ \\
\hline F54B11.4 & $-9,03$ \\
\hline ani-2 & $-6,24$ \\
\hline F31F4.11 & $-5,51$ \\
\hline cyp-33C3 & $-6,64$ \\
\hline elks-1 & 2,58 \\
\hline C03F11.2 & $-5,92$ \\
\hline K12H4.7 & $-3,58$ \\
\hline exos-4.2 & $-9,18$ \\
\hline lec-10 & $-2,53$ \\
\hline K09A9.6 & $-4,40$ \\
\hline D1046.2 & $-4,86$ \\
\hline C45E5.3 & $-9,70$ \\
\hline hpk-1 & 2,17 \\
\hline fbxa-210 & $-6,67$ \\
\hline Y51F10.7 & $-2,52$ \\
\hline oac-14 & $-6,13$ \\
\hline ZK402.3 & $-9,68$ \\
\hline T05A7.1 & $-6,55$ \\
\hline comt-2 & $-6,12$ \\
\hline C17G10.1 & $-4,75$ \\
\hline clec-242 & $-6,18$ \\
\hline gad-2 & $-8,71$ \\
\hline T22F7.5 & $-6,25$ \\
\hline pals-1 & $-8,65$ \\
\hline daf-37 & $-9,38$ \\
\hline elf-1 & $-4,93$ \\
\hline C14A4.9 & $-9,73$ \\
\hline cyp-34A8 & $-2,99$ \\
\hline R08B4.4 & $-5,68$ \\
\hline ZC376.2 & $-6,26$ \\
\hline R09H10.2 & $-9,00$ \\
\hline Y42A5A.3 & $-8,87$ \\
\hline acc-4 & 3,91 \\
\hline Y69H2.10 & $-5,67$ \\
\hline M153.3 & $-8,75$ \\
\hline daf-4 & 2,38 \\
\hline C23H4.2 & $-5,50$ \\
\hline F35D2.6 & $-7,02$ \\
\hline T19C3.7 & $-6,32$ \\
\hline W07E6.3 & $-6,20$ \\
\hline twk-10 & $-4,93$ \\
\hline sre-20 & $-8,54$ \\
\hline him-14 & $-6,65$ \\
\hline F28G4.2 & $-5,50$ \\
\hline twk-28 & $-5,69$ \\
\hline R13A1.10 & $-8,71$ \\
\hline C36B7.4 & $-8,38$ \\
\hline T21B4.15 & $-9,00$ \\
\hline R10E8.6 & $-6,47$ \\
\hline reps-1 & $-6,40$ \\
\hline ptr-22 & $-10,18$ \\
\hline arrd-28 & $-6,97$ \\
\hline
\end{tabular}

\begin{tabular}{|l|r|}
\hline gene & logFC \\
\hline R06F6.12 & $-5,66$ \\
\hline nhr-117 & $-6,08$ \\
\hline mtcu-1 & $-5,42$ \\
\hline DH11.2 & 2,55 \\
\hline clec-173 & $-5,65$ \\
\hline nspc-20 & $-3,19$ \\
\hline T06G6.3 & $-5,96$ \\
\hline srm-4 & $-6,52$ \\
\hline far-3 & $-2,45$ \\
\hline cept-1 & $-5,40$ \\
\hline K10C9.9 & $-8,45$ \\
\hline ZK1055.4 & $-8,34$ \\
\hline ift-81 & $-4,99$ \\
\hline C52E2.4 & $-6,50$ \\
\hline strm-1 & $-5,71$ \\
\hline W02D9.10 & 4,17 \\
\hline C23H4.7 & $-5,05$ \\
\hline col-89 & $-5,05$ \\
\hline ZK1307.1 & $-3,40$ \\
\hline pat-12 & $-3,17$ \\
\hline F23D12.3 & $-7,28$ \\
\hline C02G6.1 & $-7,68$ \\
\hline C53B4.1 & $-7,42$ \\
\hline Y47D3A.32 & $-6,26$ \\
\hline hlh-13 & $-6,44$ \\
\hline C39D10.7 & $-8,40$ \\
\hline H06H21.11 & $-6,25$ \\
\hline ugt-53 & $-8,99$ \\
\hline gly-18 & $-8,31$ \\
\hline nmr-1 & $-8,44$ \\
\hline F25E5.5 & $-5,92$ \\
\hline R09H10.5 & $-4,21$ \\
\hline C27A7.5 & $-3,35$ \\
\hline C55C3.1 & $-8,87$ \\
\hline F43C11.6 & $-8,29$ \\
\hline H41C03.2 & $-6,66$ \\
\hline T22D1.18 & $-6,50$ \\
\hline D2021.4 & $-6,79$ \\
\hline F35F10.7 & $-8,33$ \\
\hline R07B7.8 & $-5,52$ \\
\hline nekl-1 & $-5,81$ \\
\hline K09F6.4 & $-9,05$ \\
\hline oac-58 & $-5,05$ \\
\hline bbs-1 & $-6,53$ \\
\hline F49H6.5 & $-6,41$ \\
\hline clec-167 & $-6,41$ \\
\hline T14B4.2 & $-5,39$ \\
\hline nas-23 & $-9,73$ \\
\hline gpa-3 & $-6,39$ \\
\hline rol-3 & $-7,03$ \\
\hline T20D4.5 & $-3,71$ \\
\hline attf-3 \\
\hline dod-17 \\
\hline Y59E9AL.4 & $-6,10$ \\
\hline nhr-139 & $-6,22$ \\
\hline F35E12.9 & $-4,32$ \\
\hline amx-2 & $-4,93$ \\
\hline
\end{tabular}

\begin{tabular}{|l|r|}
\hline gene & logFC \\
\hline cyp-44A1 & $-3,80$ \\
\hline T23E1.1 & $-6,58$ \\
\hline E04D5.4 & $-5,88$ \\
\hline his-7 & $-9,26$ \\
\hline spat-2 & 2,72 \\
\hline C10G8.3 & $-6,79$ \\
\hline C56G2.4 & $-4,51$ \\
\hline F41G3.3 & $-5,84$ \\
\hline fbxc-53 & $-8,88$ \\
\hline ZK1193.2 & $-6,07$ \\
\hline C05A9.2 & $-6,80$ \\
\hline F13C5.3 & $-6,30$ \\
\hline col-139 & $-7,61$ \\
\hline fbxc-51 & $-9,71$ \\
\hline gst-42 & $-2,65$ \\
\hline cpx-1 & 4,44 \\
\hline ptr-8 & $-4,08$ \\
\hline C54E4.4 & 2,94 \\
\hline nhr-202 & $-6,72$ \\
\hline mltn-3 & $-6,51$ \\
\hline eel-1 & 2,09 \\
\hline Igc-54 & 4,41 \\
\hline F32H2.8 & $-8,71$ \\
\hline ZK829.3 & $-5,88$ \\
\hline C07B5.2 & $-8,89$ \\
\hline F35F10.4 & $-6,06$ \\
\hline hsd-3 & $-7,11$ \\
\hline R05A10.6 & $-9,57$ \\
\hline C34H4.1 & $-5,23$ \\
\hline klp-6 & $-8,37$ \\
\hline Y48G10A.2 & $-6,51$ \\
\hline Y59H11AR.4 & $-5,98$ \\
\hline egl-47 & $-6,03$ \\
\hline nas-14 & $-8,52$ \\
\hline Y51H4A.25 & $-6,95$ \\
\hline unc-76 & 2,16 \\
\hline T14B4.9 & $-5,85$ \\
\hline hum-10 & $-6,29$ \\
\hline hhat-2 & $-6,82$ \\
\hline lec-3 & 2,19 \\
\hline W01B6.3 & $-5,27$ \\
\hline zfp-1 & 2,05 \\
\hline tag-164 & $-5,65$ \\
\hline C06B8.7 & $-6,82$ \\
\hline col-107 & $-2,76$ \\
\hline pudl-1 & $-6,44$ \\
\hline F28F8.7 & $-6,09$ \\
\hline bgnt-1.1 & $-9,35$ \\
\hline osta-1 & $-6,28$ \\
\hline lgc-46 & $-6,03$ \\
\hline cnp-2 & $-9,66$ \\
\hline srz-10 & $-6,81$ \\
\hline F54H5.14 & 3,49 \\
\hline Y39A3B.1 & \\
\hline pqn-72 & \\
\hline eat-16 & cysl-1 \\
\hline
\end{tabular}




\section{Appendix}

\begin{tabular}{|l|r|}
\hline gene & logFC \\
\hline tfbm-1 & $-7,08$ \\
\hline nhr-161 & $-6,01$ \\
\hline pals-26 & $-8,98$ \\
\hline ZK1098.3 & $-5,99$ \\
\hline set-23 & $-6,30$ \\
\hline mks-1 & $-6,76$ \\
\hline W03F9.9 & $-6,68$ \\
\hline M01F1.9 & $-8,66$ \\
\hline gcy-23 & $-5,63$ \\
\hline C06C3.3 & $-5,42$ \\
\hline vps-11 & $-6,68$ \\
\hline dhs-24 & $-6,62$ \\
\hline C28H8.5 & $-5,20$ \\
\hline pezo-1 & $-2,61$ \\
\hline amt-2 & 4,56 \\
\hline mus-101 & $-6,29$ \\
\hline Y73F8A.35 & $-6,30$ \\
\hline R13A5.9 & 3,33 \\
\hline Igc-1 & $-8,92$ \\
\hline F32H2.11 & $-6,25$ \\
\hline lge-1 & $-5,06$ \\
\hline C05C8.2 & $-4,84$ \\
\hline egl-36 & $-5,17$ \\
\hline D2005.7 & $-6,41$ \\
\hline C26G2.2 & $-8,76$ \\
\hline cwn-2 & $-5,49$ \\
\hline F19C7.1 & $-2,62$ \\
\hline fbxa-108 & $-5,96$ \\
\hline ogt-1 & 2,08 \\
\hline clec-41 & $-5,06$ \\
\hline ZC416.6 & $-4,47$ \\
\hline insc-1 & $-5,96$ \\
\hline dod-24 & $-3,52$ \\
\hline F35D2.2 & $-5,97$ \\
\hline wht-1 & $-5,81$ \\
\hline K09E4.2 & $-4,34$ \\
\hline nas-36 & $-4,67$ \\
\hline Y66D12A.16 & $-6,87$ \\
\hline clec-35 & $-6,81$ \\
\hline fbxa-32 & $-6,42$ \\
\hline F35A5.4 & $-9,57$ \\
\hline F09F9.4 & $-6,38$ \\
\hline gska-3 & $-8,79$ \\
\hline mef-2 & 3,79 \\
\hline unc-3 & $-4,36$ \\
\hline trpl-4 & $-6,96$ \\
\hline C46F4.3 & $-8,49$ \\
\hline F20G2.6 & $-6,13$ \\
\hline C32D5.6 & $-6,60$ \\
\hline cyp-13A2 & $-4,42$ \\
\hline K09E2.2 & $-6,63$ \\
\hline ceh-23 & $-6,31$ \\
\hline dhs-14 & $-4,68$ \\
\hline Y32B12C.5 & $-7,70$ \\
\hline acr-25 & $-6,30$ \\
\hline M04C3.2 & $-4,27$ \\
\hline anoh-1 & $-6,53$ \\
\hline
\end{tabular}

\begin{tabular}{|l|r|}
\hline gene & logFC \\
\hline srx-80 & $-9,41$ \\
\hline C06H2.7 & $-6,75$ \\
\hline nhr-114 & $-5,47$ \\
\hline Y65B4A.6 & $-5,14$ \\
\hline D1044.7 & $-5,73$ \\
\hline R07C12.2 & $-4,79$ \\
\hline C33G3.4 & $-4,96$ \\
\hline clh-3 & $-6,94$ \\
\hline dpy-20 & $-6,70$ \\
\hline linc-96 & $-6,58$ \\
\hline daf-7 & $-4,74$ \\
\hline cyn-17 & $-4,48$ \\
\hline F47E1.2 & $-5,34$ \\
\hline pqn-42 & $-5,41$ \\
\hline T21D12.7 & $-6,32$ \\
\hline K08C9.8 & $-5,84$ \\
\hline F42A8.1 & $-3,65$ \\
\hline glr-8 & $-7,37$ \\
\hline kin-2 & 2,21 \\
\hline F23F1.2 & $-6,05$ \\
\hline npr-35 & $-6,06$ \\
\hline F17B5.8 & $-6,02$ \\
\hline ceeh-1 & $-2,83$ \\
\hline kcnl-3 & $-9,69$ \\
\hline oct-1 & $-9,42$ \\
\hline tctn-1 & $-6,57$ \\
\hline pud-2.2 & $-2,47$ \\
\hline lev-8 & $-6,49$ \\
\hline haf-9 & $-2,78$ \\
\hline T14G12.12 & $-8,56$ \\
\hline aexr-1 & $-6,90$ \\
\hline Y32F6B.1 & $-3,25$ \\
\hline acc-1 & 3,30 \\
\hline pho-6 & $-6,44$ \\
\hline F17B5.1 & $-4,86$ \\
\hline F53H2.1 & $-9,32$ \\
\hline Y39B6A.30 & $-8,72$ \\
\hline osm-12 & $-5,58$ \\
\hline C42D4.13 & $-6,53$ \\
\hline unc-130 & $-6,00$ \\
\hline gst-44 & $-7,23$ \\
\hline maea-1 & 2,60 \\
\hline F25B3.2 & $-7,68$ \\
\hline K02E2.8 & $-5,57$ \\
\hline F20B10.3 & $-7,03$ \\
\hline DY3.8 & $-8,69$ \\
\hline C27A2.12 & $-5,77$ \\
\hline B0410.3 & $-3,25$ \\
\hline H10E21.1 & $-6,56$ \\
\hline srv-7 & $-8,83$ \\
\hline ZC449.5 & $-2,91$ \\
\hline nhr-147 & $-6,80$ \\
\hline paqr-3 & $-5,89$ \\
\hline Y66D12A.13 & $-3,96$ \\
\hline T11F9.12 & $-6,26$ \\
\hline nhr-116 & $-9,04$ \\
\hline lurp-2 & \\
\hline
\end{tabular}

\begin{tabular}{|l|r|}
\hline gene & logFC \\
\hline rab-11.2 & $-9,03$ \\
\hline W07A12.4 & $-5,86$ \\
\hline hmt-1 & $-4,21$ \\
\hline Y47G6A.5 & $-5,58$ \\
\hline D1005.2 & $-2,48$ \\
\hline T04F3.5 & $-8,97$ \\
\hline F09C8.1 & $-2,87$ \\
\hline tor-1 & $-5,45$ \\
\hline Y57A10C.9 & $-6,28$ \\
\hline R10E8.7 & $-6,83$ \\
\hline catp-3 & $-4,61$ \\
\hline Iron-10 & 3,03 \\
\hline ubc-23 & $-6,08$ \\
\hline nhr-207 & $-8,63$ \\
\hline ztf-26 & $-6,23$ \\
\hline Y57G11C.41 & $-6,99$ \\
\hline F54E2.5 & $-6,32$ \\
\hline ttr-22 & $-6,43$ \\
\hline Y105C5A.15 & 2,86 \\
\hline fbxa-99 & $-6,56$ \\
\hline sfxn-5 & $-4,13$ \\
\hline C16C8.16 & $-6,44$ \\
\hline F37A8.5 & 4,23 \\
\hline clec-83 & $-4,79$ \\
\hline F01G10.6 & $-4,56$ \\
\hline clec-186 & $-4,78$ \\
\hline fbxc-50 & $-8,92$ \\
\hline Y7A9A.79 & $-6,98$ \\
\hline F09B12.3 & $-4,15$ \\
\hline frm-1 & 1,98 \\
\hline ZK1010.2 & $-4,48$ \\
\hline nspc-13 & $-7,05$ \\
\hline set-11 & 4,17 \\
\hline C12D8.15 & $-5,98$ \\
\hline poml-3 & $-2,32$ \\
\hline Y45G12C.1 & $-5,91$ \\
\hline W03B1.3 & $-5,79$ \\
\hline T12D8.5 & 3,18 \\
\hline nstp-8 & $-9,56$ \\
\hline lir-3 & $-6,24$ \\
\hline col-98 & $-2,23$ \\
\hline F16H6.10 & $-6,34$ \\
\hline col-80 & $-2,29$ \\
\hline T26H5.8 & $-7,83$ \\
\hline F59B2.9 & $-5,43$ \\
\hline C54F6.3 & $-6,63$ \\
\hline aagr-2 & $-3,04$ \\
\hline ssl-1 & 2,40 \\
\hline F54E2.1 & $-4,17$ \\
\hline dat-1 & $-5,20$ \\
\hline Y41C4A.17 & 3,84 \\
\hline C05D12.4 & $-5,05$ \\
\hline clec-85 & $-2,88$ \\
\hline mgl-2 & 5,21 \\
\hline K08FF.3 & $-7,33$ \\
\hline srh-48 & $-3,12$ \\
\hline Y87G2A.19 \\
\hline
\end{tabular}

\begin{tabular}{|l|r|}
\hline gene & logFC \\
\hline trxr-2 & 2,99 \\
\hline T08G5.15 & $-6,22$ \\
\hline hlh-1 & $-6,58$ \\
\hline myo-5 & $-2,51$ \\
\hline pitr-4 & $-9,03$ \\
\hline Y48G8AL.12 & $-4,29$ \\
\hline fil-1 & $-4,14$ \\
\hline sto-4 & 2,60 \\
\hline mam-5 & $-5,08$ \\
\hline F21H7.12 & $-9,47$ \\
\hline grd-12 & $-6,33$ \\
\hline Y57G11C.42 & $-6,57$ \\
\hline unc-29 & $-5,39$ \\
\hline tax-6 & 2,34 \\
\hline ZK973.8 & $-6,34$ \\
\hline gst-41 & $-3,23$ \\
\hline col-56 & $-6,36$ \\
\hline Cwp-5 & $-9,63$ \\
\hline W09C3.1 & $-9,31$ \\
\hline C17H12.8 & $-3,94$ \\
\hline W03G11.3 & $-5,50$ \\
\hline F35B12.3 & $-3,68$ \\
\hline Y73B6BL.36 & $-6,46$ \\
\hline H40L08.3 & $-6,25$ \\
\hline C06E7.88 & $-6,60$ \\
\hline R12C12.8 & $-5,74$ \\
\hline C54D10.5 & 3,78 \\
\hline H20E11.2 & $-6,06$ \\
\hline C36E8.4 & $-6,54$ \\
\hline trp-1 & 3,15 \\
\hline cex-1 & $-8,93$ \\
\hline W05B2.2 & $-6,97$ \\
\hline nhr-273 & $-6,52$ \\
\hline xbx-3 & $-5,86$ \\
\hline B0198.2 & 4,11 \\
\hline nhr-208 & $-6,93$ \\
\hline ZC434.3 & $-4,43$ \\
\hline arrd-10 & $-6,59$ \\
\hline adm-4 & $-4,76$ \\
\hline nhr-140 & $-6,34$ \\
\hline C01B10.10 & $-4,86$ \\
\hline nhr-286 & $-5,99$ \\
\hline E01A2.5 & $-4,70$ \\
\hline cut-6 & $-6,38$ \\
\hline irld-15 & $-9,20$ \\
\hline T13G4.4 & $-6,06$ \\
\hline rab-14 & 3,21 \\
\hline W02B12.4 & $-5,67$ \\
\hline evl-18 & $-5,94$ \\
\hline F36D1.8 & $-6,88$ \\
\hline Y73E7A.8 & $-5,23$ \\
\hline icl-1 & $-2,88$ \\
\hline ifd-2 & $-4,85$ \\
\hline H03E18.1 & $-3,98$ \\
\hline F37A4.6 & $-9,70$ \\
\hline C03H5.5 & $-6,52$ \\
\hline mvk-1 & 2,25 \\
\hline
\end{tabular}




\section{Appendix}

\begin{tabular}{|l|r|}
\hline gene & logFC \\
\hline Y43E12A.2 & 2,88 \\
\hline eol-1 & $-6,44$ \\
\hline T28C12.1 & $-6,72$ \\
\hline pud-1.2 & $-2,29$ \\
\hline F08F3.4 & $-3,26$ \\
\hline adt-2 & $-4,17$ \\
\hline T24D5.2 & $-6,03$ \\
\hline F28C6.9 & $-6,74$ \\
\hline C05D12.1 & $-5,71$ \\
\hline mca-3 & 1,94 \\
\hline egg-5 & $-6,15$ \\
\hline Y102A11A.1 & $-5,40$ \\
\hline ZC373.5 & $-5,50$ \\
\hline Igc-55 & 3,74 \\
\hline B0218.5 & $-9,01$ \\
\hline R02D5.6 & $-6,10$ \\
\hline Irr-1 & $-6,37$ \\
\hline ZK328.6 & $-6,30$ \\
\hline clh-4 & $-6,10$ \\
\hline R07B7.10 & $-5,38$ \\
\hline sdz-27 & $-6,86$ \\
\hline gst-26 & $-2,53$ \\
\hline cyp-36A1 & $-4,35$ \\
\hline F38B6.3 & $-7,18$ \\
\hline galt-1 & $-5,96$ \\
\hline gab-1 & $-4,91$ \\
\hline T04D3.5 & 2,64 \\
\hline grl-7 & $-3,82$ \\
\hline oac-24 & $-5,06$ \\
\hline Y37A1B.7 & $-5,57$ \\
\hline fbxa-187 & $-6,64$ \\
\hline myo-6 & $-3,33$ \\
\hline F23C8.13 & 4,06 \\
\hline B0554.7 & $-5,77$ \\
\hline C33D3.3 & $-6,06$ \\
\hline oac-31 & $-7,13$ \\
\hline T20D4.9 & $-10,23$ \\
\hline tag-38 & $-6,17$ \\
\hline D1014.7 & $-9,16$ \\
\hline B0212.3 & $-5,45$ \\
\hline cutl-12 & $-6,77$ \\
\hline T28C12.2 & $-6,82$ \\
\hline$R 10 H 10.3$ & $-2,85$ \\
\hline ZK180.6 & $-4,22$ \\
\hline nep-16 & $-6,16$ \\
\hline old-1 & $-5,93$ \\
\hline ttr-23 & $-4,12$ \\
\hline ZK1037.6 & $-7,71$ \\
\hline B0280.7 & $-4,80$ \\
\hline F56F11.2 & $-9,13$ \\
\hline mlt-7 & $-3,59$ \\
\hline nhr-258 & $-6,55$ \\
\hline ZC513.5 & $-4,49$ \\
\hline scav-2 & $-6,49$ \\
\hline wrt-4 & $-8,06$ \\
\hline aex-3 & 2,86 \\
\hline vbh-1 & 2,25 \\
\hline
\end{tabular}

\begin{tabular}{|l|r|}
\hline gene & logFC \\
\hline acs-5 & $-3,02$ \\
\hline K01D12.9 & $-3,38$ \\
\hline T02E1.8 & 5,38 \\
\hline linc-83 & $-8,75$ \\
\hline F45B8.3 & $-5,98$ \\
\hline T07E3.3 & 3,03 \\
\hline T23G5.2 & 2,19 \\
\hline F40A3.7 & 5,18 \\
\hline spin-2 & $-6,76$ \\
\hline F53F10.2 & 1,97 \\
\hline aqp-5 & $-6,73$ \\
\hline F01D4.8 & $-9,60$ \\
\hline F19C7.4 & $-6,07$ \\
\hline VF13D12L.3 & $-2,83$ \\
\hline clec-9 & $-7,95$ \\
\hline lgc-12 & $-4,56$ \\
\hline ugt-51 & $-5,11$ \\
\hline C49G7.3 & $-3,26$ \\
\hline Y70C5A.3 & $-5,31$ \\
\hline dhs-21 & $-3,13$ \\
\hline F13E6.2 & $-5,62$ \\
\hline B0393.5 & $-6,39$ \\
\hline nhr-145 & $-6,05$ \\
\hline F49B2.6 & $-4,75$ \\
\hline C43H6.6 & $-5,86$ \\
\hline math-35 & $-6,42$ \\
\hline F42C5.6 & $-5,69$ \\
\hline K07G5.5 & $-4,40$ \\
\hline unc-34 & 3,74 \\
\hline ztf-30 & $-5,90$ \\
\hline K09H9.8 & $-2,93$ \\
\hline hlh-6 & $-5,59$ \\
\hline lon-3 & $-3,27$ \\
\hline T12E12.6 & $-5,80$ \\
\hline F25B3.5 & $-9,85$ \\
\hline C09G9.5 & $-6,20$ \\
\hline C09D4.1 & $-3,81$ \\
\hline F07H5.3 & 1,90 \\
\hline paf-2 & 2,88 \\
\hline mdt-17 & $-5,80$ \\
\hline Y41G9A.10 & $-5,96$ \\
\hline math-14 & $-6,99$ \\
\hline lyst-1 & $-6,59$ \\
\hline rnt-1 & $-5,19$ \\
\hline F45E1.4 & $-8,35$ \\
\hline C26B9.2 & $-7,01$ \\
\hline tyr-1 & $-3,14$ \\
\hline C06H5.6 & $-4,63$ \\
\hline F41E6.11 & $-5,06$ \\
\hline Y105C5B.9 & $-5,41$ \\
\hline F15A4.6 & $-3,13$ \\
\hline sex-1 & $-6,69$ \\
\hline trk-1 & $-4,68$ \\
\hline sox-3 & $-7,15$ \\
\hline F07G11.4 \\
\hline che-3 & \\
\hline sulp-5 & \\
\hline
\end{tabular}

\begin{tabular}{|l|r|}
\hline gene & logFC \\
\hline H35N09.1 & $-4,96$ \\
\hline W02F12.8 & $-3,39$ \\
\hline lips-16 & $-6,57$ \\
\hline C06G1.2 & $-6,47$ \\
\hline hmit-1.1 & $-4,97$ \\
\hline qdpr-1 & $-2,70$ \\
\hline mlt-11 & $-2,97$ \\
\hline T03G6.3 & $-4,26$ \\
\hline C50D2.6 & $-5,80$ \\
\hline csa-1 & $-5,18$ \\
\hline spe-47 & 3,95 \\
\hline F31F4.1 & $-9,79$ \\
\hline F58E6.13 & 3,64 \\
\hline asp-3 & $-2,79$ \\
\hline dct-15 & $-6,65$ \\
\hline nekl-4 & $-6,52$ \\
\hline Y102A11A.9 & $-5,31$ \\
\hline nhr-36 & $-6,42$ \\
\hline nhr-251 & $-10,08$ \\
\hline spc-1 & 1,91 \\
\hline col-149 & $-3,40$ \\
\hline rap-3 & $-8,98$ \\
\hline F20A1.4 & $-7,35$ \\
\hline grsp-3 & $-8,43$ \\
\hline F40F9.10 & $-5,35$ \\
\hline nas-33 & $-6,78$ \\
\hline R07E3.1 & $-2,59$ \\
\hline W05F2.4 & $-2,87$ \\
\hline W03D2.6 & $-7,09$ \\
\hline R02E4.2 & $-5,35$ \\
\hline F09G2.1 & $-5,17$ \\
\hline pitp-1 & 2,28 \\
\hline pals-34 & $-6,29$ \\
\hline lact-2 & $-3,45$ \\
\hline T22B7.7 & $-6,51$ \\
\hline hmr-1 & 2,07 \\
\hline fkb-4 & $-3,03$ \\
\hline fbxc-40 & $-6,60$ \\
\hline abts-1 & 2,35 \\
\hline Inp-1 & $-6,55$ \\
\hline K07G5.4 & $-4,66$ \\
\hline Iron-2 & $-6,92$ \\
\hline Igc-20 & $-5,88$ \\
\hline Y41G9A.2 & $-5,62$ \\
\hline F10D7.10 & $-5,20$ \\
\hline K04H4.2 & $-4,53$ \\
\hline F53F4.4 & $-4,22$ \\
\hline pqn-31 & $-5,62$ \\
\hline T03F1.11 & $-4,74$ \\
\hline pqn-57 & $-2,09$ \\
\hline daf-38 & $-5,58$ \\
\hline rom-3 & $-4,30$ \\
\hline snt-5 & \\
\hline R10H10.6 & \\
\hline inx-1 & \\
\hline R08E5.3 & \\
\hline C34H4.2 & \\
\hline
\end{tabular}

\begin{tabular}{|l|r|}
\hline gene & logFC \\
\hline ZC13.2 & $-6,14$ \\
\hline abu-13 & $-4,46$ \\
\hline F47E1.3 & $-5,80$ \\
\hline gba-4 & $-3,46$ \\
\hline twk-11 & $-6,19$ \\
\hline F14D7.12 & $-6,49$ \\
\hline nhr-179 & $-5,64$ \\
\hline ceh-33 & $-6,91$ \\
\hline clec-34 & $-5,69$ \\
\hline C24A3.1 & $-5,60$ \\
\hline chil-3 & $-5,94$ \\
\hline Y97E10AR.2 & $-5,63$ \\
\hline Y81G3A.4 & $-6,08$ \\
\hline To9F5.12 & $-5,00$ \\
\hline otpl-5 & $-6,57$ \\
\hline hgo-1 & $-2,85$ \\
\hline pqn-87 & 1,88 \\
\hline tor-2 & $-6,19$ \\
\hline ptp-4 & $-5,31$ \\
\hline F54B11.11 & $-6,95$ \\
\hline chd-3 & 2,00 \\
\hline spat-1 & $-6,72$ \\
\hline M04F3.3 & $-6,45$ \\
\hline clec-258 & $-4,17$ \\
\hline pmk-2 & 2,86 \\
\hline ncx-7 & $-5,35$ \\
\hline ctsa-1 & $-3,49$ \\
\hline T27D12.1 & $-3,35$ \\
\hline str-154 & 4,41 \\
\hline F54D10.5 & $-4,65$ \\
\hline R07G3.7 & $-4,55$ \\
\hline ZK218.4 & $-7,08$ \\
\hline nhr-67 & 5,30 \\
\hline frpr-11 & $-5,19$ \\
\hline ets-5 & $-6,86$ \\
\hline R06C7.6 & $-4,88$ \\
\hline C24A8.6 & 2,82 \\
\hline pkn-1 & $-4,50$ \\
\hline pho-1 & $-3,28$ \\
\hline math-45 & $-4,97$ \\
\hline mut-2 & $-5,44$ \\
\hline K01A2.3 & $-5,80$ \\
\hline Y37D8A.2 & $-3,59$ \\
\hline svh-5 & 2,68 \\
\hline T24C4.5 & 4,27 \\
\hline ctl-1 & $-2,48$ \\
\hline F55G11.7 & $-6,89$ \\
\hline exc-4 & $-5,70$ \\
\hline F21H7.2 & $-6,03$ \\
\hline C26B9.7 & $-10,08$ \\
\hline F54E4.3 & 2,89 \\
\hline cpz-2 & $-6,72$ \\
\hline Y69A2AR.31 & 3,21 \\
\hline R09H10.1 & \\
\hline mth-2 & \\
\hline dhs-20 & kvs-4 \\
\hline
\end{tabular}




\section{Appendix}

\begin{tabular}{|l|r|}
\hline gene & logFC \\
\hline ZK262.3 & $-5,73$ \\
\hline Y40H7A.4 & $-7,59$ \\
\hline Y73B6BL.31 & $-4,20$ \\
\hline C34F6.9 & 2,64 \\
\hline ugt-13 & $-4,25$ \\
\hline npr-6 & 4,07 \\
\hline mml-1 & 2,82 \\
\hline T06E4.7 & $-5,25$ \\
\hline dct-17 & $-4,87$ \\
\hline srx-45 & $-5,32$ \\
\hline cfz-2 & 3,09 \\
\hline C03G6.6 & $-7,19$ \\
\hline nfya-1 & $-5,36$ \\
\hline mltn-12 & $-5,94$ \\
\hline R09F10.1 & $-3,11$ \\
\hline spin-1 & $-4,85$ \\
\hline F07C3.2 & 3,72 \\
\hline mks-6 & $-5,16$ \\
\hline Y39G8B.7 & $-4,72$ \\
\hline C28H8.2 & $-5,72$ \\
\hline C24A3.4 & $-5,62$ \\
\hline pacs-1 & $-2,68$ \\
\hline ser-6 & 4,15 \\
\hline T09E11.11 & $-10,33$ \\
\hline nhr-220 & $-5,41$ \\
\hline F30A10.3 & 2,46 \\
\hline pqn-44 & 4,02 \\
\hline ncx-4 & 3,09 \\
\hline D1046.4 & $-5,95$ \\
\hline Ipr-4 & $-2,96$ \\
\hline clec-165 & $-7,60$ \\
\hline aex-1 & $-5,68$ \\
\hline C17E4.10 & 3,18 \\
\hline cyp-35A4 & $-6,96$ \\
\hline Y106G6D.6 & $-3,24$ \\
\hline$n s p c-16$ & $-5,23$ \\
\hline W09H1.1 & $-4,85$ \\
\hline gbh-1 & $-4,95$ \\
\hline F08G12.11 & $-4,34$ \\
\hline prx-5 & $-4,49$ \\
\hline hid-1 & 2,72 \\
\hline cyp-32A1 & $-5,10$ \\
\hline sup-18 & $-5,54$ \\
\hline dmd-7 & 2,53 \\
\hline dyc-1 & $-3,18$ \\
\hline sek-6 & $-6,41$ \\
\hline ZC374.2 & $-5,42$ \\
\hline pptr-1 & 2,08 \\
\hline odr-1 & $-7,09$ \\
\hline poml-4 \\
\hline flp-13 & $-2,32$ \\
\hline acs-6 & $-5,47$ \\
\hline ZK673.11 \\
\hline E02H1.2 & $-5,32$ \\
\hline C44B7.11 & $-4,21$ \\
\hline ctbp-1 & $-3,68$ \\
\hline nhr-188 & 2,82 \\
\hline \\
\hline
\end{tabular}

\begin{tabular}{|l|r|}
\hline gene & logFC \\
\hline F56C9.6 & $-9,57$ \\
\hline nhr-112 & $-6,92$ \\
\hline F15D4.5 & $-7,49$ \\
\hline igdb-3 & $-7,96$ \\
\hline rsef-1 & $-5,14$ \\
\hline ZK328.7 & $-6,81$ \\
\hline C11H1.5 & $-4,99$ \\
\hline C29F3.7 & $-4,31$ \\
\hline gei-18 & $-5,42$ \\
\hline npa-1 & $-2,39$ \\
\hline grsp-2 & $-9,38$ \\
\hline ost-1 & $-2,04$ \\
\hline pole-2 & $-6,28$ \\
\hline E02C12.8 & $-5,09$ \\
\hline F01D5.3 & $-3,00$ \\
\hline ceh-57 & $-6,45$ \\
\hline ZK470.2 & 3,05 \\
\hline nhr-245 & $-2,60$ \\
\hline T21D12.12 & 3,12 \\
\hline col-20 & $-8,78$ \\
\hline F13B9.2 & $-5,24$ \\
\hline tep-1 & $-2,34$ \\
\hline glr-1 & 3,02 \\
\hline F48E3.9 & $-6,26$ \\
\hline sma-3 & $-4,68$ \\
\hline Y22D7AL.11 & $-6,14$ \\
\hline C18H7.11 & $-7,87$ \\
\hline R09B5.11 & $-4,64$ \\
\hline T13C5.7 & $-5,31$ \\
\hline C05E7.1 & $-6,48$ \\
\hline K10G6.4 & $-6,26$ \\
\hline osr-1 & $-5,27$ \\
\hline des-2 & $-5,08$ \\
\hline F28F5.6 & $-5,10$ \\
\hline Y47H9C.1 & $-3,62$ \\
\hline nphp-4 & $-5,10$ \\
\hline F20G2.5 & $-6,15$ \\
\hline Y75B12B.11 & $-5,32$ \\
\hline pals-39 & $-4,06$ \\
\hline C34E7.4 & $-3,71$ \\
\hline C36B1.9 & $-4,51$ \\
\hline ugt-32 & $-6,54$ \\
\hline mnp-1 & $-5,08$ \\
\hline cyp-13A12 & $-7,11$ \\
\hline ftn-2 & $-2,30$ \\
\hline calu-2 & 3,01 \\
\hline clec-209 & $-3,30$ \\
\hline ceh-2 & $-6,01$ \\
\hline C50B6.3 & $-5,21$ \\
\hline irld-34 & $-5,41$ \\
\hline T18D3.6 & $-4,89$ \\
\hline cdf-2 & $-4,67$ \\
\hline aip-1 & $-9,73$ \\
\hline T01C8.3 & $-3,01$ \\
\hline C04E12.5 & \\
\hline nhr-263 & \\
\hline alh-9 & \\
\hline
\end{tabular}

\begin{tabular}{|l|r|}
\hline gene & logFC \\
\hline pan-1 & 2,08 \\
\hline odc-1 & $-4,50$ \\
\hline lin-3 & $-4,73$ \\
\hline F22F4.1 & $-3,57$ \\
\hline C36A4.11 & $-5,98$ \\
\hline gnrr-5 & $-5,34$ \\
\hline M142.8 & $-4,27$ \\
\hline W09D6.1 & $-5,74$ \\
\hline clec-67 & $-3,08$ \\
\hline C46F2.1 & $-6,07$ \\
\hline nhr-151 & $-5,90$ \\
\hline C25G6.1 & $-5,94$ \\
\hline C02G6.3 & $-5,51$ \\
\hline gst-15 & $-4,92$ \\
\hline Ipr-3 & $-3,65$ \\
\hline srf-3 & $-8,71$ \\
\hline B0244.4 & $-9,46$ \\
\hline cblc-1 & 3,05 \\
\hline his-17 & $-8,80$ \\
\hline K02E10.7 & 3,58 \\
\hline Y69A2AR.16 & 2,49 \\
\hline Y102A11A.5 & $-2,57$ \\
\hline F31A3.3 & $-8,92$ \\
\hline chil-25 & $-6,84$ \\
\hline F57C7.4 & $-6,18$ \\
\hline itr-1 & $-2,75$ \\
\hline clec-265 & $-2,95$ \\
\hline F33E2.10 & $-6,22$ \\
\hline T24B8.3 & 2,54 \\
\hline Y54G2A.37 & $-7,56$ \\
\hline C49F8.1 & $-5,11$ \\
\hline R09D1.9 & $-9,49$ \\
\hline cdh-8 & $-6,90$ \\
\hline K09C4.4 & $-5,78$ \\
\hline F16C3.1 & $-4,66$ \\
\hline C38C3.4 & $-4,65$ \\
\hline K03D3.2 & $-4,40$ \\
\hline F46H5.7 & $-2,05$ \\
\hline msi-1 & 2,22 \\
\hline Y43F8B.3 & $-4,37$ \\
\hline gck-4 & $-4,46$ \\
\hline sul-1 & $-5,38$ \\
\hline F47B10.9 & $-5,44$ \\
\hline cyp-34A10 & $-9,38$ \\
\hline brd-1 & $-6,35$ \\
\hline ZK856.14 & $-9,42$ \\
\hline fbxa-93 & $-5,61$ \\
\hline R09D1.12 & $-6,17$ \\
\hline B0244.6 & $-7,06$ \\
\hline C29E4.11 & $-5,97$ \\
\hline Y6E2A.4 & $-5,59$ \\
\hline frpr-3 & $-3,54$ \\
\hline pqn-22 & $-2,19$ \\
\hline lys-8 & $-5,50$ \\
\hline cdh-4 \\
\hline nstp-6 \\
\hline C48B6.3 \\
\hline
\end{tabular}

\begin{tabular}{|l|r|}
\hline gene & logFC \\
\hline F39B2.8 & 2,37 \\
\hline T27A10.6 & $-4,54$ \\
\hline cpz-1 & $-3,25$ \\
\hline ceh-83 & $-7,38$ \\
\hline ZK896.4 & $-4,81$ \\
\hline Y119C1B.3 & $-6,32$ \\
\hline C44H9.5 & $-6,79$ \\
\hline F37H8.5 & $-2,82$ \\
\hline olrn-1 & 4,24 \\
\hline acdh-11 & $-3,12$ \\
\hline fbxb-101 & $-5,19$ \\
\hline F40G9.5 & $-4,63$ \\
\hline nas-7 & $-5,78$ \\
\hline ZC443.4 & 2,59 \\
\hline T19D7.6 & $-6,26$ \\
\hline B0464.9 & 2,90 \\
\hline F47B10.5 & $-4,30$ \\
\hline gcst-1 & $-2,48$ \\
\hline ppk-1 & 2,27 \\
\hline F44E2.3 & 2,87 \\
\hline F17C8.8 & $-5,36$ \\
\hline C14H10.2 & $-4,24$ \\
\hline npr-18 & $-5,00$ \\
\hline C15C8.8 & $-9,85$ \\
\hline F38A1.9 & $-6,65$ \\
\hline crf-1 & 2,73 \\
\hline col-182 & $-4,99$ \\
\hline ugt-12 & $-2,97$ \\
\hline Y56A3A.33 & $-5,55$ \\
\hline arrd-23 & $-5,82$ \\
\hline gsa-1 & 2,76 \\
\hline comt-1 & $-6,12$ \\
\hline sec-3 & $-4,44$ \\
\hline ugt-14 & $-6,13$ \\
\hline mab-23 & $-6,00$ \\
\hline pyk-2 & $-3,76$ \\
\hline Y34B4A.6 & $-2,32$ \\
\hline nhr-203 & $-5,27$ \\
\hline Y54G2A.41 & 4,83 \\
\hline F15B9.6 & $-4,76$ \\
\hline F35G2.5 & $-5,49$ \\
\hline fbxa-66 & $-7,37$ \\
\hline sre-1 & $-5,65$ \\
\hline F56D3.1 & $-3,59$ \\
\hline ZC449.1 & $-4,87$ \\
\hline C18E3.3 & $-4,65$ \\
\hline W03G1.5 & $-3,90$ \\
\hline ZK512.2 & $-3,41$ \\
\hline srx-58 & $-9,94$ \\
\hline D2023.1 & $-3,79$ \\
\hline Y50D7A.13 & $-5,25$ \\
\hline K08D8.4 & $-4,46$ \\
\hline K10G6.5 & $-5,15$ \\
\hline bar-1 & $-3,88$ \\
\hline Y48E1B.8 & $-3,10$ \\
\hline tcl-2 & $-7,45$ \\
\hline Y67H2A.9 & $-4,51$ \\
\hline
\end{tabular}




\section{Appendix}

\begin{tabular}{|l|r|}
\hline gene & logFC \\
\hline cul-6 & $-6,31$ \\
\hline K03A11.6 & $-5,63$ \\
\hline tdo-2 & $-2,58$ \\
\hline C41G7.8 & $-7,03$ \\
\hline D2096.10 & 3,63 \\
\hline C33A12.19 & $-2,91$ \\
\hline unc-15 & $-2,99$ \\
\hline dpy-9 & $-3,16$ \\
\hline T02C5.1 & $-3,58$ \\
\hline vps-25 & 1,90 \\
\hline F33E2.4 & $-5,96$ \\
\hline F09B12.5 & $-6,25$ \\
\hline lgc-23 & $-5,05$ \\
\hline gei-8 & 2,01 \\
\hline efn-2 & 2,77 \\
\hline F33A8.7 & $-3,27$ \\
\hline pals-37 & $-7,38$ \\
\hline akt-1 & 2,16 \\
\hline F13B12.3 & $-7,23$ \\
\hline nlg-1 & $-4,20$ \\
\hline K08D8.3 & $-5,05$ \\
\hline unc-58 & 2,44 \\
\hline srp-8 & $-5,71$ \\
\hline ZK1248.15 & $-5,97$ \\
\hline C10B5.3 & $-5,93$ \\
\hline F58B4.5 & $-2,80$ \\
\hline ttr-26 & $-3,71$ \\
\hline ppat-1 & $-3,89$ \\
\hline C17F4.12 & $-9,36$ \\
\hline fbxa-39 & $-4,69$ \\
\hline mrp-6 & 3,87 \\
\hline Y71H2AM.9 & $-4,42$ \\
\hline fbxa-189 & $-6,11$ \\
\hline F53A2.1 & 3,47 \\
\hline C05C12.4 & $-2,75$ \\
\hline bath-37 & 4,59 \\
\hline F23H11.6 & $-5,83$ \\
\hline apa-2 & 2,04 \\
\hline spon-1 & $-3,59$ \\
\hline gbb-2 & 2,69 \\
\hline ZC196.1 & $-6,42$ \\
\hline col-34 & $-2,11$ \\
\hline R11G10.3 & 3,52 \\
\hline F22E5.8 & $-5,74$ \\
\hline arl-5 & $-5,12$ \\
\hline Y32F6A.5 & $-2,98$ \\
\hline C14C6.2 & $-2,76$ \\
\hline faah-1 & $-2,26$ \\
\hline T09B9.1 & $-4,24$ \\
\hline ZC239.14 & $-7,31$ \\
\hline clec-50 & $-3,12$ \\
\hline B0491.7 & $-4,42$ \\
\hline M03F8.5 & $-5,29$ \\
\hline pals-6 & $-7,45$ \\
\hline gba-2 & $-5,81$ \\
\hline gst-5 & $-2,20$ \\
\hline hprt-1 & $-3,28$ \\
\hline
\end{tabular}

\begin{tabular}{|c|c|}
\hline gene & $\log \mathrm{FC}$ \\
\hline sto-3 & 3,48 \\
\hline slo-1 & 3,01 \\
\hline W04B5.3 & $-4,44$ \\
\hline$m e m b-1$ & $-5,55$ \\
\hline hot-7 & $-5,56$ \\
\hline sttx-1 & $-6,56$ \\
\hline$s r x-68$ & $-6,00$ \\
\hline Y71H2AM.14 & $-5,95$ \\
\hline T01B7.8 & $-5,82$ \\
\hline Y43F8B.14 & $-6,65$ \\
\hline$F 14 H 12.3$ & $-4,00$ \\
\hline Y105C5A.24 & $-4,52$ \\
\hline cey-1 & 2,33 \\
\hline oac-34 & $-6,86$ \\
\hline scl-14 & $-5,76$ \\
\hline Y37F4.8 & $-5,18$ \\
\hline$n h r-180$ & $-6,07$ \\
\hline Y6B3B.7 & 3,19 \\
\hline C14C11.2 & $-5,78$ \\
\hline htp-1 & $-5,73$ \\
\hline $\mathrm{C} 40 \mathrm{H} 1.9$ & $-6,48$ \\
\hline vha-6 & $-2,05$ \\
\hline Y105E8A.3 & $-2,45$ \\
\hline dnj-9 & $-4,64$ \\
\hline R03H10.7 & $-4,27$ \\
\hline acr-11 & $-5,22$ \\
\hline$a c d-4$ & $-6,65$ \\
\hline ссер-290 & $-4,26$ \\
\hline slcf-1 & $-5,03$ \\
\hline rgs-2 & 2,90 \\
\hline$R 102.11$ & $-4,13$ \\
\hline F13H10.5 & $-5,28$ \\
\hline F48G7.8 & $-4,69$ \\
\hline$n h r-138$ & 2,29 \\
\hline E01G6.3 & $-4,10$ \\
\hline F53B1.8 & 2,72 \\
\hline$g p b-2$ & 2,50 \\
\hline K02E7.6 & $-4,67$ \\
\hline F22D6.9 & $-5,77$ \\
\hline F01F1.15 & $-3,57$ \\
\hline glna-1 & $-4,13$ \\
\hline clec-210 & $-5,58$ \\
\hline irld-6 & $-7,24$ \\
\hline F55H12.3 & $-4,69$ \\
\hline T12D8.9 & $-3,48$ \\
\hline Y57E12AR.1 & 3,60 \\
\hline ceh-30 & $-5,92$ \\
\hline str-31 & $-4,51$ \\
\hline sqt-2 & $-2,71$ \\
\hline zer-1 & 1,84 \\
\hline acr-12 & 3,25 \\
\hline aak-2 & 2,21 \\
\hline mec-18 & $-3,43$ \\
\hline madd-2 & 2,95 \\
\hline sma-2 & $-2,77$ \\
\hline$n h r-40$ & 2,55 \\
\hline$f b p-1$ & 3,50 \\
\hline
\end{tabular}

\begin{tabular}{|l|r|}
\hline gene & logFC \\
\hline Y73C8B.3 & $-3,66$ \\
\hline Iron-5 & $-3,76$ \\
\hline R04B3.2 & $-4,12$ \\
\hline acs-12 & $-3,96$ \\
\hline frpr-9 & $-7,29$ \\
\hline C03B1.7 & 3,21 \\
\hline Y11D7A.3 & $-2,93$ \\
\hline F55F3.4 & $-7,43$ \\
\hline mua-3 & $-2,59$ \\
\hline clec-4 & $-4,54$ \\
\hline T13F2.4 & $-5,64$ \\
\hline fbxa-87 & $-5,99$ \\
\hline srr-2 & $-6,28$ \\
\hline F40F11.3 & 4,36 \\
\hline pvf-1 & $-4,31$ \\
\hline chst-1 & $-6,02$ \\
\hline irg-7 & $-2,85$ \\
\hline C46A5.6 & $-6,10$ \\
\hline sro-1 & $-4,74$ \\
\hline ncl-1 & 1,86 \\
\hline C18H7.6 & $-5,55$ \\
\hline Iron-3 & 2,54 \\
\hline cld-9 & $-4,71$ \\
\hline R03G8.3 & $-6,10$ \\
\hline F48A11.4 & $-4,37$ \\
\hline nas-3 & $-3,46$ \\
\hline Y77E11A.12 & $-5,40$ \\
\hline sre-13 & $-5,18$ \\
\hline hlh-30 & 1,84 \\
\hline F29G6.1 & $-4,15$ \\
\hline vacl-14 & $-4,99$ \\
\hline ttx-1 & $-6,21$ \\
\hline ctns-1 & $-3,92$ \\
\hline maph-9 & $-6,63$ \\
\hline sel-12 & 3,07 \\
\hline syd-1 & 2,60 \\
\hline gcy-18 & $-5,87$ \\
\hline dyf-18 & $-6,06$ \\
\hline daf-1 & 2,35 \\
\hline F56C4.1 & $-6,29$ \\
\hline F29B9.5 & 4,22 \\
\hline C17G10.13 & $-5,63$ \\
\hline T08G5.3 & $-4,30$ \\
\hline tap-1 & $-3,57$ \\
\hline ncx-10 & $-6,19$ \\
\hline unc-1 & 2,72 \\
\hline C18A11.1 & $-2,78$ \\
\hline C04F6.7 & $-9,77$ \\
\hline oac-30 & $-4,44$ \\
\hline Y54E10A.12 & $-5,18$ \\
\hline sup-1 & 2,18 \\
\hline F15A4.5 & $-4,66$ \\
\hline F33D4.6 & $-3,20$ \\
\hline K07E1.1 & $-2,22$ \\
\hline T19B10.8 & $-5,01$ \\
\hline zip-12 & $-3,82$ \\
\hline F20D6.5 & $-3,98$ \\
\hline
\end{tabular}

\begin{tabular}{|l|r|}
\hline gene & logFC \\
\hline sax-3 & 2,07 \\
\hline pha-4 & 3,02 \\
\hline Y54G2A.32 & $-4,09$ \\
\hline Y69H2.15 & $-5,66$ \\
\hline mig-21 & $-7,13$ \\
\hline pals-24 & $-3,67$ \\
\hline F40E3.5 & $-6,14$ \\
\hline mocs-1 & $-7,36$ \\
\hline fkh-7 & 2,30 \\
\hline R09A1.2 & 3,94 \\
\hline ZK993.5 & $-5,64$ \\
\hline syg-1 & $-4,85$ \\
\hline cutl-18 & $-5,85$ \\
\hline W02H5.2 & $-5,80$ \\
\hline Y23H5B.8 & $-5,19$ \\
\hline C01G6.5 & 1,78 \\
\hline F49C12.15 & $-5,77$ \\
\hline nhr-100 & 2,22 \\
\hline cyp-33D3 & $-5,88$ \\
\hline srt-28 & $-5,42$ \\
\hline ced-11 & $-5,90$ \\
\hline F28C1.3 & 2,07 \\
\hline C31C9.7 & $-2,09$ \\
\hline clec-66 & $-2,87$ \\
\hline T05C12.11 & $-7,13$ \\
\hline eat-2 & $-6,16$ \\
\hline C02H6.3 & $-7,74$ \\
\hline C06E8.5 & $-5,83$ \\
\hline F09B9.5 & 3,41 \\
\hline dct-5 & $-3,35$ \\
\hline F31C3.6 & $-4,11$ \\
\hline ttr-33 & $-2,84$ \\
\hline C44H9.4 & $-7,03$ \\
\hline F13B6.2 & $-3,97$ \\
\hline sym-3 & $-5,39$ \\
\hline Y41E3.22 & $-5,00$ \\
\hline F07A5.4 & 3,32 \\
\hline clec-169 & $-4,35$ \\
\hline C02B10.5 & 2,27 \\
\hline apm-1 & $-4,49$ \\
\hline C29F3.3 & $-4,69$ \\
\hline elo-3 & $-4,95$ \\
\hline dhrs-4 & $-4,01$ \\
\hline glc-1 & $-3,55$ \\
\hline Y119D3B.13 & $-4,03$ \\
\hline acl-12 & 2,47 \\
\hline F58G6.9 & $-4,59$ \\
\hline vglu-2 & $-3,11$ \\
\hline F20D1.1 & 2,76 \\
\hline figl-1 & $-2,81$ \\
\hline myo-3 & $-5,11$ \\
\hline mks-3 & $-6,38$ \\
\hline cat-2 & $-5,47$ \\
\hline ttr-2 & \\
\hline fbxa-74 & \\
\hline bgnt-1.3 & \\
\hline C44C10.3 & \\
\hline
\end{tabular}




\section{Appendix}

\begin{tabular}{|l|r|}
\hline gene & logFC \\
\hline clec-17 & $-3,48$ \\
\hline abf-6 & $-2,59$ \\
\hline dpy-23 & 2,57 \\
\hline C55A6.12 & $-5,78$ \\
\hline F26G1.9 & $-7,64$ \\
\hline C06C3.10 & $-5,08$ \\
\hline Y45F3A.9 & $-4,55$ \\
\hline cosa-1 & $-6,36$ \\
\hline W03D8.8 & $-5,81$ \\
\hline dlk-1 & 2,07 \\
\hline C15C7.7 & $-4,30$ \\
\hline F13H6.3 & $-2,95$ \\
\hline F38B6.2 & $-4,66$ \\
\hline Y41D4B.14 & $-4,52$ \\
\hline T28F2.2 & 2,48 \\
\hline acr-17 & 4,14 \\
\hline Y48G1A.1 & $-5,68$ \\
\hline ocr-2 & $-5,71$ \\
\hline fbxa-27 & $-4,52$ \\
\hline acox-1.3 & $-6,12$ \\
\hline cgr-1 & $-2,72$ \\
\hline F27B10.1 & 2,75 \\
\hline C27F2.1 & $-4,72$ \\
\hline eps-8 & $-2,09$ \\
\hline Igc-27 & $-2,68$ \\
\hline F01D5.2 & $-5,27$ \\
\hline dnj-28 & $-6,00$ \\
\hline F17C11.13 & $-7,78$ \\
\hline epi-1 & $-2,51$ \\
\hline ZC434.9 & 2,35 \\
\hline F57C2.5 & $-1,96$ \\
\hline fat-1 & 1,96 \\
\hline abu-7 & $-5,35$ \\
\hline T04F3.4 & $-2,52$ \\
\hline ugt-22 & $-3,79$ \\
\hline F35B3.4 & $-4,26$ \\
\hline his-41 & 1,89 \\
\hline B0507.1 & $-4,35$ \\
\hline trcs-2 & 2,33 \\
\hline nhr-213 & $-7,37$ \\
\hline ent-2 & 2,29 \\
\hline fbxa-158 & $-4,88$ \\
\hline vab-3 & $-3,94$ \\
\hline tab-1 & $-5,27$ \\
\hline R07C3.16 & $-6,95$ \\
\hline ugt-1 & $-4,03$ \\
\hline jmjc-1 & $-3,14$ \\
\hline B0563.6 & 3,00 \\
\hline odr-10 & $-5,92$ \\
\hline R11A5.3 & 4,52 \\
\hline gba-3 \\
\hline ugt-41 & $-4,59$ \\
\hline T22D1.11 & $-5,95$ \\
\hline Igc-35 & $-5,69$ \\
\hline T28A11.17 & $-5,96$ \\
\hline F58B6.1 & $-3,90$ \\
\hline T05B11.7 & 3,32 \\
\hline
\end{tabular}

\begin{tabular}{|l|r|}
\hline gene & logFC \\
\hline nas-9 & $-3,89$ \\
\hline T20F5.4 & $-5,51$ \\
\hline F40F12.9 & $-4,83$ \\
\hline myrf-1 & 1,71 \\
\hline E01B7.2 & $-5,75$ \\
\hline chil-21 & $-5,09$ \\
\hline frpr-14 & $-3,85$ \\
\hline F45D11.2 & $-2,91$ \\
\hline F45D11.3 & $-2,91$ \\
\hline F45D11.4 & $-2,91$ \\
\hline cua-1 & 2,55 \\
\hline pck-1 & 3,18 \\
\hline glc-4 & 3,08 \\
\hline nhr-198 & $-5,54$ \\
\hline hda-4 & 4,07 \\
\hline acr-9 & 3,08 \\
\hline ZK1290.10 & $-5,77$ \\
\hline B0563.7 & $-4,69$ \\
\hline C40H1.8 & $-4,21$ \\
\hline col-62 & $-5,41$ \\
\hline F52D10.2 & $-7,20$ \\
\hline acy-3 & $-4,77$ \\
\hline lip-1 & 2,74 \\
\hline C17F4.3 & $-5,98$ \\
\hline F07H5.4 & 2,34 \\
\hline dyf-6 & $-4,19$ \\
\hline dhod-1 & $-3,03$ \\
\hline cky-1 & $-5,84$ \\
\hline nhr-148 & $-5,18$ \\
\hline Y11D7A.10 & 3,31 \\
\hline R13H4.8 & $-4,39$ \\
\hline cpr-3 & $-2,82$ \\
\hline C18A11.4 & $-3,92$ \\
\hline C27A7.3 & $-7,31$ \\
\hline eff-1 & $-5,27$ \\
\hline klf-3 & $-5,43$ \\
\hline F13H10.9 & $-4,98$ \\
\hline mul-1 & $-3,27$ \\
\hline aqp-11 & $-3,18$ \\
\hline K04F1.9 & $-2,80$ \\
\hline klp-20 & 2,99 \\
\hline M03E7.1 & $-6,85$ \\
\hline C24H10.1 & $-7,10$ \\
\hline F59G1.4 & 2,73 \\
\hline clec-24 & $-6,01$ \\
\hline cyp-31A1 & 2,35 \\
\hline F26E4.3 & $-2,53$ \\
\hline cka-2 & 2,18 \\
\hline M01B2.13 & $-4,55$ \\
\hline K08F9.1 & $-5,79$ \\
\hline snf-3 & $-5,56$ \\
\hline fbxa-84 & $-4,98$ \\
\hline syx-7 & $-4,18$ \\
\hline ZC250.4 \\
\hline ceh-22 & \\
\hline mlst-8 & \\
\hline scc-1 & \\
\hline
\end{tabular}

\begin{tabular}{|l|r|}
\hline gene & logFC \\
\hline sulp-1 & 3,90 \\
\hline unc-22 & $-2,74$ \\
\hline Y51B9A.6 & $-7,10$ \\
\hline T07G12.5 & $-4,22$ \\
\hline rib-2 & $-5,69$ \\
\hline oig-2 & $-5,84$ \\
\hline C18A11.3 & $-3,77$ \\
\hline Ist-1 & $-3,43$ \\
\hline nspc-18 & $-5,24$ \\
\hline C15H9.11 & $-4,64$ \\
\hline T01B7.13 & $-3,65$ \\
\hline ugt-23 & $-3,24$ \\
\hline tpxl-1 & $-3,87$ \\
\hline clec-31 & $-6,22$ \\
\hline srd-27 & $-5,50$ \\
\hline F41E6.12 & $-4,42$ \\
\hline fbxa-176 & $-7,44$ \\
\hline ZK596.1 & $-5,04$ \\
\hline itsn-1 & 2,65 \\
\hline F32D8.10 & $-5,16$ \\
\hline clec-80 & $-4,13$ \\
\hline col-142 & $-2,06$ \\
\hline K10H10.10 & $-6,08$ \\
\hline F17B5.6 & $-5,61$ \\
\hline cil-1 & $-5,42$ \\
\hline F46F2.3 & $-2,09$ \\
\hline T08D2.2 & $-5,41$ \\
\hline F21F8.6 & $-6,72$ \\
\hline aph-2 & 2,15 \\
\hline W04E12.7 & $-2,61$ \\
\hline npr-21 & $-3,94$ \\
\hline clec-187 & $-3,12$ \\
\hline C44F1.1 & $-4,76$ \\
\hline T21C9.6 & $-4,95$ \\
\hline B0310.3 & $-6,91$ \\
\hline trx-2 & $-4,51$ \\
\hline F56A4.2 & $-4,26$ \\
\hline F32H5.1 & $-3,47$ \\
\hline T13C2.7 & $-4,73$ \\
\hline kin-9 & $-5,57$ \\
\hline cyp-35B2 & $-4,95$ \\
\hline nlp-26 & $-4,32$ \\
\hline ZK250.13 & $-4,25$ \\
\hline Y119D3B.21 & $-3,61$ \\
\hline T22F3.8 & $-6,23$ \\
\hline acd-1 & $-4,05$ \\
\hline F57F4.4 & $-2,17$ \\
\hline W03F8.3 & $-4,36$ \\
\hline vit-1 & $-5,01$ \\
\hline F52B10.3 & 2,58 \\
\hline C50F2.2 & 2,98 \\
\hline ZK809.8 & $-2,20$ \\
\hline lim-7 & $-3,37$ \\
\hline clec-185 & $-4,01$ \\
\hline cyp-33C1 & $-3,60$ \\
\hline F48E8.4 \\
\hline F30F8.1 & $-3,67$ \\
\hline
\end{tabular}

\begin{tabular}{|l|r|}
\hline gene & logFC \\
\hline C14C6.5 & $-2,54$ \\
\hline ent-4 & $-5,51$ \\
\hline K08E7.5 & $-4,07$ \\
\hline mtm-3 & 1,71 \\
\hline Y87G2A.16 & $-5,69$ \\
\hline F41G3.2 & $-5,53$ \\
\hline F36H9.2 & $-5,28$ \\
\hline D1007.10 & $-6,10$ \\
\hline ins-24 & 2,18 \\
\hline nphp-2 & $-4,62$ \\
\hline iars-2 & $-5,81$ \\
\hline Ibp-1 & $-2,34$ \\
\hline ads-1 & $-2,72$ \\
\hline T06A1.5 & $-3,18$ \\
\hline C33G8.13 & $-6,63$ \\
\hline rfip-1 & $-2,58$ \\
\hline nspe-7 & $-6,11$ \\
\hline Y39B6A.27 & $-6,86$ \\
\hline maco-1 & 2,45 \\
\hline H05C05.1 & $-5,10$ \\
\hline F10A3.4 & $-5,07$ \\
\hline F39H12.3 & 3,04 \\
\hline ZK1307.2 & $-3,15$ \\
\hline gsnl-1 & $-2,36$ \\
\hline tag-290 & $-4,18$ \\
\hline Y43F8C.13 & $-4,43$ \\
\hline F40A3.3 & $-2,03$ \\
\hline tmem-135 & $-3,60$ \\
\hline cyp-13A1 & $-6,06$ \\
\hline Y18D10A.11 & $-5,13$ \\
\hline clec-166 & $-4,57$ \\
\hline fipr-23 & $-10,03$ \\
\hline K01D12.5 & $-5,43$ \\
\hline nth-1 & $-6,20$ \\
\hline W05E10.5 & 3,02 \\
\hline gsk-3 & 2,78 \\
\hline C05E7.3 & $-4,88$ \\
\hline magu-3 & 2,55 \\
\hline M60.7 & $-6,75$ \\
\hline F45D3.4 & $-3,26$ \\
\hline cls-3 & 2,28 \\
\hline pals-32 & $-6,63$ \\
\hline dsl-5 & $-6,73$ \\
\hline kcc-2 & 2,21 \\
\hline oac-53 & $-7,10$ \\
\hline F08F1.3 & $-5,01$ \\
\hline C23G10.11 & $-6,97$ \\
\hline nhr-1 & 1,86 \\
\hline H40L08.2 & $-2,17$ \\
\hline K09H9.5 & $-4,06$ \\
\hline nmgp-1 & $-2,86$ \\
\hline F11E6.11 & $-4,52$ \\
\hline gst-38 & $-3,44$ \\
\hline duxl-1 & $-3,61$ \\
\hline smk-1 & $-5,94$ \\
\hline sodh-2 \\
\hline F55G11.3 & \\
\hline
\end{tabular}




\section{Appendix}

\begin{tabular}{|l|r|}
\hline gene & logFC \\
\hline tag-273 & $-2,46$ \\
\hline vpat-1 & $-5,32$ \\
\hline srb-16 & $-6,33$ \\
\hline H40L08.1 & $-2,80$ \\
\hline clec-10 & $-3,90$ \\
\hline T10E9.8 & $-6,43$ \\
\hline T10G3.3 & $-4,32$ \\
\hline hphd-1 & $-2,91$ \\
\hline R07B1.5 & $-4,77$ \\
\hline hasp-1 & $-5,26$ \\
\hline gst-6 & $-2,03$ \\
\hline pqe-1 & 2,03 \\
\hline R02E12.4 & $-5,45$ \\
\hline eyg-1 & $-5,62$ \\
\hline fbxc-23 & $-5,96$ \\
\hline srt-7 & $-5,78$ \\
\hline abhd-3.1 & 2,39 \\
\hline F28B12.1 & 3,71 \\
\hline rad-54 & $-6,51$ \\
\hline ppk-2 & 3,03 \\
\hline pgp-13 & $-6,15$ \\
\hline aqp-1 & $-4,17$ \\
\hline K11H12.4 & $-6,34$ \\
\hline VM106R.1 & 2,60 \\
\hline ZC155.4 & $-6,60$ \\
\hline mps-2 & 2,06 \\
\hline C35A11.4 & $-3,09$ \\
\hline F26F12.4 & $-6,70$ \\
\hline fbxa-209 & $-5,85$ \\
\hline pdl-1 & 2,95 \\
\hline otpl-1 & $-6,84$ \\
\hline skr-1 & 1,69 \\
\hline W02D7.5 & $-4,38$ \\
\hline dao-2 & $-2,28$ \\
\hline Y36E3A.2 & $-5,85$ \\
\hline F16F9.1 & 3,17 \\
\hline bli-2 & $-6,62$ \\
\hline aptf-2 & $-4,49$ \\
\hline fbxb-88 & $-7,20$ \\
\hline Y97E10AL.1 & $-7,38$ \\
\hline mec-1 & $-3,37$ \\
\hline F31D5.2 & $-6,58$ \\
\hline pyr-1 & $-1,94$ \\
\hline T06F4.1 & 2,49 \\
\hline rab-19 & 2,26 \\
\hline clec-56 & $-3,07$ \\
\hline pho-12 & $-6,45$ \\
\hline ndnf-1 & $-3,73$ \\
\hline nhr-216 & $-6,92$ \\
\hline F57B9.3 & $-6,37$ \\
\hline abhd-14 & 2,96 \\
\hline cyp-13B1 & $-3,96$ \\
\hline drag-1 & $-6,51$ \\
\hline cpr-8 & $-4,73$ \\
\hline T16G1.5 & $-6,42$ \\
\hline drd-1 & $-2,97$ \\
\hline efk-1 & 1,96 \\
\hline
\end{tabular}

\begin{tabular}{|l|r|}
\hline gene & logFC \\
\hline F47B10.3 & $-7,24$ \\
\hline nhr-236 & $-6,72$ \\
\hline sql-1 & 2,13 \\
\hline F32B4.4 & 2,72 \\
\hline T10B5.10 & 3,41 \\
\hline Idp-1 & $-3,29$ \\
\hline gba-1 & $-3,81$ \\
\hline C50B6.9 & $-6,60$ \\
\hline F56D5.4 & 2,63 \\
\hline twk-17 & 2,41 \\
\hline rpb-5 & $-3,96$ \\
\hline bath-43 & 2,14 \\
\hline K07H8.11 & $-5,71$ \\
\hline F35A5.1 & $-2,15$ \\
\hline K12H6.12 & $-4,23$ \\
\hline T28D9.3 & $-3,42$ \\
\hline set-16 & 1,74 \\
\hline Y54E10BR.2 & $-5,08$ \\
\hline rpn-11 & 2,29 \\
\hline ZC21.3 & $-3,22$ \\
\hline abu-10 & $-2,99$ \\
\hline ptr-12 & $-4,42$ \\
\hline R03A10.5 & $-4,35$ \\
\hline D1086.12 & $-1,91$ \\
\hline col-127 & $-2,60$ \\
\hline eipr-1 & 2,53 \\
\hline Y71H2B.5 & 2,33 \\
\hline stn-1 & 2,45 \\
\hline tag-147 & 2,33 \\
\hline nhr-129 & 3,03 \\
\hline svh-2 & $-2,64$ \\
\hline ZK512.1 & $-5,15$ \\
\hline Ipr-2 & $-5,13$ \\
\hline Y41D4B.15 & $-6,68$ \\
\hline C34F6.7 & $-4,53$ \\
\hline F55D12.2 & $-2,76$ \\
\hline pgrn-1 & $-3,68$ \\
\hline unc-31 & 3,26 \\
\hline K11D12.8 & $-6,85$ \\
\hline ugt-30 & $-5,65$ \\
\hline gcy-9 & $-5,15$ \\
\hline ttr-24 & $-2,07$ \\
\hline fipr-10 & $-6,23$ \\
\hline taf-3 & 2,46 \\
\hline cfim-2 & 2,13 \\
\hline acds-10 & $-2,81$ \\
\hline F14B8.6 & $-2,68$ \\
\hline gfi-1 & $-3,85$ \\
\hline Y25C1A.2 & $-4,58$ \\
\hline daf-21 & 1,69 \\
\hline inx-3 & $-6,20$ \\
\hline F48G7.13 & $-6,30$ \\
\hline Y73F4A.3 & $-2,93$ \\
\hline lipl-6 & $-2,60$ \\
\hline prx-10 & $-2,78$ \\
\hline Imp-2 & \\
\hline cyp-25A2 & \\
\hline
\end{tabular}

\begin{tabular}{|l|r|}
\hline gene & logFC \\
\hline C08F1.8 & 4,39 \\
\hline Y53F4B.18 & $-5,14$ \\
\hline fbxa-89 & $-5,41$ \\
\hline C29F5.1 & $-2,32$ \\
\hline pdhk-2 & 2,01 \\
\hline T27F6.7 & 2,94 \\
\hline lips-7 & $-5,47$ \\
\hline F08D12.7 & $-4,91$ \\
\hline daf-10 & $-4,88$ \\
\hline bbs-2 & $-5,88$ \\
\hline lat-2 & $-5,06$ \\
\hline hmg-1.1 & 1,99 \\
\hline trhr-1 & $-5,20$ \\
\hline ptr-13 & $-6,82$ \\
\hline R07H5.8 & $-2,51$ \\
\hline F49E8.6 & 2,03 \\
\hline tmc-2 & $-3,33$ \\
\hline ZK228.4 & $-6,13$ \\
\hline clec-78 & $-4,59$ \\
\hline F46A8.1 & $-5,31$ \\
\hline F46C5.10 & $-4,66$ \\
\hline dlc-5 & $-6,28$ \\
\hline W04D2.6 & 1,80 \\
\hline C32D5.3 & 1,94 \\
\hline glb-6 & $-4,26$ \\
\hline zmp-3 & $-3,73$ \\
\hline Y95B8A.12 & 3,36 \\
\hline W02B12.13 & $-5,82$ \\
\hline F16C3.3 & $-4,50$ \\
\hline abu-15 & $-3,38$ \\
\hline F44A2.5 & $-2,33$ \\
\hline hpo-19 & $-2,09$ \\
\hline F14F3.4 & $-5,02$ \\
\hline Ist-5 & 3,08 \\
\hline gfrp-1 & $-2,93$ \\
\hline pup-2 & $-5,54$ \\
\hline T05G5.1 & $-3,46$ \\
\hline B0365.9 & $-3,71$ \\
\hline C02F4.4 & $-2,15$ \\
\hline T15B7.1 & $-2,43$ \\
\hline sptl-2 & $-3,69$ \\
\hline C28A5.2 & $-6,27$ \\
\hline oac-59 & $-3,92$ \\
\hline mrp-8 & $-3,78$ \\
\hline C16B8.3 & $-2,40$ \\
\hline str-131 & $-6,09$ \\
\hline T27C5.12 & $-6,26$ \\
\hline ced-9 & 3,26 \\
\hline lact-7 & $-4,60$ \\
\hline cyp-14A5 & $-6,09$ \\
\hline W03F9.4 \\
\hline grd-14 & $-3,82$ \\
\hline scl-5 & $-3,02$ \\
\hline pqn-92 \\
\hline F13H10.8 \\
\hline stg-1 \\
\hline haly-1 \\
\hline
\end{tabular}

\begin{tabular}{|l|r|}
\hline gene & logFC \\
\hline Y38E10A.28 & $-6,57$ \\
\hline clec-1 & $-3,18$ \\
\hline Y41D4B.18 & $-5,38$ \\
\hline atf-2 & $-4,31$ \\
\hline let-526 & 1,64 \\
\hline grd-13 & $-1,86$ \\
\hline 4R79.2 & $-4,64$ \\
\hline F20C5.5 & $-5,02$ \\
\hline nduo-1 & 1,67 \\
\hline T05E12.6 & $-4,38$ \\
\hline Y110A7A.21 & $-3,97$ \\
\hline ZK54.3 & 3,87 \\
\hline clec-62 & $-4,17$ \\
\hline alg-5 & $-5,20$ \\
\hline Ibp-2 & $-1,75$ \\
\hline T24H10.4 & 2,69 \\
\hline ZC443.1 & $-2,45$ \\
\hline clec-63 & $-1,73$ \\
\hline unc-41 & 1,97 \\
\hline pitr-3 & $-6,76$ \\
\hline C17F4.7 & $-1,87$ \\
\hline hrpf-2 & 2,16 \\
\hline F47B8.8 & $-2,34$ \\
\hline pks-1 & $-4,32$ \\
\hline zak-1 & $-3,63$ \\
\hline T05E11.9 & $-1,81$ \\
\hline B0286.1 & 2,77 \\
\hline ptc-1 & 2,17 \\
\hline Y53G8AL.1 & $-3,52$ \\
\hline B0546.4 & 2,90 \\
\hline T28H10.3 & $-3,96$ \\
\hline H05C05.2 & 2,87 \\
\hline C49F8.3 & $-3,70$ \\
\hline clec-150 & $-1,89$ \\
\hline F32D8.7 & $-3,42$ \\
\hline tiar-3 & $-5,26$ \\
\hline T17H7.1 & $-3,86$ \\
\hline F48G7.5 & $-2,60$ \\
\hline R04A9.6 & 4,03 \\
\hline H20E11.3 & $-3,73$ \\
\hline sli-1 & 2,27 \\
\hline apb-1 & 2,17 \\
\hline acox-1.6 & $-2,87$ \\
\hline cyp-34A6 & 2,34 \\
\hline dmsr-8 & $-6,09$ \\
\hline dnpp-1 & $-2,25$ \\
\hline fbxa-91 & $-4,82$ \\
\hline R05H11.1 & $-3,85$ \\
\hline alh-10 & $-2,19$ \\
\hline T28A8.4 & $-6,69$ \\
\hline npr-7 & 3,25 \\
\hline Y65B4A.8 & $-2,57$ \\
\hline unc-69 & 1,83 \\
\hline H18N23.2 & 2,17 \\
\hline pqn-41 & $-2,15$ \\
\hline F53A10.2 \\
\hline pat-2 & \\
\hline
\end{tabular}




\section{Appendix}

\begin{tabular}{|l|r|}
\hline gene & logFC \\
\hline F57G8.7 & $-6,22$ \\
\hline K08E7.6 & 3,71 \\
\hline K04A8.1 & $-4,60$ \\
\hline ZK1025.8 & $-6,63$ \\
\hline glt-7 & $-4,50$ \\
\hline sym-1 & $-3,18$ \\
\hline bgal-2 & $-3,88$ \\
\hline inx-19 & $-5,00$ \\
\hline mrp-4 & $-3,80$ \\
\hline F54D5.7 & $-1,90$ \\
\hline pqn-15 & $-5,75$ \\
\hline phat-4 & $-3,28$ \\
\hline F17C8.9 & $-2,79$ \\
\hline ugt-47 & $-3,44$ \\
\hline F11A5.15 & $-5,11$ \\
\hline tom-1 & 2,21 \\
\hline jac-1 & 1,95 \\
\hline C50F4.8 & $-2,72$ \\
\hline lys-3 & $-8,20$ \\
\hline T02G5.7 & $-2,85$ \\
\hline srg-49 & $-6,24$ \\
\hline tsen-54 & $-6,10$ \\
\hline cpr-5 & $-2,88$ \\
\hline top-2 & 2,28 \\
\hline C34D10.1 & 3,62 \\
\hline H12D21.9 & $-2,88$ \\
\hline F35E12.6 & $-2,78$ \\
\hline F59B10.3 & $-3,22$ \\
\hline C24G6.2 & $-3,59$ \\
\hline C14A11.5 & 2,65 \\
\hline glh-3 & $-5,39$ \\
\hline irg-4 & $-3,78$ \\
\hline Y106G6H.6 & $-3,88$ \\
\hline hst-3.2 & 3,56 \\
\hline ceh-24 & $-4,63$ \\
\hline unc-7 & $-5,06$ \\
\hline col-83 & 3,03 \\
\hline dhc-4 & $-3,53$ \\
\hline nhr-41 & $-4,52$ \\
\hline T24E12.5 & $-4,72$ \\
\hline B0252.5 & $-6,97$ \\
\hline T05F1.9 & $-4,91$ \\
\hline cyp-33A1 & $-3,23$ \\
\hline his-37 & 1,77 \\
\hline C42D4.2 & $-7,61$ \\
\hline gdi-1 & 2,01 \\
\hline T25C12.3 & $-3,80$ \\
\hline acl-3 & $-3,91$ \\
\hline pqn-26 & $-5,40$ \\
\hline cyp-29A3 & $-3,77$ \\
\hline eef-2 & $-2,64$ \\
\hline F35C11.6 & $-4,07$ \\
\hline Y23H5B.3 & $-6,05$ \\
\hline dod-6 & $-3,14$ \\
\hline nhr-158 & $-4,63$ \\
\hline R05D11.9 & $-2,71$ \\
\hline irld-11 & $-6,18$ \\
\hline
\end{tabular}

\begin{tabular}{|l|r|}
\hline gene & logFC \\
\hline ZK669.2 & $-4,47$ \\
\hline nhr-88 & 2,49 \\
\hline K09F6.6 & $-4,72$ \\
\hline osm-11 & $-2,23$ \\
\hline T07D10.3 & $-5,49$ \\
\hline nnt-1 & $-1,99$ \\
\hline gei-14 & $-5,00$ \\
\hline trp-2 & 2,98 \\
\hline Y37H2C.1 & $-6,53$ \\
\hline F28G4.4 & $-6,82$ \\
\hline C29G2.6 & $-4,57$ \\
\hline C18B2.5 & $-2,07$ \\
\hline Y51H7BR.7 & $-6,41$ \\
\hline F48E3.2 & 2,70 \\
\hline lin-40 & 2,06 \\
\hline tnt-3 & $-2,26$ \\
\hline T13C5.9 & $-5,30$ \\
\hline ZK742.4 & $-6,71$ \\
\hline ZK470.14 & $-4,01$ \\
\hline Y50D4B.1 & 2,28 \\
\hline grl-21 & $-2,42$ \\
\hline F46C5.2 & 3,14 \\
\hline mct-3 & $-3,59$ \\
\hline F22F1.3 & 3,65 \\
\hline npr-24 & 3,65 \\
\hline hrp-2 & 2,23 \\
\hline T19D12.5 & $-4,41$ \\
\hline tnt-4 & $-3,34$ \\
\hline dsc-4 & $-4,00$ \\
\hline bbs-4 & $-4,56$ \\
\hline F53C3.4 & 4,81 \\
\hline C25F9.14 & $-2,30$ \\
\hline spg-7 & $-5,48$ \\
\hline Y11D7A.5 & $-4,04$ \\
\hline dhs-4 & $-2,10$ \\
\hline R11G1.6 & 1,99 \\
\hline dhs-27 & $-4,67$ \\
\hline irld-40 & $-5,97$ \\
\hline hxk-1 & 1,96 \\
\hline col-157 & $-2,62$ \\
\hline C45B2.2 & $-1,99$ \\
\hline ins-27 & 3,33 \\
\hline secs-1 & $-5,05$ \\
\hline C33E10.1 & $-5,21$ \\
\hline nhr-167 & $-6,55$ \\
\hline F46F11.10 & $-4,73$ \\
\hline C18E9.5 & $-2,99$ \\
\hline F23D12.11 & $-2,47$ \\
\hline clec-76 & $-3,32$ \\
\hline cyp-33C7 & $-4,83$ \\
\hline asp-14 & $-2,48$ \\
\hline R04E5.9 & 2,41 \\
\hline chil-28 & $-5,11$ \\
\hline F36H2.3 & $-3,16$ \\
\hline ensa-1 & $-6,72$ \\
\hline lin-59 & \\
\hline pitr-5 & \\
\hline
\end{tabular}

\begin{tabular}{|l|r|}
\hline gene & logFC \\
\hline ska-3 & $-3,72$ \\
\hline acsd-1 & $-3,66$ \\
\hline tsp-14 & 1,85 \\
\hline ral-1 & $-2,02$ \\
\hline acr-14 & $-3,75$ \\
\hline F42G2.5 & $-5,04$ \\
\hline acl-7 & $-3,53$ \\
\hline chil-18 & $-5,96$ \\
\hline atic-1 & 1,84 \\
\hline mpk-2 & $-3,32$ \\
\hline ain-1 & 1,63 \\
\hline mltn-10 & $-5,06$ \\
\hline Y55B1BL.1 & $-2,79$ \\
\hline saeg-2 & 2,44 \\
\hline Y71H2AM.10 & 2,13 \\
\hline F46G10.1 & $-2,46$ \\
\hline T20F7.5 & $-4,84$ \\
\hline bpl-1 & $-2,61$ \\
\hline ipgm-1 & 1,62 \\
\hline R08D7.1 & $-3,46$ \\
\hline lec-8 & $-1,76$ \\
\hline fbxa-137 & $-4,54$ \\
\hline F46A8.13 & 3,16 \\
\hline hrdl-1 & 1,82 \\
\hline M01H9.3 & 2,27 \\
\hline glb-5 & $-4,77$ \\
\hline C48B4.3 & 3,79 \\
\hline C15A7.2 & 3,36 \\
\hline sav-1 & $-3,51$ \\
\hline C53B4.3 & $-3,78$ \\
\hline vhl-1 & $-6,04$ \\
\hline T04A11.2 & $-5,14$ \\
\hline T04A11.5 & $-5,14$ \\
\hline C29F7.1 & $-4,00$ \\
\hline linc-25 & 3,27 \\
\hline vha-5 & $-1,89$ \\
\hline T25B9.3 & 3,91 \\
\hline scrm-1 & 2,85 \\
\hline lips-17 & $-4,15$ \\
\hline F18A11.2 & $-1,93$ \\
\hline col-145 & $-2,34$ \\
\hline Y105C5B.5 & $-1,88$ \\
\hline T08H10.1 & $-2,06$ \\
\hline T12G3.4 & $-2,56$ \\
\hline gar-2 & 2,23 \\
\hline F11D5.7 & $-6,64$ \\
\hline pes-5 & $-6,09$ \\
\hline nlp-30 & $-4,03$ \\
\hline F26C11.1 & $-6,18$ \\
\hline C07D10.1 & $-6,36$ \\
\hline F18E9.3 & $-3,10$ \\
\hline egas-4 & $-5,49$ \\
\hline rpn-2 & $-1,94$ \\
\hline W01C8.5 \\
\hline ubc-16 & $-3,39$ \\
\hline C23G10.5 & $-3,77$ \\
\hline ensh-1 & $-5,28$ \\
\hline
\end{tabular}

\begin{tabular}{|l|r|}
\hline gene & logFC \\
\hline Y54F10BM.1 & 3,35 \\
\hline C03H5.6 & 2,95 \\
\hline F16B4.2 & $-4,00$ \\
\hline C47B2.9 & $-4,04$ \\
\hline WO3F8.6 & $-2,26$ \\
\hline lin-9 & 2,14 \\
\hline Y54G11A.4 & $-3,37$ \\
\hline nhr-56 & 2,59 \\
\hline mtrr-1 & $-3,46$ \\
\hline F52E1.14 & $-2,54$ \\
\hline pak-2 & 2,45 \\
\hline ifc-2 & $-2,59$ \\
\hline ugt-59 & $-4,16$ \\
\hline F09F9.2 & $-3,12$ \\
\hline inx-16 & $-5,96$ \\
\hline cbl-1 & $-3,01$ \\
\hline math-22 & $-4,38$ \\
\hline F21A3.11 & $-4,14$ \\
\hline T20B6.3 & $-4,95$ \\
\hline inx-12 & $-1,63$ \\
\hline pdi-2 & $-1,93$ \\
\hline attf-4 & 1,77 \\
\hline ras-2 & $-4,79$ \\
\hline maph-1.1 & 1,92 \\
\hline B0244.5 & $-4,68$ \\
\hline cgef-1 & 2,04 \\
\hline PDB1.1 & $-2,45$ \\
\hline marg-1 & $-4,95$ \\
\hline clec-65 & $-2,39$ \\
\hline Y59C2A.1 & $-5,54$ \\
\hline pud-2.1 & $-1,91$ \\
\hline twk-25 & $-5,55$ \\
\hline ceh-44 & 1,68 \\
\hline F58H1.2 & $-4,37$ \\
\hline btb-17 & $-2,48$ \\
\hline T24C12.4 & $-3,85$ \\
\hline F49E12.12 & $-5,15$ \\
\hline gpa-15 & $-6,57$ \\
\hline trr-1 & 1,80 \\
\hline K08E3.5 & $-1,71$ \\
\hline fbxa-136 & $-7,87$ \\
\hline F23B12.4 & $-2,04$ \\
\hline fbxa-164 & $-7,26$ \\
\hline C45E5.1 & $-4,93$ \\
\hline let-268 & $-3,92$ \\
\hline mup-4 & $-3,62$ \\
\hline grdn-1 & 3,55 \\
\hline W02B12.1 & $-2,52$ \\
\hline fbxa-80 & $-3,45$ \\
\hline M117.1 & 2,23 \\
\hline his-62 & $-2,04$ \\
\hline LLC1.2 & $-3,51$ \\
\hline nduo-5 & 1,82 \\
\hline Ipr-6 & \\
\hline pals-19 & \\
\hline cyp-14A4 & F57A8.1 \\
\hline
\end{tabular}




\section{Appendix}

\begin{tabular}{|l|r|}
\hline gene & logFC \\
\hline F13H8.5 & $-4,42$ \\
\hline pqn-39 & 2,16 \\
\hline fre-1 & 2,21 \\
\hline sodh-1 & $-1,69$ \\
\hline R12A1.3 & $-2,22$ \\
\hline cyp-35A1 & $-6,42$ \\
\hline ncs-2 & 1,69 \\
\hline T20F5.6 & 1,82 \\
\hline dhs-7 & $-4,53$ \\
\hline Y32H12A.6 & 2,68 \\
\hline C26C6.8 & $-5,66$ \\
\hline F45D11.15 & $-1,98$ \\
\hline F45D11.16 & $-1,98$ \\
\hline W04G5.10 & $-6,73$ \\
\hline C06A8.3 & $-1,91$ \\
\hline cyp-29A4 & $-5,92$ \\
\hline exc-6 & $-4,65$ \\
\hline str-162 & $-6,00$ \\
\hline ubc-25 & 1,74 \\
\hline gpx-6 & $-1,80$ \\
\hline sdn-1 & 1,89 \\
\hline F59E11.7 & $-2,75$ \\
\hline fkb-3 & $-3,44$ \\
\hline clec-54 & $-2,71$ \\
\hline gpa-17 & $-2,80$ \\
\hline srh-276 & $-5,64$ \\
\hline unc-5 & $-2,39$ \\
\hline snx-14 & 2,11 \\
\hline F13H6.5 & 2,82 \\
\hline nhr-178 & $-4,55$ \\
\hline C27H5.2 & $-2,31$ \\
\hline Y50D7A.8 & 2,44 \\
\hline C52A10.2 & $-5,62$ \\
\hline C15A11.7 & $-2,93$ \\
\hline Y57G11C.38 & $-5,35$ \\
\hline cest-1 & $-4,88$ \\
\hline C25F9.10 & $-2,20$ \\
\hline pes-4 & 2,85 \\
\hline F55G11.4 & $-4,11$ \\
\hline mnr-1 & $-3,86$ \\
\hline ced-8 & $-5,81$ \\
\hline K08D9.2 & $-6,24$ \\
\hline sta-2 & $-4,35$ \\
\hline col-128 & $-2,84$ \\
\hline flp-2 & $-2,56$ \\
\hline T24G10.2 & 2,23 \\
\hline ceh-88 & 2,37 \\
\hline imb-2 & 1,89 \\
\hline dhs-28 & $-2,22$ \\
\hline fbxc-52 & $-3,40$ \\
\hline gad-3 & $-2,86$ \\
\hline R02F2.1 & 2,08 \\
\hline phg-1 & $-5,87$ \\
\hline F39D8.3 & $-5,94$ \\
\hline C27A2.5 \\
\hline C35D10.13 \\
\hline cyp-33C12 & \\
\hline
\end{tabular}

\begin{tabular}{|l|r|}
\hline gene & logFC \\
\hline T06D8.2 & $-5,35$ \\
\hline vps-32.1 & 1,99 \\
\hline nhr-193 & $-6,88$ \\
\hline upp-1 & 2,38 \\
\hline F48C1.6 & $-2,59$ \\
\hline F35H12.1 & 3,07 \\
\hline jph-1 & 2,05 \\
\hline ain-2 & 1,55 \\
\hline cyp-33C2 & $-5,42$ \\
\hline bag-1 & 2,82 \\
\hline M05B5.4 & $-2,48$ \\
\hline F55H2.7 & $-3,03$ \\
\hline ZC15.10 & 3,94 \\
\hline Y47H10A.5 & $-7,57$ \\
\hline aex-4 & $-4,99$ \\
\hline ttr-32 & $-3,82$ \\
\hline cpi-1 & $-1,58$ \\
\hline ZK896.3 & $-5,76$ \\
\hline ndx-1 & 2,62 \\
\hline fkb-7 & $-2,30$ \\
\hline denn-4 & 2,55 \\
\hline fkh-9 & 1,72 \\
\hline K03H6.5 & $-3,61$ \\
\hline H06l04.1 & 2,55 \\
\hline Y92H12A.2 & 1,90 \\
\hline igeg-2 & $-7,22$ \\
\hline C16H3.3 & 2,02 \\
\hline cal-5 & $-1,57$ \\
\hline btb-5 & 4,89 \\
\hline col-176 & $-1,94$ \\
\hline T24B8.5 & $-2,73$ \\
\hline prp-6 & 1,60 \\
\hline sulp-3 & $-3,55$ \\
\hline ceeh-2 & $-3,26$ \\
\hline K01D12.1 & $-6,50$ \\
\hline hsp-17 & $-2,82$ \\
\hline H13N06.2 & $-5,20$ \\
\hline plk-3 & $-4,48$ \\
\hline fbxa-52 & $-5,73$ \\
\hline Y43C5A.3 & $-2,50$ \\
\hline F28C6.5 & $-2,87$ \\
\hline ptl-1 & 2,37 \\
\hline M04G7.3 & 3,71 \\
\hline gtbp-1 & 1,94 \\
\hline F20G2.3 & $-1,74$ \\
\hline B0393.7 & $-4,56$ \\
\hline ZC123.1 & $-4,50$ \\
\hline clec-74 & $-7,33$ \\
\hline del-2 & $-5,16$ \\
\hline nhr-155 & $-6,97$ \\
\hline C34E11.2 & $-6,78$ \\
\hline haf-6 & $-1,95$ \\
\hline flp-18 & $-3,78$ \\
\hline C18B12.6 \\
\hline cec-1 & $-1,76$ \\
\hline M28.10 \\
\hline psd-1 & \\
\hline
\end{tabular}

\begin{tabular}{|l|r|}
\hline gene & logFC \\
\hline pitr-1 & 1,72 \\
\hline ntl-2 & 2,06 \\
\hline col-140 & $-5,14$ \\
\hline act-2 & 2,45 \\
\hline ptr-6 & $-4,82$ \\
\hline F36F12.1 & $-6,66$ \\
\hline M02E1.1 & 2,15 \\
\hline dcp-66 & 1,92 \\
\hline K06H6.1 & $-5,67$ \\
\hline F54D5.4 & $-2,40$ \\
\hline Igc-30 & $-4,56$ \\
\hline tut-1 & $-2,84$ \\
\hline phat-1 & $-5,03$ \\
\hline osm-1 & $-3,74$ \\
\hline ncs-1 & 3,77 \\
\hline unc-70 & 1,55 \\
\hline H02F09.3 & $-7,41$ \\
\hline cam-1 & 1,82 \\
\hline ctps-1 & $-5,63$ \\
\hline F53F4.15 & $-5,77$ \\
\hline C31E10.5 & $-5,27$ \\
\hline tni-4 & $-2,00$ \\
\hline che-2 & $-4,93$ \\
\hline B0454.9 & 3,09 \\
\hline pho-7 & $-5,23$ \\
\hline C25F6.8 & $-4,17$ \\
\hline suds-3 & $-3,61$ \\
\hline oac-7 & $-5,91$ \\
\hline hecd-1 & 1,47 \\
\hline lgx-1 & 2,69 \\
\hline C50B6.7 & $-5,32$ \\
\hline Y75B8A.24 & 1,71 \\
\hline col-108 & $-4,86$ \\
\hline T04C12.8 & $-4,58$ \\
\hline nrf-6 & $-4,47$ \\
\hline Y45F10B.13 & $-1,84$ \\
\hline cdo-1 & $-2,00$ \\
\hline T07D4.5 & $-3,45$ \\
\hline T19B10.2 & $-2,20$ \\
\hline fpn-1.2 & $-3,74$ \\
\hline hpd-1 & $-2,35$ \\
\hline Ipd-3 & 1,73 \\
\hline F49C12.14 & $-3,92$ \\
\hline mrp-3 & $-3,45$ \\
\hline M01B12.4 & 2,12 \\
\hline srap-1 & $-2,04$ \\
\hline clec-7 & $-3,61$ \\
\hline thn-2 & $-5,60$ \\
\hline C15B12.8 & $-4,79$ \\
\hline cdr-7 & $-2,73$ \\
\hline imp-2 \\
\hline mccc-1 \\
\hline ugt-17 & $-3,81$ \\
\hline rskn-2 \\
\hline smp-1 \\
\hline F19C6.4 & $-4,67$ \\
\hline unc-64 \\
\hline
\end{tabular}

\begin{tabular}{|l|r|}
\hline gene & logFC \\
\hline Y37D8A.4 & 2,57 \\
\hline F57F5.1 & $-2,18$ \\
\hline hizr-1 & $-4,58$ \\
\hline ttr-21 & $-2,39$ \\
\hline pho-13 & $-3,60$ \\
\hline pqn-36 & $-3,81$ \\
\hline R13D11.4 & 2,90 \\
\hline gsp-1 & 1,95 \\
\hline Y48G8AR.2 & $-4,15$ \\
\hline C49G9.2 & $-4,59$ \\
\hline Ism-6 & 3,92 \\
\hline T16G1.4 & $-3,79$ \\
\hline Y54G2A.45 & $-2,16$ \\
\hline Y54F10AM.6 & $-4,07$ \\
\hline spt-16 & 1,79 \\
\hline T10E9.3 & $-2,36$ \\
\hline F59C6.16 & $-3,62$ \\
\hline pals-17 & $-5,90$ \\
\hline F59E12.15 & 2,07 \\
\hline C30F12.5 & $-2,00$ \\
\hline srr-6 & $-6,15$ \\
\hline pisy-1 & 2,46 \\
\hline C52B11.5 & $-2,45$ \\
\hline oac-57 & $-4,14$ \\
\hline F21C10.7 & $-1,87$ \\
\hline dyb-1 & 3,45 \\
\hline fip-5 & $-2,10$ \\
\hline ugt-8 & $-2,59$ \\
\hline T24F1.4 & 3,32 \\
\hline mig-18 & $-2,74$ \\
\hline hmg-11 & 2,56 \\
\hline F10F2.2 & $-1,96$ \\
\hline maf-1 & 2,44 \\
\hline gst-31 & 3,86 \\
\hline Y42H9AR.5 & $-3,49$ \\
\hline cpr-1 & $-1,97$ \\
\hline clec-61 & $-3,16$ \\
\hline M03B6.4 & $-4,06$ \\
\hline let-99 & $-3,42$ \\
\hline npr-15 & 2,86 \\
\hline D2092.4 & $-2,28$ \\
\hline ugt-4 & $-5,84$ \\
\hline cyp-34A1 & $-6,82$ \\
\hline sop-3 & 2,22 \\
\hline pin-2 & $-3,77$ \\
\hline R05G6.9 & $-3,73$ \\
\hline H36L18.2 & 2,71 \\
\hline T22F7.3 & $-4,86$ \\
\hline C30E1.9 & 3,08 \\
\hline K09B3.1 & $-3,43$ \\
\hline clec-13 & $-3,40$ \\
\hline T22C8.3 & 2,73 \\
\hline sre-4 & 2,64 \\
\hline zfp-3 & \\
\hline cul-3 & \\
\hline ddx-15 & \\
\hline bas-1 & \\
\hline
\end{tabular}




\section{Appendix}

\begin{tabular}{|l|r|}
\hline gene & logFC \\
\hline Y37E3.1 & 1,79 \\
\hline Y61A9LA.3 & 2,14 \\
\hline bcc-1 & $-4,58$ \\
\hline T25G3.3 & $-2,12$ \\
\hline ham-3 & 2,24 \\
\hline C18A3.1 & $-3,62$ \\
\hline Y57G11C.9 & 1,47 \\
\hline gcp-2.1 & $-2,17$ \\
\hline nhr-15 & 2,53 \\
\hline mec-6 & 2,39 \\
\hline spr-5 & 2,14 \\
\hline C54D10.3 & $-2,67$ \\
\hline pole-1 & $-3,26$ \\
\hline pgp-11 & $-4,95$ \\
\hline K04F10.2 & $-4,06$ \\
\hline F53B3.5 & $-3,36$ \\
\hline F58H1.6 & $-4,18$ \\
\hline neto-1 & 2,81 \\
\hline ftt-2 & 2,25 \\
\hline fbxa-4 & $-5,16$ \\
\hline cutl-21 & $-4,26$ \\
\hline C39E9.7 & $-6,49$ \\
\hline pqn-60 & $-2,26$ \\
\hline rrc-1 & $-2,77$ \\
\hline F21C10.13 & $-4,33$ \\
\hline emb-4 & 1,78 \\
\hline pcm-1 & 1,53 \\
\hline D2045.8 & $-2,84$ \\
\hline cdc-14 & $-2,93$ \\
\hline scm-1 & 2,65 \\
\hline B0334.6 & $-4,16$ \\
\hline asp-2 & $-1,71$ \\
\hline C28C12.4 & $-1,93$ \\
\hline cit-1.2 & 2,11 \\
\hline pdi-6 & $-1,92$ \\
\hline unc-98 & $-2,09$ \\
\hline F25E5.8 & $-1,94$ \\
\hline Imn-1 & 1,48 \\
\hline F58F9.1 & 2,42 \\
\hline abu-8 & $-2,73$ \\
\hline fbxa-29 & $-5,36$ \\
\hline vars-1 & $-2,65$ \\
\hline H34l24.2 & $-2,82$ \\
\hline best-7 & $-4,69$ \\
\hline F15H10.8 & $-4,29$ \\
\hline ZC395.5 & $-1,94$ \\
\hline ZK662.2 & $-2,01$ \\
\hline supr-1 & 2,75 \\
\hline lgg-2 & 2,23 \\
\hline ugt-20 & $-4,60$ \\
\hline ugt-49 & $-1,74$ \\
\hline ZK863.8 \\
\hline ncam-1 & $-2,53$ \\
\hline kqt-3 & $-4,20$ \\
\hline T12B3.2 & $-1,92$ \\
\hline nlp-31 & $-3,76$ \\
\hline W05H7.1 & 3,76 \\
\hline
\end{tabular}

\begin{tabular}{|l|r|}
\hline gene & logFC \\
\hline C24H10.3 & $-4,26$ \\
\hline fbxa-114 & $-3,68$ \\
\hline F59C6.14 & $-2,41$ \\
\hline spp-10 & $-2,40$ \\
\hline dpy-28 & 2,03 \\
\hline elo-4 & $-6,26$ \\
\hline lgc-34 & $-1,72$ \\
\hline cpr-4 & $-1,79$ \\
\hline ptr-2 & $-3,41$ \\
\hline R07E3.2 & $-3,90$ \\
\hline inx-18 & $-2,50$ \\
\hline pmt-1 & $-2,08$ \\
\hline F19C6.3 & 3,04 \\
\hline C26E6.12 & $-2,20$ \\
\hline M03E7.2 & $-2,27$ \\
\hline nid-1 & $-1,84$ \\
\hline col-155 & $-1,85$ \\
\hline pola-1 & $-3,40$ \\
\hline C05D2.10 & 1,91 \\
\hline hsp-1 & 2,50 \\
\hline zipt-3 & $-3,35$ \\
\hline ctb-1 & 2,05 \\
\hline gst-4 & $-2,60$ \\
\hline C01H6.8 & $-1,69$ \\
\hline rad-26 & 2,01 \\
\hline C25H3.11 & $-3,52$ \\
\hline K10B3.1 & $-3,92$ \\
\hline F22G12.5 & 2,05 \\
\hline tyra-3 & 2,54 \\
\hline ZC434.10 & $-4,15$ \\
\hline nspc-14 & $-3,23$ \\
\hline unc-4 & $-4,55$ \\
\hline Y105C5B.15 & $-3,62$ \\
\hline mlc-3 & $-1,55$ \\
\hline F25E5.2 & $-3,45$ \\
\hline pmp-5 & $-1,97$ \\
\hline glb-25 & 2,95 \\
\hline nas-11 & $-3,59$ \\
\hline attf-2 & 1,78 \\
\hline asic-2 & $-4,05$ \\
\hline let-756 & $-3,25$ \\
\hline klp-7 & 1,89 \\
\hline pqn-71 & $-2,60$ \\
\hline F59B10.5 & $-2,13$ \\
\hline cdk-11.1 & $-2,34$ \\
\hline mai-1 & 1,94 \\
\hline nmy-1 & $-1,62$ \\
\hline sek-3 & $-2,39$ \\
\hline ZK1307.9 & 2,69 \\
\hline aldo-1 & $-3,27$ \\
\hline scl-3 & 3,10 \\
\hline F52E1.9 \\
\hline ubq-1 & $-4,07$ \\
\hline F22E5.21 \\
\hline sulp-8 & \\
\hline trcs-1 & \\
\hline W03D8.2 & -80 \\
\hline
\end{tabular}

\begin{tabular}{|l|r|}
\hline gene & logFC \\
\hline R02D5.1 & 2,28 \\
\hline H01G02.3 & 2,37 \\
\hline mpst-1 & $-3,83$ \\
\hline gly-6 & $-1,70$ \\
\hline B0310.1 & $-2,11$ \\
\hline F49C12.12 & 2,02 \\
\hline hot-3 & $-3,52$ \\
\hline R05F9.9 & 2,13 \\
\hline mrp-5 & $-1,90$ \\
\hline phat-5 & $-4,65$ \\
\hline nhr-115 & $-3,67$ \\
\hline haf-1 & $-5,89$ \\
\hline far-4 & $-5,92$ \\
\hline D1054.5 & $-5,91$ \\
\hline Y41C4A.29 & 2,45 \\
\hline csb-1 & $-6,50$ \\
\hline ZK185.3 & $-3,58$ \\
\hline ptd-2 & $-3,07$ \\
\hline Ifi-1 & 1,69 \\
\hline ccb-2 & 2,67 \\
\hline ins-29 & 2,32 \\
\hline F09E5.12 & 3,32 \\
\hline H23N18.5 & $-3,96$ \\
\hline dhs-25 & $-1,84$ \\
\hline math-18 & $-4,14$ \\
\hline xpa-1 & $-3,67$ \\
\hline rpa-2 & 2,05 \\
\hline C11G6.2 & 6,33 \\
\hline C06G1.1 & $-3,76$ \\
\hline acs-3 & $-4,84$ \\
\hline pyc-1 & $-1,90$ \\
\hline xpo-1 & 1,48 \\
\hline W08G11.3 & 2,73 \\
\hline W03F9.1 & 3,09 \\
\hline gsr-1 & $-1,80$ \\
\hline M162.5 & $-6,13$ \\
\hline ech-1.2 & $-2,03$ \\
\hline aho-3 & 2,27 \\
\hline cca-1 & $-2,27$ \\
\hline cogc-6 & $-3,46$ \\
\hline mtm-9 & 2,57 \\
\hline elt-2 & $-2,68$ \\
\hline ech-8 & $-4,09$ \\
\hline Y40B10B.1 & $-6,30$ \\
\hline F48D6.4 & $-2,00$ \\
\hline lips-1 \\
\hline fmo-4 & $-3,62$ \\
\hline mdt-29 & $-3,15$ \\
\hline snrp-40.2 & $-3,01$ \\
\hline Ist-6 \\
\hline his-32 & $-6,23$ \\
\hline ttr-8 \\
\hline C54D10.10 \\
\hline acs-4 & $-3,49$ \\
\hline cpna-2 & \\
\hline asp-4 & \\
\hline cht-1 & \\
\hline
\end{tabular}

\begin{tabular}{|l|r|}
\hline gene & logFC \\
\hline ocr-4 & $-5,27$ \\
\hline cdr-1 & $-2,85$ \\
\hline ZC328.3 & $-3,54$ \\
\hline C10C5.2 & $-5,83$ \\
\hline wago-2 & 3,15 \\
\hline ZK131.11 & $-2,08$ \\
\hline gly-2 & $-3,41$ \\
\hline zig-9 & $-4,96$ \\
\hline F45D3.3 & $-1,76$ \\
\hline vhp-1 & 1,91 \\
\hline ugt-57 & $-4,02$ \\
\hline F53E4.1 & $-2,71$ \\
\hline C18H9.5 & $-4,14$ \\
\hline T19A6.4 & $-4,91$ \\
\hline abf-5 & $-1,71$ \\
\hline trpp-11 & 1,79 \\
\hline C16D9.5 & $-4,94$ \\
\hline F25H8.2 & $-3,48$ \\
\hline irk-3 & 3,01 \\
\hline aagr-1 & $-3,32$ \\
\hline ZK721.3 & 3,14 \\
\hline T19H12.6 & $-3,43$ \\
\hline ceh-48 & 2,71 \\
\hline lbp-3 & $-2,44$ \\
\hline F41F3.3 & $-2,40$ \\
\hline T13F3.7 & $-3,56$ \\
\hline snx-27 & 1,87 \\
\hline dve-1 & $-3,87$ \\
\hline aars-1 & $-2,14$ \\
\hline F58D5.5 & 1,94 \\
\hline F53C11.4 & 1,78 \\
\hline endu-2 & $-1,70$ \\
\hline rsf-1 & $-1,88$ \\
\hline agt-1 & $-3,34$ \\
\hline F45G2.9 & $-3,81$ \\
\hline dpy-31 & $-2,44$ \\
\hline tre-2 & 1,82 \\
\hline T22B2.6 & $-2,47$ \\
\hline Y106G6G.6 & 3,01 \\
\hline col-126 & $-2,18$ \\
\hline F41G3.10 & $-4,47$ \\
\hline unc-112 & $-1,70$ \\
\hline Y51H4A.8 & $-2,42$ \\
\hline col-104 & $-2,63$ \\
\hline pct-1 & 1,64 \\
\hline T28H10.2 & $-3,47$ \\
\hline Y47D3B.6 & $-3,30$ \\
\hline nck-1 & 1,55 \\
\hline F34D10.6 & $-2,99$ \\
\hline unc-83 & $-1,53$ \\
\hline C14B1.3 & 2,15 \\
\hline ifb-2 & $-2,90$ \\
\hline R01E6.2 \\
\hline col-17 & $-2,51$ \\
\hline ZK1320.13 & 2,87 \\
\hline C32H11.4 & $-2,77$ \\
\hline rhr-1 & \\
\hline
\end{tabular}




\section{Appendix}

\begin{tabular}{|l|r|}
\hline gene & logFC \\
\hline F09F7.5 & $-3,27$ \\
\hline mltn-9 & $-3,11$ \\
\hline ugt-62 & $-3,32$ \\
\hline ddr-1 & $-3,98$ \\
\hline fitm-2 & $-2,26$ \\
\hline wah-1 & $-2,98$ \\
\hline ZK858.5 & 2,16 \\
\hline Y39A3CL.7 & $-3,03$ \\
\hline wrn-1 & $-3,11$ \\
\hline cyp-35B1 & $-3,97$ \\
\hline Y66H1A.5 & $-1,56$ \\
\hline trm-1 & $-2,27$ \\
\hline Y49E10.18 & $-2,53$ \\
\hline icmt-1 & 3,43 \\
\hline K06H6.2 & $-5,98$ \\
\hline nhr-106 & $-3,82$ \\
\hline pgam-5 & $-2,74$ \\
\hline C44C10.4 & $-4,57$ \\
\hline fipr-2 & $-1,88$ \\
\hline F08D12.2 & $-1,80$ \\
\hline T05H10.1 & 1,41 \\
\hline tag-234 & $-2,99$ \\
\hline nhr-68 & $-3,31$ \\
\hline ahr-1 & $-4,46$ \\
\hline F13B12.2 & $-3,94$ \\
\hline twk-29 & 2,09 \\
\hline abcf-1 & $-2,65$ \\
\hline uaf-1 & 1,85 \\
\hline math-39 & $-4,50$ \\
\hline pqn-25 & $-3,29$ \\
\hline M03D4.4 & $-4,14$ \\
\hline tat-4 & $-1,74$ \\
\hline col-141 & $-2,46$ \\
\hline C03B1.14 & $-4,50$ \\
\hline R12C12.6 & 1,63 \\
\hline zig-7 & $-1,91$ \\
\hline tre-3 & $-1,80$ \\
\hline Y37H9A.3 & 1,74 \\
\hline C18H9.6 & $-3,09$ \\
\hline trp-4 & $-3,88$ \\
\hline che-12 & $-2,75$ \\
\hline foX-1 & 2,08 \\
\hline Y22D7AL.7 & 2,68 \\
\hline T19D12.1 & $-3,57$ \\
\hline Iron-6 & $-3,51$ \\
\hline C52D10.3 & $-3,56$ \\
\hline twk-12 & 2,18 \\
\hline fipr-1 & $-2,51$ \\
\hline T06D8.3 & $-3,93$ \\
\hline M106.8 & 2,58 \\
\hline ZC376.6 & $-4,06$ \\
\hline R08F11.4 & $-3,45$ \\
\hline emb-27 & $-4,13$ \\
\hline taf-1 & 1,66 \\
\hline hpo-15 & $-2,92$ \\
\hline coh-4 & 3,16 \\
\hline D1022.3 & $-4,25$ \\
\hline
\end{tabular}

\begin{tabular}{|l|r|}
\hline gene & logFC \\
\hline tba-8 & $-1,39$ \\
\hline T01D1.4 & $-3,26$ \\
\hline C14H10.3 & 1,57 \\
\hline ape-1 & 1,47 \\
\hline pdr-1 & $-2,74$ \\
\hline ZK1010.10 & 2,26 \\
\hline mkk-4 & 2,51 \\
\hline Y26E6A.2 & 3,19 \\
\hline C25D7.5 & $-5,40$ \\
\hline F14F9.3 & $-5,39$ \\
\hline Y47D9A.1 & $-1,53$ \\
\hline alh-8 & $-1,88$ \\
\hline mecr-1 & $-1,51$ \\
\hline hoe-1 & $-3,99$ \\
\hline kynu-1 & $-2,94$ \\
\hline mig-10 & $-3,23$ \\
\hline pqn-18 & 1,77 \\
\hline F47B8.10 & $-6,02$ \\
\hline math-20 & $-4,04$ \\
\hline fbxa-79 & $-5,18$ \\
\hline cyp-34A9 & $-3,91$ \\
\hline eat-5 & $-3,23$ \\
\hline paa-1 & 1,72 \\
\hline ceh-20 & $-3,03$ \\
\hline M88.4 & $-5,53$ \\
\hline hum-8 & $-3,68$ \\
\hline jnk-1 & 2,46 \\
\hline F35D11.4 & $-4,98$ \\
\hline Y41C4A.8 & $-4,90$ \\
\hline plst-1 & $-4,26$ \\
\hline F59E11.2 & $-4,08$ \\
\hline bet-1 & 1,88 \\
\hline vamp-8 & $-2,14$ \\
\hline grl-14 & 2,63 \\
\hline ZK652.6 & 1,85 \\
\hline Y32B12B.4 & 2,46 \\
\hline lipl-5 & $-1,90$ \\
\hline C01G10.15 & $-3,89$ \\
\hline C13C4.4 & 2,51 \\
\hline pbo-5 & $-3,63$ \\
\hline idhg-1 & 1,68 \\
\hline bus-19 & $-2,16$ \\
\hline sop-2 & 2,00 \\
\hline ZK822.4 & $-2,51$ \\
\hline lact-3 & $-2,48$ \\
\hline ZK287.7 & $-4,51$ \\
\hline Y71F9B.9 & $-3,40$ \\
\hline tram-1 & 1,63 \\
\hline F13C5.5 & $-2,74$ \\
\hline vamp-7 & 2,13 \\
\hline dpy-22 & $-3,37$ \\
\hline C55A6.7 & $-3,15$ \\
\hline gbf-1 \\
\hline dcap-1 & \\
\hline acs-20 & \\
\hline cyp-33E3 & \\
\hline gcy-32 & \\
\hline
\end{tabular}

\begin{tabular}{|l|r|}
\hline gene & logFC \\
\hline cnt-2 & 1,67 \\
\hline F10D11.2 & $-2,71$ \\
\hline F59C6.11 & $-3,12$ \\
\hline nuc-1 & $-2,12$ \\
\hline R11D1.1 & 1,99 \\
\hline C48B4.13 & $-5,69$ \\
\hline T18D3.9 & 2,46 \\
\hline nhr-49 & 1,74 \\
\hline C01B4.7 & $-2,66$ \\
\hline Y19D10A.4 & $-2,66$ \\
\hline clec-204 & $-3,56$ \\
\hline dpy-6 & $-1,94$ \\
\hline dph-2 & $-3,08$ \\
\hline fipr-22 & $-6,00$ \\
\hline swsn-4 & 1,36 \\
\hline T09F5.1 & $-2,21$ \\
\hline arr-1 & 2,18 \\
\hline C56C10.4 & $-4,10$ \\
\hline nlp-27 & $-2,30$ \\
\hline Y119C1B.10 & 2,56 \\
\hline zmp-6 & 1,90 \\
\hline ubr-5 & 1,57 \\
\hline cyp-23A1 & $-4,27$ \\
\hline scav-4 & $-2,48$ \\
\hline Y105E8A.14 & 2,71 \\
\hline marc-5 & 2,48 \\
\hline F46B6.2 & $-3,43$ \\
\hline qua-1 & $-1,69$ \\
\hline C17E4.6 & 1,87 \\
\hline C23H3.9 & $-2,00$ \\
\hline C18G1.6 & $-4,53$ \\
\hline max-1 & 1,68 \\
\hline vps-22 & 1,60 \\
\hline ZK105.6 & $-2,98$ \\
\hline fahd-1 & $-1,86$ \\
\hline F33H2.2 & $-2,40$ \\
\hline alh-4 & $-1,61$ \\
\hline clec-12 & $-4,27$ \\
\hline sre-14 & 3,11 \\
\hline C33F10.4 & $-5,40$ \\
\hline mab-5 & $-3,50$ \\
\hline F11D5.1 & 1,83 \\
\hline Y34D9A.8 & 3,43 \\
\hline Y106G6D.7 & 1,73 \\
\hline unc-16 & 1,44 \\
\hline dhs-18 & $-2,43$ \\
\hline daf-9 & $-4,12$ \\
\hline Y73F8A.26 & $-3,75$ \\
\hline R08E3.1 & $-3,44$ \\
\hline Y51H7C.5 & 1,80 \\
\hline C54E10.6 & 2,49 \\
\hline lips-8 & $-2,21$ \\
\hline act-5 & $-2,53$ \\
\hline gadr-6 \\
\hline flp-4 \\
\hline grd-5 & \\
\hline E02H9.3 & \\
\hline
\end{tabular}

\begin{tabular}{|l|r|}
\hline gene & logFC \\
\hline prmt-6 & $-4,87$ \\
\hline Y62F5A.9 & $-2,38$ \\
\hline slc-25A10 & 1,62 \\
\hline C27D9.2 & $-4,13$ \\
\hline T01H3.2 & 1,82 \\
\hline mrg-1 & 1,96 \\
\hline W04A8.1 & $-4,24$ \\
\hline M60.4 & $-1,86$ \\
\hline sms-1 & 1,54 \\
\hline phy-2 & $-2,46$ \\
\hline F32H5.3 & $-2,03$ \\
\hline ekl-6 & $-2,37$ \\
\hline K10D6.2 & $-2,45$ \\
\hline F29B9.8 & $-3,59$ \\
\hline cdk-9 & 2,52 \\
\hline ndx-3 & $-3,49$ \\
\hline clec-25 & $-4,68$ \\
\hline R166.6 & 2,37 \\
\hline C18H7.1 & $-5,99$ \\
\hline col-111 & $-2,22$ \\
\hline aph-1 & 2,18 \\
\hline srt-42 & 4,25 \\
\hline F56C11.6 & $-3,63$ \\
\hline ntp-1 & $-1,59$ \\
\hline M01G12.9 & $-4,59$ \\
\hline K11G9.2 & $-4,00$ \\
\hline fbxa-180 & $-6,23$ \\
\hline ZK1320.7 & $-2,93$ \\
\hline his-65 & $-6,15$ \\
\hline ttr-27 & $-1,55$ \\
\hline cmd-1 & 2,16 \\
\hline K10D3.6 & $-2,73$ \\
\hline C49G7.7 & $-5,34$ \\
\hline hpo-28 & $-2,06$ \\
\hline Y105C5B.3 & $-5,74$ \\
\hline T01D1.3 & $-3,35$ \\
\hline F31F7.2 & $-4,75$ \\
\hline Y54E5A.8 & $-1,97$ \\
\hline scav-3 & 1,85 \\
\hline ZK813.5 & $-3,61$ \\
\hline dpyd-1 & $-2,68$ \\
\hline C30F2.2 & $-4,61$ \\
\hline fbxa-55 & $-3,88$ \\
\hline ZK909.6 & $-4,20$ \\
\hline asd-2 & $-2,16$ \\
\hline F35D2.1 & $-5,28$ \\
\hline bra-1 & 3,66 \\
\hline F44F1.4 & 3,04 \\
\hline Y39G8B.9 & $-1,35$ \\
\hline ttr-59 & $-2,50$ \\
\hline Y71G12B.25 & $-4,90$ \\
\hline F08F3.10 & $-2,77$ \\
\hline Y62H9A.15 & $-2,52$ \\
\hline oac-40 & $-5,63$ \\
\hline T03F1.6 & $-3,75$ \\
\hline Ipin-1 & $-1,72$ \\
\hline M116.2 & 2,33 \\
\hline
\end{tabular}




\section{Appendix}

\begin{tabular}{|l|r|}
\hline gene & logFC \\
\hline pcp-2 & $-3,71$ \\
\hline F56C9.8 & $-2,19$ \\
\hline kmo-2 & $-4,49$ \\
\hline H24G06.1 & 1,30 \\
\hline dpy-10 & $-1,90$ \\
\hline F21A3.3 & $-3,11$ \\
\hline W06H8.6 & 3,26 \\
\hline Y102A11A.3 & $-2,81$ \\
\hline T07D3.6 & $-5,21$ \\
\hline T28D9.1 & 2,42 \\
\hline C46F11.4 & 1,83 \\
\hline cst-2 & 2,41 \\
\hline F08G2.4 & 3,18 \\
\hline C49A9.3 & $-3,67$ \\
\hline txdc-9 & 2,35 \\
\hline skpo-3 & $-3,46$ \\
\hline srp-2 & $-2,87$ \\
\hline C25E10.8 & $-2,41$ \\
\hline C05G5.5 & $-3,94$ \\
\hline irg-6 & $-6,29$ \\
\hline irg-3 & $-1,89$ \\
\hline npr-3 & 2,48 \\
\hline ergo-1 & 2,04 \\
\hline hhat-1 & $-2,40$ \\
\hline let-92 & 1,49 \\
\hline gly-15 & $-5,22$ \\
\hline srr-4 & $-4,37$ \\
\hline ing-3 & 1,83 \\
\hline ZC239.6 & 1,96 \\
\hline zipt-20 & 4,15 \\
\hline mdl-1 & 2,30 \\
\hline gsp-2 & 1,66 \\
\hline F32D8.15 & 2,81 \\
\hline emc-2 & 1,67 \\
\hline D1086.8 & $-1,82$ \\
\hline M03F8.3 & 1,67 \\
\hline Y73F4A.1 & 1,76 \\
\hline col-73 & $-2,94$ \\
\hline nono-1 & 2,09 \\
\hline idhg-2 & $-2,03$ \\
\hline ttr-28 & $-1,83$ \\
\hline Y55F3BR.10 & 4,39 \\
\hline apr-1 & $-2,80$ \\
\hline ric-7 & 1,37 \\
\hline sptf-2 & $-4,10$ \\
\hline gcy-12 & 2,25 \\
\hline ntl-3 & 2,29 \\
\hline ras-1 & $-1,85$ \\
\hline F59D12.1 & 3,22 \\
\hline Y76A2B.4 & $-3,31$ \\
\hline K02E11.4 & $-2,82$ \\
\hline M01H9.4 & $-2,38$ \\
\hline daf-19 & 1,49 \\
\hline F07B7.12 & 6,11 \\
\hline wrt-10 & $-2,62$ \\
\hline mksr-1 \\
\hline F49F1.7 & $-5,80$ \\
\hline
\end{tabular}

\begin{tabular}{|l|r|}
\hline gene & logFC \\
\hline C39D10.8 & $-1,63$ \\
\hline C14C11.4 & $-3,72$ \\
\hline gly-10 & $-2,06$ \\
\hline Y53C10A.5 & 1,81 \\
\hline hum-4 & $-3,29$ \\
\hline acs-19 & 2,10 \\
\hline flh-1 & 2,59 \\
\hline pgp-10 & $-3,42$ \\
\hline R08D7.5 & 2,27 \\
\hline paqr-2 & 2,04 \\
\hline glb-27 & 2,41 \\
\hline B0303.14 & 2,46 \\
\hline F41G3.21 & $-2,82$ \\
\hline cyp-32B1 & $-2,41$ \\
\hline ZC8.6 & 1,87 \\
\hline ceh-89 & 2,82 \\
\hline Y95B8A.2 & $-1,88$ \\
\hline wrt-9 & $-3,10$ \\
\hline T16G1.7 & $-2,68$ \\
\hline prx-12 & $-4,70$ \\
\hline Y54G2A.7 & $-3,51$ \\
\hline T13H5.1 & $-2,71$ \\
\hline rfc-1 & $-2,01$ \\
\hline Y69H2.1 & $-2,89$ \\
\hline klo-2 & $-3,84$ \\
\hline gbh-2 & 1,89 \\
\hline F58F9.4 & $-5,29$ \\
\hline tbc-8 & 2,77 \\
\hline pdk-1 & 2,28 \\
\hline pqn-85 & 1,55 \\
\hline F22E5.13 & 3,01 \\
\hline oac-32 & $-7,21$ \\
\hline Y65B4A.2 & 1,71 \\
\hline C27H5.4 & $-2,98$ \\
\hline gei-4 & 1,70 \\
\hline lev-11 & $-1,43$ \\
\hline rsy-1 & 2,03 \\
\hline C06E7.2 & 2,10 \\
\hline xbp-1 & 2,27 \\
\hline C14A4.12 & 1,88 \\
\hline cth-1 & $-3,53$ \\
\hline mab-3 & $-5,52$ \\
\hline nspb-11 & $-3,43$ \\
\hline cnx-1 & 1,39 \\
\hline Y38H6C.16 & $-4,18$ \\
\hline F40A3.2 & $-2,27$ \\
\hline Y17G7B.8 & $-3,59$ \\
\hline mdt-26 & 2,31 \\
\hline C45G9.5 & $-2,63$ \\
\hline F53F4.12 & $-4,52$ \\
\hline F45E1.1 & 2,29 \\
\hline Y37E11B.7 & $-3,63$ \\
\hline K12B6.9 & $-1,79$ \\
\hline cima-1 & $-1,73$ \\
\hline spr-3 & $-4,41$ \\
\hline tag-131 & $-2,47$ \\
\hline elpc-1 & $-2,40$ \\
\hline
\end{tabular}

\begin{tabular}{|l|r|}
\hline gene & logFC \\
\hline Y73B6BL.35 & 1,97 \\
\hline nrde-4 & $-2,72$ \\
\hline Y37A1B.5 & $-3,78$ \\
\hline ZK1055.2 & $-5,56$ \\
\hline F36H9.7 & 3,59 \\
\hline nspc-17 & $-2,58$ \\
\hline C01B9.1 & $-4,21$ \\
\hline eat-20 & 1,69 \\
\hline efl-2 & 2,93 \\
\hline lem-3 & $-2,93$ \\
\hline arrd-6 & $-3,60$ \\
\hline F27E5.7 & $-3,26$ \\
\hline snb-2 & $-3,34$ \\
\hline xrn-1 & 1,81 \\
\hline fmi-1 & $-2,92$ \\
\hline grl-9 & 2,58 \\
\hline dhs-5 & $-2,83$ \\
\hline T26F2.2 & $-5,18$ \\
\hline Y17D7C.3 & 1,83 \\
\hline clec-15 & $-3,45$ \\
\hline C36A4.4 & $-2,22$ \\
\hline Y43F8B.24 & $-5,05$ \\
\hline sqv-3 & $-2,65$ \\
\hline ugt-39 & $-4,15$ \\
\hline clc-3 & $-3,16$ \\
\hline nspc-7 & $-3,36$ \\
\hline sdpn-1 & $-3,76$ \\
\hline W09G12.7 & $-3,85$ \\
\hline F56E10.1 & 1,83 \\
\hline alh-3 & $-1,42$ \\
\hline nkb-1 & 1,91 \\
\hline F58E6.4 & $-2,15$ \\
\hline T13F3.6 & $-3,57$ \\
\hline ZK430.7 & $-3,45$ \\
\hline cyp-29A2 & $-3,40$ \\
\hline gln-6 & 2,48 \\
\hline C48E7.1 & $-3,53$ \\
\hline Y55B1BR.2 & 2,12 \\
\hline nas-37 & $-2,04$ \\
\hline clik-1 & $-1,42$ \\
\hline usp-39 & 2,41 \\
\hline fbxa-88 & $-5,84$ \\
\hline fipr-24 & $-2,17$ \\
\hline R166.2 & 1,68 \\
\hline ketn-1 & $-1,50$ \\
\hline ubh-1 & 2,05 \\
\hline F21F3.6 & 1,46 \\
\hline vab-23 & $-2,84$ \\
\hline F39H12.1 & $-3,12$ \\
\hline cdkl-1 & 2,19 \\
\hline frm-4 & 1,37 \\
\hline nipa-1 & $-6,02$ \\
\hline K08D9.6 \\
\hline avr-14 & 2,27 \\
\hline Y69A2AR.1 & 2,12 \\
\hline ric-3 & 1,85 \\
\hline K08B12.1 & $-3,24$ \\
\hline
\end{tabular}

\begin{tabular}{|c|c|}
\hline gene & $\log F C$ \\
\hline K11G12.6 & 1,81 \\
\hline heh-1 & $-2,54$ \\
\hline C05B5.8 & $-2,22$ \\
\hline B0379.1 & $-1,73$ \\
\hline del-6 & $-1,50$ \\
\hline $\operatorname{lin}-8$ & 2,57 \\
\hline aagr-4 & $-1,96$ \\
\hline ifa-1 & $-2,87$ \\
\hline dct-18 & $-2,11$ \\
\hline$v a b-7$ & $-5,10$ \\
\hline T11B7.2 & 2,73 \\
\hline$R 13 H 4.2$ & $-1,47$ \\
\hline T07D3.4 & $-2,35$ \\
\hline pyk-1 & 1,57 \\
\hline bca-1 & $-3,01$ \\
\hline efl-1 & 2,55 \\
\hline egg-6 & $-3,57$ \\
\hline$s r x-56$ & $-6,48$ \\
\hline col-105 & $-5,43$ \\
\hline Y37H2A.14 & $-2,32$ \\
\hline C43F9.11 & $-4,80$ \\
\hline$f b x c-55$ & $-5,56$ \\
\hline athp-2 & 1,55 \\
\hline$T 28 D 6.5$ & 1,71 \\
\hline C07G3.10 & 2,45 \\
\hline$t / k-1$ & 1,32 \\
\hline pqn-24 & $-3,48$ \\
\hline K08C7.4 & 3,23 \\
\hline$R 151.2$ & $-2,27$ \\
\hline del-5 & $-3,7 \varepsilon$ \\
\hline$R 01 H 10.4$ & $-3,8 \varepsilon$ \\
\hline mboa-3 & $-3,31$ \\
\hline cut-2 & $-2,19$ \\
\hline$t t x-7$ & 1,65 \\
\hline ech-6 & $-2,7 \varepsilon$ \\
\hline unc-122 & 2,63 \\
\hline F41D9.2 & $-1,73$ \\
\hline his-20 & $-4,98$ \\
\hline his-22 & $-4,9 \varepsilon$ \\
\hline his-52 & $-4,9$ \\
\hline gex-3 & $-2,2$ \\
\hline hrpk-1 & 1,34 \\
\hline F55F3.2 & $-2,61$ \\
\hline$t \operatorname{tn}-1$ & $-1,61$ \\
\hline bet-2 & 1,7 \\
\hline eat-6 & 1,2 \\
\hline$m o g-1$ & 1,38 \\
\hline F19H8.2 & $-1,7$ \\
\hline$s q v-4$ & $-2,5$ \\
\hline $\operatorname{lin}-25$ & $-1,8$ \\
\hline clh-6 & $-4,12$ \\
\hline tpra-1 & 1,61 \\
\hline rom-2 & $-3,19$ \\
\hline Y39G10AR.32 & 2,2 \\
\hline F53A3.1 & $-1,8$ \\
\hline C25H3.3 & $-3,8$ \\
\hline H04M03.3 & $-1,43$ \\
\hline
\end{tabular}




\section{Appendix}

\begin{tabular}{|l|r|}
\hline gene & logFC \\
\hline ctg-1 & $-1,78$ \\
\hline ZK1320.2 & $-1,51$ \\
\hline F02D8.4 & $-1,72$ \\
\hline Y46D2A.1 & $-4,20$ \\
\hline akir-1 & 1,65 \\
\hline hlh-11 & 1,23 \\
\hline fhod-1 & $-2,59$ \\
\hline arid-1 & 2,85 \\
\hline B0001.8 & 1,90 \\
\hline R119.5 & 2,20 \\
\hline Y57A10A.24 & 2,77 \\
\hline Y9C12A.1 & 2,57 \\
\hline ntl-4 & 1,47 \\
\hline C54D10.13 & $-2,34$ \\
\hline F18A11.5 & 1,85 \\
\hline lec-9 & $-1,59$ \\
\hline wdr-5.3 & 3,01 \\
\hline F18A11.3 & 1,60 \\
\hline meC-4 & $-2,79$ \\
\hline F42A6.6 & $-2,86$ \\
\hline got-1.2 & 2,20 \\
\hline F17C11.11 & $-3,20$ \\
\hline C30G4.4 & $-2,38$ \\
\hline K10B2.4 & 1,18 \\
\hline fbxa-18 & $-5,28$ \\
\hline tars-1 & $-1,83$ \\
\hline F25H2.12 & $-3,10$ \\
\hline F59B8.1 & 1,93 \\
\hline gpap-1 & 1,94 \\
\hline bed-1 & 2,31 \\
\hline C25H3.10 & $-1,88$ \\
\hline H24K24.4 & $-3,95$ \\
\hline ugt-52 & $-5,34$ \\
\hline unc-52 & $-1,61$ \\
\hline ric-19 & 1,81 \\
\hline spd-2 & $-3,62$ \\
\hline F35H10.10 & $-3,38$ \\
\hline F23F1.4 & $-1,54$ \\
\hline aqp-4 & $-3,07$ \\
\hline B0035.1 & 1,59 \\
\hline srx-111 & $-6,05$ \\
\hline grld-1 & 1,56 \\
\hline C24B9.3 & $-2,59$ \\
\hline nduo-4 & 1,86 \\
\hline hot-6 & 2,25 \\
\hline mpst-3 & $-2,91$ \\
\hline W07G4.5 & 1,66 \\
\hline cpl-1 & $-1,50$ \\
\hline R166.3 & 2,21 \\
\hline nhr-103 & 2,23 \\
\hline R07A4.3 & $-1,80$ \\
\hline T10B10.8 & $-3,11$ \\
\hline maph-1.3 & 2,64 \\
\hline daf-36 & $-3,31$ \\
\hline pals-23 & $-3,49$ \\
\hline C14A4.6 & $-2,58$ \\
\hline C30F12.2 & $-4,29$ \\
\hline
\end{tabular}

\begin{tabular}{|c|c|}
\hline gene & $\log F C$ \\
\hline let-2 & $-1,99$ \\
\hline Y54E2A.10 & 2,82 \\
\hline fbxa-128 & $-3,96$ \\
\hline kle-2 & 1,82 \\
\hline D2096.6 & $-2,76$ \\
\hline lec-2 & $-1,40$ \\
\hline F53F1.2 & $-3,27$ \\
\hline C07A12.7 & 1,43 \\
\hline ZC443.3 & 1,62 \\
\hline Itd-1 & $-2,97$ \\
\hline srg-25 & $-2,89$ \\
\hline M195.2 & $-3,80$ \\
\hline $\operatorname{tag}-304$ & 1,87 \\
\hline C29F5.3 & $-4,40$ \\
\hline C09F5.1 & $-2,25$ \\
\hline C05G5.1 & 1,68 \\
\hline snap-1 & 2,06 \\
\hline$p f d-6$ & $-1,25$ \\
\hline ZC190.4 & $-1,60$ \\
\hline cat-1 & $-4,11$ \\
\hline sng-1 & 2,47 \\
\hline$h s p-25$ & $-1,38$ \\
\hline jmjd-5 & $-4,43$ \\
\hline lid-1 & $-2,40$ \\
\hline F52G2.3 & $-3,55$ \\
\hline$g r l-4$ & $-3,06$ \\
\hline glf-1 & $-2,35$ \\
\hline$r d y-2$ & $-3,68$ \\
\hline ZK185.2 & 2,07 \\
\hline ZK524.4 & 1,66 \\
\hline $\operatorname{ccg}-1$ & $-1,54$ \\
\hline$z b p-1$ & 1,61 \\
\hline fbxa-11 & $-4,20$ \\
\hline F44A2.3 & $-2,21$ \\
\hline F23B12.7 & $-1,66$ \\
\hline C01F1.5 & $-4,67$ \\
\hline let-70 & 1,54 \\
\hline ZK643.5 & 2,40 \\
\hline F53B2.8 & $-2,57$ \\
\hline$s v h-1$ & $-3,78$ \\
\hline $\operatorname{tag}-179$ & $-3,43$ \\
\hline gcy-36 & $-2,87$ \\
\hline F47G4.4 & 2,13 \\
\hline baz-2 & 1,81 \\
\hline Y73F4A.2 & $-1,37$ \\
\hline$D 2096.12$ & $-2,75$ \\
\hline$h m b x-1$ & $-3,09$ \\
\hline lam-2 & $-3,66$ \\
\hline clec-43 & $-3,45$ \\
\hline dhs -13 & $-3,14$ \\
\hline$c n b-1$ & 1,50 \\
\hline kel-8 & 1,58 \\
\hline$t b c-17$ & 2,24 \\
\hline$p p k-3$ & $-3,51$ \\
\hline$r d e-1$ & 1,51 \\
\hline Y75B8A.13 & 1,70 \\
\hline dgk-4 & 1,77 \\
\hline
\end{tabular}

\begin{tabular}{|l|r|}
\hline gene & logFC \\
\hline D1054.8 & $-1,62$ \\
\hline dhhc-3 & 1,79 \\
\hline srab-4 & $-4,76$ \\
\hline T28C6.8 & $-1,55$ \\
\hline F25A2.1 & $-4,00$ \\
\hline fars-3 & $-1,63$ \\
\hline C36B1.11 & $-2,74$ \\
\hline Co9E9.1 & 2,33 \\
\hline sulp-2 & $-4,05$ \\
\hline oxy-4 & $-2,27$ \\
\hline T27E4.1 & 1,78 \\
\hline deb-1 & $-1,60$ \\
\hline Y38H6C.8 & 2,51 \\
\hline abhd-5.1 & $-3,00$ \\
\hline R06F6.14 & $-2,53$ \\
\hline chp-1 & 1,29 \\
\hline ifo-1 & $-1,63$ \\
\hline asns-2 & $-2,81$ \\
\hline nhr-54 & $-3,58$ \\
\hline pqn-73 & $-4,71$ \\
\hline btb-16 & $-2,31$ \\
\hline gna-1 & $-2,47$ \\
\hline his-3 & $-3,26$ \\
\hline gpa-7 & 3,73 \\
\hline F22F7.7 & 2,13 \\
\hline F45G2.10 & $-2,37$ \\
\hline nep-1 & 1,62 \\
\hline cfp-1 & 1,66 \\
\hline F31C3.3 & 1,62 \\
\hline spp-16 & $-1,41$ \\
\hline TO7D1.2 & $-2,07$ \\
\hline Y54E10A.10 & $-2,34$ \\
\hline sqv-8 & 1,99 \\
\hline ugt-31 & $-5,66$ \\
\hline C39E9.8 & $-1,66$ \\
\hline T16H12.9 & $-3,24$ \\
\hline gln-3 & $-1,37$ \\
\hline F09B9.4 & $-2,94$ \\
\hline B0310.6 & $-2,56$ \\
\hline catp-8 & 1,32 \\
\hline D1086.1 & $-1,85$ \\
\hline nep-2 & 2,31 \\
\hline orc-5 & 1,88 \\
\hline sec-31 & $-1,82$ \\
\hline taf-6.1 & 2,61 \\
\hline tbx-2 & $-1,75$ \\
\hline T10E9.14 & $-2,85$ \\
\hline pgp-6 & $-5,06$ \\
\hline T01D3.3 & $-3,33$ \\
\hline sgk-1 & $-1,76$ \\
\hline R09F10.5 & 2,28 \\
\hline ZK858.6 & 1,35 \\
\hline F52H2.3 & $-2,85$ \\
\hline Y48G1BM.6 & 2,92 \\
\hline F23F12.12 & $-2,12$ \\
\hline K07A1.3 & 1,69 \\
\hline sym-2 & $-1,29$ \\
\hline
\end{tabular}

\begin{tabular}{|l|r|}
\hline gene & logFC \\
\hline B0361.9 & $-1,83$ \\
\hline T25D10.1 & $-2,11$ \\
\hline gck-1 & $-2,12$ \\
\hline apc-11 & 2,28 \\
\hline C34D1.4 & $-1,90$ \\
\hline gpc-2 & 2,08 \\
\hline ran-2 & $-1,59$ \\
\hline gta-1 & $-1,78$ \\
\hline F44D12.2 & $-3,72$ \\
\hline F35G12.12 & 1,57 \\
\hline aakg-3 & 2,73 \\
\hline H14A12.3 & 1,31 \\
\hline C14F11.6 & $-1,52$ \\
\hline dyf-13 & $-3,96$ \\
\hline R10H1.1 & $-1,64$ \\
\hline mec-17 & $-1,23$ \\
\hline F43H9.4 & $-3,19$ \\
\hline his-9 & $-2,89$ \\
\hline his-13 & $-2,89$ \\
\hline D2092.8 & $-1,42$ \\
\hline egl-13 & 1,87 \\
\hline enu-3.1 & 2,11 \\
\hline EGAP4.1 & $-1,43$ \\
\hline fbxa-146 & 2,42 \\
\hline glb-24 & 1,83 \\
\hline F11E6.6 & 2,49 \\
\hline nas-13 & $-5,11$ \\
\hline F40H3.2 & $-1,65$ \\
\hline F46F3.3 & $-4,05$ \\
\hline sac-1 & 1,63 \\
\hline strl-1 & $-1,54$ \\
\hline Y47D7A.13 & $-2,02$ \\
\hline nfyb-1 & 1,91 \\
\hline Y105C5A.1 & 1,95 \\
\hline F13G3.3 & $-3,42$ \\
\hline dpy-5 & $-2,18$ \\
\hline sup-12 & 1,77 \\
\hline dct-11 & $-2,32$ \\
\hline flcn-1 & 1,62 \\
\hline D2005.1 & 1,79 \\
\hline zig-10 & 2,42 \\
\hline ifb-1 & $-1,65$ \\
\hline Y39F10B.1 & 1,55 \\
\hline W08E12.2 & $-2,23$ \\
\hline C17H11.6 & 1,27 \\
\hline inx-13 & $-1,25$ \\
\hline C01G10.6 & $-2,20$ \\
\hline Y73B3B.5 & 2,66 \\
\hline sdc-2 & $-1,78$ \\
\hline M04D8.7 & $-3,62$ \\
\hline Y11D7A.9 & $-4,66$ \\
\hline D2024.5 & 1,91 \\
\hline R12E2.7 & $-1,40$ \\
\hline clp-1 & 1,35 \\
\hline ddx-17 & $-3,82$ \\
\hline K06A9.1 & $-2,01$ \\
\hline C50F4.1 \\
\hline
\end{tabular}


Appendix

\begin{tabular}{|l|r|}
\hline gene & logFC \\
\hline F44F4.3 & $-4,37$ \\
\hline nhx-6 & $-5,52$ \\
\hline fbn-1 & $-2,13$ \\
\hline K09G1.1 & $-1,41$ \\
\hline drr-1 & $-1,68$ \\
\hline T03G6.1 & $-2,76$ \\
\hline F12A10.1 & $-2,17$ \\
\hline pud-1.1 & $-1,65$ \\
\hline F33H12.7 & $-4,34$ \\
\hline cutl-16 & $-4,63$ \\
\hline C48B6.2 & $-2,29$ \\
\hline aly-3 & 1,67 \\
\hline C36B1.6 & $-2,50$ \\
\hline ZC443.2 & 2,41 \\
\hline ttr-16 & $-1,23$ \\
\hline ZK792.5 & 1,32 \\
\hline F32D8.1 & 2,48 \\
\hline arrd-18 & 2,11 \\
\hline M03B6.5 & $-2,28$ \\
\hline clec-5 & $-3,47$ \\
\hline xbx-1 & $-3,87$ \\
\hline Y94H6A.10 & $-1,63$ \\
\hline cdc-42 & 1,33 \\
\hline srh-28 & $-3,81$ \\
\hline F19F10.12 & $-1,95$ \\
\hline ttm-5 & $-2,27$ \\
\hline fbxa-61 & $-3,72$ \\
\hline F52C12.1 & 2,95 \\
\hline lon-2 & 1,99 \\
\hline ajm-1 & $-2,57$ \\
\hline tbc-6 & $-1,79$ \\
\hline C53A3.2 & $-3,03$ \\
\hline D2024.4 & $-1,96$ \\
\hline T26A8.1 & $-1,59$ \\
\hline W10C8.5 & $-2,29$ \\
\hline ubc-14 & 1,55 \\
\hline pgp-9 & $-2,59$ \\
\hline K06G5.1 & $-2,02$ \\
\hline nape-2 & $-1,78$ \\
\hline & \\
\hline
\end{tabular}




\section{Appendix}

Table 5 - All significantly differentially expressed genes of the "sci-RNA-seq RIS vs. all" transcriptome and their $\log F C$

\begin{tabular}{|c|c|}
\hline gene & $\log F C$ \\
\hline$f \mid p-11$ & 9,24 \\
\hline akap-1 & 3,63 \\
\hline$s r x-2$ & 3,77 \\
\hline srg-69 & 3,44 \\
\hline T05A8.3 & 4,66 \\
\hline F53F4.17 & 3,35 \\
\hline$r a b x-5$ & 3,98 \\
\hline ZK1307.7 & 4,44 \\
\hline $\operatorname{srs} x-18$ & 2,71 \\
\hline Y57G11C.46 & 3,61 \\
\hline ser-4 & 4,64 \\
\hline$R 11 F 4.2$ & 3,77 \\
\hline nep-26 & 3,40 \\
\hline$c a b-1$ & 4,09 \\
\hline$k c c-2$ & 2,99 \\
\hline$c k r-1$ & 4,44 \\
\hline egl-9 & 2,73 \\
\hline gap-1 & 3,92 \\
\hline Y39A1A.24 & 2,99 \\
\hline arrd-26 & 3,07 \\
\hline C01C4.3 & 3,09 \\
\hline$n / p-8$ & 5,06 \\
\hline K03B4.4 & 3,32 \\
\hline T12A7.2 & 3,44 \\
\hline wee-1.1 & 3,18 \\
\hline$n c s-6$ & 3,11 \\
\hline egl-3 & 4,20 \\
\hline$s c d-1$ & 3,23 \\
\hline abts-3 & 2,60 \\
\hline pck-1 & 2,63 \\
\hline pgal-1 & 4,03 \\
\hline$m b k-2$ & 2,33 \\
\hline T27C4.1 & 3,98 \\
\hline wnk-1 & 2,10 \\
\hline pamn-1 & 3,16 \\
\hline$t \operatorname{tn}-1$ & $-7,25$ \\
\hline frpr-16 & 3,47 \\
\hline egl-21 & 4,05 \\
\hline kin-1 & 2,36 \\
\hline$n / p-11$ & 4,84 \\
\hline$s b t-1$ & 4,08 \\
\hline rps-0 & $-1,98$ \\
\hline cmk-1 & 2,71 \\
\hline$n / p-13$ & 4,21 \\
\hline sca-1 & $-4,14$ \\
\hline ilys-4 & 3,37 \\
\hline flp-34 & 2,88 \\
\hline far-1 & $-5,85$ \\
\hline
\end{tabular}

\begin{tabular}{|c|c|}
\hline gene & $\log F C$ \\
\hline rpl-3 & $-1,60$ \\
\hline eef-1A.1 & $-1,33$ \\
\hline$d m d-7$ & 2,45 \\
\hline unc-108 & 2,15 \\
\hline F46C5.4 & 2,30 \\
\hline$m p z-1$ & 2,27 \\
\hline F52G3.1 & 2,21 \\
\hline unc-54 & $-6,01$ \\
\hline daf-16 & 2,14 \\
\hline rps-9 & $-1,86$ \\
\hline tpa-1 & 2,81 \\
\hline avr-15 & 3,44 \\
\hline eef-2 & $-1,64$ \\
\hline pghm-1 & 3,71 \\
\hline ins-24 & 1,82 \\
\hline Y43C5A.7 & 1,98 \\
\hline dmsr-3 & 3,46 \\
\hline ZK742.7 & 2,36 \\
\hline sem-5 & 2,49 \\
\hline ptr-5 & 2,75 \\
\hline unc-57 & 2,13 \\
\hline$n h r-71$ & 2,30 \\
\hline $\operatorname{dig}-1$ & $-4,93$ \\
\hline $\lg c-4$ & 3,18 \\
\hline unc-15 & $-5,08$ \\
\hline$t k r-1$ & 2,41 \\
\hline hif-1 & 2,10 \\
\hline K02F2.5 & 4,28 \\
\hline maf-1 & 3,10 \\
\hline F35H12.6 & 2,24 \\
\hline gsk-3 & 2,08 \\
\hline ost-1 & $-4,30$ \\
\hline cpna-2 & $-4,86$ \\
\hline H10E21.5 & 3,48 \\
\hline ren-1 & 2,76 \\
\hline T07E3.3 & 1,99 \\
\hline sprr-2 & 2,22 \\
\hline unc-89 & $-4,60$ \\
\hline F44E5.5 & 2,10 \\
\hline F44E5.5 & 2,10 \\
\hline mig-6 & $-4,08$ \\
\hline zig-5 & 3,50 \\
\hline F54D1.6 & 3,15 \\
\hline fln-1 & $-3,29$ \\
\hline ida-1 & 3,23 \\
\hline$m t m-6$ & 2,05 \\
\hline R02F2.1 & 1,88 \\
\hline$r p l-4$ & $-1,12$ \\
\hline
\end{tabular}

\begin{tabular}{|c|c|}
\hline gene & $\log F C$ \\
\hline myo-3 & $-4,23$ \\
\hline nduo-5 & $-2,09$ \\
\hline gem-1 & 2,84 \\
\hline Y105C5A.15 & 2,18 \\
\hline aptf-1 & 1,32 \\
\hline unc-13 & 2,05 \\
\hline epi-1 & $-3,88$ \\
\hline mup-2 & $-4,11$ \\
\hline F56A12.2 & 2,19 \\
\hline unc-44 & 1,72 \\
\hline gei-3 & 2,47 \\
\hline sto-4 & 1,93 \\
\hline H17B01.5 & 2,58 \\
\hline$n p r-13$ & 1,91 \\
\hline unc-22 & $-4,13$ \\
\hline rskn-1 & 2,47 \\
\hline$m / c-3$ & $-3,64$ \\
\hline tnt-2 & $-3,92$ \\
\hline W05F2.4 & $-3,43$ \\
\hline C10C6.7 & 2,38 \\
\hline$d y s-1$ & $-3,47$ \\
\hline fib-1 & $-3,09$ \\
\hline rps-2 & $-1,41$ \\
\hline F19C6.3 & 2,79 \\
\hline arrd-17 & 2,36 \\
\hline F01G4.6 & $-2,71$ \\
\hline Y41E3.7 & 2,02 \\
\hline C02B8.3 & 1,97 \\
\hline$T 21 D 12.12$ & 1,93 \\
\hline B0286.1 & 2,11 \\
\hline ser-7 & 2,13 \\
\hline let-2 & $-3,98$ \\
\hline tiam-1 & 2,95 \\
\hline ketn-1 & $-3,41$ \\
\hline clik-1 & $-3,81$ \\
\hline tag-89 & 1,83 \\
\hline pat-10 & $-3,54$ \\
\hline catp-7 & 2,10 \\
\hline$n \circ g-1$ & $-2,67$ \\
\hline F35A5.1 & $-3,21$ \\
\hline $\operatorname{csq}-1$ & $-3,20$ \\
\hline syd-9 & 1,94 \\
\hline$n p r-29$ & 2,45 \\
\hline$m v k-1$ & 1,68 \\
\hline sue-1 & 3,88 \\
\hline far-2 & $-3,78$ \\
\hline$m / c-2$ & $-3,31$ \\
\hline ace-4 & 1,59 \\
\hline
\end{tabular}

\begin{tabular}{|c|c|}
\hline gene & $\log \mathrm{FC}$ \\
\hline$d m s r-6$ & 2,25 \\
\hline tos-1 & 1,54 \\
\hline T12D8.9 & $-3,06$ \\
\hline F32D1.3 & 3,28 \\
\hline pck-2 & $-2,77$ \\
\hline$r p l-33$ & $-2,38$ \\
\hline$Y 11 D 7 A .10$ & 2,25 \\
\hline unc-27 & $-3,16$ \\
\hline$g d h-1$ & $-2,23$ \\
\hline K07H8.10 & $-2,73$ \\
\hline rpl-5 & $-1,04$ \\
\hline $\mathrm{F} 52 \mathrm{H} 2.4$ & 2,68 \\
\hline F41C3.5 & $-3,78$ \\
\hline$u b c-3$ & 1,76 \\
\hline $\operatorname{dim}-1$ & $-3,20$ \\
\hline$r p s-5$ & $-1,21$ \\
\hline nbid-1 & 2,02 \\
\hline$f b x a-3$ & 1,61 \\
\hline$m c t-6$ & 2,28 \\
\hline lam-2 & $-3,09$ \\
\hline pat-2 & $-2,84$ \\
\hline rpl-19 & $-1,19$ \\
\hline acer-1 & $-2,79$ \\
\hline his-37 & 1,74 \\
\hline his-37 & 1,74 \\
\hline his-37 & 1,74 \\
\hline ZC449.8 & 1,68 \\
\hline frpr-3 & 1,32 \\
\hline lam-1 & $-2,89$ \\
\hline$s n b-1$ & 2,38 \\
\hline DH11.5 & 2,79 \\
\hline C25G6.4 & 2,20 \\
\hline$r b f-1$ & 3,19 \\
\hline rpl-7A & $-1,58$ \\
\hline alh-8 & $-2,68$ \\
\hline$C D 4.1$ & 1,69 \\
\hline$g c y-12$ & 2,13 \\
\hline$r p l-15$ & $-1,27$ \\
\hline$m / c-1$ & $-2,98$ \\
\hline rps-18 & $-1,32$ \\
\hline F44E5.4 & 1,88 \\
\hline F44E5.4 & 1,88 \\
\hline T05E7.4 & 2,28 \\
\hline$d p y-21$ & 1,77 \\
\hline F46C5.7 & 1,15 \\
\hline Y39G10AR.11 & 1,83 \\
\hline icl-1 & $-2,95$ \\
\hline H06104.3 & $-2,48$ \\
\hline
\end{tabular}




\section{Appendix}

\begin{tabular}{|c|c|}
\hline gene & $\log \mathrm{FC}$ \\
\hline pkg-2 & 1,81 \\
\hline С39B10.1 & 1,50 \\
\hline$g / b-23$ & 2,23 \\
\hline dop-3 & 2,52 \\
\hline F21C10.7 & $-2,86$ \\
\hline$c k r-2$ & 2,25 \\
\hline ant-1.1 & $-1,25$ \\
\hline Y64G10A.6 & 1,74 \\
\hline T01H8.2 & 2,64 \\
\hline rpl-6 & $-1,16$ \\
\hline him-4 & $-3,36$ \\
\hline hda-4 & 1,80 \\
\hline F20D6.8 & 3,00 \\
\hline$F 13 H 10.1$ & 0,59 \\
\hline F40A3.7 & 2,14 \\
\hline$s p v-1$ & 2,27 \\
\hline klu-1 & 1,86 \\
\hline lev-11 & $-3,01$ \\
\hline atp-2 & $-1,36$ \\
\hline F46H5.3 & $-2,62$ \\
\hline kin-29 & 2,24 \\
\hline$h p k-1$ & 1,81 \\
\hline$n p r-32$ & 1,56 \\
\hline$p t b-1$ & 2,44 \\
\hline glb-32 & 1,71 \\
\hline ins-27 & 1,59 \\
\hline$n h r-67$ & 1,63 \\
\hline pde-3 & 1,96 \\
\hline ttr-16 & $-2,92$ \\
\hline pkc-1 & 1,85 \\
\hline act-4 & $-2,03$ \\
\hline C34F6.9 & 2,28 \\
\hline$i c d-1$ & $-2,13$ \\
\hline C34F6.10 & 2,87 \\
\hline unc-73 & 1,58 \\
\hline F57A8.4 & 1,78 \\
\hline dur-1 & $-2,80$ \\
\hline pqn-89 & 1,83 \\
\hline $\mathrm{F} 42 \mathrm{H} 10.3$ & 1,57 \\
\hline W07E11.1 & 1,72 \\
\hline goa-1 & 1,51 \\
\hline $\operatorname{ccg}-1$ & $-2,74$ \\
\hline$m g l-2$ & 3,11 \\
\hline hum-9 & $-2,55$ \\
\hline unc-32 & 1,49 \\
\hline unc-52 & $-2,73$ \\
\hline cpn-3 & $-2,48$ \\
\hline K05F1.6 & 1,74 \\
\hline
\end{tabular}

\begin{tabular}{|c|c|}
\hline gene & $\log F C$ \\
\hline$r p l-25.2$ & $-2,34$ \\
\hline calu-1 & $-2,52$ \\
\hline exp-2 & 2,51 \\
\hline C35E7.11 & 2,31 \\
\hline act-3 & $-2,63$ \\
\hline act-3 & $-2,63$ \\
\hline W02D9.10 & 2,50 \\
\hline nucb-1 & 1,69 \\
\hline plc-3 & 1,91 \\
\hline F36D4.4 & 1,90 \\
\hline$g c y-28$ & 1,36 \\
\hline F38B6.6 & 2,76 \\
\hline$h s p-6$ & $-2,33$ \\
\hline$r p s-19$ & $-1,36$ \\
\hline tps-2 & $-2,59$ \\
\hline F55C12.4 & 2,77 \\
\hline rpl-16 & $-1,11$ \\
\hline$d m s r-1$ & 1,57 \\
\hline$f \mid p-1$ & 4,01 \\
\hline snap-1 & 1,60 \\
\hline B0361.4 & 1,58 \\
\hline aqp-2 & $-2,62$ \\
\hline sma-9 & 1,49 \\
\hline$n / p-37$ & 2,05 \\
\hline T05G5.1 & $-2,47$ \\
\hline nap-1 & $-2,27$ \\
\hline nduo-4 & $-1,13$ \\
\hline osta-2 & 1,83 \\
\hline tnt-3 & $-2,63$ \\
\hline $\operatorname{lgc}-53$ & 1,89 \\
\hline unc-46 & 1,76 \\
\hline ile-1 & 1,69 \\
\hline rpl-11.1 & $-2,90$ \\
\hline col-175 & 0,88 \\
\hline rpl-13 & $-1,04$ \\
\hline unc-47 & 1,73 \\
\hline ZK792.5 & 1,69 \\
\hline pac-1 & 1,32 \\
\hline H05L03.3 & 3,67 \\
\hline gon-1 & $-2,53$ \\
\hline lec-5 & $-2,66$ \\
\hline T23F11.4 & 2,32 \\
\hline rpl-12 & $-1,21$ \\
\hline lit-1 & 1,36 \\
\hline C36E8.1 & $-2,20$ \\
\hline$r p l-28$ & $-1,70$ \\
\hline$n p r-16$ & 1,57 \\
\hline F27C1.2 & 1,58 \\
\hline
\end{tabular}

\begin{tabular}{|l|r|}
\hline gene & logFC \\
\hline sul-2 & 2,34 \\
\hline jph-1 & 1,56 \\
\hline KO9A9.6 & $-2,21$ \\
\hline C10E2.5 & 1,01 \\
\hline Y71G10AR.4 & 1,51 \\
\hline igcm-2 & 1,58 \\
\hline C27F2.8 & $-2,33$ \\
\hline icd-2 & $-1,80$ \\
\hline lars-1 & $-2,16$ \\
\hline W06H8.6 & 1,65 \\
\hline glb-7 & 1,30 \\
\hline unc-77 & 3,06 \\
\hline apl-1 & 1,84 \\
\hline bkip-1 & 1,50 \\
\hline Y45F10B.13 & $-2,31$ \\
\hline phf-5 & 2,40 \\
\hline lea-1 & $-2,07$ \\
\hline rps-6 & $-1,07$ \\
\hline inf-1 & $-1,98$ \\
\hline cpl-1 & $-2,44$ \\
\hline T10G3.8 & 1,42 \\
\hline atn-1 & $-2,16$ \\
\hline K02D3.1 & 1,34 \\
\hline rps-7 & $-1,03$ \\
\hline cyc-1 & $-2,10$ \\
\hline ZC15.10 & 0,97 \\
\hline rps-3 & $-0,88$ \\
\hline ZK822.2 & 2,52 \\
\hline unc-82 & $-2,12$ \\
\hline spp-10 & $-2,12$ \\
\hline egl-45 & $-2,10$ \\
\hline mrck-1 & $-2,20$ \\
\hline rack-1 & $-0,92$ \\
\hline rps-4 & $-0,92$ \\
\hline lgc-54 & 1,13 \\
\hline K07C5.4 & $-2,11$ \\
\hline C05G5.1 & 1,40 \\
\hline dlk-1 & 1,98 \\
\hline pqn-22 & $-2,28$ \\
\hline Y73B6BL.14 & 0,83 \\
\hline nhr-40 & 1,42 \\
\hline unc-40 & 1,67 \\
\hline dkf-2 & \\
\hline T24H7.2 & atp-6 \\
\hline F58D5.5 & $-1,72$ \\
\hline mel-28 & \\
\hline F40E10.6 & 1,28 \\
\hline
\end{tabular}

\begin{tabular}{|l|r|}
\hline gene & logFC \\
\hline let-607 & 1,26 \\
\hline zig-2 & 1,90 \\
\hline eat-16 & 1,43 \\
\hline snt-4 & 2,37 \\
\hline lec-6 & 1,94 \\
\hline imp-2 & 1,53 \\
\hline ztf-27 & 1,49 \\
\hline zig-10 & 1,55 \\
\hline ctb-1 & $-0,94$ \\
\hline M176.5 & 2,84 \\
\hline mak-1 & $-1,99$ \\
\hline atic-1 & 2,28 \\
\hline C50D2.2 & 1,33 \\
\hline pdi-3 & $-1,72$ \\
\hline unc-112 & $-2,07$ \\
\hline ser-1 & 1,49 \\
\hline sos-1 & $-2,06$ \\
\hline ZK652.8 & 1,73 \\
\hline asp-4 & $-2,17$ \\
\hline catp-6 & $-2,02$ \\
\hline vhp-1 & 1,38 \\
\hline kcnl-1 & 1,84 \\
\hline qars-1 & $-1,95$ \\
\hline egl-4 & 1,18 \\
\hline cah-1 & 1,84 \\
\hline F28C1.3 & 1,50 \\
\hline T01B7.9 & 1,92 \\
\hline sta-1 & 1,49 \\
\hline F28B12.1 & 1,39 \\
\hline col-107 & $-4,36$ \\
\hline ist-1 & 2,27 \\
\hline rps-11 & $-0,98$ \\
\hline Y82E9BR.3 & $-1,32$ \\
\hline puf-12 & $-1,84$ \\
\hline dmsr-2 & 1,92 \\
\hline adss-1 & $-1,95$ \\
\hline acs-17 & $-2,08$ \\
\hline F26F12.8 & 1,40 \\
\hline abcf-2 & $-1,70$ \\
\hline T18D3.7 & 1,55 \\
\hline rig-4 & $-1,85$ \\
\hline unc-83 \\
\hline
\end{tabular}




\section{Appendix}

Table 6 - All significantly differentially expressed genes of the "sci-RNA-seq RIS vs. neurons" transcriptome and their logFC

\begin{tabular}{|c|c|}
\hline gene & $\log F C$ \\
\hline flp-11 & 7,26 \\
\hline srg-69 & 1,88 \\
\hline$s r x-2$ & 2,08 \\
\hline$Z K 1307.7$ & 2,62 \\
\hline F53F4.17 & 1,78 \\
\hline F54D1.6 & 1,67 \\
\hline $\operatorname{srs} x-18$ & 1,35 \\
\hline gap-1 & 2,23 \\
\hline$c a b-1$ & 1,84 \\
\hline egl-3 & 1,82 \\
\hline wee-1.1 & 1,69 \\
\hline$r a b x-5$ & 2,22 \\
\hline$T 21 D 12.12$ & 0,87 \\
\hline pgal-1 & 1,65 \\
\hline pqn-89 & 0,92 \\
\hline$n / p-8$ & 3,01 \\
\hline egl-21 & 1,67 \\
\hline T27C4.1 & 1,65 \\
\hline C10C6.7 & 1,09 \\
\hline R11F4.2 & 2,06 \\
\hline akap-1 & 1,66 \\
\hline$s b t-1$ & 1,76 \\
\hline ser-4 & 2,80 \\
\hline$n / p-13$ & 2,24 \\
\hline K02F2.5 & 2,13 \\
\hline$n / p-11$ & 2,69 \\
\hline Y57G11C.46 & 1,97 \\
\hline T05A8.3 & 3,15 \\
\hline nep-26 & 2,63 \\
\hline K03B4.4 & 1,69 \\
\hline wnk-1 & 1,48 \\
\hline pghm-1 & 1,33 \\
\hline arrd-26 & 1,49 \\
\hline sma-1 & 2,07 \\
\hline$c k r-1$ & 2,54 \\
\hline plc-3 & 1,03 \\
\hline T07E3.3 & 0,88 \\
\hline frpr-16 & 1,91 \\
\hline aptf-1 & 0,54 \\
\hline chdp-1 & $-1,77$ \\
\hline Y39A1A.24 & 1,37 \\
\hline pamn-1 & 1,42 \\
\hline ced-6 & 0,54 \\
\hline let-23 & 1,47 \\
\hline Ifi-1 & $-1,51$ \\
\hline egl-9 & 1,29 \\
\hline T05E7.4 & 1,20 \\
\hline tiam-1 & 1,33 \\
\hline
\end{tabular}

\begin{tabular}{|l|r|}
\hline gene & log FC \\
\hline cle-1 & $-2,19$ \\
\hline madd-4 & $-2,30$ \\
\hline plc-1 & $-1,79$ \\
\hline abts-3 & 1,38 \\
\hline F46C5.4 & 0,98 \\
\hline H10E21.5 & 1,57 \\
\hline tpa-1 & 1,35 \\
\hline sprr-2 & 0,95 \\
\hline ins-27 & 0,65 \\
\hline sue-1 & 1,66 \\
\hline rcn-1 & 1,53 \\
\hline ncs-6 & 1,54 \\
\hline T12A7.2 & 1,70 \\
\hline ida-1 & 0,86 \\
\hline fmi-1 & $-1,64$ \\
\hline pkg-2 & 1,26 \\
\hline C01C4.3 & 1,46 \\
\hline ZK822.2 & 1,46 \\
\hline
\end{tabular}




\section{Appendix}

Table 7-All significantly differentially expressed genes of the "sci-RNA-seq ALA vs. neurons" transcriptome and their logFC

\begin{tabular}{|l|r|}
\hline gene & logFC \\
\hline flp-24 & 5,92 \\
\hline let-23 & 3,41 \\
\hline flp-7 & 3,71 \\
\hline pgal-1 & 2,26 \\
\hline mnr-1 & 3,02 \\
\hline nlp-8 & 3,89 \\
\hline nhr-93 & 1,52 \\
\hline R11.2 & 1,98 \\
\hline ptr-24 & 2,18 \\
\hline F43D9.1 & 1,31 \\
\hline T10E10.3 & 1,49 \\
\hline pbo-5 & 1,50 \\
\hline F41B4.2 & 3,69 \\
\hline gnrr-7 & 1,60 \\
\hline ver-3 & 1,58 \\
\hline plc-3 & 1,63 \\
\hline Y42A5A.1 & 2,75 \\
\hline pde-3 & 2,10 \\
\hline flp-13 & 4,61 \\
\hline vab-8 & 2,06 \\
\hline C04A11.1 & 1,19 \\
\hline Y71A12B.12 & 1,68 \\
\hline
\end{tabular}




\section{Appendix}

Table 8 - Genes enriched in all three RIS transcriptomes

\begin{tabular}{|c|c|c|c|c|}
\hline gene & $\begin{array}{l}\text { mean } \\
\text { logFC }\end{array}$ & $\begin{array}{c}\text { FACS/RNA-seq } \\
\text { (RIS vs all) } \\
\text { logFC }\end{array}$ & $\begin{array}{c}\text { sci-RNA-seq } \\
\text { (RIS vs all) } \\
\text { logFC }\end{array}$ & $\begin{array}{c}\text { sci-RNA-seq } \\
\text { (RIS vs neurons) } \\
\text { logFC }\end{array}$ \\
\hline$f \mid p-11$ & 8,75 & 9,75 & 9,24 & 7,26 \\
\hline$Z K 1307.7$ & 5,51 & 9,49 & 4,44 & 2,62 \\
\hline ser-4 & 5,28 & 8,39 & 4,64 & 2,80 \\
\hline$c k r-1$ & 5,22 & 8,69 & 4,44 & 2,54 \\
\hline T05A8.3 & 5,22 & 7,83 & 4,66 & 3,15 \\
\hline$s r x-2$ & 5,19 & 9,72 & 3,77 & 2,08 \\
\hline$n / p-8$ & 5,14 & 7,34 & 5,06 & 3,01 \\
\hline srg-69 & 5,05 & 9,83 & 3,44 & 1,88 \\
\hline$n / p-11$ & 5,02 & 7,52 & 4,84 & 2,69 \\
\hline$R 11 F 4.2$ & 4,88 & 8,80 & 3,77 & 2,06 \\
\hline K02F2.5 & 4,77 & 7,89 & 4,28 & 2,13 \\
\hline Y57G11C.46 & 4,71 & 8,55 & 3,61 & 1,97 \\
\hline$n / p-13$ & 4,64 & 7,47 & 4,21 & 2,24 \\
\hline C10C6.7 & 4,41 & 9,77 & 2,38 & 1,09 \\
\hline F46C5.4 & 4,37 & 9,84 & 2,30 & 0,98 \\
\hline egl-3 & 4,27 & 6,80 & 4,20 & 1,82 \\
\hline T27C4.1 & 4,24 & 7,10 & 3,98 & 1,65 \\
\hline sue-1 & 4,18 & 7,00 & 3,88 & 1,66 \\
\hline nep-26 & 4,07 & 6,18 & 3,40 & 2,63 \\
\hline$r a b x-5$ & 3,98 & 5,73 & 3,98 & 2,22 \\
\hline arrd-26 & 3,88 & 7,07 & 3,07 & 1,49 \\
\hline pgal-1 & 3,87 & 5,92 & 4,03 & 1,65 \\
\hline$s b t-1$ & 3,85 & 5,72 & 4,08 & 1,76 \\
\hline T05E7.4 & 3,79 & 7,89 & 2,28 & 1,20 \\
\hline$n c s-6$ & 3,78 & 6,70 & 3,11 & 1,54 \\
\hline H10E21.5 & 3,78 & 6,30 & 3,48 & 1,57 \\
\hline$c a b-1$ & 3,68 & 5,11 & 4,09 & 1,84 \\
\hline egl-21 & 3,64 & 5,21 & 4,05 & 1,67 \\
\hline sprr-2 & 3,59 & 7,61 & 2,22 & 0,95 \\
\hline pghm-1 & 3,53 & 5,55 & 3,71 & 1,33 \\
\hline aptf-1 & 3,48 & 8,59 & 1,32 & 0,54 \\
\hline Y39A1A.24 & 3,42 & 5,90 & 2,99 & 1,37 \\
\hline tiam-1 & 3,38 & 5,87 & 2,95 & 1,33 \\
\hline ida-1 & 3,31 & 5,82 & 3,23 & 0,86 \\
\hline K03B4.4 & 3,30 & 4,90 & 3,32 & 1,69 \\
\hline C01C4.3 & 3,27 & 5,26 & 3,09 & 1,46 \\
\hline ZK822.2 & 3,13 & 5,41 & 2,52 & 1,46 \\
\hline pamn-1 & 3,11 & 4,74 & 3,16 & 1,42 \\
\hline frpr-16 & 3,08 & 3,86 & 3,47 & 1,91 \\
\hline akap-1 & 3,03 & 3,81 & 3,63 & 1,66 \\
\hline$T 12 A 7.2$ & 3,02 & 3,92 & 3,44 & 1,70 \\
\hline$a b t s-3$ & 2,85 & 4,56 & 2,60 & 1,38 \\
\hline egl-9 & 2,53 & 3,57 & 2,73 & 1,29 \\
\hline tpa-1 & 2,53 & 3,44 & 2,81 & 1,35 \\
\hline wnk-1 & 2,36 & 3,50 & 2,10 & 1,48 \\
\hline pkg-2 & 2,22 & 3,58 & 1,81 & 1,26 \\
\hline plc-3 & 2,11 & 3,38 & 1,91 & 1,03 \\
\hline pqn-89 & 2,10 & 3,54 & 1,83 & 0,92 \\
\hline$T 21 D 12.12$ & 1,98 & 3,12 & 1,93 & 0,87 \\
\hline T07E3.3 & 1,96 & 3,03 & 1,99 & 0,88 \\
\hline ins-27 & 1,86 & 3,33 & 1,59 & 0,65 \\
\hline
\end{tabular}




\section{Appendix}




\section{Acknowledgements}

First, I want to thank my supervisor Dr. Henrik Bringmann for giving me the opportunity to do my $\mathrm{PhD}$ in his lab and to work with those fascinating little worms. I highly appreciate the constant support I got, the trust he had in my project and the insights about the life of a scientist.

Furthermore, I also want to thank Prof. Ralf Heinrich and Dr. Oliver Valerius, for being members of my thesis committee, for the support they gave me during the meetings, but also besides it.

The MPI BPC, with all of its scientists and non-scientists, is an honorable institute, for which I am proud that I had been a part of it. Also the GGNB with its great support for its students and my beautiful city Göttingen, have to be mentioned at this place.

I also thank my collaboration partners, which were mentioned throughout the thesis, for working with me on this exciting story.

One name has to be emphasized here: Maximilian Fritz

Science was his passion. And, although he passed away way too early, he will leave a footprint in science, for being a key part of the story of this thesis and the paper we plan to publish about it. I guess, he would have been proud of it.

I want to thank all my colleagues, with whom I was able to work with, in the last four years. Thanks for Silvia Gremmler for keeping the lab running in the background! And the group we have right now provides such an enjoyable atmosphere during working hours and outside of it. For this, I want to thank: Inka Busack, Yang Hu, Anastasios Koutsoumparis, Elisabeth Maluck, Marina Sinner, and Yin Wu. For those who will join, I am looking forward to our time in Marburg and Royal Worm Force, season two.

One old colleague and now friend, I want to mention here separately, is Michał Turek. Thank you for explaining me the lab and all the methods in the beginning, and now for proof reading my thesis. I hope we will meet soon again so I can pay my beer dept. 


\section{Acknowledgements}

Also, thanks to the student assists I had over time, for keeping my worms growing and happy, while I was busy with experiments. By name: Yelena Sargsyan, Konstantina Kolotourou, and Natalia M. Parra.

Coming close to the end of my thesis, I want to thank all my friends in- and outside the world of science who supported me and had an open ear, whenever I felt overwhelmed by scientific reality.

This is also true for my lovely girlfriend Nadine Storjohann, who is there for me on so many levels. Thanks for that, and I am also looking forward to our next step and the time together in Marburg.

Finally, I want to thank my family. My sister and her boyfriend, for providing a warm place, which always feels like home when I visit. And my parents, for what I can hardly describe with words. I am grateful for all the support you gave to me in various ways over all the years. Without you two, I could not have been the scientist I am today, and I know that. Thank you. 